2007 National Roadside Survey of Alcohol and Drug Use by Drivers

\title{
DRUG RESULTS
}
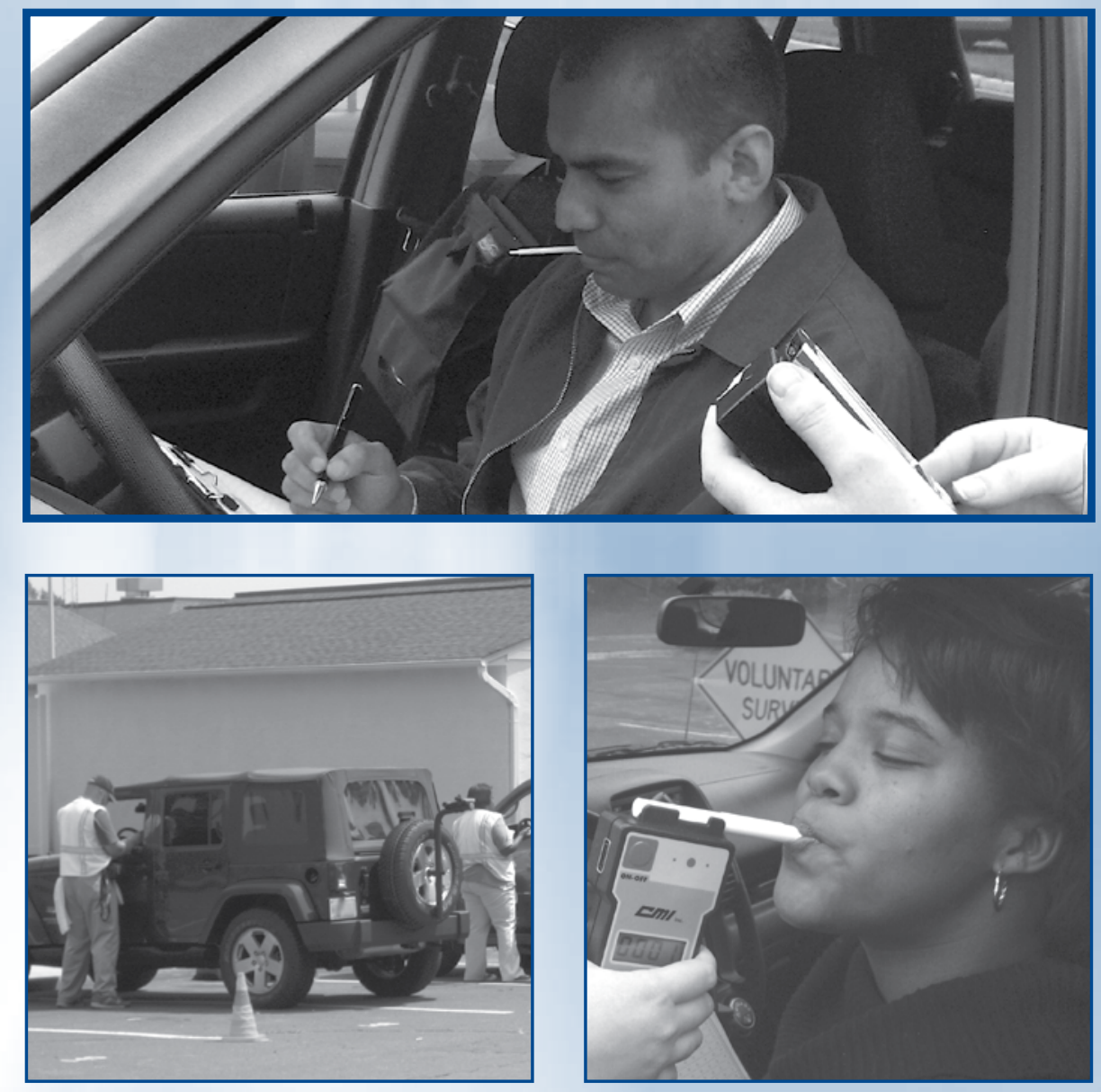
This publication is distributed by the U.S. Department of Transportation, National Highway Traffic Safety Administration, in the interest of information exchange. The opinions, findings and conclusions expressed in this publication are those of the author(s) and not necessarily those of the Department of Transportation or the National Highway Traffic Safety Administration. The United States Government assumes no liability for its content or use thereof. If trade or manufacturers' names or products are mentioned, it is because they are considered essential to the object of the publication and should not be construed as an endorsement. The United States Government does not endorse products or manufacturers. 
Technical Report Documentation Page

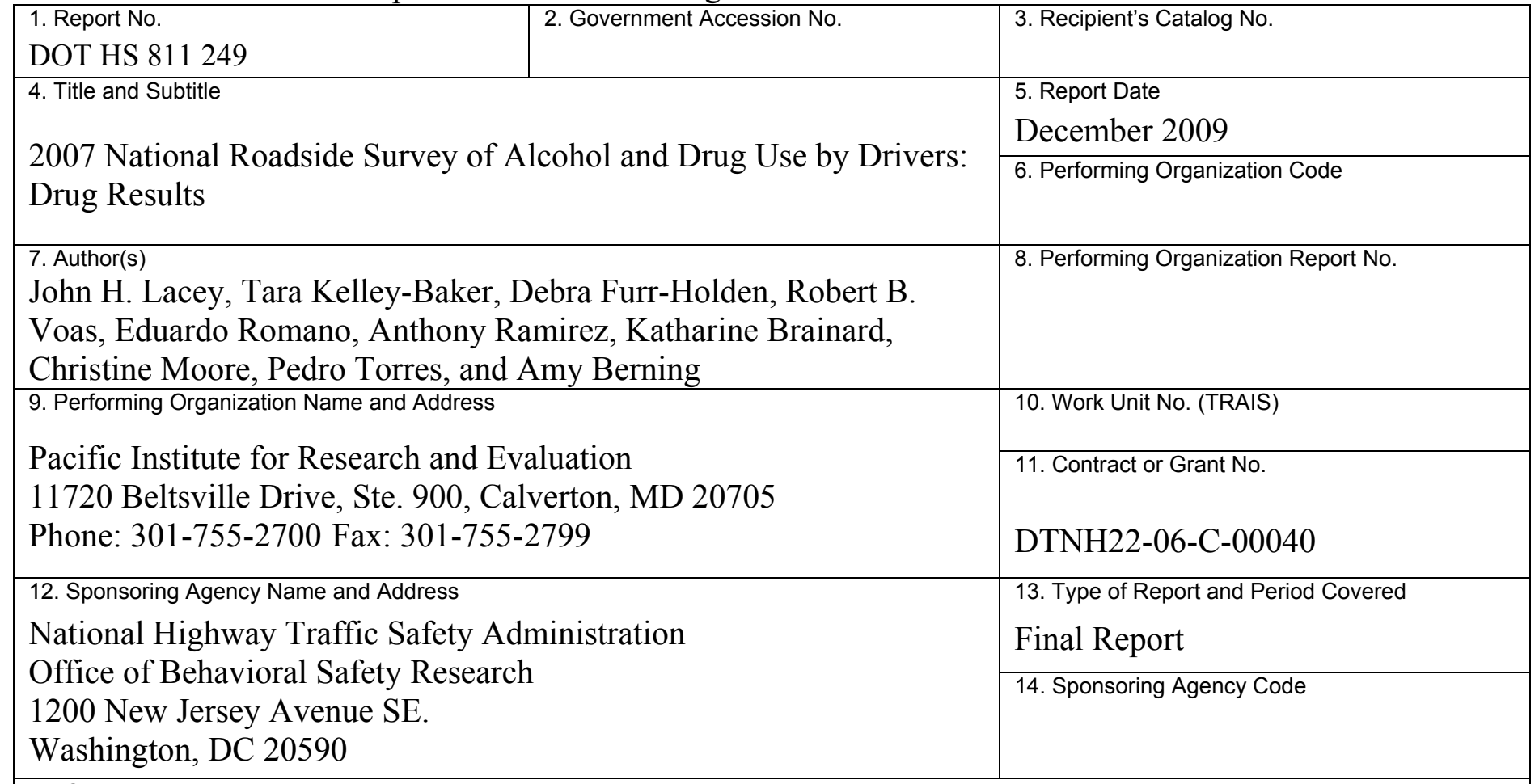

15. Supplementary Notes

Amy Berning served as the project's Contracting Officer's Technical Representative.

The National Institute on Alcohol Abuse and Alcoholism (NIAAA) provided funding and support for the assessment of alcohol use disorders.

The National Institute on Drug Abuse (NIDA) provided funding for the collection of additional blood samples and the administration of the drug use disorders assessment.

The National Institute of Justice (NIJ) provided support for querying participants about interaction with the criminal justice system.

16. Abstract

This report presents the first national prevalence estimates for drug-involved driving derived from the recently completed 2007 National Roadside Survey (NRS). The NRS is a national field survey of alcohol- and drug-involved driving conducted primarily among nighttime weekend drivers, but also daytime Friday drivers. The survey involved randomly stopping drivers at 300 locations across the continental United States; sites were selected through a stratified random sampling procedure. This included data that we collected during a two-hour Friday daytime session at 60 locations and during four 2-hour nighttime periods (10 p.m. to midnight and $1 \mathrm{a} . \mathrm{m}$. to $3 \mathrm{a} . \mathrm{m}$. on both Friday and Saturday) at 240 locations. Both self-report and biological measures were taken. Biological measures included breath alcohol measurements on 9,413 respondents, oral fluid from 7,719 respondents, and blood samples from 3,276 respondents. Oral fluid and blood samples were subjected to laboratory screening and LC/MS-MS and GC/MS confirmation for 75 drugs and metabolites, including illegal, prescription, and over-the-counter drugs. These data were analyzed to develop the first national prevalence estimate of alcohol- and drug-involved driving. Two prior reports on the 2007 NRS described: (1) the sampling plan and data collection methodology, summarizing the response patterns to the various stages of the multi-part survey; and (2) the prevalence estimates for alcohol-involved driving derived from the study, and comparing them with the three previous National Roadside Surveys (NRS).

\section{Key Words}

Alcohol and driving, drugs and driving, roadside survey, impaired driving, drugged driving, alcoholinvolved driving, drug-involved driving 19 Security Classif
Unclassified

\section{Security Classif. (of this page)} Unclassified
18. Distribution Statement

Document is available to the public from the National Technical Information Service www.ntis.gov

Form DOT F 1700.7 (8/72)
21 No. of Pages 148 


\section{Acknowledgements}

The authors received extensive assistance from State and local officials in the conduct of this project. Our data collection procedures were not routine. The willingness of officials to help us identify cooperating local law enforcement agencies and the willingness of agencies to participate in the project were essential to our success. To all those who helped in conducting this study, the authors express their sincere gratitude. 


\section{Table of Contents}

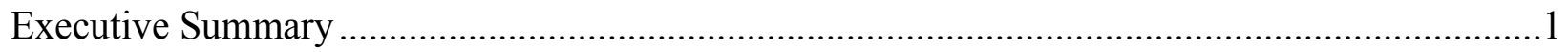

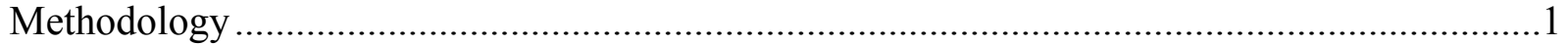

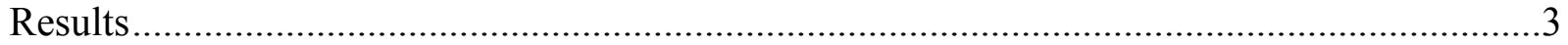

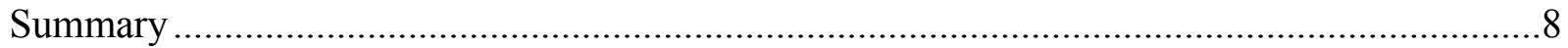

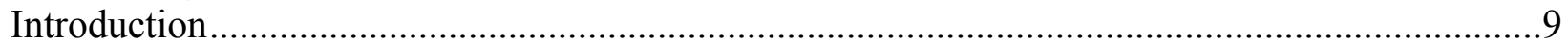

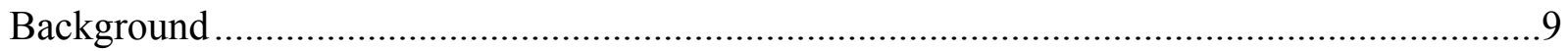

Prevalence of Drug-Involved Driving ...............................................................................

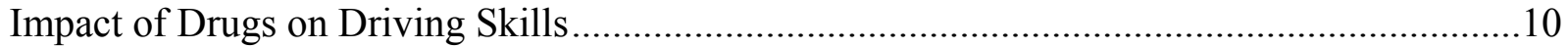

Laboratory Studies .............................................................................................1 10

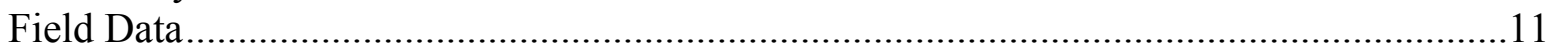

Challenges in Measurement and Today's Drug Testing Opportunities.....................................13

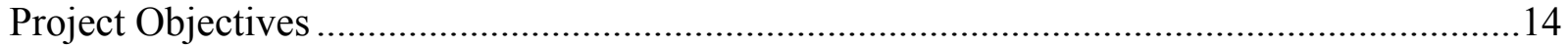

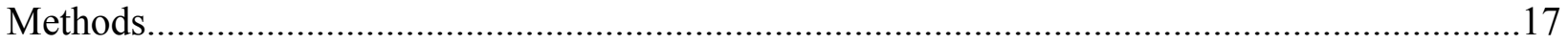

Survey Sampling Procedures ...................................................................................1

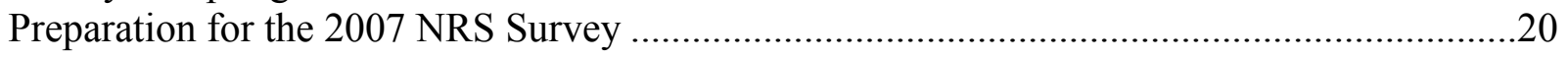

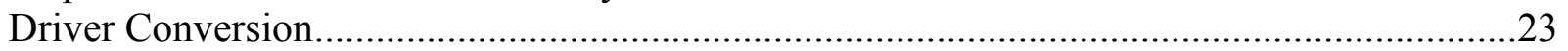

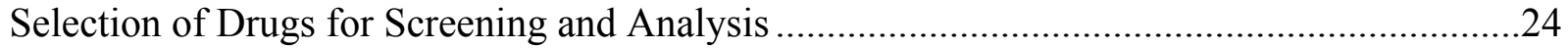

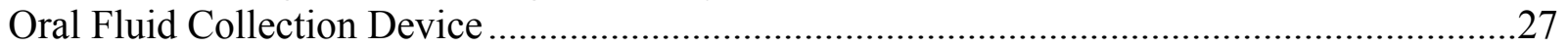

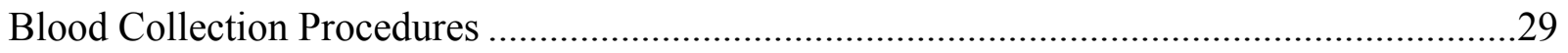

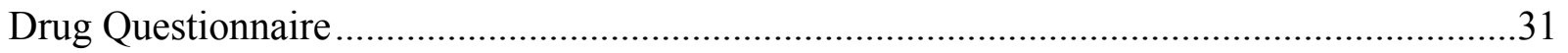

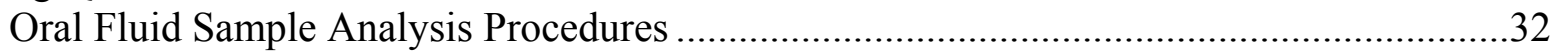

Gas Chromatography-Mass Spectrometry (GC/MS) ……….............................................

Liquid Chromatography-Tandem Mass Spectrometry (LC/MS-MS).....................................32

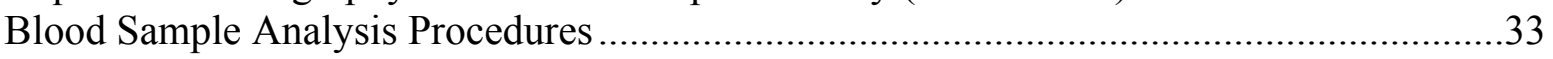

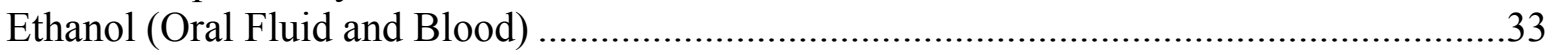

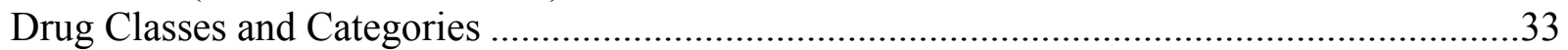

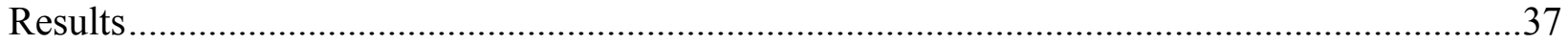

Oral Fluid Results (Daytime and Nighttime Samples) …….......................................................37

Driver Drug Use Prevalence Based on Oral Fluid Results .................................................. 37

Driver Drug Use Prevalence by Drug Class Based on Oral Fluid Results ............................44

Driver Drug Use Prevalence by Drug Category Based on Oral Fluid Results ......................48

Driver Drug Prevalence Based on Oral Fluid and BAC Results .........................................53

Drugs: Oral Fluid Results and Agreement With Self-Reported Drug Use...........................59

Observed Safety Measures of Daytime and Nighttime Drivers (Oral Fluid) .........................66

Reported Contact With the Criminal Justice System (Oral Fluid) ........................................66

Reported Contact With the Health System (Oral Fluid) .....................................................69

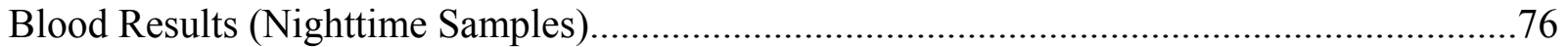

Driver Drug Use Prevalence Based on Blood Results..........................................................

Driver Drug Use Prevalence by Drug Class Based on Blood Results...................................8 80

Driver Drug Use Prevalence by Drug Category Based on Blood Results ..............................82

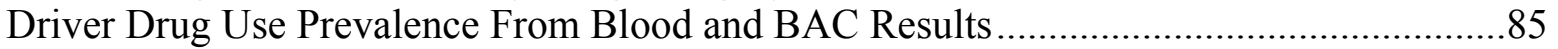

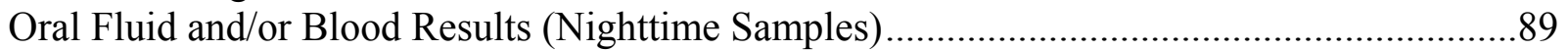

Driver Drug Use Prevalence Based on Oral Fluid and/or Blood Results ..............................89 
Driver Drug Use Prevalence by Drug Class Based on Oral Fluid and/or Blood Results ......94 Driver Drug Use Prevalence by Drug Category Based on Oral Fluid and/or Blood Results 96 Driver Drug Use Prevalence From Oral Fluid and/or Blood and BAC Results .....................98 Individual Drug Prevalence Estimates from Oral Fluid, and Oral Fluid and/or Blood

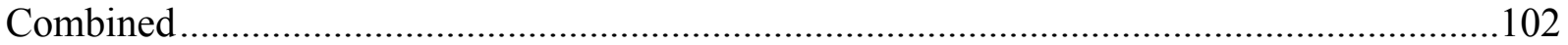

Overall Individual Drug Prevalence in Daytime and Nighttime ......................................103

Individual Drug Prevalence in Nighttime Oral Fluid and/or Blood ....................................105

Individual Drug Prevalence Sorted by Drug Type from Oral Fluid,

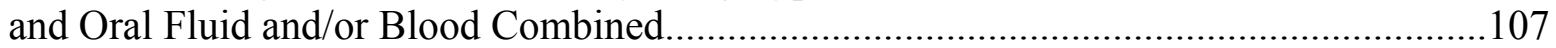

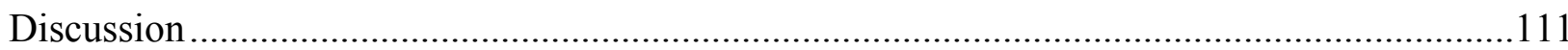

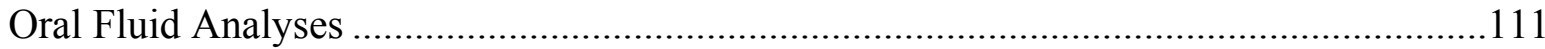

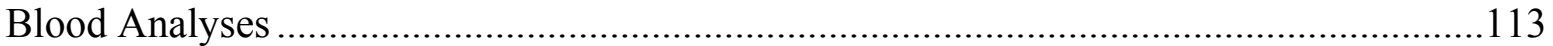

Oral Fluid and/or Blood Analyses Combined.............................................................114

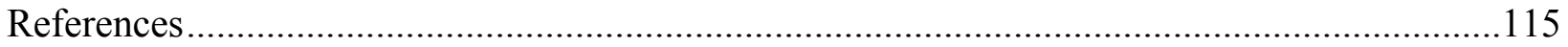

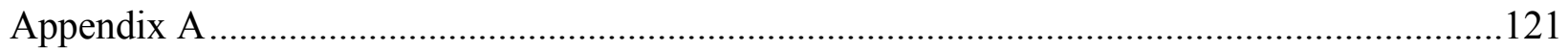

2007 National Roadside Survey Additional Tables........................................................122

\section{Tables}

Table 1. Participating Drivers (Percentages in Parentheses) .........................................................

Table 2. Drug Prevalence by Time of Day (Oral Fluid) ................................................................

Table 3. Drug Categories Distribution by Time of Day (Oral Fluid) .............................................

Table 4. BAC Among Drug-Positive Drivers by Drug Category and Time of Day (Oral Fluid) ...5

Table 5. Drug Classes by Time of Day and Region (Oral Fluid) …………...................................6

Table 6. Number and Distribution of Drug Classes by Time of Day (Oral Fluid) ..........................6

Table 7. Drug Categories Distribution (Blood) .......................................................................

Table 8. BAC Among Drug-Positive Drivers by Drug Category (Percentage by Row) (Blood)....7

Table 9. Comparison of Number of Nighttime Participants by Year in the National Roadside

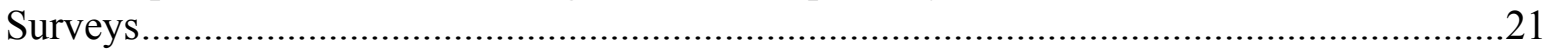

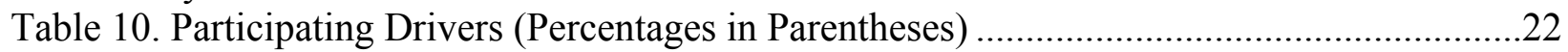

Table 11. Oral Fluid Analysis Results Among Converted Drivers ……………...........................23

Table 12. Blood Analysis Results Among Converted Drivers ...................................................23

Table 13. Selected Drugs and Minimum Detection Concentrations $\dagger$..........................................24

Table 14. Extraction Efficiency of Quantisal ${ }^{\mathrm{TM}}$ Oral Fluid Collection Device Over a Range of

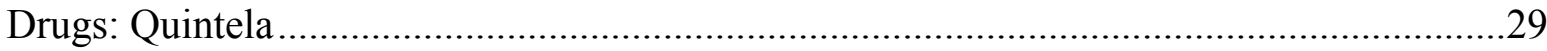

Table 15. Extraction Efficiency of Quantisal ${ }^{\mathrm{TM}}$ Oral Fluid Collection Device Over a Range of

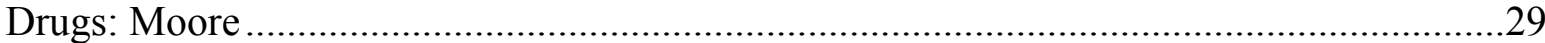

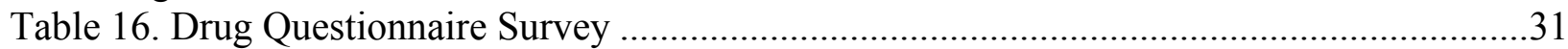

Table 17. Drug Class Composition — Oral Fluid and Blood Combined ........................................34

Table 18. Drug Category Composition — Oral Fluid and Blood Combined .....................................35

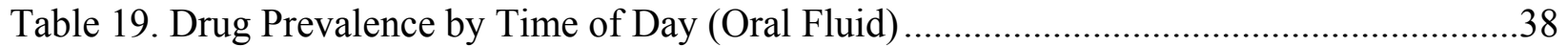

Table 20. Drug Prevalence by Time of Day/Session (Oral Fluid)...............................................38

Table 21. Drug Prevalence by Time of Day and Region (Oral Fluid).........................................39

Table 22. Drug Prevalence by Time of Day and Gender (Oral Fluid) ..........................................39

Table 23. Drug Prevalence by Time of Day and Age (Oral Fluid).............................................40

Table 24. Drug Prevalence by Time of Day, Age, and Gender (Oral Fluid) .................................41 
Table 25. Drug Prevalence by Race/Ethnicity (Oral Fluid)........................................................42

Table 26. Drug Prevalence by Education Level (Oral Fluid) ……...............................................42

Table 27. Drug Prevalence by Employment Status (Oral Fluid) ..................................................43

Table 28. Drug Prevalence by Vehicle Type (Oral Fluid) .............................................................4

Table 29. Number and Distribution of Drug Classes by Time of Day (Oral Fluid) .......................44

Table 30. Number and Distribution of Drug Classes by Time of Day (Drug Positives Only)

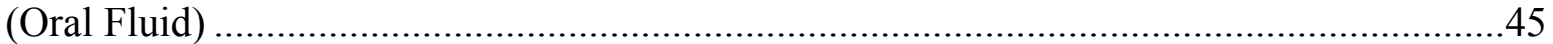

Table 31. Drug Classes by Time of Day and Region (Oral Fluid) ………..................................46

Table 32. Drug Classes Distribution by Time of Day and Gender (Oral Fluid) ...........................47

Table 33. Drug Class Distribution by Time of Day and Age (Oral Fluid) ....................................48

Table 34. Drug Categories Distribution by Time of Day (Oral Fluid) …………........................49

Table 35. Drug Categories Distribution by Time of Day and Region (Oral Fluid).......................50

Table 36. Drug Categories Distribution by Time of Day and Gender (Oral Fluid).......................51

Table 37. Drug Categories Distribution by Time of Day and Age (Oral Fluid)............................52

Table 38. Drug Prevalence by Time of Day and BAC (Percentages Calculated by Row)

(Oral Fluid)

Table 39. Drug Prevalence by Time of Day and BAC

(Percentages Calculated by Column) (Oral Fluid)..............................................................54

Table 40. BAC Among Drug-Positive Drivers by Time of Day and Age (Oral Fluid).................55

Table 41. BAC Among Drug-Positive Drivers by Number of Drug Classes and Time of Day

(Percentages Calculated by Column) (Oral Fluid)

Table 42. BAC Among Drug-Positive Drivers by Number of Drug Classes and Time of Day

(Percentages Calculated by Row) (Oral Fluid)....

Table 43. BAC Among Drug-Positive Drivers by Drug Category and Time of Day

(Oral Fluid)

Table 44. BAC of Drivers by Drug Category, Age, and Time of Day (Oral Fluid) .....................57

Table 45. BAC of Drivers by Drug Category, Gender, and Time of Day (Oral Fluid)..................58

Table 46. Oral Fluid Results and Agreement With Self-Reported by Drug Type (Oral Fluid) ....60

Table 47. Daytime: Seat Belt Observation By Drug Prevalence (Oral Fluid) ...............................62

Table 48. Nighttime: Seat Belt Observation by Drug Prevalence (Oral Fluid) ............................62

Table 49. Daytime: Seat Belt Observation by Drug Class (Percentages Calculated by Row)

(Oral Fluid)

Table 50. Nighttime: Seat Belt Observation by Drug Class (Percentages Calculated by Row)

(Oral Fluid)

Table 51. Daytime: Seat Belt Observation by Drug Category (Percentages Calculated by Row)

(Oral Fluid)

Table 52. Nighttime: Belt Observation by Drug Category (Percentages Calculated by Row)

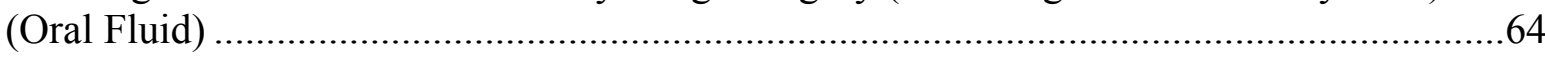

Table 53. Daytime: Helmet Use for Motorcycle Riders (Operators), by Drug Positive

(Oral Fluid)

Table 54. Nighttime: Helmet Use for Motorcycle Riders (Operators), by Drug Positive

(Oral Fluid)

Table 55. Daytime: Helmet Use for Motorcycle Riders (Operators), by Drug Class

(Oral Fluid)

Table 56. Nighttime: Helmet Use for Motorcycle Riders (Operators) by Drug Class

(Percentages Calculated by Row) (Oral Fluid)..... 
Table 57. Daytime: Helmet Use for Motorcycle Riders (Operators), by Drug Category (Oral Fluid)

Table 58. Nighttime: Helmet Use for Motorcycle Riders (Operators), by Drug Category (Percentages Calculated by Row) (Oral Fluid)....

Table 59. Arrests and Drug Positives, Daytime (Oral Fluid): "During the past 12 months, were you arrested and booked for driving under the influence of alcohol or drugs?"

Table 60. Arrests and Drug Positives, Nighttime (Oral Fluid): "During the past 12 months, were you arrested and booked for driving under the influence of alcohol or drugs?",

Table 61. Arrests and Drug Class, Daytime (Oral Fluid): "During the past 12 months, were you arrested and booked for driving under the influence of alcohol or drugs?"

Table 63. Arrests and Drug Categories, Daytime (Oral Fluid): "During the past 12 months, were you arrested and booked for driving under the influence of alcohol or drugs?"

Table 64. Arrests and Drug Categories, Nighttime (Oral Fluid): "During the past 12 months, were you arrested and booked for driving under the influence of alcohol or drug?"

Table 65. Past Treatment Program and Drug Positive, Daytime (Oral Fluid):

"During the past 12 months, did you ever stay at least overnight in an inpatient or residential drug or alcohol treatment program?"

Table 66. Past Treatment Program and Drug Positive, Nighttime (Oral Fluid):

"During the past 12 months, did you ever stay at least overnight in an inpatient or residential drug or alcohol treatment program?".

Table 67. Outpatient and Drug Positive, Daytime (Oral Fluid): "Have you ever been admitted to an outpatient drug or alcohol treatment program, NOT including meetings like AA or NA?"

Table 68. Outpatient and Drug Positive, Nighttime (Oral Fluid): "Have you ever been admitted to an outpatient drug or alcohol treatment program, NOT including meetings like AA or NA?"

Table 69. AA or NA and Drug Positives, Daytime (Oral Fluid): "During the past 12 months, have you received treatment for your drug or alcohol use in a self-help group such as Alcoholics Anonymous or Narcotics Anonymous?"

Table 70. AA or NA and Drug Positives, Nighttime (Oral Fluid): "During the past 12 months, have you received treatment for your drug or alcohol use in a self-help group such as Alcoholics Anonymous of Narcotics Anonymous?".

Table 71. Inpatient and Drug Class, Daytime (Oral Fluid): "During the past 12 months, did you ever stay at least overnight in an impatient or residential drug or alcohol treatment program, for example, detox, rehab, a therapeutic community, or a hospital?" ....71

Table 72. Inpatient and Drug Class, Nighttime (Oral Fluid): "During the past 12 months, did you ever stay at least overnight in an impatient or residential drug or alcohol treatment program, for example, detox, rehab, a therapeutic community, or a hospital?"....72

Table 73. Inpatients and Drug Category, Daytime (Oral Fluid): "During the past 12 months, were you arrested and booked for driving under the influence of alcohol or drugs?"...........72

Table 74. Inpatients and Drug Category, Nighttime (Oral Fluid): "During the past 12 months, were you arrested and booked for driving under the influence of alcohol or drugs?"... .72

Table 75. Outpatient and Drug Class, Daytime (Oral Fluid): "Have you ever been admitted to an outpatient drug or alcohol treatment program, NOT including meetings like AA or NA?" 
Table 76. Outpatient and Drug Class, Nighttime (Oral Fluid): "Have you ever been admitted to an outpatient drug or alcohol treatment program, NOT including meetings like AA or NA?"

Table 77. Outpatient and Categories, Daytime (Oral Fluid): "Have you ever been admitted to an outpatient drug or alcohol treatment program, NOT including meetings like AA or NA?".74

Table 78. Outpatient and Categories, Nighttime (Oral Fluid): "Have you ever been admitted to an outpatient drug or alcohol treatment program, NOT including meetings like AA or NA?".74

Table 79. AA, NA and Classes, Daytime (Oral Fluid): "During the past 12 months, have you received treatment for your drug or alcohol use in a self-help group such as AA or NA?"..74

Table 80. AA, NA and Classes, Nighttime (Oral Fluid): "During the past 12 months, have you received treatment for your drug or alcohol use in a self-help group such as AA or NA?"..75

Table 81. NA, AA and Drug Categories, Daytime (Oral Fluid): "During the past 12 months, have you received treatment for your drug or alcohol use in a self-help group such as AA or NA?"

Table 82. NA, AA and Drug Categories, Nighttime (Oral Fluid): "During the past 12 months, have you received treatment for your drug or alcohol use in a self-help group such as AA or NA?" .76

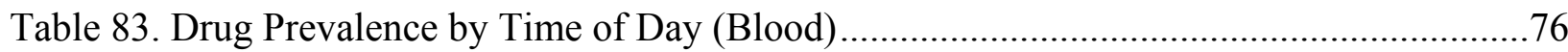

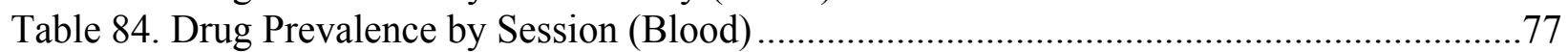

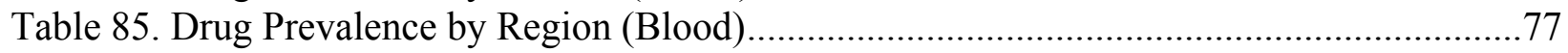

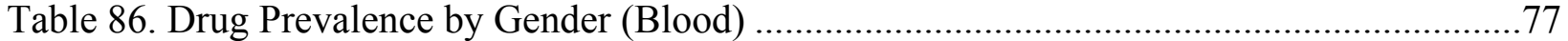

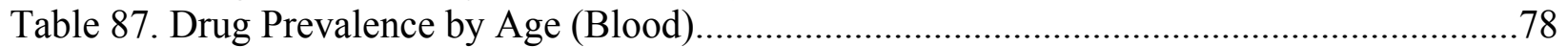

Table 88. Drug Prevalence by Age and Gender (Blood) ........................................................78

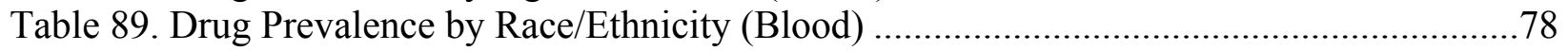

Table 90. Drug Prevalence by Education Level (Blood) ............................................................79

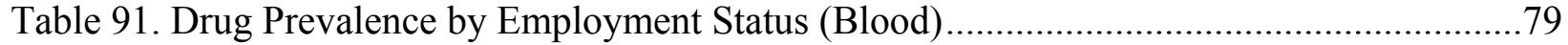

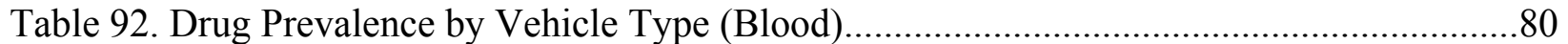

Table 93. Number and Distribution of Drug Classes (Blood) ...................................................80

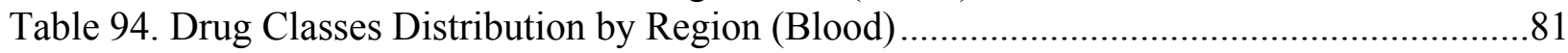

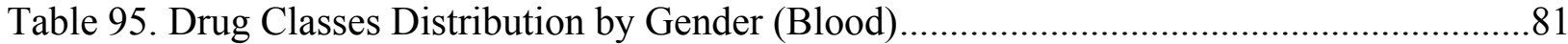

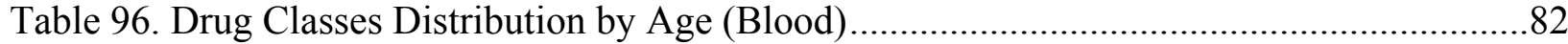

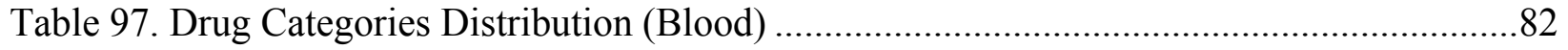

Table 98. Drug Categories Distribution by Region (Blood) ....................................................83

Table 99. Drug Categories Distribution by Gender (Blood).....................................................84

Table 100. Drug Categories Distribution by Age (Blood).....................................................85

Table 101. Drug Prevalence by BAC (Percentages Calculated by Row) (Blood).......................86

Table 102. Drug Prevalence by BAC (Percentages Calculated by Column) (Blood) ..................86

Table 103. BAC Among Drug-Positive Drivers by Age (Blood)...............................................86

Table 104. BAC Among Drug-Positive Drivers by Number of Drug Classes

(Percentages Calculated by Column) (Blood) ..................................................................8

Table 105. BAC Among Drug-Positive Drivers by Number of Drug Classes

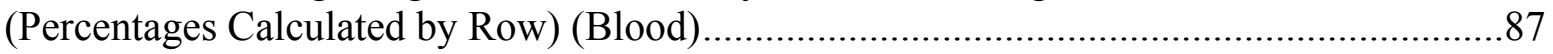

Table 106. BAC Among Drug-Positive Drivers by Drug Category

(Percentage by Row) (Blood)

Table 107. BAC Among Drug-Positive Drivers by Drug Category

(Percentage by Column) (Blood). 
Table 108. BAC of Drivers by Drug Category and Age (Blood) .................................................8

Table 109. BAC of Drivers by Drug Category and Gender (Blood) ............................................89

Table 110. Nighttime Drug Prevalence by Time of Day (Oral Fluid and/or Blood).....................90

Table 111. Drug Prevalence by Session (Oral Fluid and/or Blood) ………..................................90

Table 112. Drug Prevalence by Region (Oral Fluid and/or Blood) ...............................................90

Table 113. Drug Prevalence by Gender (Oral Fluid and/or Blood).............................................91

Table 114. Drug Prevalence by Age (Oral Fluid and/or Blood) ...................................................91

Table 115. Drug Prevalence by Age and Gender (Oral Fluid and/or Blood) ……........................92

Table 116. Drug Prevalence by Race/Ethnicity (Oral Fluid and/or Blood)...................................92

Table 117. Drug Prevalence by Education Level (Oral Fluid and/or Blood) ................................93

Table 118. Drug Prevalence by Employment Status (Oral Fluid and/or Blood) ............................93

Table 119. Drug Prevalence by Vehicle Type (Oral Fluid and/or Blood)....................................93

Table 120. Number and Distribution of Drug Classes (Oral Fluid and/or Blood) .........................94

Table 121. Number and Distribution of Drug Classes (Drug Positives Only)

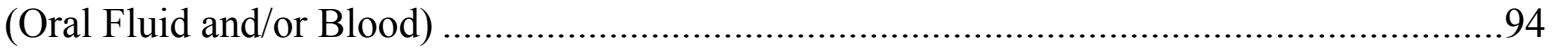

Table 122. Drug Classes Distribution by Region (Oral Fluid and/or Blood) ...............................95

Table 123. Drug Classes Distribution by Gender (Oral Fluid and/or Blood) ................................95

Table 124. Drug Classes Distribution by Age (Oral Fluid and/or Blood) .....................................96

Table 125. Drug Categories Distribution (Oral Fluid and/or Blood)............................................96

Table 126. Drug Categories Distribution by Region (Oral Fluid and/or Blood) ............................97

Table 127. Drug Categories by Gender (Oral Fluid and/or Blood) ..............................................97

Table 128. Drug Categories Distribution by Age (Oral Fluid and/or Blood) ................................98

Table 129. Drug Prevalence by BAC (Percentages Calculated by Row)

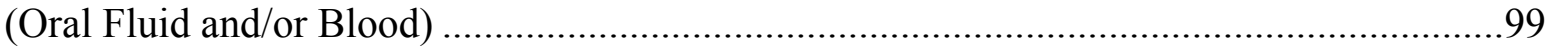

Table 130. Drug Prevalence by BAC (Percentages Calculated by Column)

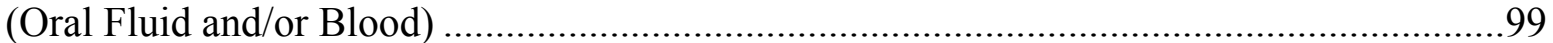

Table 131. BAC Among Drug-Positive Drivers by Age (Oral Fluid and/or Blood) .....................99

Table 132. BAC Among Drug-Positive Drivers by Number of Drug Classes

(Percentages Calculated by Column) (Oral Fluid and/or Blood)........................................100

Table 133. BAC Among Drug-Positive Drivers by Number of Drug Classes

(Percentages Calculated by Row) (Oral Fluid and/or Blood)...

Table 134. BAC Among Drug-Positive Drivers by Drug Category

(Oral Fluid and/or Blood)

Table 135. BAC of Drivers by Drug Category and Age (Oral Fluid and/or Blood) ....................101

Table 136. BAC of Drivers by Drug Category and Gender (Oral Fluid and/or Blood) ...............102

Table 137. Prevalence of Drugs in Daytime and Nighttime Drivers (Oral Fluid).......................104

Table 138. Prevalence of Drugs in All Drug-Tested Nighttime Drivers

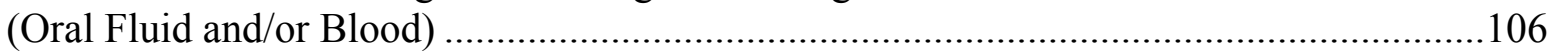

Table 139. Prevalence of Drugs in Daytime and Nighttime Drivers (Oral Fluid).......................108

Table 140. Prevalence of Drugs in All Drug-Tested Nighttime Drivers

(Oral Fluid and/or Blood)

Table 141. Nighttime: Blood Results and Agreement With Self-Reported by

Drug Type (Blood).

Table 142. Nighttime: Seat Belt Observation by Drug Prevalence (Blood) .................................125

Table 143. Nighttime: Seat Belt Observation by Drug Class

(Percentages Calculated by Row) (Blood). 
Table 144. Nighttime: Seat Belt Observation by Drug Category (Blood)................................126

Table 145. Nighttime: Helmet Use for Motorcycle Riders (Operators), by Drug Positive (Blood)

Table 146. Nighttime: Helmet Use for Motorcycle Riders (Operators), by Drug Class (Percentages Calculated by Row) (Blood)....

Table 147. Nighttime: Helmet Use for Motorcycle Riders (Operators), by Drug Category (Percentages Calculated by Row) (Blood).....

Table 148. Nighttime: Arrests and Drug Positives (Blood): "During the past 12 months, were you arrested and booked for driving under the influence of alcohol or drugs?".

Table 149. Nighttime: Arrests and Drug Class (Blood): "During the past 12 months, were you arrested and booked for driving under the influence of alcohol or drugs?".

Table 150. Nighttime: Arrests and Drug Categories (Blood): "During the past 12 months, were you arrested and booked for driving under the influence of alcohol or drugs?"......

Table 151. Nighttime: Past Treatment Program and Drug Positive (Blood):

"During the past 12 months, did you ever stay at least overnight in an inpatient or residential drug or alcohol treatment program?"

Table 152. Nighttime: Inpatient and Drug Class (Blood): "During the past 12 months, did you ever stay at least overnight in an impatient or residential drug or alcohol treatment program, for example, detox, rehab, a therapeutic community, or a hospital?"..128

Table 153. Nighttime: Inpatient and Drug Category (Blood): "During the past 12 months, did you ever stay at least overnight in an impatient or residential drug or alcohol treatment program, for example, detox, rehab, a therapeutic community, or a hospital?"..128

Table 154. Nighttime: Outpatient and Drug Positive (Blood): "Have you ever been admitted to an outpatient drug or alcohol treatment program, NOT including meetings like AA or NA?"

Table 155. Nighttime: Outpatient and Drug Class (Blood): "Have you ever been admitted to an outpatient drug or alcohol treatment program, NOT including meetings like AA or NA?"

Table 156. Nighttime: Outpatient and Categories (Blood): "Have you ever been admitted to an outpatient drug or alcohol treatment program, NOT including meetings like AA or NA?"

Table 157. Nighttime: AA or NA, and Drug Positives (Blood): "During the past 12 months, have you received treatment for your drug or alcohol use in a self-help group such as AA or NA?"

Table 158. Nighttime: AA or NA, and Class (Blood): "During the past 12 months, have you received treatment for your drug or alcohol use in a self-help group such as AA or NA?"

Table 159. Nighttime: AA or NA, and Drug Categories (Blood): "During the past 12 months, have you received treatment for your drug or alcohol use in a self-help group such as AA or NA?"

\section{Figures}

Figure 1. Map of Sixty 2007 National Roadside Survey Sites ...............................................19

Figure 2. Collecting an Oral Fluid Sample with the Quantisal ${ }^{\mathrm{TM}}$ Oral Fluid Collection Device ..28 


\section{Executive Summary}

This report presents the first U.S. national prevalence estimate of drug-involved driving. It is based on the results of analyses of oral fluid, blood, and breath specimens collected during the 2007 National Roadside Survey of Alcohol and Drug Use by Drivers. It is one of the three reports that summarize the results of a 2007 study conducted by the Pacific Institute for Research and Evaluation (PIRE) for the National Highway Traffic Safety Administration (NHTSA) under Contract DTNH22-06-C-00040, "2007 Roadside Survey of Alcohol and Drugged Driving." There are two prior reports on the 2007 National Roadside Survey (NRS): (1) "2007 National Roadside Survey of Alcohol and Drug Use by Drivers: Methodology" (Lacey, Kelley-Baker, Furr-Holden, Voas, Moore, Brainard, Tippetts, Romano, Torres, \& Berning, 2009a) which describes the sampling plan and data collection methodology, and summarizes the response patterns to the various stages of the multi-part survey; and (2) "2007 National Roadside Survey of Alcohol and Drug Use by Drivers: Alcohol Results" (Lacey, Kelley-Baker, Furr-Holden, Voas, Romano, Tippetts, Ramirez, Brainard, \& Berning, 2009b) which presents the prevalence estimates for alcohol-involved driving derived from the study, and compares those estimates with data from the three previous National Roadside Surveys.

\section{Methodology}

Three prior national roadside surveys of drivers to estimate prevalence of drinking and driving and determine changes over time have been conducted in the United States. These surveys, which included a brief interview and a breath sample to determine blood alcohol concentration (BAC), were conducted on a stratified random sample of weekend nighttime drivers in the 48 contiguous States. The first National Roadside Survey (NRS), sponsored by NHTSA, was conducted in 1973 (Wolfe, 1974). The second NRS was sponsored by the Insurance Institute for Highway Safety (IIHS) and conducted in 1986 (Lund \& Wolfe, 1991), and the third, jointly funded by IIHS and NHTSA, was conducted in 1996 (Voas, Wells, Lestina, Williams, \& Greene, 1998). NHTSA sponsored the 2007 NRS described in this report, with additional funding from the National Institute on Alcohol Abuse and Alcoholism (NIAAA), the National Institute on Drug Abuse (NIDA), and the National Institute of Justice (NIJ). Like its predecessors, the 2007 NRS covered the 48 contiguous States.

As in previous NRS studies, the 2007 NRS data were collected during the following periods on both Friday and Saturday nights: 10 p.m. to midnight and 1 a.m. to 3 a.m. ${ }^{1}$ In addition, the 2007 survey also included a Friday daytime data collection period either from 9:30 a.m. to 11:30 a.m. or from 1:30 p.m. to 3:30 p.m. The prior three surveys did not include commercial vehicles and motorcycles in the sample; this survey, however, included motorcycles. In addition to a daytime survey and the inclusion of motorcycles, the 2007 NRS included other features that the prior surveys did not: (1) more data collectors per survey site to achieve a larger sample size; (2) the collection of biological samples (oral fluid and blood) to determine the presence of drugs other than alcohol in the driving population; (3) a questionnaire to allow an estimation of alcohol use disorders (AUDs) among drinking drivers; (4) a questionnaire to study drivers' patterns of drug

\footnotetext{
${ }^{1}$ In this report, a "Friday night" or a "Saturday night" includes the early hours of the following day.
} 
consumption; (5) questions about interaction with the criminal justice system and the treatment system; and (6) collection of information on passengers.

In all four NRS studies, police officers directed vehicles to a safe location, where an interviewer approached the driver and requested participation in a survey followed by a breath test. Random selection of drivers was insured by selecting the next vehicle when an interviewer became available. Any driver suspected of impairment was subjected to a safety protocol designed to dissuade his/her continued driving on that trip. See the Methodology Report for details (Lacey et al., 2009a).

As noted above, the original 1973 survey used a four-stage sampling plan, and the 1986 NRS attempted to replicate the 1973 locations. In the 1996 and 2007 surveys, the first stage was taken from the NHTSA's National Automotive Sampling System/Crashworthiness Data System (NASS/CDS, 1995). The second stage involved the selection of police jurisdictions within the NASS/CDS primary sampling units. The third stage of the sampling design involved the selection of survey sites within police jurisdictions, and the fourth stage consisted of selecting drivers at random from the traffic flow at these sites. Details regarding the sampling plan can be found in the Methodology Report (Lacey et al., 2009a).

New to the 2007 survey was the collection of additional types of biological samples (oral fluid and blood) to determine the presence of drugs other than alcohol in the driving population. Oral fluid and blood samples were analyzed in a laboratory using enzyme-linked immunosorbent assay (ELISA) screening, followed by a confirmatory analysis by Liquid ChromatographyTandem Mass Spectrometry (LC/MS-MS) or Gas Chromatography/Mass Spectrometry (GC/MS). This 2007 NRS is more extensive than any previous NRS study and provides a much broader perspective on alcohol and drug use in the driving population than previously available. These data are essential to developing more precise estimates of the presence of alcohol and other drugs in drivers, and in measuring the prevalence of alcohol- and drug-involved driving.

This report summarizes the drug-involved driving prevalence estimates obtained through analyses of oral fluid and blood specimen results, and combined with alcohol using breath alcohol measurements. It should be emphasized that prevalence estimates do not necessarily imply "impairment," but rather, in this case, the presence of drugs and alcohol in the driver population. For many drug types, drug presence can be detected long after any impairment that might affect driving has passed. ${ }^{2}$ Other studies are required to assess whether that presence implies an increased risk of crash involvement. In this study, we developed driver-prevalence estimates for illegal, prescription, and over-the-counter drugs which were determined by a panel of experts to possibly cause impairment. It should be noted that prescription and over-the-counter drugs can be used according to medical advice or extra-medicinally. Again, the prevalence estimates indicate the presence of the drugs in drivers but do not necessarily indicate that the drivers were impaired. Alcohol presence above the legal limit implies impairment; alcohol below the legal limit may not imply impairment.

\footnotetext{
${ }^{2}$ For example, traces of metabolites of marijuana can be detected in blood samples several days after chronic users stop ingestion. Also, whereas the impairment effects for various concentration levels of alcohol is well understood, little evidence is available to link concentrations of other drug types to driver performance.
} 
As discussed earlier, we gathered data from drivers on U.S. roadways during Friday daytime hours, and Friday nights and Saturday nights. As indicated in Table 1, we obtained oral fluid samples from drivers in each of those data collection periods $(1,850$ during daytime and 5,869 during nighttime). We also collected blood samples during the nighttime data collection periods $(3,276)$.

Table 1. Participating Drivers (Percentages in Parentheses)

\begin{tabular}{|c|c|c|c|}
\hline & \multicolumn{3}{|c|}{2007} \\
\hline & Daytime & Nighttime & Total \\
\hline Signaled to enter site & 3,516 & 9,553 & 13,069 \\
\hline Did not enter site & 933 & 1,016 & 1,949 \\
\hline Entered site & 2,583 & 8,537 & 11,120 \\
\hline Eligible & 2,525 & 8,384 & 10,909 \\
\hline Entered site and interviewed & $2,174(86.1 \%)^{\dagger}$ & $6,920(82.5 \%)^{\dagger}$ & $9,094(83.4 \%)^{\dagger}$ \\
\hline Valid breath sample & $2,254(89.3 \%)^{\dagger}$ & $7,159(85.4 \%)^{\dagger}$ & $9,413(86.3 \%){ }^{\dagger}$ \\
\hline Oral Fluid sample & $1,850(73.3 \%)^{\dagger}$ & $5,869(70.0 \%)^{\dagger}$ & $7,719(70.7 \%)^{\dagger}$ \\
\hline Blood sample & NA & $3,276(39.1 \%)^{\dagger}$ & NA \\
\hline AUD \&/or Drug Questionnaire & $1,889(75.2 \%){ }^{\dagger}$ & $5,983(71.4 \%)^{\dagger}$ & $7,882(72.2 \%){ }^{\dagger}$ \\
\hline
\end{tabular}

\section{Results}

In this study, analyses of the oral fluid and blood samples were conducted to identify the presence of some 75 drugs and metabolites, including illegal, prescription, and over-the-counter drugs.

Comparison of overall drug prevalence by time of day (Table 2) indicates that 11 percent of drivers in the daytime sample were drug-positive. This level was significantly lower than the 14.4 percent of nighttime drivers who tested positive for drugs $(p<.01) .^{3}$

Table 2. Drug Prevalence by Time of Day (Oral Fluid)

\begin{tabular}{lcc}
\hline \multicolumn{1}{c}{ Time of Day } & $\begin{array}{c}\mathbf{N} \\
\text { (Unweighted) }\end{array}$ & $\begin{array}{c}\text { \% Drug Positive } \\
\text { (Weighted) }\end{array}$ \\
\hline Daytime & 1,850 & $11.0 \%$ \\
Nighttime & 5,869 & $14.4 \%$ \\
\hline
\end{tabular}

To make the presentation of results most useful, we identified three broad categories of drugs: illegal, prescription, and over-the-counter. Because few over-the-counter drugs were found, the prescription and over-the-counter drugs were combined for many analyses and labeled

${ }^{3} p<.01$ indicates that under the null hypothesis, the probability of encountering this difference by chance is less than 1 percent; $p<.05$ indicates that the probability of encountering this difference by chance is less than 5 percent. 
"Medications." Additionally, some respondents tested positive for more than one category of drug. Thus, tables presenting drug categories present four mutually exclusive categories: Illegal; Medications; Illegal and Medications; and Negative. So as not to double count individual positive results, an individual's result appears in only one of these categories. However, for example in Table 3, to determine the proportion of daytime drivers who tested positive for illegal drugs, one could sum the daytime values for the "Illegal" category $(5.8 \%)$ and for the "Illegal \& Medications" category ( $0.5 \%)$ to arrive at a prevalence estimate of $6.3 \%$ of daytime drivers who were positive for at least one illegal drug. Detailed summaries of prevalence estimates for individual drugs appear in Tables 137-140 later in the report. As indicated in Table 3, comparison of drug categories by time of day revealed that, based on oral fluid analyses, almost 6 percent of daytime drivers tested positive for drugs in the "Illegal" category (primarily marijuana and cocaine), as opposed to over 10 percent of nighttime drivers. There was a statistically significant difference between daytime and nighttime drivers $(p<.01)$.

Table 3. Drug Categories Distribution by Time of Day (Oral Fluid)

\begin{tabular}{l|lcr}
\hline \multirow{2}{*}{ Time of Day } & Drug Category & $\begin{array}{c}\text { N } \\
\text { (Unweighted) }\end{array}$ & $\begin{array}{c}\% \\
\text { (Weighted) }\end{array}$ \\
\hline \multirow{5}{*}{ Daytime } & Illegal & 125 & $5.8 \%$ \\
& Medications & 107 & $4.8 \%$ \\
& Illegal \& Medications & 14 & $0.5 \%$ \\
& Negative & 1,604 & $89.0 \%$ \\
& Overall Daytime & 1,850 & $100.0 \%$ \\
\hline \multirow{5}{*}{ Nighttime } & Illegal & 575 & $10.5 \%$ \\
& Medications & 201 & $3.0 \%$ \\
& Illegal \& Medications & 60 & $0.9 \%$ \\
& Negative & 5,033 & $85.6 \%$ \\
& Overall Nighttime & 5,869 & $100.0 \%$ \\
\hline
\end{tabular}

"Medications" includes prescription and over-the-counter drugs.

Positive results in the "Medications" category, though not statistically significant, were found to be slightly higher among the daytime drivers (almost 5\%) than nighttime drivers (3\%). Additionally, some drivers tested positive for both "Illegal drugs and Medications" $(0.5 \%$ of daytime drivers and $0.9 \%$ of nighttime drivers). This indicates that drugs were not detected in 89.0 percent of daytime drivers and 85.6 percent of nighttime drivers.

When oral fluid drug category findings were combined with BAC results we found that, in both the daytime and nighttime samples, the drug-positive drivers who were also alcohol-positive were more likely to be positive for "Illegal" drugs than "Medications" (Table 4). This was particularly true in the nighttime sample, in which 17.3 percent of drivers in the illegal category had BACs between zero and .08 grams per deciliter (g/dL) (compared to 6.3\% in the "Medications" category) and 5.7 percent had BACs greater than .08 (compared to $1.2 \%$ in the "Medications" category) $(p<.01)$. In the daytime sample, however, the differences were statistically non-significant ( $p$ value $=.05$ ). 
Table 4. BAC Among Drug-Positive Drivers by Drug Category and Time of Day (Oral Fluid)

\begin{tabular}{c|l|c|ccc}
\hline \multirow{2}{*}{$\begin{array}{c}\text { Time of } \\
\text { Day }\end{array}$} & Drug Category & N & \multicolumn{3}{|c}{ BAC (g/dL) } \\
\cline { 3 - 5 } Daytime & (Unweighted) & Zero & $\begin{array}{c}\text { Between } \\
\text { Zero and .08 }\end{array}$ & $.08+$ \\
\hline \multirow{3}{*}{ Nighttime } & Illegal & 125 & $97.1 \%$ & $2.3 \%$ & $0.6 \%$ \\
& Medications & 107 & $99.6 \%$ & $0.4 \%$ & $0.0 \%$ \\
& Illegal \& Medications & 14 & $98.3 \%$ & $1.7 \%$ & $0.0 \%$ \\
& Negative & 1,604 & $99.2 \%$ & $0.6 \%$ & $0.2 \%$ \\
\hline & Illegal & 575 & $77.0 \%$ & $17.3 \%$ & $5.7 \%$ \\
& Medications & 199 & $92.5 \%$ & $6.3 \%$ & $1.2 \%$ \\
& Illegal \& Medications & 60 & $81.4 \%$ & $17.7 \%$ & $0.9 \%$ \\
& Negative & 5,033 & $90.2 \%$ & $8.1 \%$ & $1.7 \%$ \\
\hline
\end{tabular}

"Medications" includes prescription and over-the-counter drugs.

In this table, percentages are weighted.

In addition to the three drug categories, we also examined drug class (Table 5). The drug classes were antidepressants, marijuana, narcotic-analgesics, sedatives, stimulants, and other, plus a "more than one drug" class. To avoid double counting individual positive results, the classes were mutually exclusive. Thus, for example, since marijuana is both a class by itself and could appear in the "More than 1 class" cell as well (as could other classes of drugs) from this table one cannot arrive at an overall prevalence estimate for marijuana alone. However, detailed summaries of prevalence estimates for individual drugs appear in Tables 137-140 later in the report. In comparing prevalence of drug classes by time and region, ${ }^{4}$ we found that marijuana was generally the most common drug class across all the regions both in daytime $(3.9 \%)$ and nighttime (6.1\%) samples. Among the nighttime sample, drivers in the Midwest and Northeast regions were more likely to test positive for marijuana than daytime drivers $(p<.05)$. In the South and West regions, however, there was little difference between daytime and nighttime drivers with respect to marijuana. For stimulants, a higher percentage of nighttime drivers in all regions tested positive than did daytime drivers. However, the difference was statistically significant only in the Midwest $(p<.01)$ and West $(p<.05)$.

When one examines the "All" column of Table 5, one finds that, overall, sedatives were found in 1.6 percent of daytime drivers and in 0.6 percent of nighttime drivers. Stimulants were found in 1.6 percent of daytime drivers and in 3.2 percent of nighttime drivers.

\footnotetext{
${ }^{4}$ Regions are defined by the NASS/GES system according to U.S. Census Regions (Midwest includes the West North Central and East North Central States, Northeast includes New England and Middle Atlantic States, South includes the West South Central, East South Central, and South Atlantic States, and West includes West and Mountain States.
} 
Table 5. Drug Classes by Time of Day and Region (Oral Fluid)

\begin{tabular}{|c|c|c|c|c|c|c|}
\hline $\begin{array}{c}\text { Time of } \\
\text { Day }\end{array}$ & Drug Class & $\begin{array}{c}\text { Midwest } \\
\% \\
\end{array}$ & $\begin{array}{c}\text { Northeast } \\
\% \\
\end{array}$ & $\begin{array}{c}\text { South } \\
\%\end{array}$ & $\begin{array}{c}\text { West } \\
\%\end{array}$ & $\begin{array}{l}\text { All } \\
\%\end{array}$ \\
\hline \multirow{10}{*}{ Daytime } & & $N=546$ & $N=379$ & $\mathrm{~N}=472$ & $N=453$ & $N=1,850$ \\
\hline & Antidepressants & $0.4 \%$ & $0.6 \%$ & $0.5 \%$ & $0.5 \%$ & $0.5 \%$ \\
\hline & Marijuana & $3.4 \%$ & $3.0 \%$ & $5.5 \%$ & $4.0 \%$ & $3.9 \%$ \\
\hline & Narcotic-Analgesics & $2.7 \%$ & $2.1 \%$ & $1.3 \%$ & $0.6 \%$ & $1.6 \%$ \\
\hline & Sedatives & $1.9 \%$ & $2.6 \%$ & $2.1 \%$ & $0.7 \%$ & $1.6 \%$ \\
\hline & Stimulants & $0.8 \%$ & $1.7 \%$ & $2.2 \%$ & $2.0 \%$ & $1.6 \%$ \\
\hline & Other & $0.0 \%$ & $1.3 \%$ & $0.0 \%$ & $0.0 \%$ & $0.2 \%$ \\
\hline & More than 1 Class & $2.2 \%$ & $1.0 \%$ & $1.4 \%$ & $1.2 \%$ & $1.5 \%$ \\
\hline & Overall Drug Positive Daytime & $11.5 \%$ & $12.5 \%$ & $13.1 \%$ & $8.9 \%$ & $11.0 \%$ \\
\hline & Negative & $88.5 \%$ & $87.5 \%$ & $86.9 \%$ & $91.1 \%$ & $89.0 \%$ \\
\hline \multirow{10}{*}{ Nighttime } & & $\mathrm{N}=1,694$ & $N=1,111$ & $\mathrm{~N}=1,559$ & $\mathrm{~N}=1,505$ & $N=5,869$ \\
\hline & Antidepressants & $0.5 \%$ & $0.2 \%$ & $0.0 \%$ & $0.1 \%$ & $0.2 \%$ \\
\hline & Marijuana & $7.7 \%$ & $7.6 \%$ & $6.3 \%$ & $4.1 \%$ & $6.1 \%$ \\
\hline & Narcotic-Analgesics & $1.0 \%$ & $2.8 \%$ & $1.2 \%$ & $1.8 \%$ & $1.6 \%$ \\
\hline & Sedatives & $1.1 \%$ & $0.2 \%$ & $0.7 \%$ & $0.4 \%$ & $0.6 \%$ \\
\hline & Stimulants & $3.0 \%$ & $2.3 \%$ & $2.7 \%$ & $4.0 \%$ & $3.2 \%$ \\
\hline & Other & $0.2 \%$ & $0.0 \%$ & $0.1 \%$ & $0.5 \%$ & $0.3 \%$ \\
\hline & More than 1 Class & $1.6 \%$ & $4.1 \%$ & $2.9 \%$ & $2.0 \%$ & $2.3 \%$ \\
\hline & Overall Drug Positive Nighttime & $15.0 \%$ & $17.3 \%$ & $14.0 \%$ & $12.9 \%$ & $14.4 \%$ \\
\hline & Negative & $85.0 \%$ & $82.7 \%$ & $86.0 \%$ & $87.1 \%$ & $85.6 \%$ \\
\hline
\end{tabular}

In this table, percentages are weighted.

"More than 1 Class" - Drivers testing positive for more than one drug class are counted only in this category.

Further, as indicated in Table 6, comparison of number of drug classes by time of day indicated that nighttime drivers $(2.3 \%)$ were significantly more likely to test positive for more than one drug class than daytime drivers $(1.5 \%)(p<.01)$.

Table 6. Number and Distribution of Drug Classes by Time of Day (Oral Fluid)

\begin{tabular}{l|ccc}
\hline \multirow{2}{*}{ Time of Day } & $\begin{array}{c}\text { Number of } \\
\text { Drug Classes }\end{array}$ & $\begin{array}{c}\text { N } \\
\text { (Unweighted) }\end{array}$ & $\begin{array}{c}\text { \% } \\
\text { (Weighted) }\end{array}$ \\
\hline \multirow{4}{*}{ Daytime } & 1 & 206 & $9.5 \%$ \\
& $2+$ & 40 & $1.5 \%$ \\
& Negative & 1,604 & $89.0 \%$ \\
& Overall Daytime & 1,850 & $100.0 \%$ \\
\hline \multirow{3}{*}{ Nighttime } & 1 & 680 & $12.1 \%$ \\
& $2+$ & 156 & $2.3 \%$ \\
& Negative & 5,033 & $85.6 \%$ \\
& Overall Nighttime & 5,869 & $100.0 \%$ \\
\hline
\end{tabular}


As mentioned earlier, 3,276 blood samples were obtained from nighttime drivers. As expected, the results of the blood analyses were quite close to those obtained by the nighttime driver oral fluid analyses. For example (Table 7), among nighttime drivers, 9.1 percent tested positive for "Illegal" drugs, 4 percent for "Medications," and 0.7 percent for the combination of both "Illegal and Medications."

Table 7. Drug Categories Distribution (Blood)

\begin{tabular}{lcc}
\hline \multicolumn{1}{c}{ Drug Category } & $\begin{array}{c}\text { N } \\
\text { (Unweighted) }\end{array}$ & $\begin{array}{c}\text { \% } \\
\text { (Weighted) }\end{array}$ \\
\hline Illegal & 267 & $9.1 \%$ \\
Medications & 169 & $4.0 \%$ \\
Illegal \& Medications & 30 & $0.7 \%$ \\
Negative & 2,810 & $86.2 \%$ \\
Overall & 3,276 & $100.0 \%$ \\
\hline "Medications" includes prescription and over-the-counter drugs.
\end{tabular}

Additionally, as indicated in Table 8, 28.3 percent of nighttime drivers testing positive for "Illegal" drugs in blood also tested positive for alcohol, as did 6.4 percent of drivers who tested positive for "Medications" and 23.2 percent of those testing positive for both "Illegal drugs and Medications."

Table 8. BAC Among Drug-Positive Drivers by Drug Category (Percentage by Row) (Blood)

\begin{tabular}{l|c|ccc}
\hline & & \multicolumn{3}{|c}{ BAC (g/dL) } \\
\cline { 3 - 5 } \multicolumn{1}{c|}{ Drug Category } & N & \multicolumn{3}{|c}{ Between } \\
(Unweighted) & Zero & Zero and .08 & $\mathbf{. 0 8 +}$ \\
\hline Illegal & 267 & $71.7 \%$ & $20.4 \%$ & $7.9 \%$ \\
Medications & 169 & $93.6 \%$ & $4.9 \%$ & $1.5 \%$ \\
Illegal \& Medications & 30 & $76.8 \%$ & $23.2 \%$ & $0.0 \%$ \\
\hline
\end{tabular}

"Medications" includes prescription and over-the-counter drugs.

In this table, percentages are weighted.

As indicated in Table 6, some individuals tested positive for more than one drug. Thus, we also present the drug analysis results by individual drug where drug is the unit of analysis (Tables 137-140). Those results indicate that the most prevalent drug, other than alcohol, was marijuana. The overall marijuana prevalence rate in oral fluid was 4.5 percent daytime and 7.7 percent nighttime.

When we examined the analysis results of the combination of oral fluid and/or blood in the nighttime driver population, we found that the marijuana prevalence rate was 8.7 percent. The next most frequently encountered individual drug was cocaine, with a daytime oral fluid prevalence rate of 1.5 percent, and a nighttime rate of 3.9 percent. 


\section{Summary}

Overall, analyses of the oral fluid samples obtained indicated a drug use prevalence rate of 11 percent for daytime drivers and 14.4 percent for nighttime drivers. This difference between day and night is statistically significant $(p<.01)$. Among nighttime drivers providing blood samples, 13.8 percent overall tested positive for at least one of the drugs in our panel. This includes all drugs for which we tested, whether illegal, prescription, or over-the-counter. Additionally, of the 9.8 percent of drivers testing positive for "Illegal" drugs in blood, 28 percent, also tested positive for alcohol as did 6.4 percent who tested positive for "Medications" and 23.2 percent for those testing for both "Illegal drugs and Medications." The most frequently encountered individual drug, other than alcohol, was marijuana.

Again, it is important to emphasize that the results presented in this report are estimates of the prevalence of drug use among drivers. Further research is needed to determine the effect of drug prevalence on crash risk. This report provides detailed displays of the data discussed above. 


\section{Introduction}

This report presents prevalence estimates for drug-involved driving obtained from the 2007 National Roadside Survey of alcohol- and drug-involved driving. Though national roadside surveys of alcohol-involved driving have been conducted on a decennial basis since the mid1970s, this is the first U.S. national roadside survey where biological measures of drugs other than alcohol were obtained.

\section{Background}

Forty years ago, when the Department of Transportation (DOT) was established, it was well understood that alcohol was an important factor in traffic crashes. In 1968, a new agency that was to become the National Highway Traffic Safety Administration (NHTSA) delivered its Report to the Congress on Alcohol and Highway Safety, pointing to the need for improved data on drinking and driving (USDOT, 1968). This need led to the establishment of incentives for States to conduct blood alcohol concentration (BAC) tests on all fatally injured drivers and pedestrians, and eventually to the establishment of the Fatality Analysis Reporting System ${ }^{5}$ (FARS) in 1975. Initially, this data file was limited by the low level of testing for alcohol by the States, but since 1982, through the use of an imputation system and increased testing by states, it has provided a reliable means of assessing the Nation's progress in reducing crashes in which drivers have been drinking. It is important to note, however, that FARS provides very limited information related to drugs. While States routinely test drivers involved in fatal vehicle crashes for alcohol, only a few also routinely test for other drugs. According to the Centers for Disease Control and Prevention, less than half of the fatalities in the 2005 FARS had drug test results available (CDC, 2006). In our review of the FARS data, we identified a lack of information related to drug use.

In addition to FARS, the national roadside survey (NRS) series estimates the prevalence of drinking and driving on weekends in the 48 contiguous States and assesses changes in prevalence over time. The first NRS was conducted in 1973 (Wolfe, 1974), the second in 1986 (Lund \& Wolfe, 1991), and the third in 1996 (Voas, Wells, Lestina, Williams, \& Greene, 1998). Each of these surveys included a brief verbal survey and a breath sample to determine BAC. Together, the first three national surveys and FARS (1995) document reductions in the number of drinking drivers on U.S. roadways and alcohol-related fatalities over three decades. The fourth NRS, conducted in 2007, followed the general methodology of the three prior surveys in obtaining BACs to enable comparison with the earlier surveys, but also incorporated several new features. These included questionnaires on drug and alcohol use disorders, and biological sampling of oral fluid and blood to determine the extent of the presence of drugs other than alcohol (i.e., illegal, prescription, and over-the-counter) among drivers.

In 2005, NHTSA conducted a pilot study as a precursor to this full decennial 2007 NRS (Lacey et al., 2007). The primary objective of the pilot study was to determine whether it was feasible to collect data for drugs other than alcohol through oral fluid and blood samples. The pilot study consisted of six rounds of nighttime data collection, with over 800 drivers participating in the survey. Approximately 78 percent of the drivers participating in the survey agreed to provide an

\footnotetext{
${ }^{5}$ FARS was originally called the Fatal Accident Reporting System.
} 
oral fluid sample, and almost 50 percent of the drivers participating in the survey provided blood samples. The pilot study showed that it was clearly feasible to conduct a survey that included drugs other than alcohol. Such data are essential to developing more precise estimates of the presence of alcohol and other drugs in drivers and for estimating the prevalence of alcohol- and drug-involved driving.

\section{Prevalence of Drug-Involved Driving}

In their review of the research literature, Kelly, Darke, and Ross (2004) cite the 2001 National Household Survey to report that 4 percent of U.S. residents reported driving while under the influence of drugs in the preceding 12 months. These data, based on self-report, did not distinguish between legal and illegal drugs. Using data collected in Tennessee in December 1986, Lund, Preusser, Blomberg and Williams (1988) studied a sample of truck drivers to report prevalence of marijuana (15\%); cocaine (2\%); prescription stimulants (5\%); and nonprescription stimulants $(12 \%)$ among the drivers. According to a literature review by Jones, Shinar, and Walsh (2003), the Lund et al. study (1988) was at that time the only U.S. study that had performed chemical tests of drivers stopped at a roadside location.

With respect to prescription drugs, Jones et al. (2003) reported that benzodiazepines (tranquilizers) were found in four percent of non-crash-involved drivers. De Gier (2006) reviewed the literature and reported that benzodiazepines were more commonly found in middleaged to older drivers, "presumably due to the high rates of benzodiazepine prescriptions among these age groups." Neutel (1998) estimated a lower crash risk for older persons (OR =2.8) after benzodiazepine use than younger persons $(\mathrm{OR}=3.2)$.

\section{Impact of Drugs on Driving Skills}

\section{Laboratory Studies}

A number of laboratory studies have been conducted on the impact of both legal and illegal drugs on driving-related skills. Still, results from these experimental studies are not straightforward and are sometimes contradictory. One confounding factor is that different drugs have different effects on driving-related skills, with the thresholds at which those different effects occur varying as a function of the measure used (Shinar, 2006). Additionally, Shinar found that because of the large individual variation in human response to drug consumption, attempts to define a "norm" for the behavioral response to drugs is difficult.

Some studies have found that drugs that stimulate the central nervous system, (e.g., amphetamines, cocaine, caffeine) sometimes may improve laboratory driving performance (Ward, Kelly, Foltin, \& Fischman, 1997; Burns, 1993; Higgins et al., 1990; Hurst, 1976). However, in the Jones et al. (2003) literature review, it is reported that amphetamines are not usually associated with easily observable behavioral impairments.

There is considerable evidence from laboratory studies that cannabis (marijuana) impairs reaction time, attention, tracking, hand-eye coordination, and concentration, although not all of these impairments were equally detected by all studies (Couper \& Logan, 2004a; Heishman, Stitzer, \& Yingling, 1989; Gieringer, 1988; Moskowitz, 1985). In reviewing the literature on marijuana, Smiley (1998) concluded that marijuana impairs performance in divided attention tasks (i.e., a poorer performance on subsidiary tasks). Jones et al. (2003) adds that Smiley's finding is relevant to the multitasking essence of driving, in particular by making marijuana- 
impaired drivers perhaps less able to handle unexpected events. Interestingly, there is also evidence showing that, unlike alcohol, marijuana enhances rather than mitigates the individual's perception of impairment (Lamers \& Ramaekers, 1999; Robbe \& O'Hanlon, 1993; Perez-Reyes, Hicks, Bumberry, Jeffcoat, \& Cook, 1988). Robbe and O'Hanlon (1993) reported that in laboratory conditions, drivers under the influence of marijuana were aware of their impairment, which led them to decrease speed, avoid passing other vehicles, and reduce other risk-taking behaviors. Such was not the case with alcohol; for the authors reported that alcohol-impaired drivers were generally not aware of impairment, and therefore did not adjust their driving accordingly.

There is laboratory evidence that benzodiazepines impair some driving skills (Drummer, 2002). However, there are some contradictory results. Mathijssen et al. (2002) reported on a casecontrol study conducted in the Netherlands that found there is an increased risk for benzodiazepine and alcohol use together, but no increased risk for benzodiazepine use alone. Additionally, there is evidence that the impairing effects of benzodiazepine might be circumscribed to the first days of benzodiazepine use, before tolerance develops (Lucki, Rickels, \& Geller, 1985) leading some to conclude that the extent to which benzodiazepines increase crash risk has to be balanced against the health benefits for those taking these drugs for medicinal purposes (Beirness, Simpson, \& Williams, 2006).

Laboratory reports are not necessarily the best indicators of the impact of drugs on driving skills. As Beirness et al. (2006, pages 16-17) stated: "an impairment or skill enhancement identified in a laboratory test may not show up on the road because the drugs may lead to other changes in driver behavior. Additionally, laboratory tests can address the effects of drugs only on skills, not judgment, and the latter may be as important when it comes to driving. Thus even if drugs are found to affect driving skills in laboratory tests, actual crash risk may or may not be affected."

\section{Field Data}

Data from drivers apprehended for impaired driving have been used to estimate the prevalence of drug use. Jones et al. (2003) reviewed the literature on drug involvement among arrested drivers and reported a variety of drug prevalence levels based on the location and the population under study. White et al. (1981) reported the following prevalence of drugs among drivers arrested for impaired driving in California in the 1970s with BACs lower than $10 \mathrm{~g} / \mathrm{dL}$ : sedative/hypnotic (30 to 47\%); phencyclidine or PCP (79\%); and morphine (62\%). In contrast, Polkis, Maginn, and Barr (1987) reported the following prevalence rates among drivers arrested in St. Louis, Missouri, in the 1980s: phencyclidine or PCP (47\%); marijuana (47\%); benzodiazepines (22\%); barbiturates (15\%); opiates (11\%); and cocaine $(9 \%)$. Walsh et al. (2000) reported that marijuana and cocaine were the primary drugs detected (19\% and $16 \%$, respectively) among arrested drivers in Tampa, Florida, with narcotics and amphetamines found in less than 1 percent of the drivers. Thus, as studies of drug-use patterns in the United States have shown, the types of substances consumed vary across locations and time, making it difficult to characterize the drug involvement of drivers.

As part of the Drug Evaluation and Classification (DEC) Program, trained drug recognition experts are used to determine drug usage by looking for relevant signs and symptoms. Preusser, Ulmer, and Preusser (1992) evaluated DEC programs in Arizona, California, Colorado, New York, and Texas from 1986 to 1991 reported that about 1 to 3 percent of the drivers arrested for driving while intoxicated (DWI) were classified as drug-impaired by Drug Recognition Experts 
trained in the DEC Program. The most prevalent substances found were marijuana (42\%), stimulants (36\%), depressants (16\%), narcotic analgesics (13\%), and PCP (5\%). As Jones et al. (2003) pointed out, these estimates apply only to the restricted group of driving-under-theinfluence-of-drugs (DUID) suspects that were evaluated by officers who participated in the DEC program, rather than to all drivers arrested for DWI or all drivers on the road.

Other studies have been conducted using crash data to estimate the prevalence of drugs among injured drivers and their role in crashes. Terhune et al. (1992) used a responsibility-analysis approach $^{6}$ in studying fatally injured drivers and reported no increase in crash risk due to marijuana or cocaine use alone, although multiple drug use could be associated with increased responsibility. They also reported that "drivers with alcohol in their systems had the highest crash responsibility rates" and "an alcohol-drug combined impairment effect was suggested by the responsibility analysis" (pg. ix). Leveille et al. (1994) used a small matched-case control study design to study crash risk among drivers aged 65 or older in Seattle, Washington. The authors did not find an association between crash risk and benzodiazepine or sedating antihistamines among this group, although they acknowledged that the sample size (234 drivers) might have been too small for significance. Ray, Fought, and Decker (1992) also studied crash risk for drivers aged 65 years or older using data from the Tennessee Medicaid program. With this larger sample (16,262 drivers), they found an association between presence of benzodiazepines or tricyclic antidepressants and crash risk. However, they did not find a correlation for people taking oral opioid analgesics. Other studies of drug over-involvement in crashes report contradictory results (e.g., Hemmelgarn, Suissa, Huang, Boivin, \& Pinard, 1997). These results should be considered cautiously due to data limitations such as small sample size.

In summary, Jones et al. (2003, pp. 85-86) stated: "The role of drugs as a causal factor in traffic crashes involving drug-positive drivers is still not understood. Drug risk factors are still not known with acceptable precision, with some evidence suggesting little or no increase in crash risk at drug levels being detected by current chemical test procedures. Further, current research does not enable one to predict whether a driver testing positive for a drug, even at some measured level of concentration, was actually impaired by that drug at the time of crash. This is in sharp contrast to alcohol where BAC measurements can provide a good estimate of impairment."

Jones et al. (2003, p. 86) also stated: "Another complicating factor is the role of drugs taken in combination with alcohol. For many drugs, a drug in combination with alcohol accounts for a significant percentage of the occurrences of that drug in crash victims. Waller et al. (1995) found that roughly one-half of the occurrences of drivers positive for marijuana, cocaine, and / or opiates had elevated BACs, and that the crashes of drivers testing positive for drugs alone were very similar to the crashes of drivers testing negative for both alcohol and drugs. This adds further doubts about the role of drugs in the impairment of crash-involved drivers, and suggests that it may be much smaller than had been suspected."

\footnotetext{
${ }^{6}$ Responsibility-analysis was used to suggest which drugs contributed to the occurrence of the crashes. This method involves examining crash reports which have no indication of driver drug use, and rating each driver's crash responsibility. If proportionately more drug-present drivers are judged responsible than are those free of drugs, this is considered evidence of drug impairment effects.
} 


\section{Challenges in Measurement and Today's Drug Testing Opportunities}

According to the review of the drug impaired literature conducted by Jones et al. (2003), blood is usually the "gold standard" for linking drug concentration to behavioral impairment. However, the collection of other types of biological fluids (e.g., sweat, oral fluid, urine) is less invasive and easier to collect in both field studies and law enforcement operations, and thus, oral fluid has emerged as a valid alternative to blood collection for field use. Oral fluids normally contain the parent drug substance rather than drug metabolites that are present in urine. Additionally, Jones et al. (2003) concluded that collection of oral fluid is generally considered less invasive than either blood or urine, and "could be an excellent matrix to tie recent drug use with behavioral impairment."

In some applications, oral fluid samples are collected and then subjected to a screening analysis in the field or at the police station to develop a basis for more definitive collection of and laboratory analysis of urine or blood. In the application used for this study, the oral fluid sample was collected and then sent to a laboratory for a more refined enzyme-linked immunosorbent assay (ELISA) screening followed by a confirmatory analysis by Liquid ChromatographyTandem Mass Spectrometry (LC/MS-MS) or Gas Chromatography/Mass Spectrometry (GC/MS).

In a recent study conducted by Cone et al. (2002), oral fluid testing of 77,218 subjects in private industry showed a 5 percent positive rate for any of the five Substance Abuse and Mental Health Services Administration drug categories (marijuana, cocaine, opiates, phencyclidine, and amphetamines). The pattern and frequency of drug positives was remarkably similar to urine drug prevalence rates in the general workplace from other surveys (Cone et al., 2002). Further, in a study of 180 drivers given blood, urine, and oral fluid tests which were analyzed using quantitative Gas Chromatography/Mass Spectrometry (GC/MS), the positive predictive value of oral fluids was 98 percent for amphetamines, 92 percent for cocaine, and 90 percent for cannabinoids (Samyn et al., 2002).

However, in an analysis of blood, urine, saliva, and sweat from 198 injured drivers admitted to a hospital, saliva detected only 14 positives for cannabinoids, while 22 positives were detected in the urine (Klintz et al. 2000). According to the study authors, the amount of matrix (body fluid) collected in saliva appears to be smaller when compared to urine, and the levels of drugs are typically higher in urine than in saliva. In a study of saliva and sweat, Samyn and van Haeren (2000) concluded that saliva should be considered a useful analytical matrix for the detection of recent drug use when analyzed using GC/MS. This finding indicates oral fluid testing would be desirable in the roadside testing of drivers.

Yacoubian et al. (2001) tested 114 adult arrestees using saliva and urine and concluded that saliva testing may have certain advantages over urine testing for drugs, including (1) ease of sample collection, (2) subject preference for giving saliva over urine, (3) less vulnerability of adulteration in saliva, (4) little concern for subjects producing an adequate sample with saliva, and (5) saliva storage is easier than urine. The authors found a sensitivity of 100 percent and a specificity $^{7}$ of 99 percent for cocaine in saliva and a sensitivity of 88 percent and specificity of

\footnotetext{
${ }^{7}$ Sensitivity: Sensitivity is the ability of a test to measure what it purports to measure or in this case the ability of the oral fluid tests to correctly identify active drug users. It is operationalized as a proportion represented by the true
} 
100 percent for heroin. However, saliva results only had a sensitivity of five percent for marijuana, likely reflecting only detection of very recent smoking, as marijuana does not migrate from the blood supply to the oral fluid. Thus, some positives may indicate residual marijuana remaining in the mouth after ingestion. This may well be a positive factor for this study in that, when marijuana is detected in saliva, it is more likely to be in its active phase in the body rather than simply evidence the marijuana has been consumed during a "look-back" period that could be as long as two weeks, and may no longer have a potential impairing effect.

Hold et al. (1999) conducted a review of the literature concerning using oral fluid for drug testing; the review included 135 references and provided guidelines for techniques for collecting and measuring drugs in saliva. In an earlier review of drug use evidence found in oral fluid, Schramm et al. (1992) concluded that initial studies with cocaine and phencyclidine or PCP suggested a correlation between oral fluid and blood concentration, but that tetrahydrocannabinol (THC) does not appear to be transferred from blood to saliva. Recent marijuana smoking, however, can be detected in saliva from the buccal cavity. ${ }^{8}$

With regard to oral fluid and BAC, Bates et al. (1993) found a high correlation between saliva strips and breath tester results for alcohol $(\mathrm{r}=.89-.90)$. Blood sample analyses, however, still remain the "gold standard" measurement of drugs in the human body because evidence supporting accuracy is best established for that approach.

\section{Project Objectives}

New to the 2007 National Roadside Survey was the collection of biological samples that could be used to determine the extent of the presence of drugs other than alcohol in the nighttime driving population. These additional data are essential to estimating the national progress in reducing the prevalence of alcohol- and drug-involved driving.

The objective of this report is to present the first U.S. national prevalence estimates of druginvolved driving. The first report stemming from this study described the methods used in the sampling, data collection, and biological specimen analysis portions of the 2007 NRS (Lacey et al, 2009a). The second report describes the study's analytic approach and summarizes the alcohol data; we place the set of descriptive estimates of alcohol use within the context of societal trends by comparing these measures with similar ones from the prior surveys over the

positives (i.e., those who are drug positive and actually test positive) divided by all persons who are drug positive (i.e., those who are positive and test positive [i.e., true positives] plus those who are positive and test negative [false negatives]). The formula for sensitivity is $\mathrm{Sn}=\mathrm{TP} /(\mathrm{TP}+\mathrm{FN})$ where TP and FN are the number of true positive and false negative results, respectively. Sensitivity can also be thought of as 1 minus the false negative rate. Notice that the denominator for sensitivity is the number of drug positive persons.

Specificity: Specificity is the ability of a test to correctly identify non-cases of disease or in this case the ability of the oral fluid tests to correctly identify non-drug users. It is operationalized as a proportion represented by the true negatives (i.e., those who are drug negative and test negative) divided by all persons who are drug negative (i.e., those who are negative and test negative [true negatives] plus those who are negative, but falsely test positive [false positives]). The formula for specificity is $\mathrm{Sp}=\mathrm{TN} /(\mathrm{TN}+\mathrm{FP})$ where $\mathrm{TN}$ and FP are the number of true negative and false positive results, respectively. Specificity can be thought of as 1 minus the false-positive rate. Notice that the denominator for specificity is the number of nondrug users.

${ }^{8}$ The buccal cavity includes that part of the mouth bounded anteriorly and laterally by the lips and the cheeks, posteriorly and medially by the teeth and/or gums, and above and below by the reflections of the mucosa from the lips and cheeks to the gums. 
last four decades. These trend analyses enable detection of changes in our population's rates and degree of alcohol-involved driving over time (Lacey et al, 2009b). The current report provides insight into the use of drugs other than alcohol (illegal, prescription, and over the counter) in the driving population and will provide a baseline for future studies to assess trends and changes.

The report will first present a summary of the methods and procedures used in survey sampling and biological sampling. This is followed by a description of the drugs selected for analysis, and then, a description of the actual drug-collection instruments and how they were administered.

The results of our analyses are divided into three sections. The first presents the analyses of the oral fluid results, with BAC measurement obtained through breath tests. These data include both daytime and nighttime drivers. The second section will report the results of the blood analysis, again with the $\mathrm{BAC}$ measurements from breath tests. In both of these sections, we also contrast the results obtained from the biological specimens with drivers' self-report drug use. Additionally, we present drug prevalence estimates for nighttime weekend drivers based on the combination of results of analyses of both oral fluid and blood combined. Finally, we discuss the implications of these analyses in terms of estimating the prevalence of drug use among Friday daytime drivers and weekend nighttime drivers. Additional tables with further blood results are included in Appendix A. These analyses include results of self-reported drug use by drug type, safety observation measures (seatbelt, helmet use, etc.), as well as the results on items relating to interaction with the criminal justice and treatment systems. The presence of drugs in these drivers does not necessarily imply that they are impaired and at greater risk of crash involvement. Indication of impairment and increased risk will be addressed in an upcoming study of the potential contribution of drugs to crash risk. 


\section{Methods}

This section of the report briefly summarizes the methodology used in conducting the 2007 NRS, with special emphasis on sampling procedures. A separate Methodology Report (Lacey et al., 2009a) provides detailed descriptions of the multiple components of the data collection process.

\section{Survey Sampling Procedures}

This section presents an abridged description of the sampling approach we followed in conducting the 2007 NRS. Because it is infeasible to conduct surveys on all the roads in the United States, we constructed a sampling system for the 2007 NRS that represented the whole Nation but required interviewing only a practical portion of the almost 203 million drivers on U.S. roads (FHWA, 2006). As in the three prior surveys, the area covered in this study was limited to the 48 contiguous States.

For practicality, we limited locations to roadways where surveys could be performed safely and with sufficient traffic to recruit the number of participants required for valid estimates of the national prevalence of drinking and drug involved-drivers, as did prior NRS studies.

The past three national surveys provided information on private four-wheel vehicle operators at representative, then randomly selected, locations during weekend, nighttime periods when drinking and driving is most prevalent. The 2007 NRS covered the same time periods and added two Friday daytime periods. As in the three earlier surveys, the 2007 NRS excluded commercial vehicles but, unlike previous practice, included motorcycles.

The 2007 NRS followed the practice of the 1973, 1986, and 1996 national surveys by using a multistage sampling system that represented the drivers at risk for crash involvement in the 48 contiguous States. In this process, the initial sample structure was taken from NHTSA's National Automotive Sampling System/General Estimates System (NASS/GES) (NHTSA, 1995), which was constructed to provide a basis for making nationally representative estimates of highway crashes. The four steps included:

1. Selecting the primary sampling units (PSUs), which are cities, large counties, or groups of counties from within four regions of the United States and three levels of population density.

2. Randomly selecting 30 specific square-mile-grid areas within each PSU, and randomly numbering them to form an order of priority from among the total of all the square mile sectors comprising the PSU area. Then we attempted to recruit the cooperation of local law enforcement agencies that had jurisdiction over the selected grids. One law enforcement agency often would cover several of the selected square mile areas.

3. Identifying appropriate survey sites within the square-mile-grid areas. Appropriate sites had a safe area large enough to accommodate the survey operation and had sufficient traffic flow to generate an adequate number of subjects. In some cases, more than one such location was available within a square mile grid. In this case, the survey manager exercised her/his judgment to select the optimal location for safe data collection. This resulted in selection of five data collection or survey sites within each PSU. 
4. Selecting at random drivers to be interviewed from the traffic passing by the survey site. The total number of eligible vehicles was counted to determine the proportion of the traffic passing by each survey site that was sampled.

These sampling procedures were followed to ensure that the probability of selecting a PSU, a survey location within the PSU, and a driver at a survey location was known at each of the sample design stages. Knowing these probabilities permitted the computation of the probability that a given driver would be interviewed in the survey. This was done by multiplying the sampling probabilities at each of the four steps to obtain the final overall probability of being sampled. The weight given to each case in the final totals (sampling weight) was computed as the inverse of the sampling probability. This statistical procedure accounts for differences among PSUs in the size of the driver population. In other words, although we sampled approximately the same number of drivers at each PSU, the actual number of individuals driving at each sampling site was not uniform. To make the sample of drivers at each site representative of the actual number of drivers, we applied the above-described weights. As a result, drivers interviewed at sites with a relatively heavy traffic flow (i.e., a relatively large pool of actual drivers) carry a larger weight than drivers sampled from sites with less traffic loads. This ensured that the basic requirement of sampling theory - that every driver has an equal chance of being interviewed - was met by adjusting for the biases inherent in the selection of locations within the sampling frame.

The major barrier to carrying out this staged sampling system was obtaining law enforcement support for the survey. In some localities, city attorneys or law enforcement leadership with concerns such as potential liability and scare resources declined to participate. In these cases, substitution PSUs were obtained. Although this process was time-consuming, similar difficulties had also been experienced in all three previous NRS studies. Replacement PSUs were chosen from within the same GES geographic region ${ }^{9}$ and the same GES PSU type (city, large suburban area, all others) as the unavailable PSU. For more information on PSU replacement, see Lacey et al. (2009a). The 60 PSUs used in the 2007 NRS are shown in Figure 1.

${ }^{9}$ GES defines four geographic strata. 


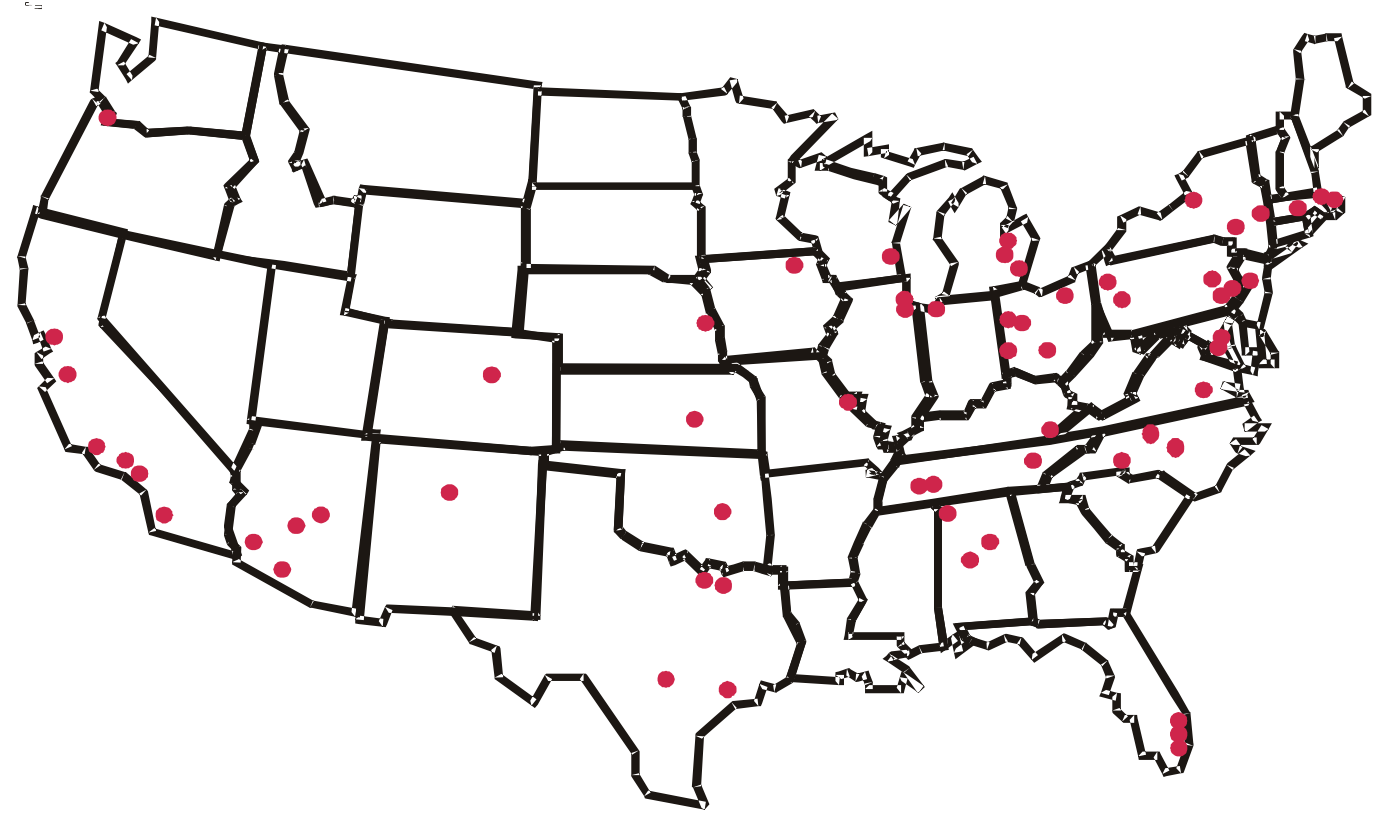

Figure 1. Map of Sixty 2007 National Roadside Survey Sites

As mentioned, the roadside survey procedures used in the 2007 NRS followed, as closely as possible, those used in the previous three surveys (see Lacey et al., 2009a; Lestina et al., 1999). However, the 2007 NRS departed from the earlier surveys in several important ways. The earlier surveys included only a brief questionnaire and a breath test that generally required less than 5 minutes of a participant's time. The 2007 NRS included a more extensive set of questions (base survey, a drug questionnaire, questions about interaction with the criminal justice and treatment systems, an alcohol-use disorder and a drug-use disorder survey). The 2007 survey protocol also attempted to collect two biological samples (oral fluid and blood) from participants, as well as a breath test. Data collection for the earlier surveys was conducted by three teams of three interviewers; the 2007 NRS consisted of 6 teams of 10 to 12 members. The earlier surveys were conducted at 24 PSUs, whereas the 2007 survey was conducted at 60 PSUs. This increase in the number of PSUs allowed us to maximize the use of all possible PSUs defined by the NASS/GES and increase the representativeness of the sample. The earlier surveys had four 2-hour data collection periods on weekend nights; the 2007 survey added a 2-hour data collection period during the daytime on Fridays, for a total of five 2-hour survey periods during the weekend. Finally, the number of participants in the 2007 survey was about three times as many as in the 1973 study.

PIRE employed and trained six specialized teams of interviewers from both the east and west coasts of the United States. All staff was trained during the summer of 2007. Surveys began the weekend of July 20 and 21, 2007, and concluded 20 weeks later on December 1, 2007. As in the three previous NRS studies, nighttime surveys were conducted between 10 p.m. and midnight, and between 1 a.m. and 3 a.m. on both Friday and Saturday. For the 2007 survey, a 2-hour Friday daytime data collection period was added, either between 9:30 a.m. and 11:30 a.m. or between 1:30 p.m. and 3:30 p.m. The daytime data collection period was randomly selected for each PSU. The daytime periods were added to determine the extent of alcohol- and drug- 
involved driving during the day and whether the number of drivers using drugs and the types of drugs used differed between day and night. Each component used in the roadside survey is thoroughly described in the Methodology Report (Lacey et al., 2009a).

\section{Preparation for the 2007 NRS Survey}

The size and complexity of the 2007 NRS required extensive preparation that NHTSA began years before the actual survey was initiated, including a pilot test of survey procedures (Lacey, Kelley-Baker, Furr-Holden, Voas, Brainard, \& Moore, 2007). The preparation activitiesselection and testing of equipment for collecting biological samples; recording and organizing the self-report and observational data at the roadside; recruiting and training of survey staff; pretesting of survey procedures; developing procedures for protection of survey respondents and the public - are fully described in the Methodology Report (Lacey et al., 2009a). Only a brief overview of this work is described here.

Survey equipment: Interviewers recorded the responses to the traditional NRS interview on a handheld, portable digital assistant (PDA). Through a special program developed for the 2007 NRS, the PDA provided a means of prompting the interviewer through each step of the data collection process.

As part of the program, to protect survey participants and the public, it was important to know the extent of the drivers' drinking. To this end, a passive alcohol sensor (PAS), attached to the PDA with Velcro ${ }^{\mathrm{TM}}$, was used to collect mixed expired air from approximately 6 inches in front of the driver's face (we used the PAS Vr. ${ }^{\mathrm{TM}}$ manufactured by PAS International, Inc. of Fredericksburg, Virginia). This small handheld unit was used because it was less obvious and intimidating than the larger flashlight-based passive sensors. We researched three available styles of PAS models: (1) the handheld unit that was used in the pilot study; (2) the flashlight PAS; and (3) a clipboard device with an alcohol sensor built into one corner. We tested the devices for accuracy, ease of use, and reliability and found that the PAS Vr. ${ }^{\mathrm{TM}}$ was best suited to the needs of this study. The PAS unit can detect alcohol in emitted breath around the face (Kiger, Lestina, $\&$ Lund, 1993). The PAS was held within 6 inches of the participant's face, and when the subject spoke, the interviewer activated the small electrical pump, which pulled in the exhaled breath from the participant and produced an estimate of the participant's breath alcohol level.

Data collection: To compare results from the 2007 survey to prior surveys, a strong effort was made to follow the same data collection protocol employed in the three prior NRS studies, despite the addition of a large number of questions and new biological specimen collections following the traditional questionnaire and breath test. As described in the Methodology Report (Lacey et al., 2009a), we placed the traditional NRS interview and breath-test collection before the new NRS questions and the specimen collections. We believed that by structuring data collection in this way, the additions to the basic survey would not affect our ability to compare the responses to the basic survey with responses from the three earlier surveys. Nevertheless, the 2007 NRS experienced a somewhat larger refusal rate than the 1996 NRS (see Table 9).

To determine whether the 2007 survey procedure accounted for producing the lower response rate, we conducted a replica of the 1996 NRS procedure in one of our 2007 sites (Knox County, Tennessee). The simpler protocol followed that used in the 1996 and earlier surveys, collecting the traditional interview and a breath sample only. About 16 percent of all drivers signaled to stop by the officer during this "replica survey" failed to stop and/or enter the site. This is similar 
to the 15 percent that failed to stop (when the police signaled) in the 2007 NRS study. Among those who entered the research bay and were eligible for the survey, the proportion of refusals in the replica survey was similar to the full 2007 NRS (16.3\% and $17.5 \%$, respectively). Thus, it appears that the lower response rate in the 2007 NRS reflects a change in the driving public's willingness to be interviewed, rather than an effect of the more elaborate survey procedures implemented in 2007.

\section{Table 9. Comparison of Number of Nighttime Participants by Year in the} National Roadside Surveys

\begin{tabular}{lcccc}
\hline & $\mathbf{1 9 7 3}$ & $\mathbf{1 9 8 6}$ & $\mathbf{1 9 9 6}$ & $\mathbf{2 0 0 7}$ \\
\hline Signaled to enter site & Not reported & 3,260 & 6,480 & 9,553 \\
Did not enter site & Not reported & 217 & 182 & 1,016 \\
Entered site & 3,698 & 3,043 & 6,298 & 8,537 \\
Eligible for survey & Not reported & Not reported & Not reported & $8,384^{\dagger}$ \\
Entered site and interviewed & $3,353(90.7 \%)$ & $2,971(97.6 \%)$ & $6,045(96.0 \%)$ & $6,920(82.5 \%)^{\dagger \dagger}$ \\
Valid breath sample & $3,192(86.3 \%)$ & $2,850(93.7 \%)$ & $6,028(95.7 \%)$ & $7,159(85.4 \%)^{\dagger \dagger}$ \\
\hline
\end{tabular}

$\dagger$ Commercial vehicles not eligible.

${ }^{\dagger \dagger}$ Because previous surveys did not inform about the eligibility of the drivers, percentages for the years 1973,1986 , and 1996 are based on drivers who stopped and entered the site. Percentages for 2007 are based on drivers who not only were stopped and entered site, but also were eligible for the survey (i.e., noncommercial drivers, drivers aged 16 and older, and not constrained by language barriers). Percentages are based on nighttime drivers.

$\mathrm{t \dagger}^{\dagger}$ Some drivers provided breath samples but declined to be interviewed.

In this table, percentages are unweighted.

The basic procedure in the 2007 NRS, as well as in the prior three surveys, was for the law enforcement officer working with the survey team to direct the potential respondent into the survey site without speaking to the driver. Once in the site, the driver was directed into a research bay and was approached by an interviewer and recruited to participate in the interview. Prospective participants were informed that they had done nothing wrong and that the interview concerned traffic safety and was anonymous. A PAS reading was also taken at this point. If the individual agreed to participate, the interviewer asked the 22 questions on the traditional NRS protocol and requested a breath sample. Only after the completion of the standard NRS procedure did the additional data collection for the 2007 NRS begin. A detailed description of the survey procedures is provided in the Methodology Report (Lacey et al., 2009a).

As indicated in Table 10, which presents response patterns for both the daytime and nighttime data collection periods, over 13,000 vehicles were selected to participate in the $2007 \mathrm{NRS}$; of these, 10,909 entered the data collection site and the drivers were determined to be eligible for survey participation (for example, commercial vehicles such as pizza delivery vehicles, drivers under the age of 16, and drivers who could not communicate with us either in English or Spanish were not eligible to participate). Eighty-three percent of eligible drivers participated in the survey, and because some of those that refused the survey did agree to provide a breath sample, BACs from the PBTs were available on 86 percent of the eligible drivers. Among eligible drivers, 71 percent provided an oral fluid sample, 72 percent completed a drug questionnaire 
and/or the AUD questionnaire, and 39 percent of eligible nighttime drivers provided a blood sample. $^{10}$

Table 10. Participating Drivers (Percentages in Parentheses)

\begin{tabular}{lccc}
\hline & \multicolumn{3}{c}{$\mathbf{2 0 0 7}$} \\
\cline { 2 - 4 } & Daytime & Nighttime & Total \\
\hline Signaled to enter site & 3,516 & 9,553 & 13,069 \\
Did not enter site & 933 & 1,016 & 1,949 \\
Entered site & 2,583 & 8,537 & 11,120 \\
Eligible & 2,525 & 8,384 & 10,909 \\
Entered site and interviewed & $2,174(86.1 \%)^{\dagger}$ & $6,920(82.5 \%)^{\dagger}$ & $9,094(83.4 \%)^{\dagger}$ \\
Valid breath sample & $2,254(89.3 \%)^{\dagger}$ & $7,159(85.4 \%)^{\dagger}$ & $9,413(86.3 \%)^{\dagger}$ \\
Oral Fluid sample & $1,850(73.3 \%)^{\dagger}$ & $5,869(70.0 \%)^{\dagger}$ & $7,719(70.7 \%)^{\dagger}$ \\
Blood sample & $\mathrm{NA}$ & $3,276(39.1 \%)^{\dagger}$ & $\mathrm{NA}$ \\
AUD \&/or Drug Questionnaire & $1,889(75.2 \%)^{\dagger}$ & $5,983(71.4 \%)^{\dagger}$ & $7,882(72.2 \%)^{\dagger}$ \\
\hline
\end{tabular}

NA (not applicable): Blood samples were not collected during daytime sessions.

In this table, percentages are unweighted.

$\dagger$ Percent of eligible.

To prevent impaired drivers from continuing to drive, a special "Impaired Driver Protocol" was developed to ensure the safety of both the drivers and the public. Impairment was determined by the interviewer's observation of the driver's behavior and by the use of a PAS. If there was any sign of possible impairment, the interviewer signaled the survey manager who administered a breath test with a preliminary breath test (PBT) device that displayed the actual BAC. If the driver's BAC was $.05 \mathrm{~g} / \mathrm{dL}$ (grams per deciliter) or higher, the survey manager provided the participant with several options for getting home without driving. ${ }^{11}$ This system has been successful in preventing identified impaired drivers from returning to the road where they could be a danger to themselves or others. A full description of the Impaired Driver Protocol is provided in Appendix E of the Methodology Report (Lacey et al., 2009a).

A significant concern for all four NRS studies was that high BAC drivers might be less likely to agree to participate, resulting in an underestimate of the number of risky drinking drivers on the road. Data from the 1996 NRS and from relative risk studies, such as that of Blomberg, Peck, Moskowitz, Burns, and Fiorentino (2001, p. 117), have suggested that drivers who refuse the breath test are likely to have higher BACs than those who agree to participate. This was corrected somewhat in the 1996 and 2007 NRS studies by using the PAS data collected as part of the consent process. During the data collection process, a PAS was used when the driver was first approached to participate in the survey. The PAS provides a nine-unit estimate of what a true BAC measure collected by the PBT device would be. We correlated the PAS and other measures (specifically, gender and time of night) to impute the BACs of drivers who entered the site but refused to provide a breath sample. Thus, the actual BACs collected in both the 1996 and the 2007 NRS studies were corrected for nonparticipating drivers.

10 Typically, only drivers who had completed the oral fluid step provided a blood sample.

11 Our threshold of $.05 \mathrm{~g} / \mathrm{dL}$ was more conservative than the legal per se limit of $.08 \mathrm{~g} / \mathrm{dL}$. 


\section{Driver Conversion}

As presented in the Methodology Report (Lacey et al., 2009a), there were 444 attempts to convert drivers who had initially declined to participate in our study (i.e., to change their minds and provide us with at least a breath sample). This was done to develop an understanding of whether drivers who refused to participate were more or less likely to be alcohol or drug positive than those who initially agreed to participate. Drivers who refused were offered a $\$ 100$ incentive as an inducement to convert. Of the 444 total attempts, 50 percent were successfully converted (i.e., provided a breath sample). Among those converted drivers, $156(70 \%)$ also provided an oral fluid sample and 49 drivers $(22 \%)$ also provided a blood sample.

Tables 11 and 12 show the outcome of the Oral Fluid and Blood analyses (respectively) performed on the converted drivers. Among converted drivers who provided an oral fluid sample, the distribution of drivers who were drug positive appears to be somewhat higher than that of the total sample of daytime and nighttime participants, where 11.0 percent of the general daytime samples were positive (as compared to $16.2 \%$ of converted drivers) and 14.4 percent of the general nighttime samples were positive (compared to the $17.0 \%$ of converted drivers). These differences, however, were not statistically significant.

Table 11. Oral Fluid Analysis Results Among Converted Drivers

\begin{tabular}{|c|c|c|c|c|}
\hline \multirow[b]{2}{*}{$\begin{array}{l}\text { Presence of Drugs } \\
\text { in Oral Fluid }\end{array}$} & \multicolumn{2}{|c|}{ Daytime } & \multicolumn{2}{|c|}{ Nighttime } \\
\hline & $\begin{array}{c}\mathbf{N} \\
\text { (Unweighted) }\end{array}$ & $\begin{array}{c}\% \\
\text { (Weighted) }\end{array}$ & $\begin{array}{c}\mathbf{N} \\
\text { (Unweighted) }\end{array}$ & $\begin{array}{c}\% \\
\text { (Weighted) }\end{array}$ \\
\hline Negative & 27 & $83.8 \%$ & 107 & $83.1 \%$ \\
\hline Positive & 6 & $16.2 \%$ & 16 & $17.0 \%$ \\
\hline All & 33 & $100 \%$ & 123 & $100 \%$ \\
\hline
\end{tabular}

Among drivers who were converted and provided a blood sample, 12.7 percent were drug positive. This distribution is very similar to that of the total nighttime participants who provided blood, where 13.8 percent were drug positive (blood was not collected in the daytime sample). Given the low sample size, statistical tests were not performed.

Table 12. Blood Analysis Results Among Converted Drivers

\begin{tabular}{|c|c|c|}
\hline \multirow[b]{2}{*}{$\begin{array}{l}\text { Presence of } \\
\text { Drugs in Blood }\end{array}$} & \multicolumn{2}{|c|}{ Nighttime } \\
\hline & $\begin{array}{c}\mathbf{N} \\
\text { (Unweighted) }\end{array}$ & $\begin{array}{c}\% \\
\text { (Weighted) }\end{array}$ \\
\hline Negative & 43 & $87.3 \%$ \\
\hline Positive & 6 & $12.7 \%$ \\
\hline All & 49 & $100 \%$ \\
\hline
\end{tabular}




\section{Selection of Drugs for Screening and Analysis}

PIRE and NHTSA jointly developed an initial list of drugs to be detected based on the literature (e.g., Jones, Shinar, \& Walsh, 2003; Couper \& Logan, 2004) and experience with drug-involved driving research. The drugs were selected because of a combination of their potential impaireddriving effects, their likelihood of appearing in drivers, and in the case of oral fluid, the availability of scientific techniques to analyze oral fluid to detect and quantify the drug. NHTSA then provided this list to experts in the field of epidemiology of drug use, driving, and toxicology both in the United States and abroad. The experts responded to the list with additions and deletions.

The list of selected drugs is shown in Table 13. The first five categories of drugs listed constitute the National Institute on Drug Abuse (NIDA)-5, which are prevalent drugs of abuse and of universal interest in the study of drug involvement. The NIDA-5 are routine components of a drug-screening panel. The other drugs on the list (with the exception of barbiturates) appear in the NHTSA publication titled "Drugs and Human Performance Fact Sheets" (Couper \& Logan, 2004) and are of interest because the expert panel for that effort believed those drugs presented potential traffic safety risks. The drugs we tested for represented illegal, prescription, and overthe-counter drugs that (1) have the potential to impair driving performance and (2) could reasonably be expected to appear in the driver population.

Table 13. Selected Drugs and Minimum Detection Concentrations ${ }^{\dagger}$

\begin{tabular}{|c|c|c|c|c|c|}
\hline \multirow[t]{2}{*}{ Drug Class } & \multicolumn{2}{|c|}{$\begin{array}{c}\text { Minimum Concentration } \\
\text { Oral Fluid (ng/mL) }\end{array}$} & \multicolumn{2}{|c|}{$\begin{array}{c}\text { Minimum Concentration } \\
\text { Blood (ng/mL) }\end{array}$} & \multirow[t]{2}{*}{ Self-report Item } \\
\hline & Screen & Confirm & Screen & Confirm & \\
\hline $\begin{array}{l}\text { Cocaine } \\
\text { (Cocaine, } \\
\text { benzoylecgonine) }\end{array}$ & 20 & 8 & 25 & 10 & $\begin{array}{l}\text { Cocaine (e.g., crack } \\
\text { or coke) }\end{array}$ \\
\hline $\begin{array}{l}\text { Opiates } \\
\text { (6-AM, codeine, } \\
\text { morphine, } \\
\text { hydrocodone, } \\
\text { hydromorphone) }\end{array}$ & 40 & 10 & 25 & 10 & $\begin{array}{l}\text { Heroin } \\
\text { Morphine or Codeine } \\
\text { (e.g., Tylenol }{ }^{\circledR} \text { with } \\
\text { codeine) }\end{array}$ \\
\hline $\begin{array}{l}\text { Amphetamine/ } \\
\text { Methamphetamine } \\
\text { (MDMA, MDA, MDEA, } \\
\text { Ephedrine, } \\
\text { Psuedoephedrine) }\end{array}$ & $\begin{array}{l}50 \\
50\end{array}$ & 50 & $\begin{array}{l}20 \\
20\end{array}$ & 10 & $\begin{array}{l}\text { Amphetamine or } \\
\text { Methamphetamine } \\
\text { (e.g., speed, crank, } \\
\text { crystal meth) } \\
\text { Ecstasy }\end{array}$ \\
\hline $\begin{array}{l}\text { Cannabinoids } \\
\text { (THC, THC- } \\
\text { COO[THCA]) }\end{array}$ & 4 & 2 & 10 & 1 & $\begin{array}{l}\text { Marijuana (e.g., pot, } \\
\text { hash, weed) }\end{array}$ \\
\hline Phencyclidine & 10 & 10 & 10 & 10 & PCP (e.g., angeldust) \\
\hline $\begin{array}{l}\text { Benzodiazepines } \\
\text { (oxazepam, } \\
\text { nordiazepam, } \\
\text { bromazepam, } \\
\text { flurazepam, }\end{array}$ & 10 & 5 & 20 & 10 & $\begin{array}{l}\text { Benzodiazepines } \\
\text { (e.g., Valium }^{\circledR} \text { or } \\
\text { tranquilizers) }\end{array}$ \\
\hline
\end{tabular}




\begin{tabular}{|c|c|c|c|c|c|}
\hline \multirow[t]{2}{*}{ Drug Class } & \multicolumn{2}{|c|}{$\begin{array}{l}\text { Minimum Concentration } \\
\text { Oral Fluid (ng/mL) }\end{array}$} & \multicolumn{2}{|c|}{$\begin{array}{l}\text { Minimum Concentration } \\
\text { Blood (ng/mL) }\end{array}$} & \multirow[t]{2}{*}{ Self-report Item } \\
\hline & Screen & Confirm & Screen & Confirm & \\
\hline \multicolumn{6}{|l|}{$\begin{array}{l}\text { flunitrazepam, } \\
\text { lorazepam, } \\
\text { chlordiazepoxide, } \\
\text { temazepam, diazepam, } \\
\text { clonazepam, } \\
\text { alprazolam, triazolam, } \\
\text { midazolam, } \\
\text { nitrazepam) }\end{array}$} \\
\hline $\begin{array}{l}\text { Barbiturates } \\
\text { (Phenobarbital, } \\
\text { pentobarb, } \\
\text { secobarbital, butalbital) }\end{array}$ & 50 & 50 & 500 & 500 & $\begin{array}{l}\text { Barbiturates (e.g., } \\
\text { phenobarbital) }\end{array}$ \\
\hline Methadone & 50 & 25 & 50 & 10 & Methadone \\
\hline Ethyl alcohol & $.02 \%$ & $.02 \%$ & $.02 \%$ & $.02 \%$ & Alcohol \\
\hline Oxycodone (Percocet $\left.{ }^{\circledR}\right)$ & 25 & 10 & 25 & 10 & \multirow{5}{*}{$\begin{array}{l}\text { Prescription pain } \\
\text { killers (e.g., } \\
\text { Percocet巴, } \\
\text { OxyContin }{ }^{\circledR}, \\
\text { oxycodone, Demerol }^{\circledR} \text {, } \\
\text { Darvon }^{\circledR} \text { ) }\end{array}$} \\
\hline $\begin{array}{l}\text { Propoxyphene } \\
\left(\text { Darvon }^{\circledR}\right)\end{array}$ & 10 & 10 & 10 & 10 & \\
\hline Tramadol $\left(\right.$ Ultram $\left.{ }^{\circledR}\right)$ & 50 & 25 & 50 & 10 & \\
\hline Carisoprodol $\left(\right.$ Soma $\left.^{\circledR}\right)$ & 100 & 50 & 500 & 500 & \\
\hline Meperidine $\left(\right.$ Demerol $\left.^{(8)}\right)$ & & & & & \\
\hline Sertraline (Zoloft $囚)$ & 50 & 25 & 50 & 10 & \multirow{3}{*}{$\begin{array}{l}\text { Antidepressants (e.g., } \\
\left.\text { Prozac }^{\circledR}, \text { Zolof }^{\circledR}\right)\end{array}$} \\
\hline Fluoxetine $\left(\right.$ Prozac $\left.^{\mathbb{B}}\right)$ & 50 & 25 & 50 & 10 & \\
\hline $\begin{array}{l}\text { Tricyclic } \\
\text { Antidepressants } \\
\text { (amitryptiline, } \\
\text { nortriptyline) }\end{array}$ & 25 & 25 & 25 & 10 & \\
\hline Zolpidem $\left(\right.$ Ambien $\left.{ }^{\circledR}\right)$ & 10 & 10 & 10 & 10 & $\begin{array}{l}\text { Ambien }{ }^{\Theta} \text { or other } \\
\text { sleep aids }\end{array}$ \\
\hline $\begin{array}{l}\text { Methylphenidate } \\
\left.\text { (Ritalin }{ }^{\circledR}\right)\end{array}$ & 10 & 10 & 10 & 10 & $\begin{array}{l}\text { ADHD medications } \\
\left.\text { (e.g., Ritalin }{ }^{\circledR}\right)\end{array}$ \\
\hline Dextromethorphan & 50 & 20 & 50 & 20 & $\begin{array}{l}\text { Cough medicines } \\
\text { (e.g., Robitussin }^{\circledR}, \\
\text { Vicks } 44^{\circledR} \text {, etc.) }\end{array}$ \\
\hline Ketamine & 10 & 10 & 10 & 10 & Ketamine/Special K \\
\hline
\end{tabular}

${ }^{\dagger}$ Screening utilizes ELISA micro-plate and confirmation utilizes GC/MS or LC/MS/MS technology.

We screened using ELISA micro-plate technology. Confirmation was performed using GC/MS or LC/MS/MS technology. Our toxicological laboratory, Immunalysis Corporation, provided all necessary confirmations.

Cocaine, which can be used as a local anesthetic, is often abused because of its stimulating effects on the central nervous system (CNS). At low doses, cocaine might actually have performance enhancing effects; however, little is known about its effects on human performance at higher levels and in conjunction with alcohol. It is clearly a drug of abuse in the United States and worthy of study in drivers.

Opiates are narcotic analgesics used both medicinally and as drugs of abuse. After an initial rush, opiates act as CNS depressants and certainly could have performance-decreasing effects. 
Amphetamines are CNS stimulants and are used both medicinally and as drugs of abuse. Amphetamines are generally taken recreationally and to enhance performance (e.g., truck drivers staying awake). Ecstasy falls within this category, and as a methylated amphetamine derivative it also has hallucinogenic properties. Amphetamines have been associated with crash occurrence and could logically be associated with driving impairment both in the stimulation and withdrawal stages; in the latter case especially as the drug interacts with fatigue. The analytical methodology is described in an article by Moore, Coulter, and Crompton (2007).

Cannabinoids have a variety of effects on humans and can be associated with stimulant, sedative, and hallucinogenic effects. Both the experimental and epidemiologic evidence on cannabinoids' effects on driving are mixed. When marijuana is found in drivers, however, it is often in conjunction with alcohol, where an impairing effect is more likely. The most prevalent drug detected in the pilot study was marijuana (Lacey et al., 2007). There appeared to be a strong positive correlation between the oral fluid and blood tests, and the only discrepancies found in the pilot study (negative oral fluid and a positive blood) were from 10 cases in which the inactive metabolites were detected in blood but not the active tetrahydrocannabinol (THC). A positive metabolite result (THCA) with a negative parent compound (THC) is consistent with less recent use (e.g., in the days before sample was taken). A positive oral fluid for the parent compound is likely to be associated with very recent THC use, the timeframe consistent with potential impairing effects. Thus, such oral fluid results can be very informative. The laboratory procedures for testing the oral fluid results have been previously published in several articles (Moore et al., 2006; Moore, Rana, \& Coulter, 2007c; Coulter, Miller, Crompton, \& Moore, 2008).

Phencyclidine (PCP) is related to veterinary tranquilizers such as ketamine, that impair motor ability, but it also has hallucinogenic effects and is used as a recreational drug. PCP has serious performance diminishing effects and has been found in impaired-driving cases. Its determination in oral fluid has recently been published in Coulter, Crompton, and Moore (2008).

Benzodiazepines include many widely prescribed drugs (e.g., Valium ${ }^{\circledR}$, Xanax ${ }^{\circledR}$ ) to reduce anxiety. These drugs act as CNS depressants, show cross-tolerance to ethanol, and are potentially associated with driver impairment. Different types of benzodiazepines have very short to very long half-lives. For example, the desired/therapeutic effect of lorazepam (Ativan ${ }^{\circledR}$ ) is sedation, which would obviously have a detrimental effect on driving a motor vehicle. The most common benzodiazepine is diazepam (Valium $\left.{ }^{\circledR}\right)$ and/or its metabolites: nordiazepam, oxazepam, and temazepam. The confirmation procedure for the 2007 study included LC/MS/MS confirmation using the method described in Moore, Coulter, Crompton, and Zumwalt (2007).

Barbiturates are still widely prescribed CNS depressants and in some cases as anti-epileptic medications. Because of their depressive effects, barbiturates are associated with delayed reaction times and possibly loss of concentration; both effects likely to affect driving performance.

Methadone, a narcotic analgesic, is used both medicinally for opiate detoxification and maintenance, and for pain relief. It has also been used as a drug of abuse. It may have differential performance effects in naïve or recreational users versus tolerant therapeutic users, and certainly deserves study.

Painkillers are a class of drugs that may lead to driving impairment. Commonly used painkillers include oxycodone (an opioid). Oxycodone has similar effects to morphine and heroin. If used in 
combination with other depressants of the CNS, such as alcohol or benzodiazepines, it can cause severe impairment or lead to death. Tramadol, an opiate analgesic, has similar effects to oxycodone. Propoxyphene and meperidine, also atypical opiates, are included in the panel. The methods used for their analysis are described (Rana et al., 2006; Moore, Rana et al., 2007b). Other painkillers such as carisoprodol, a CNS depressant, and muscle relaxant (Soma® also called Miltown $\left.{ }^{\circledR}\right)$, are used as prescription drugs but can lead to abuse. Even at therapeutic concentrations, carisoprodol and its metabolite meprobamate may cause driving impairment as the desired effect is sedation.

Antidepressants are most commonly in the form of selective serotonin uptake inhibitors (SSRIs), such as fluoxetine (Prozac $\left.{ }^{\circledR}\right)$ and sertraline $\left(\right.$ Zoloft $\left.{ }^{\circledR}\right)$. They can cause impairment, especially in circumstances where extremely high blood concentrations are measured or if they are taken outside of medical need or therapeutic treatment. There is also an additional risk of impairment associated with combined use with alcohol.

Sleep aids such as Ambien ${ }^{\circledR}$ cause drowsiness and may cause dizziness. If consumed with alcohol, there is an increased likelihood of these symptoms. Sleep aids alone or in combination with alcohol could have a detrimental effect on driving ability.

Other stimulants, such as methylphenidate (sold as Ritalin $®$ ), are amphetamine-like prescription drugs commonly used to treat Attention Deficit Hyperactivity Disorder (ADHD) in children and adults. They are CNS stimulants. Some people abuse these drugs by crushing the tablets and snorting them. The effect of this other stimulant abuse is similar to that of cocaine or amphetamine.

Dextromethorphan, a synthetic analog of codeine, is an antitussive widely used in cough medicines (e.g., Robitussin ${ }^{\circledR}$, Sucrets ${ }^{\circledR}$, Vicks Formula $44 \AA$ ). When consumed in high doses in recreational use, it is a CNS depressant and may have driving impairment effects at those levels. The analytical method has recently been published in Rodrigues et al. (2008).

Ketamine (Special K) is used medicinally as a veterinary tranquilizer, but it is also abused as a recreational drug for its psychedelic effects. Ketamine use by humans would likely be associated with decrements in skills related to driving.

\section{Oral Fluid Collection Device}

Following the NRS interview and collection of the breath test, the interviewer requested an oral fluid sample and offered a \$10 incentive for providing one. We used the Quantisal ${ }^{\mathrm{TM}}$ (manufactured by Immunalysis Corporation) oral fluid collection device (see Appendix F of the Methodology Report [Lacey et al., 2009a]). The subject placed this device under his/her tongue and its pad changed color (blue) when $1 \mathrm{~mL}$ of oral fluid (the necessary sample volume) was collected. The collection device was then placed into a tube containing $3 \mathrm{~mL}$ of a stabilizing buffer solution, and capped for storage and transport to the laboratory. The steps are illustrated in Figure 2. 


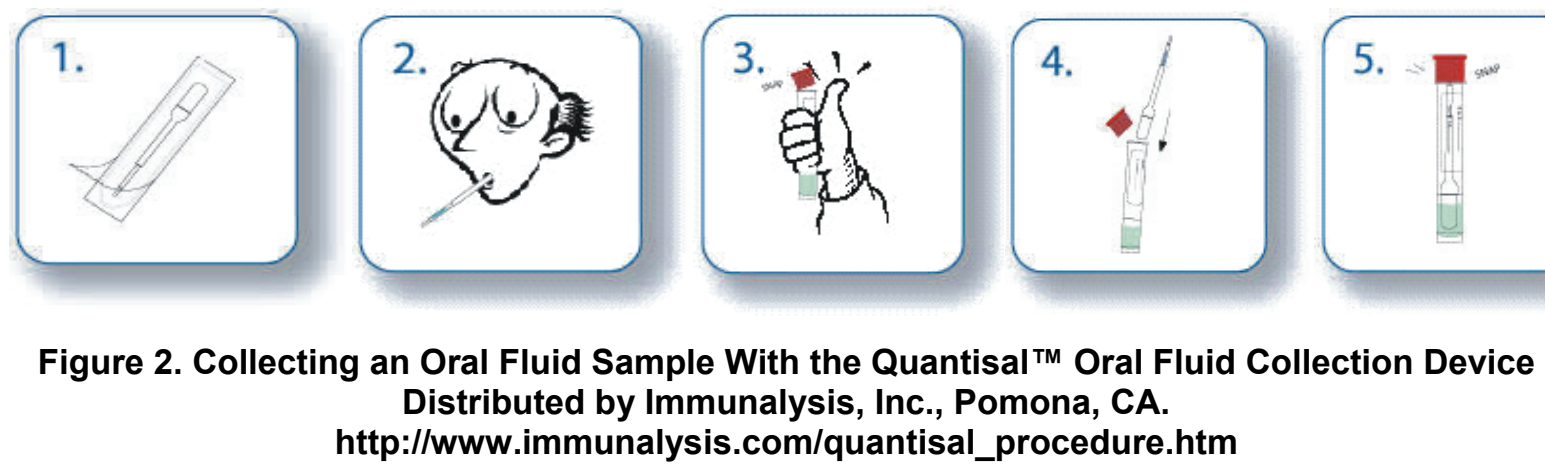

The oral fluid samples were labeled with pre-printed Chain-of-Custody (CoC) labels to be linked with the subject and additional data collected. This allowed the specimen to be tracked throughout the project. The $\mathrm{CoC}$ labels contained a unique identifier that corresponded to that sample. This number was also entered into the PDA. CoC numbers were preprinted by the laboratory and were used to maintain a documented link between each sample collected and the respondent who provided it. A different $\mathrm{CoC}$ number was assigned to the oral fluid and blood sample for an individual subject and the laboratory was blinded to any link between them. This assured the oral fluid and blood analyses and results were independent of one another.

The collection of oral fluid, while less invasive than the collection of blood or urine, has some associated difficulties (O'Neal, Crouch, Rollins, \& Fatah, 2000). Various researchers have noted that the method of collection and the medium itself (oral fluid) significantly affect drug concentration in the specimen and, consequently, whether some drugs can be detected at all. However, while some collection devices give no indication of the amount of oral fluid actually collected (rendering a quantitative result meaningless), the Quantisal ${ }^{\mathrm{TM}}$ oral fluid collection device collects $1 \mathrm{~mL}( \pm 10 \%)$ of clear oral fluid from the donor. Researchers have studied the device to assess the efficiency of drug release from the collection pad (Quintela, Crouch, \& Andrenyak, 2006; Moore et al., 2006; Moore, Rana, \& Coulter, 2007b) and have found a high rate of extraction efficiency. Tables 14 and 15 summarize the effectiveness of the Quantisal ${ }^{\mathrm{TM}}$ oral fluid collection device across a range of drugs by two different research groups. Findings above 100 percent are due to slight variations in the amount of the substances actually added to the scientific control samples (scientific error). 
Table 14. Extraction Efficiency of Quantisal ${ }^{\mathrm{TM}}$ Oral Fluid Collection Device Over a Range of Drugs: Quintela

\begin{tabular}{lcc}
\hline \multicolumn{1}{c}{ Drug } & Target Value $(\mathbf{n g} / \mathbf{m L})$ & Mean Recovery from the Pad (\%) \\
\hline Amphetamine & 50 & $94.3 \%$ \\
Methamphetamine & 50 & $103.8 \%$ \\
Cocaine & 20 & $91.2 \%$ \\
Benzoylecgonine & 20 & $86.9 \%$ \\
Codeine & 40 & $95.6 \%$ \\
Morphine & 40 & $92.6 \%$ \\
6-acetylmorphine & 4 & $92.2 \%$ \\
THC & 4 & $91.4 \%$ \\
Methadone & 50 & $99.7 \%$ \\
Oxazepam & 20 & $101.3 \%$ \\
\hline
\end{tabular}

Source: Quintela et al., 2006.

Table 15. Extraction Efficiency of Quantisal ${ }^{\mathrm{TM}}$ Oral Fluid Collection Device Over a Range of Drugs: Moore

\begin{tabular}{lcc}
\hline \multicolumn{1}{c}{ Drug } & Target Value $(\mathbf{n g} / \mathbf{m L})$ & Mean Recovery from the Pad (\%) \\
\hline Meperidine & 25 & $86.7 \%$ \\
Tramadol & 25 & $87.7 \%$ \\
Oxycodone & 20 & $96.6 \%$ \\
\hline Source: Moore, Rana, \& Coulter, 2007a; Moore et al, 2006: THC recovery from the pad $>80 \%$.
\end{tabular}

Source: Moore, Rana, \& Coulter, 2007a; Moore et al., 2006: THC recovery from the pad $>80 \%$.

For a more thorough discussion of the Quantisal device, see the pilot study report (Lacey et al., 2007).

\section{Blood Collection Procedures}

After completion of the oral fluid sample and the drug questionnaire, the interviewer requested that the subject provide a blood sample in exchange for an additional $\$ 50$ incentive. The incentives were given as money orders so subjects could not spend the money immediately, especially on items such as alcohol and other drugs.

Licensed phlebotomists conducted the blood draws. The phlebotomist set up the blood draw station in the rear seat of a rental van. The subject sat in the back seat of the van and the phlebotomist stood just outside the van or sat in the adjoining seat.

During blood draws, one gray-top tube $(10 \mathrm{~mL})$ of the subject's blood was drawn. There are several types of tubes available for the collection of blood specimens, with different color tops. The choice of tube is dependent upon the type of test to be performed on the blood. The Federal Aviation Administration (FAA) recommends the gray-topped tube for drug and alcohol testing of blood specimens. The gray-top tube contains two preservatives: potassium oxalate and sodium fluoride. The oxalate is an anti-coagulant, and the sodium fluoride is an anti-bacterial stabilizer. These preservatives reduce the need for refrigeration but do not affect the ability to detect and quantify drugs. Both additives are inorganic; therefore, they oxidize very slowly and are extremely stable. The preservative helps inhibit the degradation of cocaine in storage to its 
metabolite, benzoylecgonine (Toennes \& Kauert, 2001). The presence of sodium fluoride, with or without refrigeration, and potassium oxalate, effectively inhibits cocaine degradation, with 86 to 91 percent of the drug present after 48 hours. In contrast, substantial degradation of cocaine occurs in the samples stored without sodium fluoride (Brogan et al., 1992). The presence of the parent drug is particularly useful in the determination of recent use since more cocaine per se (prior to its transformation to benzoylecgonine) indicates more recent drug use. Additionally, gray-top tubes are helpful in conducting ethanol analysis because the sodium fluoride is an effective antibacterial agent that helps inhibit endogenous alcohol production.

For this study, glass tubing was used, as opposed to plastic, to better maintain reliable drug results. For example, in a study by Christophersen (1986) on the stability of THC in whole blood during storage, THC concentration in blood stored in glass vials for four weeks at -20 C remained unchanged; however, blood stored in plastic vials lost 60 to 100 percent of its THC content during storage. Thus, glass vials are recommended for collection of blood samples where marijuana content is suspected. In this study, approximately 10 percent of the blood samples were analyzed immediately upon receipt by the laboratory. However, the remaining samples were stored at 4 degrees Centigrade until additional funding was obtained for their analyses, approximately one year later. As a check, on 13 samples, which had been analyzed initially and were found to be positive for THC and/or its metabolites, reanalysis for THC and its metabolites one year later revealed that, though values obtained were generally lower than in the initial analyses, each specimen tested positive for THC and/or a metabolite at the retest. Additionally, six samples which initially had been found to be positive for cocaine and/or its metabolites were reanalyzed and though parent drug values had eroded, metabolite values had increased and all were still positive for cocaine at retest. For eight opiate samples and six amphetamine samples, the results at retest remained positive after one year.

The blood sample tubes were labeled with pre-printed Chain-of-Custody $(\mathrm{CoC})$ labels that linked the blood sample to the oral fluid sample to the subject, so the specimen could be tracked throughout the project. The $\mathrm{CoC}$ labels contained a unique identifier that corresponded to that sample, thus there was no identifying information traceable to the subject. This number was also entered into the PDA. CoC numbers were preprinted by the laboratory and were used to maintain a documented link between each sample collected and the respondent who provided it. As noted above, a different $\mathrm{CoC}$ number was assigned to the oral fluid and blood sample for an individual subject and the laboratory was blinded to any link between them.

In the few cases where phlebotomists were not able to draw a full tube for a subject because some individuals had small and/or difficult-to-locate veins, the laboratory was able to conduct an initial screening test; however, it was not able to conduct a confirmatory analysis by GC/MS due to the insufficient volume.

At the conclusion of the blood draw procedure, the subject received the $\$ 50$ incentive and sat for a moment in the blood draw station. The subject was offered a piece of candy before being directed safely out of the survey site and back onto the roadway.

Once collected, blood samples were stored either in refrigerators or in coolers with blue ice packs if no refrigeration was available. The samples were subsequently shipped to the laboratory with blue ice as an additional precaution.

Spanish-speaking participants were escorted to the phlebotomist by the Spanish-speaking interviewer, and a Spanish consent form was given to the participant. The interviewer read the 
consent form to them and stayed with the participant to answer any questions and provide translation between the phlebotomist and participant.

\section{Drug Questionnaire}

While they provided an oral fluid sample, drivers were asked to complete a drug questionnaire. The 27-item questionnaire (Table 16) included a list of drugs including tobacco, cough medicine, other illegal, prescription, and over-the-counter drugs. For items 1-23, subjects indicated when they last used a particular medication/drug, by responding "Tonight," "Past 2 days," "Past month," Past year," "Over a year ago," or "Never."

\section{Table 16. Drug Questionnaire Survey}

\begin{tabular}{cl}
\hline Item \# & \\
\hline 1 & Tobacco (e.g., cigarettes, cigars) \\
2 & Cough medicines (e.g., Robitussin, Vicks 44, etc.) \\
3 & Other over-the-counter medicines \\
4 & Prescription Pain Killers (e.g., Percocet, OxyContin, Oxycodone, Demerol, Darvon) \\
5 & Ambien or other sleep aids \\
6 & ADHD medications (e.g., Ritalin, Aderall, Concerta) \\
7 & Muscle relaxants (e.g., Soma, Miltown) \\
8 & Prescription dietary supplements (e.g., Phentermine) \\
9 & Antidepressants (e.g., Prozac, Zoloft) \\
10 & Marijuana (e.g., pot, hash, weed) \\
11 & Cocaine (e.g., crack or coke) \\
12 & Heroin \\
13 & Methadone \\
14 & LSD (acid) \\
15 & Morphine or Codeine (e.g., Tylenol with Codeine) \\
16 & Ecstasy (e.g., "E", Extc, MDMA, "X") \\
17 & Amphetamine or Methamphetamine ( e.g., speed, crank, crystal meth) \\
18 & GHB \\
19 & PCP (e.g., Angeldust) \\
20 & Rohypnol (Ruffies) \\
21 & Ketamine (Special K) \\
22 & Benzodiazepines (e.g., Valium or tranquilizers) \\
23 & Barbiturates (e.g., Phenobarbital) \\
24 & Do you believe any of the medications/drugs you have taken (or are taking) could affect your \\
25 & driving? \\
26 & Have you taken any medications or drugs in the past YEAR that you think may have affected your \\
27 & Have you taken any medications or drugs TODAY that you think may affect your driving? \\
& Have you ever NOT driven because you were on a medication/drug? \\
\hline
\end{tabular}




\section{Biological Sample Analysis Procedures}

The following sections briefly describe the analytic techniques used in the analyses of oral fluid and blood samples to determine the presence of the drugs of interest in this study.

\section{Oral Fluid Sample Analysis Procedures}

Each weekend, the tubes from each data-collection period were packaged together and sent overnight to a laboratory for analysis. Upon receipt of the specimens in the testing facility, screening analysis was carried out using enzyme-linked immunosorbent assays (ELISA) at the cut-off concentrations described in Table 13. Screen positive specimens were then reanalyzed, using a separate sample of the fluid, using gas chromatography-mass spectrometry (GC/MS) or liquid chromatography with tandem mass spectral detection (LC/MS/MS) according to standard operating procedures. All methods were fully validated according to good laboratory practices, and all standard operating procedures are on file at Immunalysis Corporation.

\section{Gas Chromatography-Mass Spectrometry (GC/MS)}

Instrumentation:

Agilent 6890 gas chromatography - 5973 or 5975 mass selective detector (GC/MSD); electron impact (EI) mode.

Extraction:

Oral fluid (1 mL) of diluted specimen (1:3 buffer) was extracted using mixed mode solid phase methods with drug specific column phases.

Derivatization:

Drug specific derivatives used for maximum detectability and stability.

Drugs included in the confirmation profile are shown in Table 13.

\section{Liquid Chromatography-Tandem Mass Spectrometry (LC/MS-MS)}

Instrumentation:

Agilent LC/MS-MS System: 1200 Series LC pump 6410 Triple Quadropole.

Zorbax Eclipse XDB C18 (4.6 x 50mm x $1.8 \mu \mathrm{m})$ column.

\section{Extraction:}

Blood $(1 \mathrm{~mL})$; protein precipitate with cold acetonitrile; mixed mode solid phase extraction using drug specific column phases. 


\section{Blood Sample Analysis Procedures}

Upon receipt of the specimens by the testing facility, screening analysis for 10 percent of the sample was carried out using enzyme-linked immunosorbent assays (ELISA) at the cut-off concentrations described in Table 13. The remaining 90 percent of the sample was stored at $4^{\circ}$ centigrade until funding was provided for their analysis. Again, specific drugs tested are shown in Table 13. Screen positive specimens were confirmed using either gas chromatography with mass spectral detection (GC/MS) or liquid chromatography with tandem mass spectral detection (LC/MS/MS). All methods were fully validated according to good laboratory practices. See above for instrumentation.

\section{Ethanol (Oral Fluid and Blood)}

Screen positive alcohol specimens were sent for confirmation to BioTox Laboratories or Immunalysis Corporation.

\section{Instrumentation:}

Perkin-Elmer: Model F-45 Gas Chromatograph.

Flame ionization detector (FID).

0.2 percent Carbowax 1500 Graphpac-GC, 80/100 column (6 ft. x 1/8 in. ID).

\section{Extraction:}

Whole blood or 1:3 buffered oral fluid $(0.1 \mathrm{~mL})$, add $1 \mathrm{~mL}$ double deionized water containing 0.1 percent propanol.

Analyzed using headspace GC/FID.

\section{Drug Classes and Categories}

Due to the large number of drugs tested, results were consolidated into drug classes and categories. Drug classes are defined according to potential drug effects and include stimulants, sedatives, marijuana, antidepressants, narcotic analgesics, and other. Drugs were separately categorized as illegal, prescription, and over-the-counter. ${ }^{12}{ }^{13}$ Though some drugs could logically fall into more than one category, we made the categories mutually exclusive and assigned each drug to only one category. This approach facilitates clear presentation of results.

Tables 17 and 18 present drug classes and categories. In the tables, the shaded entries indicate drugs that were identified only through blood analyses. The non-shaded entries are drugs that were identified through both oral fluid and blood analyses.

\footnotetext{
${ }^{12}$ Drugs may be classified in different ways depending on the use of the classification system. For example, in NHTSA's drug evaluation and classification (DEC) program the categories CNS Depressants, CNS Stimulants, Hallucinogens, Dissociative Anesthetic (PCP), Narcotic Analgesics, Inhalants, and Cannabis are used.

${ }^{13}$ Due to relative small sample sizes and for analytical purposes, the over-the-counter and prescription categories were further collapsed into a single category ("Medications")
} 


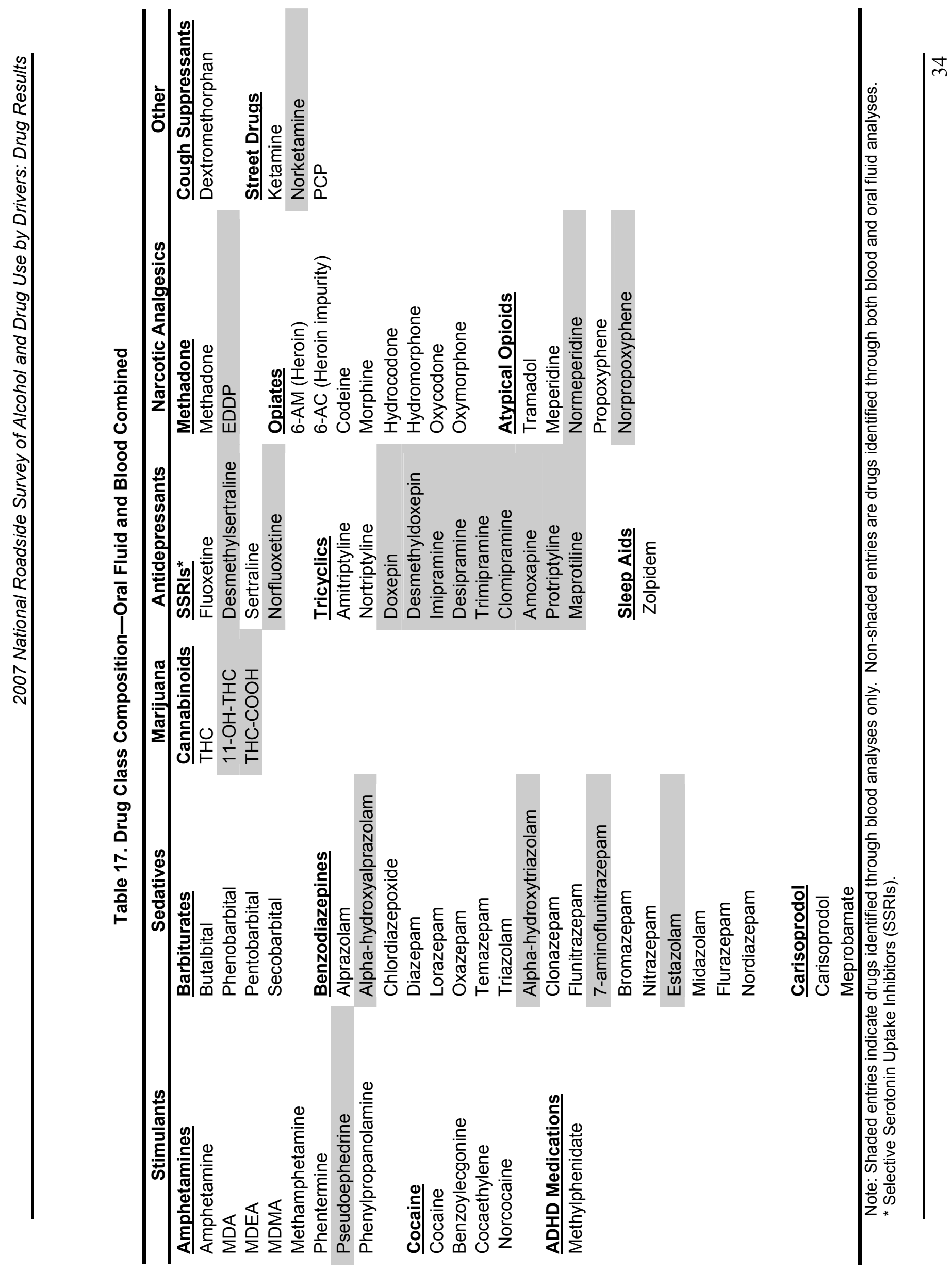



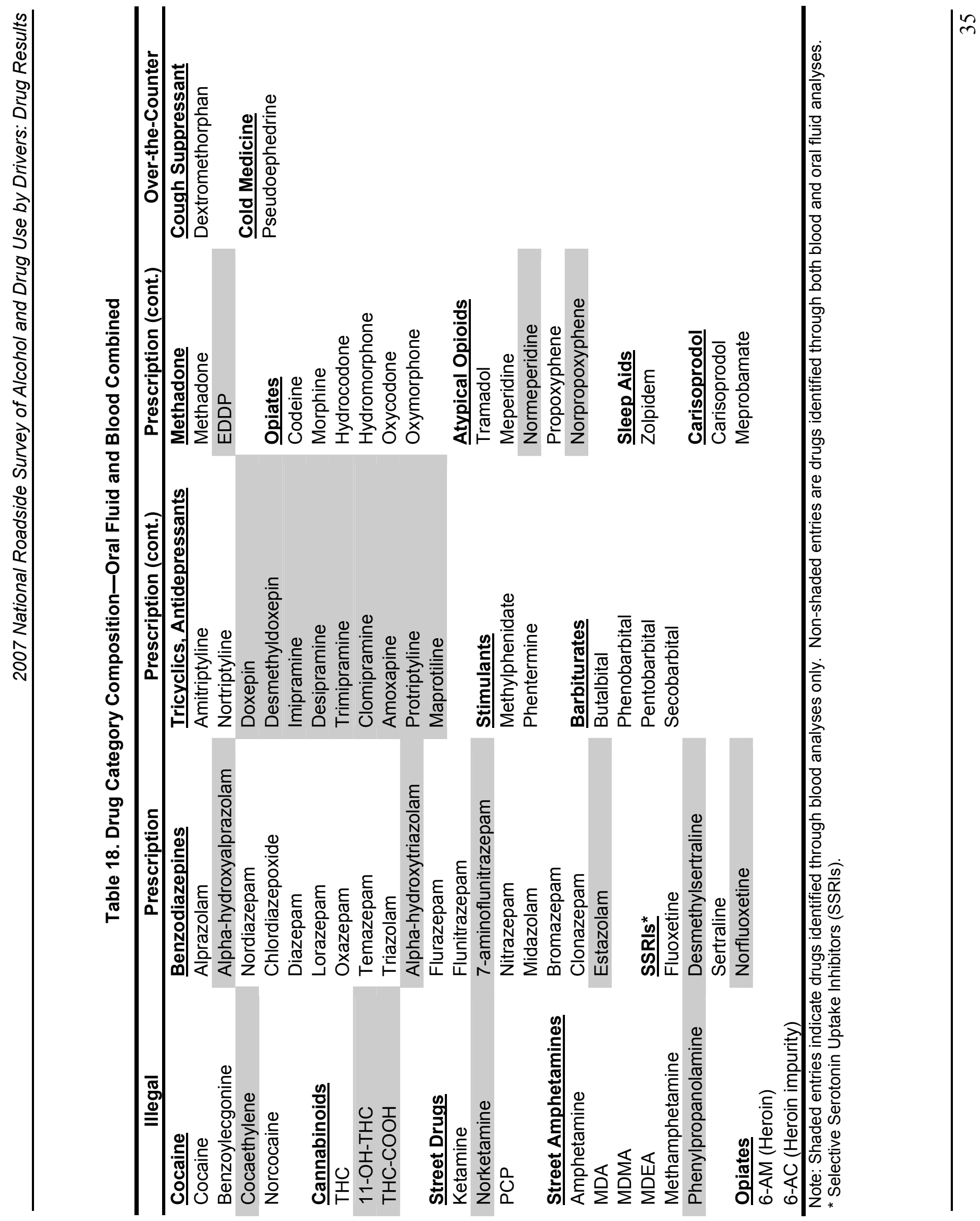


\section{Results}

Since two different biological matrices (oral fluid and blood) were gathered to be analyzed for the presence of drugs, we present prevalence estimates in three different ways in this report.

1) We present both daytime and nighttime drug prevalence estimates based on the analyses of the oral fluid samples alone, and then in combination with alcohol using breath alcohol test results. Tables reporting self-report drug use, observed safety measures, and reports with contact with the criminal justice system and the health care system follow these results.

2) We next present nighttime drug prevalence estimates based on analyses of blood, ${ }^{14}$ and then in combination with alcohol using breath alcohol test results.

3) The third section presents nighttime prevalence results based on the combination of the results of the oral fluid / blood analyses, and subsequently in combination with alcohol using breath alcohol test results. We conclude this section by presenting prevalence estimates for specific drugs from oral fluid and/or blood combined. In each of the sections, the results are presented first in terms of drivers who were positive for any drug, then by class, followed by category as described in Tables 17 and 18.

Throughout this report, we do not combine results for daytime and nighttime survey respondents, but display the two groups separately because the sampling frame is different for the two groups. The daytime drivers were sampled during a single Friday two-hour period in each PSU, while the nighttime drivers were sampled during four two-hour periods (two on Friday night and two on Saturday night in each PSU). Thus, combining the daytime and nighttime samples would not result in a meaningful representation of driver drug use overall.

Each of the various sampling stages (or frames) required a separate calculation of probability, which then became a component of the final probability computation, reflecting all levels or frames. The total weighted number of the sample was identical to the total number of eligible drivers entering the survey bays, including refusers, but was adjusted to reflect the estimated distribution of those drivers in the 48 contiguous States. Error terms for the analyses were computed by STATA (Stat Corp., 2006) to account for the differential weights, and the amount of variance attributable to the various sampling frames. Further information on the weighting of the data can be found in the Methodology Report (Lacey et al., 2009a).

\section{Oral Fluid Results (Daytime and Nighttime Samples) Driver Drug Use Prevalence Based on Oral Fluid Results}

This section of the report presents the overall results of oral fluid analyses for all of the drugs indicated in the introductory section. Drivers who tested positive for one or more of the drugs we tested in oral fluid are categorized as drug-positive. It should be emphasized that this set of tables aggregates over-the-counter, prescription, and illegal drugs and metabolites of drugs in each category, indicating only that those who tested positive have recently consumed at least one of the tested drugs and not that they were necessarily impaired by the substance.

\footnotetext{
${ }^{14}$ Daytime data collection did not include requests for blood samples.
} 
Unless explicitly indicated, sample size $(\mathrm{N})$ refers to the actual, unweighted number of respondents. Percentages are weighted. Sample size may vary between tables because of missing values.

Comparison of drug prevalence by time of day (Table 19) indicates that 11 percent of drivers in the daytime sample were drug-positive. This level was significantly lower than the 14.4 percent of nighttime drivers who tested positive for drugs $(p<.01)$.

Table 19. Drug Prevalence by Time of Day (Oral Fluid)

\begin{tabular}{lcc}
\hline \multicolumn{1}{c}{ Time of Day } & $\begin{array}{c}\mathbf{N} \\
\text { (Unweighted) }\end{array}$ & $\begin{array}{c}\text { \% Drug Positive } \\
\text { (Weighted) }\end{array}$ \\
\hline Daytime & 1,850 & $11.0 \%$ \\
Nighttime & 5,869 & $14.4 \%$ \\
\hline
\end{tabular}

Further, when we examined drug prevalence by time of day/session (Table 20), we found that late night (Sessions 3 and 5) drivers were significantly more likely to be drug-positive (17.2\% and $17.4 \%$ respectively) than Friday daytime (Session 1) drivers (11\%) or Friday and Saturday early evening (Sessions 2 and 4 ) drivers $(12.9 \%$ and $13.6 \%$ respectively) $(p<.01)$.

Table 20. Drug Prevalence by Time of Day/Session (Oral Fluid)

\begin{tabular}{lcc}
\hline \multicolumn{1}{c}{ Session } & $\begin{array}{c}\mathbf{N} \\
\text { (Unweighted) }\end{array}$ & $\begin{array}{c}\text { \% Drug Positive } \\
\text { (Weighted) }\end{array}$ \\
\hline 1: Friday, 9:30 a.m. - 11:30 a.m. or & 1,850 & $11.0 \%$ \\
1:30 p.m. - 3:30 p.m. & 1,610 & $12.9 \%$ \\
\hline 2: Friday, 10:00 p.m. - Midnight & 1,299 & $17.2 \%$ \\
\hline 3: Friday, 1:00 a.m. - 3:00 a.m. & 1,684 & $13.6 \%$ \\
\hline 4: Saturday, 10:00 p.m. - Midnight & 1,276 & $17.4 \%$ \\
\hline 5: Saturday, 1:00 a.m. - 3:00 a.m. & & \\
\hline
\end{tabular}

Comparison of drug prevalence by time and region (Table 21) revealed that the Northeast region had the greatest percentage of drug-positive findings in the nighttime driving sample, at 17.3 percent $(p<.05)$. The Northeast region also had the second highest percentage in the daytime driving sample at 12.5 percent (although there were no statistical differences by region during the daytime). In spite of the Northeast regions' relatively high prevalence of drug-positives, no clear pattern by region emerged. 
Table 21. Drug Prevalence by Time of Day and Region ${ }^{15}$ (Oral Fluid)

\begin{tabular}{l|lcc}
\hline \multirow{2}{*}{ Time of Day } & \multicolumn{1}{c}{ Region } & $\begin{array}{c}\text { N } \\
\text { (Unweighted) }\end{array}$ & $\begin{array}{c}\text { \% Drug Positive } \\
\text { (Weighted) }\end{array}$ \\
\hline \multirow{5}{*}{ Daytime } & Midwest & 546 & $11.5 \%$ \\
& Northeast & 379 & $12.5 \%$ \\
& South & 472 & $13.1 \%$ \\
& West & 453 & $8.9 \%$ \\
& Overall Daytime & 1,850 & $11.0 \%$ \\
\hline \multirow{5}{*}{ Nighttime } & Midwest & 1,694 & $15.0 \%$ \\
& Northeast & 1,111 & $17.3 \%$ \\
& South & 1,559 & $14.0 \%$ \\
& West & 1,505 & $12.9 \%$ \\
& Overall Nighttime & 5,869 & $14.4 \%$ \\
\hline
\end{tabular}

Although the daytime driving sample showed no statistically significant difference in drug prevalence between males and females (Table 22), in the nighttime driving sample, male drivers were significantly more likely to be drug-positive $(16.5 \%)$ than female drivers $(11.3 \%)(p<.01)$.

Table 22. Drug Prevalence by Time of Day and Gender (Oral Fluid)

\begin{tabular}{l|lcc}
\hline \multirow{2}{*}{ Time of Day } & \multicolumn{1}{c}{ Gender } & $\begin{array}{c}\text { N } \\
\text { (Unweighted) }\end{array}$ & $\begin{array}{c}\text { \% Drug Positive } \\
\text { (Weighted) }\end{array}$ \\
\hline \multirow{3}{*}{ Daytime } & Males & 1,032 & $11.0 \%$ \\
& Females & 811 & $11.3 \%$ \\
& Overall Daytime & 1,843 & $11.0 \%$ \\
\hline \multirow{3}{*}{ Nighttime } & Males & 3,605 & $16.5 \%$ \\
& Females & 2,250 & $11.3 \%$ \\
& Overall Nighttime & 5,855 & $14.4 \%$ \\
\hline
\end{tabular}

Comparison of drug prevalence by time of day and age (Table 23) showed that, within the daytime driving sample, drivers aged 45-64 showed the highest percentage of drug positives, and drivers aged 16-20 and aged 65+ were significantly less likely to be positive than other ages of drivers $(p<.05)$. In the nighttime driving sample, drivers aged 45-64 and 65+ were significantly less likely to be drug positive $(p<.01)$. Drivers aged 16-20, 21-34 years, and 35-44 years all had results similar to each other. Age was self-reported by respondent. Note that in Table 23 as well as upcoming tables, the age ranges are not of equal intervals but were developed to roughly

\footnotetext{
${ }^{15}$ Regions are defined by the NASS/GES system according to U.S. Census Regions (Midwest includes the West North Central and East North Central States, Northeast includes New England and Middle Atlantic States, South includes the West South Central, East South Central, and South Atlantic States, and West includes West and Mountain States.
} 
categorize underage drivers (16-20), young drivers (21-34), followed by middle age and late middle age (35-44 and 45-64), and finally by senior drivers (65+ years).

Table 23. Drug Prevalence by Time of Day and Age (Oral Fluid)

\begin{tabular}{l|ccc}
\hline \multirow{2}{*}{ Time of Day } & Age & $\begin{array}{c}\text { N } \\
\text { (Unweighted) }\end{array}$ & $\begin{array}{c}\text { \% Drug Positive } \\
\text { (Weighted) }\end{array}$ \\
\hline \multirow{5}{*}{ Daytime } & $16-20$ & 99 & $6.2 \%$ \\
& $21-34$ & 436 & $11.2 \%$ \\
& $35-44$ & 374 & $11.6 \%$ \\
& $45-64$ & 668 & $13.3 \%$ \\
& $65+$ & 245 & $6.4 \%$ \\
& Overall Daytime & 1,822 & $11.1 \%$ \\
\hline \multirow{5}{*}{ Nighttime } & $16-20$ & 961 & $16.1 \%$ \\
& $21-34$ & 2,437 & $17.1 \%$ \\
& $35-44$ & 1,042 & $15.2 \%$ \\
& $45-64$ & 1,216 & $9.5 \%$ \\
& $65+$ & 148 & $2.0 \%$ \\
& Overall Nighttime & 5,804 & $14.6 \%$ \\
\hline
\end{tabular}

Gender comparisons within age groups (Table 24) revealed that, within the daytime sample, drug prevalence among female daytime drivers aged 45-64 (16.8\%) was significantly higher than male drivers of the same age group $(9.7 \%)(p<.05)$. The same was true of the nighttime sample, with drug prevalence among female drivers aged 45-64 (13.1\%) being significantly higher than male drivers of the same age group $(7.2 \%)(p<.01)$.

Within the daytime sample, drug prevalence among male drivers aged 21-34 years was statistically higher than among female drivers of the same age group $(13.9 \%$ versus $7.5 \%)(p<$ $.05)$. Additionally, in the nighttime sample, drug prevalence among male drivers in age categories 16-20 years, 21-34 years, and 35-44 years was significantly higher than the sameaged female counterparts $(p<.01)$. 
Table 24. Drug Prevalence by Time of Day, Age, and Gender (Oral Fluid)

\begin{tabular}{|c|c|c|c|c|}
\hline Time of Day & Gender & Age & $\begin{array}{c}\mathbf{N} \\
\text { (Unweighted) }\end{array}$ & $\begin{array}{c}\% \text { Drug Positive } \\
\text { (Weighted) }\end{array}$ \\
\hline \multirow{12}{*}{ Daytime } & \multirow{6}{*}{ Males } & $16-20$ & 59 & $4.5 \%$ \\
\hline & & $21-34$ & 243 & $13.9 \%$ \\
\hline & & $35-44$ & 192 & $13.7 \%$ \\
\hline & & $45-64$ & 362 & $9.7 \%$ \\
\hline & & $65+$ & 161 & $7.1 \%$ \\
\hline & & Overall Males - Daytime & 1,017 & $11.0 \%$ \\
\hline & \multirow{6}{*}{ Females } & $16-20$ & 39 & $10.3 \%$ \\
\hline & & $21-34$ & 192 & $7.5 \%$ \\
\hline & & $35-44$ & 181 & $10.1 \%$ \\
\hline & & $45-64$ & 304 & $16.8 \%$ \\
\hline & & $65+$ & 84 & $4.8 \%$ \\
\hline & & Overall Females - Daytime & 800 & $11.4 \%$ \\
\hline \multirow{12}{*}{ Nighttime } & \multirow{6}{*}{ Males } & $16-20$ & 598 & $20.7 \%$ \\
\hline & & $21-34$ & 1,492 & $20.2 \%$ \\
\hline & & $35-44$ & 630 & $18.2 \%$ \\
\hline & & $45-64$ & 734 & $7.2 \%$ \\
\hline & & $65+$ & 101 & $1.9 \%$ \\
\hline & & Overall Males - Nighttime & 3,555 & $16.7 \%$ \\
\hline & \multirow{6}{*}{ Females } & $16-20$ & 362 & $9.5 \%$ \\
\hline & & $21-34$ & 940 & $11.9 \%$ \\
\hline & & $35-44$ & 409 & $10.9 \%$ \\
\hline & & $45-64$ & 480 & $13.1 \%$ \\
\hline & & $65+$ & 47 & $2.3 \%$ \\
\hline & & Overall Females - Daytime & 2,238 & $11.3 \%$ \\
\hline
\end{tabular}

Comparisons by self-reported race and ethnicity (Table 25) showed that, in both the daytime and nighttime samples, drivers who identified themselves as Asian were significantly less likely to be drug-positive (4.1\% and 1.8\% respectively) than drivers who identified themselves as African American, Hispanic, White, or Other ( $p<.05$ at daytime, $p<.01$ at nighttime). Although statistically non-significant, African American drivers were found to have the highest percentage of drug-positive results in both daytime (14.4\%) and nighttime (20.5\%) samples, followed by Other (12.8\% daytime and $16.2 \%$ nighttime), and White (11.6\% daytime and $15 \%$ nighttime). 
Table 25. Drug Prevalence by Race/Ethnicity (Oral Fluid)

\begin{tabular}{llrr}
\hline \multirow{2}{*}{ Time of Day } & Race/Ethnicity & $\begin{array}{c}\text { N } \\
\text { (Unweighted) }\end{array}$ & $\begin{array}{c}\text { \% Drug Positive } \\
\text { (Weighted) }\end{array}$ \\
\hline \multirow{5}{*}{ Daytime } & African American & 267 & $14.4 \%$ \\
& Asian & 46 & $4.1 \%$ \\
& Hispanic & 253 & $8.9 \%$ \\
& White & 1,192 & $11.6 \%$ \\
& Other & 59 & $12.8 \%$ \\
& Overall Daytime & 1,817 & $11.2 \%$ \\
\hline \multirow{5}{*}{ Nighttime } & African American & 973 & $20.5 \%$ \\
& Asian & 191 & $1.8 \%$ \\
& Hispanic & 1,006 & $11.8 \%$ \\
& White & 3,355 & $15.0 \%$ \\
& Other & 272 & $16.2 \%$ \\
& Overall Nighttime & 5,797 & $14.6 \%$ \\
\hline
\end{tabular}

Race/Ethnic groups other than "Hispanic" are always "non-Hispanic."

Comparisons of drug prevalence by education level (Table 26) revealed that prevalence of drug use increased from the daytime sample to the nighttime sample across all education levels except "some college." Daytime drivers who identified themselves as college graduates or having some graduate experience were statistically less likely to be drug-positive than those with less education $(p<.01)$. This remained the case within the nighttime sample, but only for drivers who identified themselves as college graduates $(p<.01)$.

Table 26. Drug Prevalence by Education Level (Oral Fluid)

\begin{tabular}{l|lcc}
\hline \multirow{2}{*}{ Time of Day } & \multicolumn{1}{c}{ Education Level } & $\begin{array}{c}\text { N } \\
\text { (Unweighted) }\end{array}$ & $\begin{array}{c}\text { \% Drug Positive } \\
\text { (Weighted) }\end{array}$ \\
\hline \multirow{5}{*}{ Daytime } & Not a High School Graduate & 162 & $15.4 \%$ \\
& High School Graduate & 476 & $15.0 \%$ \\
& Some College & 593 & $13.9 \%$ \\
& College Graduate & 419 & $5.5 \%$ \\
& Some Graduate Work & 173 & $4.1 \%$ \\
& Overall Daytime & 1,823 & $11.1 \%$ \\
\hline \multirow{5}{*}{ Nighttime } & Not a High School Graduate & 573 & $18.4 \%$ \\
& High School Graduate & 1,470 & $22.4 \%$ \\
& Some College & 2,218 & $11.6 \%$ \\
& College Graduate & 1,156 & $9.5 \%$ \\
& Some Graduate Work & 387 & $15.7 \%$ \\
& Overall Nighttime & 5,804 & $14.6 \%$ \\
\hline
\end{tabular}

Comparing drug prevalence by employment status (Table 27) showed that, in the daytime sample, drug prevalence among unemployed drivers and drivers on disability was significantly higher than that of employed drivers or homemakers, students and those who reported they were 
retired $(p<.01)$. In the nighttime sample, drug prevalence among drivers on disability was again significantly higher than employed drivers $(p<.01)$, while no statistical difference in drug prevalence was found in the nighttime sample between unemployed and employed drivers. Within the nighttime sample, employed drivers had significantly higher drug prevalence than "homemaker" and "retired" drivers $(p<.01)$.

Table 27. Drug Prevalence by Employment Status (Oral Fluid)

\begin{tabular}{l|lrc}
\hline \multirow{2}{*}{ Time of Day } & \multicolumn{1}{c}{ Gender } & $\begin{array}{c}\text { N } \\
\text { (Unweighted) }\end{array}$ & $\begin{array}{c}\text { \% Drug Positive } \\
\text { (Weighted) }\end{array}$ \\
\hline \multirow{5}{*}{ Daytime } & Employed/Self Employed & 1,240 & $10.4 \%$ \\
& Homemaker & 90 & $4.2 \%$ \\
& Student & 73 & $7.2 \%$ \\
& Unemployed & 78 & $21.3 \%$ \\
& Retired & 286 & $13.9 \%$ \\
& On Disability & 45 & $38.7 \%$ \\
& Other & 11 & $30.7 \%$ \\
& Overall Daytime & 1,823 & $11.1 \%$ \\
\hline \multirow{5}{*}{ Nighttime } & Employed/Self Employed & 4,618 & $15.0 \%$ \\
& Homemaker & 104 & $5.9 \%$ \\
& Student & 585 & $13.2 \%$ \\
& Unemployed & 204 & $16.8 \%$ \\
& Retired & 205 & $7.4 \%$ \\
& On Disability & 67 & $41.2 \%$ \\
& Other & 22 & $4.3 \%$ \\
& Overall Nighttime & 5,805 & $14.6 \%$ \\
\hline
\end{tabular}

Drug prevalence rates among drivers of various vehicle types (passenger vehicle, pickup, sports utility vehicles (SUV), van/minivan, and motorcycles) (Table 28) were not statistically different in the daytime sample. Note, however, that motorcyclists had the greatest percentage of drugpositive results in both the daytime and nighttime samples, although this difference was found to be statistically significant only in the nighttime sample $(p<.01)$. 
Table 28. Drug Prevalence by Vehicle Type (Oral Fluid)

\begin{tabular}{cllc}
\hline $\begin{array}{c}\text { Time of } \\
\text { Day }\end{array}$ & Vehicle Type & $\begin{array}{c}\text { N } \\
\text { (Unweighted) }\end{array}$ & $\begin{array}{c}\text { \% Drug } \\
\text { Positive } \\
\text { (Weighted) }\end{array}$ \\
\hline \multirow{5}{*}{ Daytime } & Passenger Vehicle & 952 & $12.1 \%$ \\
& Pickup & 285 & $6.6 \%$ \\
& SUV & 394 & $9.7 \%$ \\
& Van \& Minivan & 177 & $12.6 \%$ \\
& Motorcycle & 30 & $24.8 \%$ \\
& Overall Daytime & 1,838 & $11.0 \%$ \\
\hline \multirow{5}{*}{ Nighttime } & Passenger Vehicle & 3,623 & $15.1 \%$ \\
& Pickup & 695 & $14.4 \%$ \\
& SUV & 1055 & $12.1 \%$ \\
& Van \& Minivan & 381 & $13.0 \%$ \\
& Motorcycle & 73 & $32.4 \%$ \\
& Overall Nighttime & 5,827 & $14.5 \%$ \\
\hline
\end{tabular}

\section{Driver Drug Use Prevalence by Drug Class Based on Oral Fluid Results}

In this section of the report, we display driver drug use prevalence by class of drug. The classes of drugs for which we tested were: antidepressants, marijuana, narcotic-analgesics, sedatives, stimulants, and other (see Table 17). Because some drivers tested positive for drugs in more than one class, an additional, mutually exclusive category "More than 1 Class" appears in the drug class tables. This was done to avoid double counting individual positive results. Thus, for example, since marijuana is both a class by itself and could appear in the "More than 1 class" cell as well (as could other classes of drugs) from these tables one cannot arrive at an overall prevalence estimate for marijuana alone. Detailed summaries of prevalence estimates for individual drugs appear in Tables 137-140 later in the report.

\section{Drug Class}

Comparison of drug classes by time of day (Table 29) indicated that, when examining all drivers, nighttime drivers were significantly more likely to test positive for more than one drug class $(2.3 \%)$ than daytime drivers $(1.5 \%)(p<.01)$.

Table 29. Number and Distribution of Drug Classes by Time of Day (Oral Fluid)

\begin{tabular}{l|ccc}
\hline \multirow{2}{*}{ Time of Day } & $\begin{array}{c}\text { Number of } \\
\text { Drug Classes }\end{array}$ & $\begin{array}{c}\text { N } \\
\text { (Unweighted) }\end{array}$ & $\begin{array}{c}\% \\
\text { (Weighted) }\end{array}$ \\
\hline \multirow{4}{*}{ Daytime } & 1 & 206 & $9.5 \%$ \\
& $2+$ & 40 & $1.5 \%$ \\
& Negative & 1,604 & $89.0 \%$ \\
& Overall Daytime & 1,850 & $100.0 \%$ \\
\hline \multirow{4}{*}{ Nighttime } & 1 & 680 & $12.1 \%$ \\
& $2+$ & 156 & $2.3 \%$ \\
& Negative & 5,033 & $85.6 \%$ \\
& Overall Nighttime & 5,869 & $100.0 \%$ \\
\hline
\end{tabular}


However, when examining only drug-positive drivers (Table 30), there were no significant differences between daytime and nighttime drivers in the percentage of single-drug users $(86.2 \%$ versus $83.7 \%)$ or multi-drug users $(13.8 \%$ versus $16.3 \%)$.

Table 30. Number and Distribution of Drug Classes by Time of Day (Drug Positives Only) (Oral Fluid)

\begin{tabular}{l|ccc}
\hline \multirow{2}{*}{ Time of Day } & $\begin{array}{c}\text { Number of } \\
\text { Drug Classes }\end{array}$ & $\begin{array}{c}\mathbf{N} \\
\text { (Unweighted) }\end{array}$ & $\begin{array}{c}\text { \% } \\
\text { (Weighted) }\end{array}$ \\
\hline \multirow{3}{*}{ Daytime } & 1 & 206 & $86.2 \%$ \\
& $2+$ & 40 & $13.8 \%$ \\
& Overall Daytime & 246 & $100.0 \%$ \\
\hline \multirow{3}{*}{ Nighttime } & 1 & 680 & $83.7 \%$ \\
& $2+$ & 156 & $16.3 \%$ \\
& Overall Nighttime & 836 & $100.0 \%$ \\
\hline
\end{tabular}

In comparing prevalence of drug classes by time and region (Table 31), it was found that marijuana was generally the most common drug class across all the regions both in daytime $(3.9 \%)$ and nighttime (6.1\%) samples. Nighttime drivers in the Midwest and Northeast regions were more likely to test positive for marijuana than daytime drivers $(p<.05)$. However, marijuana results in the South and West regions did not differ between daytime and nighttime drivers. For stimulants, a higher percentage of nighttime drivers in all regions tested positive than did daytime drivers. However, the difference was statistically significant only in the Midwest $(p<.01)$ and West $(p<.05)$. 
Table 31. Drug Classes by Time of Day and Region (Oral Fluid)

\begin{tabular}{|c|c|c|c|c|c|c|}
\hline $\begin{array}{c}\text { Time of } \\
\text { Day }\end{array}$ & Drug Class & $\begin{array}{c}\text { Midwest } \\
\% \\
\end{array}$ & $\begin{array}{c}\text { Northeast } \\
\% \\
\end{array}$ & $\begin{array}{c}\text { South } \\
\%\end{array}$ & $\begin{array}{c}\text { West } \\
\%\end{array}$ & $\begin{array}{l}\text { All } \\
\%\end{array}$ \\
\hline \multirow{10}{*}{ Daytime } & & $\mathrm{N}=546$ & $\mathrm{~N}=379$ & $\mathrm{~N}=472$ & $N=453$ & $N=1,850$ \\
\hline & Antidepressants & $0.4 \%$ & $0.6 \%$ & $0.5 \%$ & $0.5 \%$ & $0.5 \%$ \\
\hline & Marijuana & $3.4 \%$ & $3.0 \%$ & $5.5 \%$ & $4.0 \%$ & $3.9 \%$ \\
\hline & Narcotic-Analgesics & $2.7 \%$ & $2.1 \%$ & $1.3 \%$ & $0.6 \%$ & $1.6 \%$ \\
\hline & Sedatives & $1.9 \%$ & $2.6 \%$ & $2.1 \%$ & $0.7 \%$ & $1.6 \%$ \\
\hline & Stimulants & $0.8 \%$ & $1.7 \%$ & $2.2 \%$ & $2.0 \%$ & $1.6 \%$ \\
\hline & Other & $0.0 \%$ & $1.3 \%$ & $0.0 \%$ & $0.0 \%$ & $0.2 \%$ \\
\hline & More than 1 Class & $2.2 \%$ & $1.0 \%$ & $1.4 \%$ & $1.2 \%$ & $1.5 \%$ \\
\hline & Overall Drug Positive Daytime & $11.5 \%$ & $12.5 \%$ & $13.1 \%$ & $8.9 \%$ & $11.0 \%$ \\
\hline & Negative & $88.5 \%$ & $87.5 \%$ & $86.9 \%$ & $91.1 \%$ & $89.0 \%$ \\
\hline \multirow{10}{*}{ Nighttime } & & $\mathrm{N}=1,694$ & $N=1,111$ & $N=1,559$ & $N=1,505$ & $\mathrm{~N}=5,869$ \\
\hline & Antidepressants & $0.5 \%$ & $0.2 \%$ & $0.0 \%$ & $0.1 \%$ & $0.2 \%$ \\
\hline & Marijuana & $7.7 \%$ & $7.6 \%$ & $6.3 \%$ & $4.1 \%$ & $6.1 \%$ \\
\hline & Narcotic-Analgesics & $1.0 \%$ & $2.8 \%$ & $1.2 \%$ & $1.8 \%$ & $1.6 \%$ \\
\hline & Sedatives & $1.1 \%$ & $0.2 \%$ & $0.7 \%$ & $0.4 \%$ & $0.6 \%$ \\
\hline & Stimulants & $3.0 \%$ & $2.3 \%$ & $2.7 \%$ & $4.0 \%$ & $3.2 \%$ \\
\hline & Other & $0.2 \%$ & $0.0 \%$ & $0.1 \%$ & $0.5 \%$ & $0.3 \%$ \\
\hline & More than 1 Class & $1.6 \%$ & $4.1 \%$ & $2.9 \%$ & $2.0 \%$ & $2.3 \%$ \\
\hline & Overall Drug Positive Nighttime & $15.0 \%$ & $17.3 \%$ & $14.0 \%$ & $12.9 \%$ & $14.4 \%$ \\
\hline & Negative & $85.0 \%$ & $82.7 \%$ & $86.0 \%$ & $87.1 \%$ & $85.6 \%$ \\
\hline
\end{tabular}

"More than 1 Class" - Drivers testing positive for more than one drug are only counted in this category.

In this table, percentages are weighted.

Comparison of drug class by time and gender (Table 32) showed that males were significantly more likely to test positive for marijuana than females in samples of both daytime $(5.9 \%$ males versus $1.7 \%$ females) and nighttime ( $7.4 \%$ males versus $4.1 \%$ females) drivers $(p<.01)$. In the daytime sample, females were more likely to test positive for narcotic-analgesics and sedatives than were males $(p<.01)$; however, a statistical difference of this kind was not detected in the nighttime sample. 
Table 32. Drug Classes Distribution by Time of Day and Gender (Oral Fluid)

\begin{tabular}{l|lrrc}
\hline $\begin{array}{c}\text { Time of } \\
\text { Day }\end{array}$ & \multicolumn{1}{c}{ Drug Class } & $\begin{array}{c}\text { Males } \\
\%\end{array}$ & $\begin{array}{c}\text { Females } \\
\%\end{array}$ & $\begin{array}{c}\text { Total } \\
\%\end{array}$ \\
\hline \multirow{5}{*}{ Daytime } & $\mathbf{N = 1 , 0 3 2}$ & $\mathbf{N = 8 1 1}$ & $\mathbf{N = 1 , 8 4 3}$ \\
& Antidepressants & $0.1 \%$ & $0.9 \%$ & $0.5 \%$ \\
& Marijuana & $5.9 \%$ & $1.7 \%$ & $4.0 \%$ \\
& Narcotic-Analgesics & $1.0 \%$ & $2.5 \%$ & $1.7 \%$ \\
& Sedatives & $1.2 \%$ & $2.2 \%$ & $1.6 \%$ \\
& Stimulants & $1.8 \%$ & $1.4 \%$ & $1.6 \%$ \\
& Other & $0.0 \%$ & $0.5 \%$ & $0.2 \%$ \\
& More than 1 Class & $1.0 \%$ & $2.1 \%$ & $1.5 \%$ \\
& Overall Drug Positive Daytime & $11.0 \%$ & $11.3 \%$ & $11.1 \%$ \\
& Negative & $89.0 \%$ & $88.7 \%$ & $88.9 \%$ \\
\hline \multirow{5}{*}{ Nighttime } & $\mathbf{N = 3 , 6 0 5}$ & $\mathbf{N = 2 , 2 5 0}$ & $\mathbf{N = 5 , 8 5 5}$ \\
& Antidepressants & $0.3 \%$ & $0.1 \%$ & $0.2 \%$ \\
& Marijuana & $7.4 \%$ & $4.1 \%$ & $6.1 \%$ \\
& Narcotic-Analgesics & $1.8 \%$ & $1.3 \%$ & $1.6 \%$ \\
& Sedatives & $0.4 \%$ & $1.0 \%$ & $0.6 \%$ \\
& Stimulants & $3.3 \%$ & $3.1 \%$ & $3.2 \%$ \\
& Other & $0.3 \%$ & $0.3 \%$ & $0.3 \%$ \\
& More than 1 Class & $3.0 \%$ & $1.4 \%$ & $2.4 \%$ \\
& Overall Drug Positive Nighttime & $16.5 \%$ & $11.3 \%$ & $14.5 \%$ \\
& Negative & $83.5 \%$ & $88.7 \%$ & $85.5 \%$ \\
\hline
\end{tabular}

"More than 1 Class" - Drivers testing positive for more than one drug are only counted in this category.

In this table, percentages are weighted.

When we examined drug classes by time of day and age (Table 33), we found that daytime drivers aged 21-34 were more likely to use marijuana (7.4\%) than daytime drivers in other age groups $(p<.01)$. However, drivers aged $16-20$ years had the highest marijuana use $(9.8 \%)$ in the nighttime sample, followed by the 21-34 year age group $(8.5 \%)$ both of which were statistically higher than the other age groups $(p<.01)$. The prevalence of narcotic-analgesics was highest among daytime drivers aged 44-64 (2.9\%) $(p<.01)$; however, in the nighttime sample, the 35-44 age group recorded the highest prevalence of narcotic-analgesics $(4.2 \%)(p<.01)$. 
Table 33. Drug Class Distribution by Time of Day and Age (Oral Fluid)

\begin{tabular}{|c|c|c|c|c|c|c|c|}
\hline $\begin{array}{l}\text { Time of } \\
\text { Day }\end{array}$ & Drug Class & $\begin{array}{c}16-20 \\
\%\end{array}$ & $\begin{array}{c}21-34 \\
\%\end{array}$ & $\begin{array}{c}35-44 \\
\%\end{array}$ & $\begin{array}{c}45-64 \\
\%\end{array}$ & $\begin{array}{c}65+ \\
\%\end{array}$ & $\begin{array}{c}\text { Total } \\
\%\end{array}$ \\
\hline \multirow{10}{*}{ Daytime } & & $\mathrm{N}=99$ & $\mathrm{~N}=436$ & $N=374$ & $\mathrm{~N}=668$ & $\mathrm{~N}=245$ & $\mathrm{~N}=1,822$ \\
\hline & Antidepressants & $0.9 \%$ & $0.2 \%$ & $0.3 \%$ & $0.8 \%$ & $0.3 \%$ & $0.5 \%$ \\
\hline & Marijuana & $4.4 \%$ & $7.4 \%$ & $4.8 \%$ & $1.7 \%$ & $0.7 \%$ & $4.0 \%$ \\
\hline & Narcotic-Analgesics & $0.0 \%$ & $0.7 \%$ & $1.9 \%$ & $2.9 \%$ & $0.8 \%$ & $1.7 \%$ \\
\hline & Sedatives & $0.7 \%$ & $0.2 \%$ & $1.4 \%$ & $2.3 \%$ & $4.0 \%$ & $1.6 \%$ \\
\hline & Stimulants & $0.3 \%$ & $2.2 \%$ & $1.2 \%$ & $2.2 \%$ & $0.1 \%$ & $1.6 \%$ \\
\hline & Other & $0.0 \%$ & $0.0 \%$ & $0.0 \%$ & $0.7 \%$ & $0.0 \%$ & $0.2 \%$ \\
\hline & More than 1 Class & $0.0 \%$ & $0.6 \%$ & $2.1 \%$ & $2.6 \%$ & $0.3 \%$ & $1.5 \%$ \\
\hline & $\begin{array}{l}\text { Overall Drug Positive } \\
\text { Daytime }\end{array}$ & $6.2 \%$ & $11.2 \%$ & $11.6 \%$ & $13.3 \%$ & $6.4 \%$ & $11.1 \%$ \\
\hline & Negative & $93.8 \%$ & $88.8 \%$ & $88.4 \%$ & $86.7 \%$ & $93.6 \%$ & $88.9 \%$ \\
\hline \multirow{10}{*}{ Nighttime } & & $\mathrm{N}=961$ & $N=2,437$ & $N=1,042$ & $\mathrm{~N}=1,216$ & $\mathrm{~N}=148$ & $\mathrm{~N}=5,804$ \\
\hline & Antidepressants & $0.3 \%$ & $0.1 \%$ & $0.4 \%$ & $0.1 \%$ & $0.3 \%$ & $0.2 \%$ \\
\hline & Marijuana & $9.8 \%$ & $8.5 \%$ & $4.1 \%$ & $1.1 \%$ & $0.0 \%$ & $6.2 \%$ \\
\hline & Narcotic-Analgesics & $1.1 \%$ & $0.8 \%$ & $4.2 \%$ & $1.4 \%$ & $0.4 \%$ & $1.6 \%$ \\
\hline & Sedatives & $0.0 \%$ & $0.6 \%$ & $1.2 \%$ & $0.7 \%$ & $1.3 \%$ & $0.7 \%$ \\
\hline & Stimulants & $2.0 \%$ & $3.6 \%$ & $2.8 \%$ & $4.5 \%$ & $0.0 \%$ & $3.3 \%$ \\
\hline & Other & $0.2 \%$ & $0.5 \%$ & $0.2 \%$ & $0.1 \%$ & $0.0 \%$ & $0.3 \%$ \\
\hline & More than 1 Class & $2.7 \%$ & $2.9 \%$ & $2.2 \%$ & $1.5 \%$ & $0.0 \%$ & $2.4 \%$ \\
\hline & $\begin{array}{l}\text { Overall Drug Positive } \\
\text { Nighttime }\end{array}$ & $16.1 \%$ & $17.1 \%$ & $15.2 \%$ & $9.5 \%$ & $2.0 \%$ & $14.6 \%$ \\
\hline & Negative & $83.9 \%$ & $82.9 \%$ & $84.8 \%$ & $90.5 \%$ & $98.0 \%$ & $85.4 \%$ \\
\hline
\end{tabular}

"More than 1 Class" - Drivers testing positive for more than one drug are only counted in this category.

In this table, percentages are weighted.

\section{Driver Drug Use Prevalence by Drug Category Based on Oral Fluid Results}

In this section of the report, we display drug use prevalence results from oral fluid tests by drug category. The three drug categories were: illegal, prescription, and over-the-counter. Because there were very few positive results for over-the-counter drugs, the prescription and over-thecounter categories are combined in these tables into a single category ("Medications").

Additionally, some respondents tested positive for more than one category of drug. Thus, tables presenting drug categories present four mutually exclusive categories: Illegal; Medications; Illegal and Medications; and Negative. So as not to double count individual positive results, an individual's result appears in only one of these categories. However, for example in Table 34, to determine the proportion of daytime drivers who tested positive for illegal drugs, one could sum the daytime values for the "Illegal" category (5.8\%) and for the "Illegal \& Medications" category $(0.5 \%)$ to arrive at a prevalence estimate of $6.3 \%$ of daytime drivers who were positive for at least one illegal drug. Detailed summaries of prevalence estimates for individual drugs appear in Tables 137-140 later in the report.

As previously noted, drugs may be classified in different ways depending on the use of the classification system. For example, in NHTSA's drug evaluation and classification (DEC) 
program, the categories CNS Depressants, CNS Stimulants, Hallucinogens, Dissociative Anesthetic (PCP), Narcotic Analgesics, Inhalants, and Cannabis are used.

Comparison of drug categories by time of day (Table 34) reveal that almost 6 percent of daytime drivers tested positive for drugs in the "Illegal" category as opposed to over 10 percent of nighttime drivers. This was a statistically significant difference between the two groups $(p<.01)$. Positive results in the "Medications" category, although not statistically significant, were found to be slightly higher among the daytime drivers (almost 5\%) than nighttime drivers (3\%).

Table 34. Drug Categories Distribution by Time of Day (Oral Fluid)

\begin{tabular}{l|lrr}
\hline \multirow{2}{*}{ Time of Day } & Drug Category & $\begin{array}{c}\text { N } \\
\text { (Unweighted) }\end{array}$ & $\begin{array}{c}\text { \% } \\
\text { (Weighted) }\end{array}$ \\
\hline \multirow{5}{*}{ Daytime } & Illegal & 125 & $5.8 \%$ \\
& Medications & 107 & $4.8 \%$ \\
& Illegal \& Medications & 14 & $0.5 \%$ \\
& Negative & 1,604 & $89.0 \%$ \\
& Overall Daytime & 1,850 & $100.0 \%$ \\
\hline \multirow{3}{*}{ Nighttime } & Illegal & 575 & $10.5 \%$ \\
& Medications & 201 & $3.0 \%$ \\
& Illegal \& Medications & 60 & $0.9 \%$ \\
& Negative & 5,033 & $85.6 \%$ \\
& Overall Nighttime & 5,869 & $100.0 \%$ \\
\hline
\end{tabular}

"Medications" includes prescription and over-the-counter drugs.

Comparison of drug categories by time of day and region (Table 35) showed that, of daytime drivers, the South region had the highest percentage of positive results for "Illegal" followed by the West region, however these differences were not statistically significant. In the nighttime sample, the Midwest region had the highest percentage of "Illegal" drug prevalence, although this difference was not statistically significant. 
Table 35. Drug Categories Distribution by Time of Day and Region (Oral Fluid)

\begin{tabular}{|c|c|c|c|c|}
\hline Time & Region & Drug Category & $\begin{array}{c}\mathbf{N} \\
\text { (Unweighted) }\end{array}$ & $\begin{array}{c}\% \\
\text { (Weighted) }\end{array}$ \\
\hline \multirow{20}{*}{ Daytime } & \multirow{5}{*}{ Midwest } & Illegal & 38 & $4.2 \%$ \\
\hline & & Medications & 47 & $6.7 \%$ \\
\hline & & Illegal \& Medications & 5 & $0.5 \%$ \\
\hline & & Negative & 456 & $88.5 \%$ \\
\hline & & Overall & 546 & $100.0 \%$ \\
\hline & \multirow{5}{*}{ Northeast } & Illegal & 20 & $4.9 \%$ \\
\hline & & Medications & 20 & $7.5 \%$ \\
\hline & & Illegal \& Medications & 2 & $0.1 \%$ \\
\hline & & Negative & 337 & $87.5 \%$ \\
\hline & & Overall & 379 & $100.0 \%$ \\
\hline & \multirow{5}{*}{ South } & Illegal & 35 & $8.2 \%$ \\
\hline & & Medications & 22 & $4.6 \%$ \\
\hline & & Illegal \& Medications & 5 & $0.3 \%$ \\
\hline & & Negative & 410 & $86.9 \%$ \\
\hline & & Overall & 472 & $100.0 \%$ \\
\hline & \multirow{5}{*}{ West } & Illegal & 32 & $6.3 \%$ \\
\hline & & Medications & 18 & $2.0 \%$ \\
\hline & & Illegal \& Medications & 2 & $0.7 \%$ \\
\hline & & Negative & 401 & $91.1 \%$ \\
\hline & & Overall & 453 & $100.0 \%$ \\
\hline \multirow{20}{*}{ Nighttime } & \multirow{5}{*}{ Midwest } & Illegal & 185 & $11.5 \%$ \\
\hline & & Medications & 68 & $3.0 \%$ \\
\hline & & Illegal \& Medications & 14 & $0.4 \%$ \\
\hline & & Negative & 1,427 & $85.0 \%$ \\
\hline & & Overall & 1,694 & $100.0 \%$ \\
\hline & \multirow{5}{*}{ Northeast } & Illegal & 112 & $10.8 \%$ \\
\hline & & Medications & 32 & $4.2 \%$ \\
\hline & & Illegal \& Medications & 14 & $2.3 \%$ \\
\hline & & Negative & 953 & $82.7 \%$ \\
\hline & & Overall & 1,111 & $100.0 \%$ \\
\hline & \multirow{5}{*}{ South } & Illegal & 131 & $10.2 \%$ \\
\hline & & Medications & 59 & $2.5 \%$ \\
\hline & & Illegal \& Medications & 22 & $1.3 \%$ \\
\hline & & Negative & 1,347 & $86.0 \%$ \\
\hline & & Overall & 1,559 & $100.0 \%$ \\
\hline & \multirow{5}{*}{ West } & Illegal & 147 & $9.8 \%$ \\
\hline & & Medications & 42 & $2.6 \%$ \\
\hline & & Illegal \& Medications & 10 & $0.5 \%$ \\
\hline & & Negative & 1,306 & $87.1 \%$ \\
\hline & & Overall & 1,505 & $100.0 \%$ \\
\hline
\end{tabular}

"Medications" includes prescription and over-the-counter drugs. 
When examining prevalence by drug category and gender (Table 36), we found that, in the daytime sample, male drivers were more likely to test positive for "Illegal" drugs $(8.2 \%)$ than female drivers $(3.0 \%)(p<.01)$. Conversely, daytime female drivers were more likely to show positive results for "Medications" $(7.6 \%)$ than daytime male drivers $(2.5 \%)(p<.01)$. In the nighttime sample, 12.5 percent of male drivers tested positive for "Illegal" drugs, as opposed to 7.5 percent of female drivers $(p<.01)$. The difference in percentage of positive results for "Medications" between male and female drivers was not as striking in the nighttime sample as in the daytime sample and was not statistically significant.

Table 36. Drug Categories Distribution by Time of Day and Gender (Oral Fluid)

\begin{tabular}{|c|c|c|c|c|}
\hline Time of Day & Gender & Drug Category & $\begin{array}{c}\mathrm{N} \\
\text { (Unweighted) }\end{array}$ & $\begin{array}{c}\% \\
\text { (Weighted) }\end{array}$ \\
\hline \multirow{10}{*}{ Daytime } & \multirow{5}{*}{ Male } & Illegal & 87 & $8.2 \%$ \\
\hline & & Medications & 35 & $2.5 \%$ \\
\hline & & Illegal \& Medications & 9 & $0.3 \%$ \\
\hline & & Negative & 901 & $89.0 \%$ \\
\hline & & Overall & 1,032 & $100.0 \%$ \\
\hline & \multirow{5}{*}{ Female } & Illegal & 38 & $3.0 \%$ \\
\hline & & Medications & 72 & $7.6 \%$ \\
\hline & & Illegal \& Medications & 5 & $0.6 \%$ \\
\hline & & Negative & 696 & $88.7 \%$ \\
\hline & & Overall & 811 & $100.0 \%$ \\
\hline \multirow{10}{*}{ Nighttime } & \multirow{5}{*}{ Male } & Illegal & 410 & $12.5 \%$ \\
\hline & & Medications & 106 & $2.8 \%$ \\
\hline & & Illegal \& Medications & 41 & $1.1 \%$ \\
\hline & & Negative & 3,048 & $83.5 \%$ \\
\hline & & Overall & 3,605 & $100.0 \%$ \\
\hline & \multirow{5}{*}{ Female } & Illegal & 164 & $7.5 \%$ \\
\hline & & Medications & 95 & $3.3 \%$ \\
\hline & & Illegal \& Medications & 19 & $0.5 \%$ \\
\hline & & Negative & 1,972 & $88.7 \%$ \\
\hline & & Overall & 2,250 & $100.0 \%$ \\
\hline
\end{tabular}

"Medications" includes prescription and over-the-counter drugs.

In this table, percentages are weighted.

In comparing drug categories by time of day and age (Table 37), it was clear that, within the daytime sample, "Illegal" drug use was highest for drivers aged 21-34 (9.9\%) followed by drivers aged 35-44 (6.5\%). The prevalence of "Illegal" drugs for these age groups differed significantly from that in the remaining age groups $(p<.01)$. In the nighttime sample, drivers in the 21-34 year age group still maintained the highest percentage (14.2\%) of positive results for "Illegal" drugs; however, that group was followed by the youngest age group (16-20 years) for "Illegal" drugs $(13.1 \%)(p<.01)$. The use of "Medications" was highest among the 45-64 year age group (8.8\%) in the daytime sample (non-significant), and in the 35-44 year old age group the nighttime sample $(6.9 \%)(p<.01)$. 
Table 37. Drug Categories Distribution by Time of Day and Age (Oral Fluid)

\begin{tabular}{|c|c|c|c|c|}
\hline Time of Day & Age & Drug Category & $\begin{array}{c}\mathrm{N} \\
\text { (Unweighted) } \\
\end{array}$ & $\begin{array}{c}\% \\
\text { (Weighted) } \\
\end{array}$ \\
\hline \multirow{25}{*}{ Daytime } & \multirow{5}{*}{$16-20$} & Illegal & 9 & $4.6 \%$ \\
\hline & & Medications & 2 & $1.6 \%$ \\
\hline & & Illegal \& Medications & 0 & $0.0 \%$ \\
\hline & & Negative & 88 & $93.8 \%$ \\
\hline & & Overall & 99 & $100.0 \%$ \\
\hline & \multirow{5}{*}{$21-34$} & Illegal & 54 & $9.9 \%$ \\
\hline & & Medications & 14 & $1.2 \%$ \\
\hline & & Illegal \& Medications & 4 & $0.1 \%$ \\
\hline & & Negative & 364 & $88.8 \%$ \\
\hline & & Overall & 436 & $100.0 \%$ \\
\hline & \multirow{5}{*}{$35-44$} & Illegal & 25 & $6.5 \%$ \\
\hline & & Medications & 23 & $4.2 \%$ \\
\hline & & Illegal \& Medications & 3 & $1.0 \%$ \\
\hline & & Negative & 323 & $88.4 \%$ \\
\hline & & Overall & 374 & $100.0 \%$ \\
\hline & \multirow{5}{*}{$45-64$} & Illegal & 32 & $3.9 \%$ \\
\hline & & Medications & 51 & $8.8 \%$ \\
\hline & & Illegal \& Medications & 7 & $0.6 \%$ \\
\hline & & Negative & 578 & $86.7 \%$ \\
\hline & & Overall & 668 & $100.0 \%$ \\
\hline & \multirow{5}{*}{$65+$} & Illegal & 3 & $0.8 \%$ \\
\hline & & Medications & 17 & $5.6 \%$ \\
\hline & & Illegal \& Medications & 0 & $0.0 \%$ \\
\hline & & Negative & 225 & $93.6 \%$ \\
\hline & & Overall & 245 & $100.0 \%$ \\
\hline \multirow[t]{14}{*}{ Nighttime } & \multirow{5}{*}{$16-20$} & Illegal & 120 & $13.1 \%$ \\
\hline & & Medications & 11 & $1.6 \%$ \\
\hline & & Illegal \& Medications & 12 & $1.4 \%$ \\
\hline & & Negative & 818 & $83.9 \%$ \\
\hline & & Overall & 961 & $100.0 \%$ \\
\hline & \multirow{5}{*}{$21-34$} & Illegal & 308 & $14.2 \%$ \\
\hline & & Medications & 55 & $1.9 \%$ \\
\hline & & Illegal \& Medications & 28 & $1.0 \%$ \\
\hline & & Negative & 2,045 & $82.9 \%$ \\
\hline & & Overall & 2,436 & $100.0 \%$ \\
\hline & \multirow[t]{4}{*}{$35-44$} & Illegal & 82 & $7.6 \%$ \\
\hline & & Medications & 57 & $6.9 \%$ \\
\hline & & Illegal \& Medications & 11 & $0.7 \%$ \\
\hline & & Negative & 892 & $84.8 \%$ \\
\hline
\end{tabular}




\begin{tabular}{|c|c|c|c|c|}
\hline Time of Day & Age & Drug Category & $\begin{array}{c}\mathrm{N} \\
\text { (Unweighted) }\end{array}$ & $\begin{array}{c}\% \\
\text { (Weighted) }\end{array}$ \\
\hline & & Overall & 1,042 & $100.0 \%$ \\
\hline & \multirow{5}{*}{$45-64$} & Illegal & 64 & $5.7 \%$ \\
\hline & & Medications & 67 & $3.0 \%$ \\
\hline & & Illegal \& Medications & 9 & $0.7 \%$ \\
\hline & & Negative & 1,075 & $90.5 \%$ \\
\hline & & Overall & 1,215 & $100.0 \%$ \\
\hline & \multirow{5}{*}{$65+$} & Illegal & 0 & $0.0 \%$ \\
\hline & & Medications & 9 & $2.0 \%$ \\
\hline & & Illegal \& Medications & 0 & $0.0 \%$ \\
\hline & & Negative & 139 & $98.0 \%$ \\
\hline & & Overall & 148 & $100.0 \%$ \\
\hline
\end{tabular}

"Medications" includes prescription and over-the-counter drugs.

In this table, percentages are weighted.

\section{Driver Drug Prevalence Based on Oral Fluid and BAC Results}

The following section presents the results of the oral fluid drug analyses combined with the blood alcohol concentration (BAC) results obtained from breath tests. ${ }^{16}$ Categories for BAC by grams per deciliter (g/dL) are indicated as "zero" (BAC less than $.005 \mathrm{~g} / \mathrm{dL}$ ), "between zero and .08 " (greater than .005 up to $.08 \mathrm{~g} / \mathrm{dL}$ ), and ".08+" (BAC greater than $.08 \mathrm{~g} / \mathrm{dL}$ ). Note that the daytime sample consisted of very few drug positive drivers with alcohol positive results, which limited the statistical testing that could be done.

In comparing the number of drug-positive drivers by time of day and BAC level (Tables 38 and 39), a statistically significant association was found between drug-positive and alcohol-positive drivers within the nighttime driving sample. In other words, the percentage of nighttime drivers with BAC g/dL .08+ was significantly higher among drug-positive drivers than among drugnegative drivers $(p<.01)$.

The same association was observed with the "between zero and .08" category among drugpositive nighttime drivers $(p<.01)$ relative to drug-negative drivers. However, for daytime drivers, no statistical association was found, largely because of the small number of alcoholpositive drivers in the daytime sample.

Note that, because of the small number of alcohol-positive drivers in the daytime sample ( $\mathrm{n}=$ 23), comparisons involving drug-positive drivers for this group of drivers were not attempted in the remaining portion of this report.

\footnotetext{
${ }^{16}$ More complete information on the alcohol results (not including drug results) is available in Lacey et al. (2009b).
} 
Table 38. Drug Prevalence by Time of Day and BAC (Percentages Calculated by Row) (Oral Fluid)

\begin{tabular}{c|c|c|ccc}
\hline \multirow{2}{*}{$\begin{array}{c}\text { Time of } \\
\text { Day }\end{array}$} & $\begin{array}{c}\text { Drug } \\
\text { Result }\end{array}$ & \begin{tabular}{c} 
N \\
\cline { 3 - 5 }
\end{tabular} & (Unweighted) & Zero & $\begin{array}{c}\text { Between } \\
\text { Zero and .08 }\end{array}$ \\
\hline \multirow{3}{*}{ Daytime } & Positive & 246 & $98.2 \%$ & $1.4 \%$ & $0.3 \%$ \\
& Negative & 1,599 & $99.2 \%$ & $0.6 \%$ & $0.2 \%$ \\
& Overall Daytime & 1,845 & $99.1 \%$ & $0.7 \%$ & $0.2 \%$ \\
\hline \multirow{3}{*}{ Nighttime } & Positive & 836 & $80.5 \%$ & $15.0 \%$ & $4.5 \%$ \\
& Negative & 5,031 & $90.2 \%$ & $8.1 \%$ & $1.7 \%$ \\
& Overall Nighttime & 5,867 & $88.8 \%$ & $9.1 \%$ & $2.1 \%$ \\
\hline
\end{tabular}

In this table, percentages are weighted.

Table 39. Drug Prevalence by Time of Day and BAC (Percentages Calculated by Column) (Oral Fluid)

\begin{tabular}{|c|c|c|c|c|c|}
\hline \multirow[b]{2}{*}{$\begin{array}{c}\text { Time of } \\
\text { Day }\end{array}$} & \multirow[b]{2}{*}{$\begin{array}{l}\text { Drug } \\
\text { Result }\end{array}$} & \multicolumn{4}{|c|}{ BAC (g/dL) } \\
\hline & & Zero & $\begin{array}{c}\text { Between } \\
\text { Zero and } .08\end{array}$ & $.08+$ & All \\
\hline \multirow{3}{*}{ Daytime } & & $\mathrm{N}=1,822$ & $\mathrm{~N}=18$ & $\mathrm{~N}=5$ & $\mathrm{~N}=1,845$ \\
\hline & Positive & $10.9 \%$ & $22.2 \%$ & $17.1 \%$ & $11.0 \%$ \\
\hline & Negative & $89.1 \%$ & $77.8 \%$ & $82.9 \%$ & $89.0 \%$ \\
\hline \multirow{3}{*}{ Nighttime } & & $\mathrm{N}=5,207$ & $N=530$ & $N=130$ & $\mathrm{~N}=5,867$ \\
\hline & Positive & $13.1 \%$ & $23.9 \%$ & $30.6 \%$ & $14.4 \%$ \\
\hline & Negative & $86.9 \%$ & $76.1 \%$ & $69.4 \%$ & $85.6 \%$ \\
\hline
\end{tabular}

In this table, "Ns" are unweighted and percentages are weighted.

Table 40 shows that, within the daytime sample, drug-positive drivers in the age groups 16-20 and 21-34 had the greatest percentage of alcohol-positive results; however, it should be noted that the sample size for the youngest group was only 11. Among nighttime drug-positive participants, drivers aged 21-34 had the greatest percentage of alcohol positives (in both the categories BAC between zero and .08, and BAC .08+) $(p<.01)$. As noted earlier, the number of years within age categories is not equivalent. 
Table 40. BAC Among Drug-Positive Drivers by Time of Day and Age (Oral Fluid)

\begin{tabular}{|c|c|c|c|c|c|}
\hline \multirow[b]{2}{*}{$\begin{array}{l}\text { Time of } \\
\text { Day }\end{array}$} & \multirow[b]{2}{*}{ Age } & \multirow[b]{2}{*}{$\begin{array}{c}\mathbf{N} \\
\text { (Unweighted) }\end{array}$} & \multicolumn{3}{|c|}{ BAC (g/dL) } \\
\hline & & & Zero & $\begin{array}{c}\text { Between } \\
\text { Zero and .08 }\end{array}$ & $.08+$ \\
\hline \multirow{6}{*}{ Daytime } & $16-20$ & 11 & $89.7 \%$ & $0.0 \%$ & $10.3 \%$ \\
\hline & $21-34$ & 72 & $95.5 \%$ & $4.5 \%$ & $0.0 \%$ \\
\hline & $35-44$ & 51 & $99.2 \%$ & $0.8 \%$ & $0.0 \%$ \\
\hline & $45-64$ & 90 & $99.8 \%$ & $0.2 \%$ & $0.0 \%$ \\
\hline & $65+$ & 20 & $100.0 \%$ & $0.0 \%$ & $0.0 \%$ \\
\hline & Overall Positive Daytime & 244 & $98.2 \%$ & $1.4 \%$ & $0.3 \%$ \\
\hline \multirow{6}{*}{ Nighttime } & $16-20$ & 143 & $86.8 \%$ & $10.0 \%$ & $3.2 \%$ \\
\hline & $21-34$ & 392 & $75.0 \%$ & $19.7 \%$ & $5.3 \%$ \\
\hline & $35-44$ & 150 & $87.8 \%$ & $8.5 \%$ & $3.7 \%$ \\
\hline & $45-64$ & 141 & $81.0 \%$ & $14.3 \%$ & $4.7 \%$ \\
\hline & $65+$ & 9 & $83.6 \%$ & $16.4 \%$ & $0.0 \%$ \\
\hline & Overall Positive Nighttime & 835 & $80.4 \%$ & $15.0 \%$ & $4.5 \%$ \\
\hline
\end{tabular}

In this table, percentages are weighted.

Among both daytime and nighttime drivers, there were fewer alcohol-positive drivers among drug-positive drivers with $2+$ classes of drugs than among those with one class of drug (Tables 41 and 42); however, due to the small sample size, there was no statistical difference.

Table 41. BAC Among Drug-Positive Drivers by Number of Drug Classes and Time of Day (Percentages Calculated by Column) (Oral Fluid)

\begin{tabular}{|c|c|c|c|c|c|}
\hline \multirow[b]{2}{*}{ Time of Day } & \multirow[b]{2}{*}{$\begin{array}{c}\text { Number of Drug } \\
\text { Classes }\end{array}$} & \multirow[b]{2}{*}{$\begin{array}{c}\mathrm{N} \\
\text { (Unweighted) }\end{array}$} & \multicolumn{3}{|c|}{ BAC $(g / d L)$} \\
\hline & & & Zero & $\begin{array}{c}\text { Between } \\
\text { Zero and } .08\end{array}$ & $.08+$ \\
\hline \multirow{3}{*}{ Daytime } & 1 & 206 & $86.0 \%$ & $95.1 \%$ & $100.0 \%$ \\
\hline & $2+$ & 40 & $14.0 \%$ & $4.9 \%$ & $0.0 \%$ \\
\hline & Overall Daytime & 246 & $100.0 \%$ & $100.0 \%$ & $100.0 \%$ \\
\hline \multirow{3}{*}{ Nighttime } & 1 & 680 & $83.4 \%$ & $81.6 \%$ & $96.3 \%$ \\
\hline & $2+$ & 156 & $16.6 \%$ & $18.4 \%$ & $3.7 \%$ \\
\hline & Overall Nighttime & 836 & $100.0 \%$ & $100.0 \%$ & $100.0 \%$ \\
\hline
\end{tabular}

In this table, percentages are weighted. 
Table 42. BAC Among Drug-Positive Drivers by Number of Drug Classes and Time of Day (Percentages Calculated by Row) (Oral Fluid)

\begin{tabular}{l|c|c|ccc}
\hline \multirow{2}{*}{ Time of Day } & \multirow{2}{*}{$\begin{array}{c}\text { Number of Drug } \\
\text { Classes }\end{array}$} & N & \multicolumn{3}{|c}{ BAC (g/dL) } \\
\cline { 4 - 6 } Daytime & 1 & 206 & $98.0 \%$ & $1.6 \%$ & $0.4 \%$ \\
& $2+$ & 40 & $99.5 \%$ & $0.5 \%$ & $0.0 \%$ \\
& (Unweighted) & Zero & Zero and .08 & .08+ \\
\hline \multirow{3}{*}{ Nighttime } & 1 & 246 & $98.2 \%$ & $1.4 \%$ & $0.3 \%$ \\
\cline { 4 - 6 } & Overall Daytime & 680 & $80.1 \%$ & $14.7 \%$ & $5.2 \%$ \\
& $2+$ & 156 & $82.0 \%$ & $17.0 \%$ & $1.0 \%$ \\
\hline
\end{tabular}

In this table, percentages are weighted.

When oral fluid drug category findings were combined with BAC results we found that, in both the daytime and nighttime samples, the drug-positive drivers who were also alcohol-positive were more likely to be positive for "Illegal" drugs than "Medications" (Table 43). This was particularly true in the nighttime sample, in which 17.3 percent had BACs between zero and .08 (compared to $6.3 \%$ in the "Medications" category) and 5.7 percent had BACs greater than .08 (compared to $1.2 \%$ in the "Medications" category) $(p<.01)$. In the daytime sample, however, the differences were statistically non-significant $(p$ value $=.05)$.

Table 43. BAC Among Drug-Positive Drivers by Drug Category and Time of Day (Oral Fluid)

\begin{tabular}{|c|c|c|c|c|c|}
\hline \multirow[b]{2}{*}{$\begin{array}{c}\text { Time of } \\
\text { Day }\end{array}$} & \multirow[b]{2}{*}{ Drug Category } & \multirow[b]{2}{*}{$\begin{array}{c}\mathrm{N} \\
\text { (Unweighted) }\end{array}$} & \multicolumn{3}{|c|}{ BAC $(g / d L)$} \\
\hline & & & Zero & $\begin{array}{c}\text { Between } \\
\text { Zero and .08 }\end{array}$ & $.08+$ \\
\hline \multirow{4}{*}{ Daytime } & Illegal & 125 & $97.1 \%$ & $2.3 \%$ & $0.6 \%$ \\
\hline & Medications & 107 & $99.6 \%$ & $0.4 \%$ & $0.0 \%$ \\
\hline & Illegal \& Medications & 14 & $98.3 \%$ & $1.7 \%$ & $0.0 \%$ \\
\hline & Negative & 1,604 & $99.2 \%$ & $0.6 \%$ & $0.2 \%$ \\
\hline \multirow{4}{*}{ Nighttime } & Illegal & 575 & $77.0 \%$ & $17.3 \%$ & $5.7 \%$ \\
\hline & Medications & 199 & $92.5 \%$ & $6.3 \%$ & $1.2 \%$ \\
\hline & Illegal \& Medications & 60 & $81.4 \%$ & $17.7 \%$ & $0.9 \%$ \\
\hline & Negative & 5,033 & $90.2 \%$ & $8.1 \%$ & $1.7 \%$ \\
\hline
\end{tabular}

"Medications" includes prescription and over-the-counter drugs.

In this table, percentages are weighted.

Table 44 presents the findings by drug category, age, and time of day. Due to the number of groupings (and thus, relatively small sample sizes in included cells), caution should be exercised in the interpretation of the findings, especially among the daytime driving sample. Overall, among the nighttime driving sample, the high alcohol-positive drivers (i.e., drivers registering greater than $.08 \mathrm{BAC} \mathrm{g} / \mathrm{dL}$ ) tested positive for drugs in the "Illegal" category more frequently than "Medications" across all age groups except 65+ (an age group producing a very small sample size for drug positives). Further, the same pattern emerged among drivers with BACs 
between zero and .08 across all age groups, except for the age category $45-64$, where a high proportion of drivers tested positive for both "Illegal and Medications."

Table 44. BAC of Drivers by Drug Category, Age, and Time of Day (Oral Fluid)

\begin{tabular}{|c|c|c|c|c|c|c|}
\hline \multirow[b]{2}{*}{$\begin{array}{c}\text { Time of } \\
\text { Day }\end{array}$} & \multirow[b]{2}{*}{ Age } & \multirow[b]{2}{*}{ Drug Category } & \multirow[b]{2}{*}{$\begin{array}{c}\mathbf{N} \\
\text { (Unweighted) }\end{array}$} & \multicolumn{3}{|c|}{ BAC $(g / d L)$} \\
\hline & & & & Zero & $\begin{array}{c}\text { Between } \\
\text { Zero and } .08\end{array}$ & $.08+$ \\
\hline \multirow{25}{*}{ Daytime } & \multirow{5}{*}{$16-20$} & Illegal & 9 & $86.1 \%$ & $0.0 \%$ & $13.9 \%$ \\
\hline & & Medications & 2 & $100.0 \%$ & $0.0 \%$ & $0.0 \%$ \\
\hline & & Illegal \& Medications & 0 & NA & NA & NA \\
\hline & & Negative & 88 & $99.3 \%$ & $0.7 \%$ & $0.0 \%$ \\
\hline & & Overall & 99 & $98.7 \%$ & $0.7 \%$ & $0.6 \%$ \\
\hline & \multirow{5}{*}{$21-34$} & Illegal & 54 & $95.7 \%$ & $4.3 \%$ & $0.0 \%$ \\
\hline & & Medications & 14 & $93.2 \%$ & $6.8 \%$ & $0.0 \%$ \\
\hline & & Illegal \& Medications & 4 & $100.0 \%$ & $0.0 \%$ & $0.0 \%$ \\
\hline & & Negative & 364 & $99.4 \%$ & $0.5 \%$ & $0.1 \%$ \\
\hline & & Overall & 436 & $99.0 \%$ & $1.0 \%$ & $0.1 \%$ \\
\hline & \multirow{5}{*}{$35-44$} & Illegal & 25 & $98.6 \%$ & $1.4 \%$ & $0.0 \%$ \\
\hline & & Medications & 23 & $100.0 \%$ & $0.0 \%$ & $0.0 \%$ \\
\hline & & Illegal \& Medications & 3 & $100.0 \%$ & $0.0 \%$ & $0.0 \%$ \\
\hline & & Negative & 323 & $99.1 \%$ & $0.7 \%$ & $0.2 \%$ \\
\hline & & Overall & 374 & $99.1 \%$ & $0.7 \%$ & $0.1 \%$ \\
\hline & \multirow{5}{*}{$45-64$} & Illegal & 32 & $100.0 \%$ & $0.0 \%$ & $0.0 \%$ \\
\hline & & Medications & 51 & $100.0 \%$ & $0.0 \%$ & $0.0 \%$ \\
\hline & & Illegal \& Medications & 7 & $95.8 \%$ & $4.2 \%$ & $0.0 \%$ \\
\hline & & Negative & 578 & $98.7 \%$ & $0.9 \%$ & $0.4 \%$ \\
\hline & & Overall & 668 & $98.9 \%$ & $0.8 \%$ & $0.3 \%$ \\
\hline & \multirow{5}{*}{$65+$} & Illegal & 3 & $100.0 \%$ & $0.0 \%$ & $0.0 \%$ \\
\hline & & Medications & 17 & $100.0 \%$ & $0.0 \%$ & $0.0 \%$ \\
\hline & & Illegal \& Medications & 0 & NA & NA & NA \\
\hline & & Negative & 225 & $99.8 \%$ & $0.1 \%$ & $0.1 \%$ \\
\hline & & Overall & 245 & $99.8 \%$ & $0.1 \%$ & $0.1 \%$ \\
\hline \multirow[t]{15}{*}{ Nighttime } & \multirow{5}{*}{$16-20$} & Illegal & 120 & $83.9 \%$ & $12.1 \%$ & $4.0 \%$ \\
\hline & & Medications & 11 & $100.0 \%$ & $0.0 \%$ & $0.0 \%$ \\
\hline & & Illegal \& Medications & 12 & $99.0 \%$ & $1.0 \%$ & $0.0 \%$ \\
\hline & & Negative & 818 & $94.4 \%$ & $5.1 \%$ & $0.5 \%$ \\
\hline & & Overall & 961 & $93.1 \%$ & $5.9 \%$ & $1.0 \%$ \\
\hline & \multirow{5}{*}{$21-34$} & Illegal & 308 & $73.6 \%$ & $20.4 \%$ & $6.1 \%$ \\
\hline & & Medications & 55 & $80.9 \%$ & $17.0 \%$ & $2.1 \%$ \\
\hline & & Illegal \& Medications & 28 & $84.6 \%$ & $15.4 \%$ & $0.0 \%$ \\
\hline & & Negative & 2,045 & $87.8 \%$ & $9.8 \%$ & $2.4 \%$ \\
\hline & & Overall & 2,436 & $85.6 \%$ & $11.5 \%$ & $2.9 \%$ \\
\hline & \multirow{5}{*}{$35-44$} & Illegal & 82 & $77.7 \%$ & $15.9 \%$ & $6.4 \%$ \\
\hline & & Medications & 57 & $98.5 \%$ & $0.4 \%$ & $1.1 \%$ \\
\hline & & Illegal \& Medications & 11 & $92.7 \%$ & $7.3 \%$ & $0.0 \%$ \\
\hline & & Negative & 892 & $91.9 \%$ & $6.7 \%$ & $1.4 \%$ \\
\hline & & Overall & 1,042 & $91.3 \%$ & $7.0 \%$ & $1.7 \%$ \\
\hline
\end{tabular}




\begin{tabular}{|c|c|c|c|c|c|c|}
\hline \multirow{12}{*}{$\begin{array}{c}\text { Time of } \\
\text { Day }\end{array}$} & \multirow[b]{2}{*}{ Age } & \multirow[b]{2}{*}{ Drug Category } & \multirow[b]{2}{*}{$\begin{array}{c}\mathrm{N} \\
\text { (Unweighted) }\end{array}$} & \multicolumn{3}{|c|}{ BAC $(g / d L)$} \\
\hline & & & & Zero & $\begin{array}{c}\text { Between } \\
\text { Zero and .08 }\end{array}$ & $.08+$ \\
\hline & & Illegal & 64 & $80.8 \%$ & $12.6 \%$ & $6.6 \%$ \\
\hline & & Medications & 67 & $92.2 \%$ & $7.0 \%$ & $0.8 \%$ \\
\hline & $45-64$ & Illegal \& Medications & 9 & $33.3 \%$ & $60.9 \%$ & $5.8 \%$ \\
\hline & & Negative & 1,075 & $90.1 \%$ & $8.7 \%$ & $1.3 \%$ \\
\hline & & Overall & 1,215 & $89.2 \%$ & $9.2 \%$ & $1.6 \%$ \\
\hline & & Illegal & 0 & NA & NA & $\overline{N A}$ \\
\hline & & Medications & 9 & $83.6 \%$ & $16.4 \%$ & $0.0 \%$ \\
\hline & $65+$ & Illegal \& Medications & 0 & NA & NA & NA \\
\hline & & Negative & 139 & $88.7 \%$ & $6.6 \%$ & $4.7 \%$ \\
\hline & & Overall & 148 & $88.6 \%$ & $6.8 \%$ & $4.6 \%$ \\
\hline
\end{tabular}

"Medications" includes prescription and over-the-counter drugs.

In this table, percentages are weighted.

When examining drug category by gender and time of day (Table 45), male drivers who tested positive for "Illegal" drugs in both the daytime and nighttime samples also had greater percentages of alcohol-positive results than their female counterparts. However, the small sample size precluded valid statistical testing on the daytime sample. Within the nighttime sample, differences were statistically significant $(p<.01)$.

Table 45. BAC of Drivers by Drug Category, Gender, and Time of Day (Oral Fluid)

\begin{tabular}{|c|c|c|c|c|c|c|}
\hline \multirow[b]{2}{*}{$\begin{array}{l}\text { Time of } \\
\text { Day }\end{array}$} & \multirow[b]{2}{*}{ Gender } & \multirow[b]{2}{*}{ Drug Category } & \multirow[b]{2}{*}{$\begin{array}{c}\mathbf{N} \\
\text { (Unweighted) }\end{array}$} & \multicolumn{3}{|c|}{ BAC (g/dL) } \\
\hline & & & & Zero & $\begin{array}{c}\text { Between } \\
\text { Zero and } .08\end{array}$ & $.08+$ \\
\hline \multirow{10}{*}{ Daytime } & \multirow{5}{*}{ Males } & Illegal & 87 & $96.7 \%$ & $2.5 \%$ & $0.8 \%$ \\
\hline & & Medications & 35 & $98.5 \%$ & $1.5 \%$ & $0.0 \%$ \\
\hline & & Illegal \& Medications & 9 & $95.6 \%$ & $4.4 \%$ & $0.0 \%$ \\
\hline & & Negative & 901 & $99.1 \%$ & $0.8 \%$ & $0.1 \%$ \\
\hline & & Overall & 1,032 & $98.9 \%$ & $0.9 \%$ & $0.2 \%$ \\
\hline & \multirow{5}{*}{ Females } & Illegal & 38 & $98.4 \%$ & $1.6 \%$ & $0.0 \%$ \\
\hline & & Medications & 72 & $100.0 \%$ & $0.0 \%$ & $0.0 \%$ \\
\hline & & Illegal \& Medications & 5 & $100.0 \%$ & $0.0 \%$ & $0.0 \%$ \\
\hline & & Negative & 696 & $99.3 \%$ & $0.5 \%$ & $0.3 \%$ \\
\hline & & Overall & 811 & $99.3 \%$ & $0.5 \%$ & $0.2 \%$ \\
\hline \multirow{10}{*}{ Nighttime } & \multirow{5}{*}{ Males } & Illegal & 410 & $74.3 \%$ & $18.0 \%$ & $7.6 \%$ \\
\hline & & Medications & 106 & $96.0 \%$ & $3.1 \%$ & $1.0 \%$ \\
\hline & & Illegal \& Medications & 41 & $76.6 \%$ & $22.3 \%$ & $1.1 \%$ \\
\hline & & Negative & 3,048 & $90.0 \%$ & $7.9 \%$ & $2.1 \%$ \\
\hline & & Overall & 3,605 & $88.1 \%$ & $9.2 \%$ & $2.7 \%$ \\
\hline & \multirow{5}{*}{ Females } & Illegal & 164 & $84.2 \%$ & $15.2 \%$ & $0.6 \%$ \\
\hline & & Medications & 95 & $87.5 \%$ & $11.0 \%$ & $1.5 \%$ \\
\hline & & Illegal \& Medications & 19 & $99.0 \%$ & $1.0 \%$ & $0.0 \%$ \\
\hline & & Negative & 1,972 & $90.4 \%$ & $8.3 \%$ & $1.2 \%$ \\
\hline & & Overall & 2,250 & $89.9 \%$ & $8.9 \%$ & $1.2 \%$ \\
\hline
\end{tabular}

"Medications" includes prescription and over-the-counter drugs.

In this table, percentages are weighted. 


\section{Drugs: Oral Fluid Results and Agreement with Self-Reported Drug Use}

Table 46 compares the results of the oral fluid analyses with responses to the self-reported drug use questionnaire. This questionnaire was administered to all drivers who provided an oral fluid sample, and was completed while the oral fluid device was collecting the saliva.

The cross tabulation results of self-reported drug use (in the past 24 hours, past 2 days, past month, past year, over a year, and never) and oral fluid analysis results (by drug category) revealed interesting findings. Note that this table only reports on drivers who were drug-positive. Agreement between reported past 24-hour use and drug-positive analysis results for the nighttime driving sample was greatest (highest percentage) among antidepressants, cough suppressants, and pain killers.

The lowest correspondence (lowest percentages) was found for amphetamines and barbiturates. Interestingly, approximately one-quarter of marijuana-positive nighttime drivers admitted to marijuana use in the previous 24 hours; this increased to over one-third when combined within the past two days. A smaller proportion ( $7.5 \%$ and $5.8 \%$ respectively) admitted to recent use of cocaine.

Among nighttime drivers who tested positive for antidepressants, the majority $(66.4 \%)$ indicated they in fact used the substance in the past 24 hours. Thus, in this example, agreement between self-reports and oral fluid analysis results are fairly high. However, when we examine amphetamines (typically viewed as a recreational or illegal drug), agreement between self-report and a positive test analysis is low. Here, about 72 percent of nighttime positive drivers indicated they "never" had used the substance yet the drug analysis revealed a positive result. In some instances this may be related to a reluctance to disclose; however, in other instances a driver may not have been aware that the substance they were taking contained the drug being reported (for example, some drivers may not be aware that some diet pills contain amphetamines). Similar results were obtained for nighttime drivers providing blood samples. A table reflecting those results appears in Appendix A. 
Table 46. Oral Fluid Results and Agreement With Self-Reported by Drug Type (Oral Fluid)

\begin{tabular}{|c|c|c|c|c|c|}
\hline \multirow[b]{3}{*}{ Drug Category } & \multirow[b]{3}{*}{$\begin{array}{l}\text { Self-Reported } \\
\text { Drug Use }\end{array}$} & \multicolumn{4}{|c|}{ Oral Fluid: Positive for that Drug } \\
\hline & & \multicolumn{2}{|c|}{ Daytime } & \multicolumn{2}{|c|}{ Nighttime } \\
\hline & & $\begin{array}{c}\mathrm{N} \\
\text { (Unwtd) }\end{array}$ & $\begin{array}{c}\% \\
\text { (Weighted) }\end{array}$ & $\begin{array}{c}\mathrm{N} \\
\text { (Unwtd) }\end{array}$ & $\begin{array}{c}\% \\
\text { (Weighted) }\end{array}$ \\
\hline \multirow{7}{*}{ Antidepressants } & Past 24 Hours & 13 & $85.7 \%$ & 18 & $66.4 \%$ \\
\hline & Past 2 Days & 0 & $0.0 \%$ & 0 & $0.0 \%$ \\
\hline & Past Month & 0 & $0.0 \%$ & 2 & $9.6 \%$ \\
\hline & Past Year & 1 & $4.7 \%$ & 0 & $0.0 \%$ \\
\hline & Over a Year & 0 & $0.0 \%$ & 1 & $21.2 \%$ \\
\hline & Never & 4 & $9.6 \%$ & 4 & $2.8 \%$ \\
\hline & Overall & 18 & $100.0 \%$ & 25 & $100.0 \%$ \\
\hline \multirow{7}{*}{ Amphetamines } & Past 24 Hours & 0 & $0.0 \%$ & 1 & $2.0 \%$ \\
\hline & Past 2 Days & 0 & $0.0 \%$ & 0 & $0.0 \%$ \\
\hline & Past Month & 0 & $0.0 \%$ & 4 & $8.6 \%$ \\
\hline & Past Year & 0 & $0.0 \%$ & 3 & $8.9 \%$ \\
\hline & Over a Year & 1 & $3.2 \%$ & 10 & $8.8 \%$ \\
\hline & Never & 13 & $96.8 \%$ & 51 & $71.8 \%$ \\
\hline & Overall & 14 & $100.0 \%$ & 69 & $100.0 \%$ \\
\hline \multirow{7}{*}{ Barbiturates } & Past 24 Hours & 1 & $1.4 \%$ & 2 & $3.1 \%$ \\
\hline & Past 2 Days & 0 & $0.0 \%$ & 0 & $0.0 \%$ \\
\hline & Past Month & 1 & $0.8 \%$ & 0 & $0.0 \%$ \\
\hline & Past Year & 0 & $0.0 \%$ & 0 & $0.0 \%$ \\
\hline & Over a Year & 0 & $0.0 \%$ & 0 & $0.0 \%$ \\
\hline & Never & 4 & $97.8 \%$ & 8 & $96.9 \%$ \\
\hline & Overall & 6 & $100.0 \%$ & 10 & $100.0 \%$ \\
\hline \multirow{7}{*}{ Benzodiazepines } & Past 24 Hours & 11 & $15.8 \%$ & 14 & $24.4 \%$ \\
\hline & Past 2 Days & 0 & $0.0 \%$ & 4 & $3.4 \%$ \\
\hline & Past Month & 0 & $0.0 \%$ & 2 & $2.6 \%$ \\
\hline & Past Year & 0 & $0.0 \%$ & 0 & $0.0 \%$ \\
\hline & Over a Year & 3 & $3.8 \%$ & 5 & $2.2 \%$ \\
\hline & Never & 20 & $80.4 \%$ & 37 & $67.4 \%$ \\
\hline & Overall & 34 & $100.0 \%$ & 62 & $100.0 \%$ \\
\hline \multirow{7}{*}{ Cocaine } & Past 24 Hours & 1 & $0.4 \%$ & 10 & $7.5 \%$ \\
\hline & Past 2 Days & 2 & $2.2 \%$ & 7 & $5.8 \%$ \\
\hline & Past Month & 1 & $0.6 \%$ & 10 & $4.8 \%$ \\
\hline & Past Year & 0 & $0.0 \%$ & 17 & $6.8 \%$ \\
\hline & Over a Year & 3 & $18.6 \%$ & 29 & $17.0 \%$ \\
\hline & Never & 30 & $78.2 \%$ & 146 & $57.9 \%$ \\
\hline & Overall & 37 & $100.0 \%$ & 219 & $100.0 \%$ \\
\hline \multirow{7}{*}{$\begin{array}{c}\text { Cough } \\
\text { Suppressants }\end{array}$} & Past 24 Hours & 2 & $94.5 \%$ & 6 & $39.3 \%$ \\
\hline & Past 2 Days & 0 & $0.0 \%$ & 2 & $19.8 \%$ \\
\hline & Past Month & 0 & $0.0 \%$ & 3 & $12.9 \%$ \\
\hline & Past Year & 0 & $0.0 \%$ & 1 & $2.3 \%$ \\
\hline & Over a Year & 0 & $0.0 \%$ & 1 & $3.7 \%$ \\
\hline & Never & 1 & $5.5 \%$ & 2 & $22.0 \%$ \\
\hline & Overall & 3 & $100.0 \%$ & 15 & $100.0 \%$ \\
\hline
\end{tabular}




\begin{tabular}{|c|c|c|c|c|c|}
\hline \multirow[b]{3}{*}{ Drug Category } & \multirow[b]{3}{*}{$\begin{array}{l}\text { Self-Reported } \\
\text { Drug Use }\end{array}$} & \multicolumn{4}{|c|}{ Oral Fluid: Positive for that Drug } \\
\hline & & \multicolumn{2}{|c|}{ Daytime } & \multicolumn{2}{|c|}{ Nighttime } \\
\hline & & $\begin{array}{c}\mathbf{N} \\
\text { (Unwtd) }\end{array}$ & $\begin{array}{c}\% \\
\text { (Weighted) }\end{array}$ & $\begin{array}{c}\mathbf{N} \\
\text { (Unwtd) }\end{array}$ & $\begin{array}{c}\% \\
\text { (Weighted) }\end{array}$ \\
\hline \multirow{7}{*}{ Ketamine } & Past 24 hrs & 0 & NA & 0 & $0.0 \%$ \\
\hline & Past 2 days & 0 & NA & 0 & $0.0 \%$ \\
\hline & Past Month & 0 & NA & 0 & $0.0 \%$ \\
\hline & Past Year & 0 & NA & 0 & $0.0 \%$ \\
\hline & Over a Year & 0 & NA & 0 & $0.0 \%$ \\
\hline & Never & 0 & NA & 1 & $100.0 \%$ \\
\hline & Overall & 0 & NA & 1 & $100.0 \%$ \\
\hline \multirow{7}{*}{ Marijuana } & Past 24 hrs & 21 & $21.7 \%$ & 91 & $25.7 \%$ \\
\hline & Past 2 days & 10 & $14.9 \%$ & 37 & $10.5 \%$ \\
\hline & Past Month & 15 & $15.2 \%$ & 55 & $11.4 \%$ \\
\hline & Past Year & 6 & $4.6 \%$ & 44 & $7.4 \%$ \\
\hline & Over a Year & 19 & $16.7 \%$ & 65 & $13.1 \%$ \\
\hline & Never & 28 & $26.7 \%$ & 134 & $32.1 \%$ \\
\hline & Overall & 99 & $100.0 \%$ & 426 & $100.0 \%$ \\
\hline \multirow{7}{*}{ Methadone } & Past 24 hrs & 1 & $96.6 \%$ & 6 & $29.8 \%$ \\
\hline & Past 2 days & 0 & $0.0 \%$ & 0 & $0.0 \%$ \\
\hline & Past Month & 1 & $2.9 \%$ & 0 & $0.0 \%$ \\
\hline & Past Year & 0 & $0.0 \%$ & 0 & $0.0 \%$ \\
\hline & Over a Year & 0 & $0.0 \%$ & 0 & $0.0 \%$ \\
\hline & Never & 1 & $0.4 \%$ & 4 & $70.2 \%$ \\
\hline & Overall & 3 & $100.0 \%$ & 10 & $100.0 \%$ \\
\hline \multirow{7}{*}{ Opiates } & Past 24 hrs & 4 & $13.0 \%$ & 11 & $11.1 \%$ \\
\hline & Past 2 days & 2 & $3.7 \%$ & 7 & $4.5 \%$ \\
\hline & Past Month & 6 & $18.7 \%$ & 8 & $18.7 \%$ \\
\hline & Past Year & 4 & $1.9 \%$ & 13 & $2.4 \%$ \\
\hline & Over a Year & 2 & $11.6 \%$ & 17 & $15.7 \%$ \\
\hline & Never & 13 & $51.1 \%$ & 51 & $47.6 \%$ \\
\hline & Overall & 31 & $100.0 \%$ & 107 & $100.0 \%$ \\
\hline \multirow{7}{*}{ Pain Killers } & Past 24 hrs & 13 & $27.5 \%$ & 24 & $59.9 \%$ \\
\hline & Past 2 days & 5 & $12.9 \%$ & 11 & $12.9 \%$ \\
\hline & Past Month & 6 & $13.1 \%$ & 8 & $4.6 \%$ \\
\hline & Past Year & 4 & $6.5 \%$ & 7 & $2.9 \%$ \\
\hline & Over a Year & 2 & $30.9 \%$ & 7 & $13.8 \%$ \\
\hline & Never & 4 & $9.2 \%$ & 9 & $5.8 \%$ \\
\hline & Overall & 34 & $100.0 \%$ & 66 & $100.0 \%$ \\
\hline \multirow{7}{*}{ PCP } & Past 24 hrs & 1 & $100.0 \%$ & 0 & $0.0 \%$ \\
\hline & Past 2 days & 0 & $0.0 \%$ & 0 & $0.0 \%$ \\
\hline & Past Month & 0 & $0.0 \%$ & 1 & $22.9 \%$ \\
\hline & Past Year & 0 & $0.0 \%$ & 0 & $0.0 \%$ \\
\hline & Over a Year & 0 & $0.0 \%$ & 0 & $0.0 \%$ \\
\hline & Never & 0 & $0.0 \%$ & 1 & $77.1 \%$ \\
\hline & Overall & 1 & $100.0 \%$ & 2 & $100.0 \%$ \\
\hline
\end{tabular}




\section{Observed Safety Measures of Daytime and Nighttime Drivers (Oral Fluid)}

In the 2007 NRS, interviewers observed and recorded seat belt use of drivers and helmet use of motorcycle riders. Additionally, participating drivers were asked if they were acting as designated drivers (“Tonight/Today, are you, or have you been a designated driver?"). The results of analyses of these variables by alcohol level are discussed in some detail in a previous report summarizing the alcohol results (Lacey et al., 2009b). One issue that arose in that analysis was that many respondents appeared to not understand the 'designated driver' question. Thus, in this report we are not reporting on the designated driver results. Additionally, since the nighttime results are quite similar, whether summarized by oral fluid results or blood results, we are presenting these tables on observed seat belt and helmet use only in the oral fluid results section of the body of the report. The nighttime blood results are presented in Appendix A.

Information on seat belt and helmet use is presented by overall prevalence (daytime and nighttime), drug class (daytime and nighttime), and drug category (daytime and nighttime) in Tables 47-52, respectively.

In Table 47, there was no statistically significant association between overall daytime drug prevalence among drivers and seat belt use in the daytime sample.

Table 47. Daytime: Seat Belt Observation By Drug Prevalence (Oral Fluid)

\begin{tabular}{lccc}
\hline & $\begin{array}{c}\text { N } \\
\text { (Unweighted) }\end{array}$ & $\begin{array}{c}\text { \% Drug } \\
\text { Negative } \\
\text { (Weighted) }\end{array}$ & $\begin{array}{c}\text { \% Drug } \\
\text { Positive } \\
\text { (Weighted) }\end{array}$ \\
\hline Driver Seat Belt Observation & & & \\
Yes & 1,750 & $89.0 \%$ & $11.0 \%$ \\
No & 92 & $86.2 \%$ & $13.8 \%$ \\
\hline
\end{tabular}

When examining nighttime drug use as measured in oral fluid by observed seat belt use (Table 48), drug prevalence among nighttime drivers was significantly higher among those who did not wear a seat belt than among those who did $(p<.01)$.

Table 48. Nighttime: Seat Belt Observation by Drug Prevalence (Oral Fluid)

\begin{tabular}{lccc}
\hline & $\begin{array}{c}\text { N } \\
\text { (Unweighted) }\end{array}$ & $\begin{array}{c}\text { \% Drug } \\
\text { Negative } \\
\text { (Weighted) }\end{array}$ & $\begin{array}{c}\text { \% Drug } \\
\text { Positive } \\
\text { (Weighted) }\end{array}$ \\
\hline Driver Seat Belt Observation & & & \\
Yes & 5,654 & $85.9 \%$ & $14.1 \%$ \\
No & 192 & $75.4 \%$ & $24.6 \%$ \\
\hline
\end{tabular}


Table 49 shows the daytime distribution of drug classes in oral fluid by observed seat belt use. Most of the observed differences in this distribution were not statistically significant. The exception was marijuana, which was significantly more prevalent among daytime drivers who did not wear a seat belt than among drivers who did $(p<.01)$.

Table 49. Daytime: Seat Belt Observation by Drug Class (Percentages Calculated by Row) (Oral Fluid)

\begin{tabular}{|c|c|c|c|c|c|c|c|c|c|}
\hline & $x$ 总 & 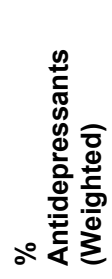 & 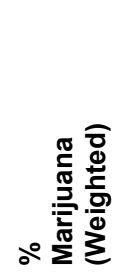 & 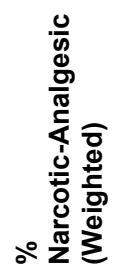 & 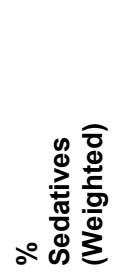 & 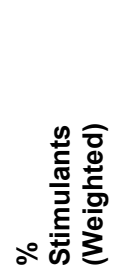 & 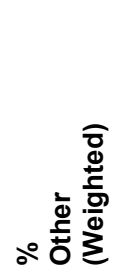 & 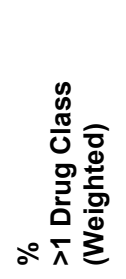 & 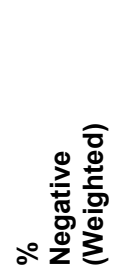 \\
\hline \multicolumn{10}{|c|}{ Driver Seat Belt Observation } \\
\hline Yes & 1,750 & $0.5 \%$ & $3.7 \%$ & $1.7 \%$ & $1.7 \%$ & $1.7 \%$ & $0.2 \%$ & $1.5 \%$ & $89.0 \%$ \\
\hline No & 92 & $0.8 \%$ & $9.8 \%$ & $1.3 \%$ & $0.4 \%$ & $0.0 \%$ & $0.0 \%$ & $1.5 \%$ & $86.2 \%$ \\
\hline
\end{tabular}

Table 50 shows the nighttime distribution of drug classes by seat belt use. Stimulants were significantly more prevalent among those drivers who did not wear a safety belt than those who $\operatorname{did}(p<.01)$.

Table 50. Nighttime: Seat Belt Observation by Drug Class (Percentages Calculated by Row) (Oral Fluid)

\begin{tabular}{|c|c|c|c|c|c|c|c|c|c|}
\hline & $z$ 氖 & 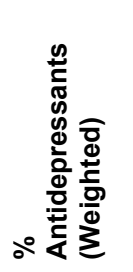 & 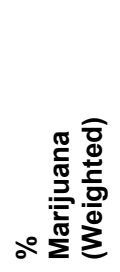 & 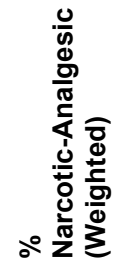 & 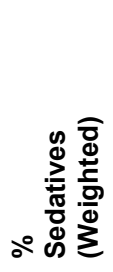 & 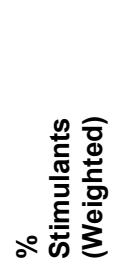 & ○워 & 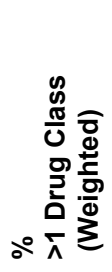 & ○ 료 \\
\hline \multicolumn{10}{|c|}{ Driver Seat Belt Observation } \\
\hline Yes & 5,654 & $0.1 \%$ & $6.1 \%$ & $1.6 \%$ & $0.7 \%$ & $3.1 \%$ & $0.3 \%$ & $2.2 \%$ & $85.9 \%$ \\
\hline No & 192 & $2.3 \%$ & $6.3 \%$ & $2.1 \%$ & $0.0 \%$ & $7.9 \%$ & $0.6 \%$ & $5.3 \%$ & $75.4 \%$ \\
\hline
\end{tabular}


Table 51 shows the daytime distribution of drug categories by seat belt use. Differences in daytime oral fluid drug category results involving seat belt use by the driver were not statistically significant.

Table 51. Daytime: Seat Belt Observation by Drug Category (Percentages Calculated by Row) (Oral Fluid)

\begin{tabular}{|c|c|c|c|c|c|}
\hline & $\underset{\text { (Unwtd) }}{\mathbf{N}}$ & $\begin{array}{c}\% \\
\text { Illegal } \\
\text { (Weighted) }\end{array}$ & $\begin{array}{c}\% \\
\text { Medications } \\
\text { (Weighted) }\end{array}$ & $\begin{array}{l}\% \text { Illegal \& } \\
\text { Medications } \\
\text { (Weighted) }\end{array}$ & $\begin{array}{c}\% \\
\text { Negative } \\
\text { (Weighted) }\end{array}$ \\
\hline Driver Seat Belt Obse & & & & & \\
\hline $\begin{array}{l}\text { Yes } \\
\text { No }\end{array}$ & $\begin{array}{r}1,750 \\
92\end{array}$ & $\begin{array}{r}5.6 \% \\
10.3 \%\end{array}$ & $\begin{array}{l}5.0 \% \\
2.7 \%\end{array}$ & $\begin{array}{l}0.4 \% \\
0.7 \%\end{array}$ & $\begin{array}{l}89.0 \% \\
86.2 \%\end{array}$ \\
\hline
\end{tabular}

Table 52 shows the nighttime distribution of drug categories by seat belt use. The prevalence of illegal ("Illegal" and "Illegal and Medication" combined) drugs was higher among those who did not use a seat belt $(p<.01)$.

Table 52. Nighttime: Belt Observation by Drug Category (Percentages Calculated by Row) (Oral Fluid)

\begin{tabular}{|c|c|c|c|c|c|}
\hline & $\underset{(U n w t d)}{N}$ & $\begin{array}{c}\% \\
\text { Illegal } \\
\text { (Weighted) }\end{array}$ & $\begin{array}{c}\% \\
\text { Medications } \\
\text { (Weighted) }\end{array}$ & $\begin{array}{c}\text { \% Illegal \& } \\
\text { Medications } \\
\text { (Weighted) }\end{array}$ & $\begin{array}{l}\text { \% Negative } \\
\text { (Weighted) }\end{array}$ \\
\hline \multicolumn{6}{|c|}{ Driver Seat Belt Observation } \\
\hline $\begin{array}{l}\text { Yes } \\
\text { No }\end{array}$ & $\begin{array}{r}5,353 \\
192\end{array}$ & $\begin{array}{l}10.2 \% \\
18.1 \%\end{array}$ & $\begin{array}{l}3.0 \% \\
5.0 \%\end{array}$ & $\begin{array}{l}0.9 \% \\
1.5 \%\end{array}$ & $\begin{array}{l}85.9 \% \\
75.4 \%\end{array}$ \\
\hline
\end{tabular}

The number of motorcyclists sampled in the daytime was very small, thus limiting our ability to perform meaningful statistical comparisons. However, we display daytime and nighttime helmet use (for the operator) by overall drug use prevalence, class and category in Tables 53-58. Note there were an extremely low number of motorcycle riders with passengers. Thus, these are excluded from our tables and our analyses.

Table 53. Daytime: Helmet Use for Motorcycle Riders (Operators), by Drug Positive (Oral Fluid)

\begin{tabular}{lcc}
\hline & $\begin{array}{c}\text { N } \\
\text { (Unweighted) }\end{array}$ & $\begin{array}{c}\text { \% Drug Positive } \\
\text { (Weighted) }\end{array}$ \\
\hline Motorcycle Riders (Operators) & 30 & $24.8 \%$ \\
Helmet & 23 & $23.8 \%$ \\
No Helmet Use & 6 & $29.9 \%$ \\
Unknown & 1 & $0.0 \%$ \\
\hline Small sample size precluded meaningful statistical comparisons.
\end{tabular}


Table 54 shows a statistically significant difference in nighttime drug prevalence as measured in oral fluid among riders with and without helmets. Drug prevalence was higher for riders who were not using helmets $(p<.01)$.

Table 54. Nighttime: Helmet Use for Motorcycle Riders (Operators), by Drug Positive (Oral Fluid)

\begin{tabular}{lcc}
\hline & $\begin{array}{c}\text { N } \\
\text { (Unweighted) }\end{array}$ & $\begin{array}{c}\text { \% Drug Positive } \\
\text { (Weighted) }\end{array}$ \\
\hline Motorcycle Riders (Operators) & 73 & $32.4 \%$ \\
Helmet & 57 & $14.7 \%$ \\
No Helmet Use & 14 & $65.3 \%$ \\
Unknown & 2 & $0.0 \%$ \\
\hline
\end{tabular}

Examining daytime and nighttime motorcycle riders by drug class as measured in oral fluid, some classes had no positives, perhaps due to the small sample size (Tables 55 and 56), thus rendering statistical tests inappropriate.

Table 55. Daytime: Helmet Use for Motorcycle Riders (Operators), by Drug Class (Oral Fluid)

\begin{tabular}{|c|c|c|c|c|c|c|c|c|c|}
\hline & $z$ 氖 & 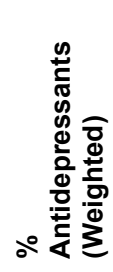 & 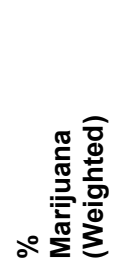 & 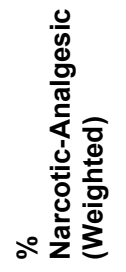 & 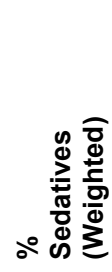 & 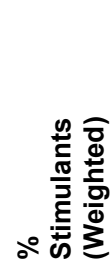 & 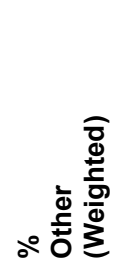 & 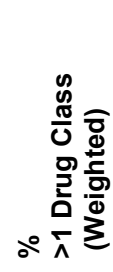 & ○리 \\
\hline Motorcycle Riders (Operators) & 30 & $0.0 \%$ & $13.2 \%$ & $0.0 \%$ & $1.3 \%$ & $2.8 \%$ & $0.0 \%$ & $7.6 \%$ & $75.2 \%$ \\
\hline Helmet & 23 & $0.0 \%$ & $16.9 \%$ & $0.0 \%$ & $1.7 \%$ & $3.6 \%$ & $0.0 \%$ & $1.7 \%$ & $76.2 \%$ \\
\hline No Helmet Use & 6 & $0.0 \%$ & $0.0 \%$ & $0.0 \%$ & $0.0 \%$ & $0.0 \%$ & $0.0 \%$ & $29.9 \%$ & $70.1 \%$ \\
\hline Unknown & 1 & $0.0 \%$ & $0.0 \%$ & $0.0 \%$ & $0.0 \%$ & $0.0 \%$ & $0.0 \%$ & $0.0 \%$ & $100.0 \%$ \\
\hline
\end{tabular}

Small sample size precluded meaningful statistical comparisons.

Table 56. Nighttime: Helmet Use for Motorcycle Riders (Operators) by Drug Class (Percentages Calculated by Row) (Oral Fluid)

\begin{tabular}{|c|c|c|c|c|c|c|c|c|c|}
\hline & 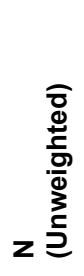 & 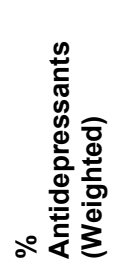 & 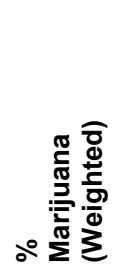 & 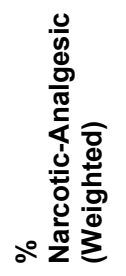 & 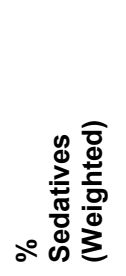 & 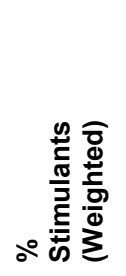 & 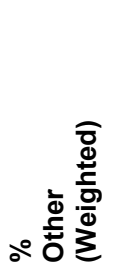 & 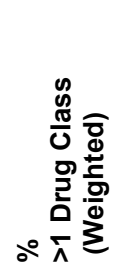 & ○゚ \\
\hline Motorcycle Riders (Operators) & 73 & $6.3 \%$ & $4.5 \%$ & $0.0 \%$ & $0.0 \%$ & $8.3 \%$ & $0.5 \%$ & $12.8 \%$ & $67.6 \%$ \\
\hline Helmet & 57 & $1.0 \%$ & $2.9 \%$ & $0.0 \%$ & $0.0 \%$ & $1.3 \%$ & $0.7 \%$ & $8.7 \%$ & $85.3 \%$ \\
\hline No Helmet Use & 14 & $16.1 \%$ & $7.5 \%$ & $0.0 \%$ & $0.0 \%$ & $21.2 \%$ & $0.0 \%$ & $20.5 \%$ & $34.7 \%$ \\
\hline Unknown & 2 & $0.0 \%$ & $0.0 \%$ & $0.0 \%$ & $0.0 \%$ & $0.0 \%$ & $0.0 \%$ & $0.0 \%$ & $100.0 \%$ \\
\hline
\end{tabular}

Small sample size precluded meaningful statistical comparisons. 
The small sample size encountered when examining daytime motorcycle riders by drug category as measured in oral fluid (Table 57) rendered statistical tests inappropriate.

Table 57. Daytime: Helmet Use for Motorcycle Riders (Operators), by Drug Category (Oral Fluid)

\begin{tabular}{lccccc}
\hline & $\begin{array}{c}\text { N } \\
\text { (Unwtd) }\end{array}$ & $\begin{array}{c}\text { \% } \\
\text { (Wegal } \\
\text { (Weighted) }\end{array}$ & $\begin{array}{c}\text { Medications } \\
\text { (Weighted) }\end{array}$ & $\begin{array}{c}\text { \% Illegal \& } \\
\text { Medications } \\
\text { (Weighted) }\end{array}$ & $\begin{array}{c}\text { \% } \\
\text { (Weightive } \\
\text { (Weighted) }\end{array}$ \\
\hline Motorcycle Riders (Operators) & 30 & $15.9 \%$ & $1.3 \%$ & $7.6 \%$ & $75.2 \%$ \\
Helmet & 23 & $20.4 \%$ & $1.7 \%$ & $1.7 \%$ & $76.2 \%$ \\
No Helmet Use & 6 & $0.0 \%$ & $0.0 \%$ & $29.9 \%$ & $70.1 \%$ \\
Unknown & 1 & $0.0 \%$ & $0.0 \%$ & $0.0 \%$ & $100.0 \%$ \\
\hline
\end{tabular}

Small sample size precluded meaningful statistical comparisons.

Table 58 shows that, overall, drug prevalence was higher for riders who were not using a helmet $(p<.01)$. However, no statistically significant difference was observed between riders who consumed "Illegal" and "Illegal and Medications," and those who consumed "Medications" alone.

Table 58. Nighttime: Helmet Use for Motorcycle Riders (Operators), by Drug Category (Percentages Calculated by Row) (Oral Fluid)

\begin{tabular}{lccccc}
\hline & $\begin{array}{c}\text { N } \\
\text { (Unwt) }\end{array}$ & $\begin{array}{c}\text { \% } \\
\text { (Wlegal } \\
\text { (Weighted) }\end{array}$ & $\begin{array}{c}\text { Medications } \\
\text { (Weighted) }\end{array}$ & $\begin{array}{c}\text { \% Illegal \& } \\
\text { Medications } \\
\text { (Weighted) }\end{array}$ & $\begin{array}{c}\text { \% } \\
\text { (Wegative } \\
\text { (Weighted) }\end{array}$ \\
\hline Motorcycle Riders (Operators) & 73 & $20.0 \%$ & $6.8 \%$ & $5.6 \%$ & $67.6 \%$ \\
Helmet & 57 & $4.2 \%$ & $1.8 \%$ & $8.7 \%$ & $85.3 \%$ \\
No Helmet Use & 14 & $49.2 \%$ & $16.1 \%$ & $0.0 \%$ & $34.7 \%$ \\
Unknown & 2 & $0.0 \%$ & $0.0 \%$ & $0.0 \%$ & $0.0 \%$ \\
\hline
\end{tabular}

\section{Reported Contact with the Criminal Justice System (Oral Fluid)}

Of the 1,790 daytime NRS participants who provided an oral fluid sample and responded to the question, "During the past 12 months, were you arrested and booked for driving under the influence of alcohol or drugs?" about 3 percent indicated "Yes" ( $n=47$ unweighted). Of these, almost 29 percent were drug positive (Table 59). The difference between daytime drivers who indicated "Yes" to this question and were drug positive is statistically different from those who indicated "No" $(p<.01)$.

Table 59. Arrests and Drug Positives, Daytime (Oral Fluid): "During the past 12 months, were you arrested and booked for driving under the influence of alcohol or drugs?"

\begin{tabular}{lcc}
\hline & $\begin{array}{c}\text { N } \\
\text { (Unweighted) }\end{array}$ & $\begin{array}{c}\text { \% Drug Positive } \\
\text { (Weighted) }\end{array}$ \\
\hline Yes & 47 & $28.9 \%$ \\
No & 1,743 & $10.8 \%$ \\
Total & 1,790 & $11.3 \%$ \\
\hline
\end{tabular}


Among the nighttime NRS participants who provided an oral fluid sample and responded to the question, "During the past 12 months, were you arrested and booked for driving under the influence of alcohol or drugs?" (Table 60) approximately 4 percent indicated "Yes" (n= 234 unweighted). Of these, 29 percent were drug positive compared to the 14 percent who were drug positive and indicated "No" $(p<.01)$.

Additionally, since the nighttime results are quite similar, whether summarized by oral fluid results or blood results, we are presenting these tables on contact with the criminal justice system based on nighttime blood results in Appendix A.

Table 60. Arrests and Drug Positives, Nighttime (Oral Fluid): "During the past 12 months, were you arrested and booked for driving under the influence of alcohol or drugs?"

\begin{tabular}{lcc}
\hline & $\begin{array}{c}\mathbf{N} \\
\text { (Unweighted) }\end{array}$ & $\begin{array}{c}\text { \% Drug Positive } \\
\text { (Weighted) }\end{array}$ \\
\hline Yes & 234 & $29.1 \%$ \\
No & 5,458 & $14.0 \%$ \\
Total & 5,692 & $14.5 \%$ \\
\hline
\end{tabular}

Of the daytime drivers who were drug positive and responded to the question, "During the past 12 months, were you arrested and booked for driving under the influence of alcohol or drugs?" (Table 61) the majority tested positive for marijuana $(20.7 \%)$.

Table 61. Arrests and Drug Class, Daytime (Oral Fluid): "During the past 12 months, were you arrested and booked for driving under the influence of alcohol or drugs?"

\begin{tabular}{|c|c|c|c|c|c|c|c|c|c|}
\hline & 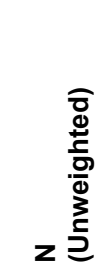 & 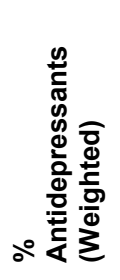 & 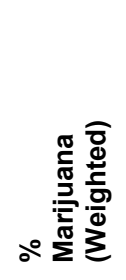 & 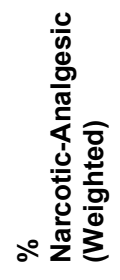 & 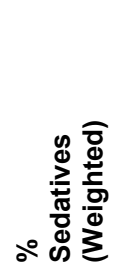 & 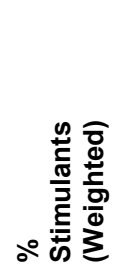 & 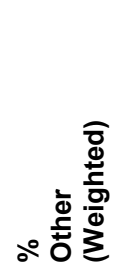 & 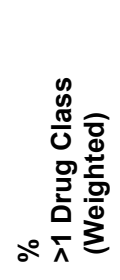 & 일 \\
\hline Yes & 47 & $0.0 \%$ & $20.7 \%$ & $2.0 \%$ & $2.6 \%$ & $2.4 \%$ & $0.0 \%$ & $1.1 \%$ & $71.1 \%$ \\
\hline No & 1,743 & $1.6 \%$ & $3.6 \%$ & $1.7 \%$ & $1.6 \%$ & $1.6 \%$ & $0.2 \%$ & $1.6 \%$ & $89.2 \%$ \\
\hline Total & 1,790 & $1.6 \%$ & $4.0 \%$ & $1.7 \%$ & $1.6 \%$ & $1.6 \%$ & $0.2 \%$ & $1.6 \%$ & $88.7 \%$ \\
\hline
\end{tabular}

Similar to results in the daytime sample, the nighttime drivers who were drug positive and responded to the question, "During the past 12 months, were you arrested and booked for driving under the influence of alcohol or drugs?" (Table 62) the majority tested positive for marijuana $(11.8 \%)$. 
Table 62. Arrests and Drug Class, Nighttime (Oral Fluid): "During the past 12 months, were you arrested and booked for driving under the influence of alcohol or drugs?"

\begin{tabular}{|c|c|c|c|c|c|c|c|c|c|}
\hline & 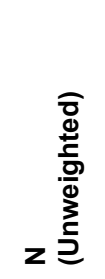 & 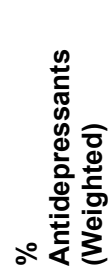 & 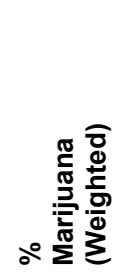 & 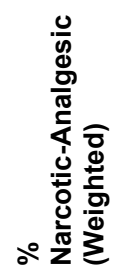 & 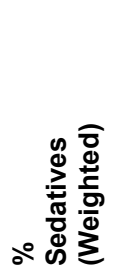 & 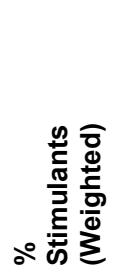 & 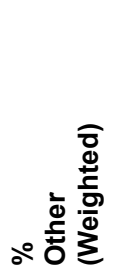 & 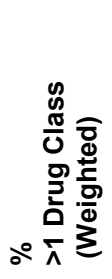 & 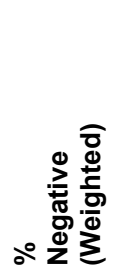 \\
\hline Yes & 234 & $0.0 \%$ & $11.8 \%$ & $0.2 \%$ & $0.2 \%$ & $10.8 \%$ & $0.0 \%$ & $6.0 \%$ & $\overline{70.9 \%}$ \\
\hline No & 5,458 & $0.2 \%$ & $5.8 \%$ & $1.7 \%$ & $0.7 \%$ & $3.0 \%$ & $0.3 \%$ & $2.3 \%$ & $86.0 \%$ \\
\hline Total & 5,692 & $0.2 \%$ & $6.0 \%$ & $1.7 \%$ & $0.7 \%$ & $3.3 \%$ & $0.3 \%$ & $2.4 \%$ & $85.5 \%$ \\
\hline
\end{tabular}

When examining the data by drug category, among daytime participants who responded to the question, "During the past 12 months, were you arrested and booked for driving under the influence of alcohol or drugs?" (Table 63) more participants tested positive for "Illegal" drugs than any other drug category $(23.3 \%)$.

Table 63. Arrests and Drug Categories, Daytime (Oral Fluid): "During the past 12 months, were you arrested and booked for driving under the influence of alcohol or drugs?"

\begin{tabular}{lccccc}
\hline & $\begin{array}{c}\text { N } \\
\text { (Unwt) }\end{array}$ & $\begin{array}{c}\text { Illegal } \\
\text { (Weighted) }\end{array}$ & $\begin{array}{c}\text { Medications } \\
\text { (Weighted) }\end{array}$ & $\begin{array}{c}\text { \% Illegal \& } \\
\text { Medications } \\
\text { (Weighted) }\end{array}$ & $\begin{array}{c}\text { \%egative } \\
\text { (Weighted) }\end{array}$ \\
\hline Yes & 47 & $23.3 \%$ & $5.3 \%$ & $0.2 \%$ & $71.1 \%$ \\
No & 1,743 & $5.4 \%$ & $4.9 \%$ & $0.5 \%$ & $89.2 \%$ \\
Total & 1,790 & $5.9 \%$ & $4.9 \%$ & $0.5 \%$ & $88.7 \%$ \\
\hline
\end{tabular}

Among nighttime participants who responded to the question, "During the past 12 months, were you arrested and booked for driving under the influence of alcohol or drugs?" (Table 64) more tested positive for "Illegal" drugs than any other drug category (26\%). Although this was slightly higher than the daytime population, the difference was not statistically different.

Table 64. Arrests and Drug Categories, Nighttime (Oral Fluid): "During the past 12 months, were you arrested and booked for driving under the influence of alcohol or drug?"

\begin{tabular}{lccccc}
\hline & $\begin{array}{c}\text { N } \\
\text { (Unwtd) }\end{array}$ & $\begin{array}{c}\text { Illegal } \\
\text { (Weighted) }\end{array}$ & $\begin{array}{c}\text { Medications } \\
\text { (Weighted) }\end{array}$ & $\begin{array}{c}\text { \% Illegal \& } \\
\text { Medications } \\
\text { (Weighted) }\end{array}$ & $\begin{array}{c}\% \\
\text { Negative } \\
\text { (Weighted) }\end{array}$ \\
\hline Yes & 234 & $26.0 \%$ & $1.3 \%$ & $1.7 \%$ & $70.9 \%$ \\
No & 5,458 & $9.9 \%$ & $3.1 \%$ & $0.9 \%$ & $86.0 \%$ \\
Total & 5,692 & $10.5 \%$ & $3.1 \%$ & $0.9 \%$ & $85.5 \%$ \\
\hline
\end{tabular}




\section{Reported Contact with the Health System (Oral Fluid)}

As indicated in previous reports on the 2007 NRS, questions relating to the criminal sanctions for drinking and drug use while driving were added to the survey items, as well as questions related to treatment for drug and alcohol use. These questions were added to the survey to investigate potential intervention opportunities.

As shown in Table 65, less than 1 percent of daytime drivers responded "Yes" to the question, "During the past 12 months, did you ever stay at least overnight in an inpatient or residential drug or alcohol treatment program?" Of these, almost 45 percent were drug positive.

Table 65. Past Treatment Program and Drug Positive, Daytime (Oral Fluid): "During the past 12 months, did you ever stay at least overnight in an inpatient or residential drug or alcohol treatment program?"

\begin{tabular}{lcc}
\hline & $\begin{array}{c}\mathbf{N} \\
\text { (Unweighted) }\end{array}$ & $\begin{array}{c}\text { \% Drug Positive } \\
\text { (Weighted) }\end{array}$ \\
\hline Yes & 7 & $44.7 \%$ \\
No & 1,738 & $11.2 \%$ \\
Total & 1,745 & $11.2 \%$ \\
\hline
\end{tabular}

Among nighttime drivers, less than 1 percent responded "Yes" to the question, "During the past 12 months, did you ever stay at least overnight in an inpatient or residential drug or alcohol treatment program?" (Table 66) Of these, 37 percent were drug positive.

The response patterns to these questions by nighttime drivers providing blood samples are quite similar to those reported here for nighttime oral fluid, and are presented separately in Appendix A.

Table 66. Past Treatment Program and Drug Positive, Nighttime (Oral Fluid): "During the past 12 months, did you ever stay at least overnight in an inpatient or residential drug or alcohol treatment program?"

\begin{tabular}{lcc}
\hline & $\begin{array}{c}\mathbf{N} \\
\text { (Unweighted) }\end{array}$ & $\begin{array}{c}\text { \% Drug Positive } \\
\text { (Weighted) }\end{array}$ \\
\hline Yes & 51 & $37.0 \%$ \\
No & 5,449 & $14.5 \%$ \\
Total & 5,500 & $14.6 \%$ \\
\hline$(p<.01)$ & &
\end{tabular}

Of daytime drivers who responded to the question, "Have you ever been admitted to an outpatient drug or alcohol treatment program, NOT including meetings like AA or NA?"17 approximately 2.5 percent responded "Yes" (Table 67). Of these, 38.4 percent were drug positive.

\footnotetext{
17 AA is Alcoholics Anonymous and NA is Narcotics Anonymous.
} 
Table 67. Outpatient and Drug Positive, Daytime (Oral Fluid): "Have you ever been admitted to an outpatient drug or alcohol treatment program, NOT including meetings like AA or NA?"

\begin{tabular}{lcc}
\hline & $\begin{array}{c}\text { N } \\
\text { (Unweighted) }\end{array}$ & $\begin{array}{c}\text { \% Drug Positive } \\
\text { (Weighted) }\end{array}$ \\
\hline Yes & 44 & $38.4 \%$ \\
No & 1,754 & $10.7 \%$ \\
Total & 1,798 & $11.2 \%$ \\
\hline$(p<.01)$ & \multicolumn{3}{|}{}
\end{tabular}

Of nighttime drivers who responded to the question, "Have you ever been admitted to an outpatient drug or alcohol treatment program, NOT including meetings like AA or NA?" approximately 2.8 percent responded "Yes" (Table 68). Of these, 36 percent were drug positive.

Table 68. Outpatient and Drug Positive, Nighttime (Oral Fluid): "Have you ever been admitted to an outpatient drug or alcohol treatment program, NOT including meetings like AA or NA?"

\begin{tabular}{lcc}
\hline & $\begin{array}{c}\text { N } \\
\text { (Unweighted) }\end{array}$ & $\begin{array}{c}\text { \% Drug Positive } \\
\text { (Weighted) }\end{array}$ \\
\hline Yes & 159 & $36.1 \%$ \\
No & 5,541 & $14.1 \%$ \\
Total & 5,700 & $14.5 \%$ \\
\hline$(p<.01)$ & \multicolumn{2}{l}{}
\end{tabular}

Of daytime drivers who responded to the question, "During the past 12 months, have you received treatment for your drug or alcohol use in a self-help group such as Alcoholics Anonymous or Narcotics Anonymous?" approximately 1 percent responded "Yes" (Table 69). Of these, 43 percent were drug positive. Of the nighttime drivers who were asked the same question, approximately 2 percent responded "Yes" (Table 70), and approximately 18 percent of those were drug positive.

Table 69. AA or NA and Drug Positives, Daytime (Oral Fluid): "During the past 12 months, have you received treatment for your drug or alcohol use in a self-help group such as Alcoholics Anonymous or Narcotics Anonymous?"

\begin{tabular}{lcc}
\hline & $\begin{array}{c}\mathbf{N} \\
\text { (Unweighted) }\end{array}$ & $\begin{array}{c}\text { \% Drug Positive } \\
\text { (Weighted) }\end{array}$ \\
\hline Yes & 17 & $43.1 \%$ \\
No & 1,778 & $10.9 \%$ \\
Total & 1,795 & $11.2 \%$ \\
\hline
\end{tabular}


Table 70. AA or NA and Drug Positives, Nighttime (Oral Fluid): "During the past 12 months, have you received treatment for your drug or alcohol use in a self-help group such as Alcoholics Anonymous of Narcotics Anonymous?"

\begin{tabular}{lcc}
\hline & $\begin{array}{c}\mathbf{N} \\
\text { (Unweighted) }\end{array}$ & $\begin{array}{c}\text { \% Drug Positive } \\
\text { (Weighted) }\end{array}$ \\
\hline Yes & 107 & $18.3 \%$ \\
No & 5,587 & $14.5 \%$ \\
Total & 5,694 & $14.6 \%$ \\
\hline
\end{tabular}

Of daytime drivers who responded to the question, "During the past 12 months, did you ever stay at least overnight in an impatient or residential drug or alcohol treatment program, for example, detox, rehab, a therapeutic community, or a hospital?" less than .5 percent responded "Yes" (Table 71). Of these, approximately 20 percent tested positive for marijuana and nearly 25 percent tested positive for more than one drug.

Table 71. Inpatient and Drug Class, Daytime (Oral Fluid): "During the past 12 months, did you ever stay at least overnight in an impatient or residential drug or alcohol treatment program, for example, detox, rehab, a therapeutic community, or a hospital?"

\begin{tabular}{|c|c|c|c|c|c|c|c|c|c|}
\hline & $x$ 氖 & 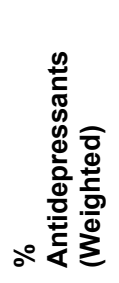 & 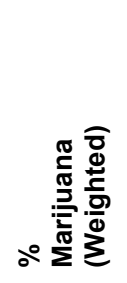 & 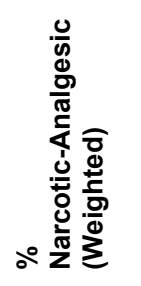 & 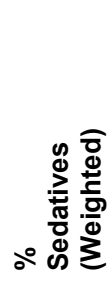 & 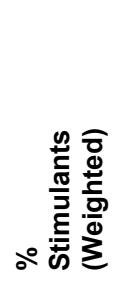 & 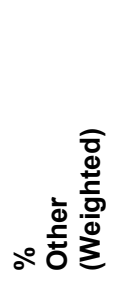 & 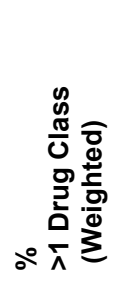 & 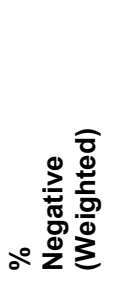 \\
\hline Yes & 7 & $0.0 \%$ & $20.3 \%$ & $0.0 \%$ & $0.0 \%$ & $0.0 \%$ & $0.0 \%$ & $24.5 \%$ & $55.3 \%$ \\
\hline No & 1,738 & $0.5 \%$ & $3.9 \%$ & $1.7 \%$ & $1.7 \%$ & $1.6 \%$ & $0.2 \%$ & $1.6 \%$ & $88.8 \%$ \\
\hline Total & 1,745 & $0.5 \%$ & $3.9 \%$ & $1.7 \%$ & $1.7 \%$ & $1.6 \%$ & $0.2 \%$ & $1.6 \%$ & $88.8 \%$ \\
\hline
\end{tabular}

Of the nighttime drivers who were asked the same question, approximately 1 percent responded "Yes" (Table 72). Of those, approximately 14 percent tested positive for marijuana, and approximately 12 percent tested positive for more than one drug. Although a higher percentage responded "Yes" to the marijuana item during the day than at night, this difference was not statistically significant. 
Table 72. Inpatient and Drug Class, Nighttime (Oral Fluid): "During the past 12 months, did you ever stay at least overnight in an impatient or residential drug or alcohol treatment program, for example, detox, rehab, a therapeutic community, or a hospital?"

\begin{tabular}{|c|c|c|c|c|c|c|c|c|c|}
\hline & 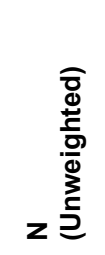 & 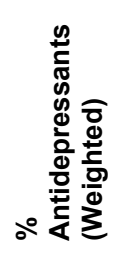 & 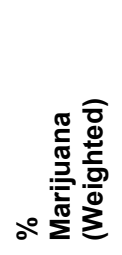 & 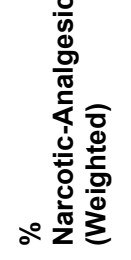 & 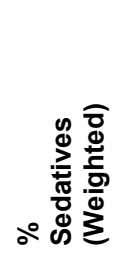 & 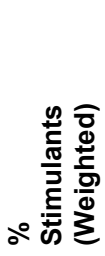 & 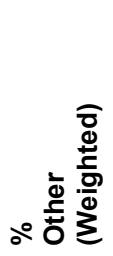 & 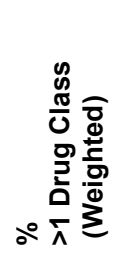 & 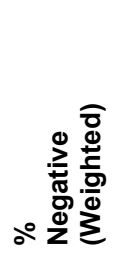 \\
\hline Yes & 51 & $0.0 \%$ & $14.4 \%$ & $0.3 \%$ & $1.4 \%$ & $9.4 \%$ & $0.0^{\circ}$ & $11.5 \%$ & $63.0 \%$ \\
\hline No & 5,449 & $0.2 \%$ & $6.1 \%$ & $1.6 \%$ & $0.7 \%$ & $3.2 \%$ & $0.3 \%$ & $2.4 \%$ & $85.5 \%$ \\
\hline Total & 5,500 & $0.2 \%$ & $6.1 \%$ & $1.6 \%$ & $0.7 \%$ & $3.2 \%$ & $0.3 \%$ & $2.4 \%$ & $85.4 \%$ \\
\hline
\end{tabular}

Of daytime drivers who responded to the question, "During the past 12 months, were you arrested and booked for driving under the influence of alcohol or drugs?" less than .5 percent responded "Yes" (Table 73).

Table 73. Inpatients and Drug Category, Daytime (Oral Fluid): "During the past 12 months, were you arrested and booked for driving under the influence of alcohol or drugs?"

\begin{tabular}{lccccc}
\hline & $\begin{array}{c}\mathbf{N} \\
\text { (Unwtd) }\end{array}$ & $\begin{array}{c}\text { \% } \\
\text { (Weighted) }\end{array}$ & $\begin{array}{c}\text { Medications } \\
\text { (Weighted) }\end{array}$ & $\begin{array}{c}\text { \% Illegal \& } \\
\text { Medications } \\
\text { (Weighted) }\end{array}$ & $\begin{array}{c}\text { \%egative } \\
\text { (Weighted) }\end{array}$ \\
\hline Yes & 7 & $44.7 \%$ & $0.0 \%$ & $0.0 \%$ & $55.3 \%$ \\
No & 1,738 & $5.7 \%$ & $5.0 \%$ & $0.5 \%$ & $88.8 \%$ \\
Total & 1,745 & $5.8 \%$ & $5.0 \%$ & $0.5 \%$ & $88.8 \%$ \\
\hline
\end{tabular}

Of these, nearly 45 percent tested positive for "Illegal" drugs. Of the nighttime drivers who were asked the same question, approximately 1 percent responded "Yes" (Table 74), and approximately 23 percent of those tested positive for "Illegal" drugs. The difference in "Illegal" drug use from daytime to nighttime was not significant.

Table 74. Inpatients and Drug Category, Nighttime (Oral Fluid): "During the past 12 months, were you arrested and booked for driving under the influence of alcohol or drugs?"

\begin{tabular}{lccccc}
\hline & $\begin{array}{c}\text { N } \\
\text { (Unwtd) }\end{array}$ & $\begin{array}{c}\text { Illegal } \\
\text { (Weighted) }\end{array}$ & $\begin{array}{c}\text { Medications } \\
\text { (Weighted) }\end{array}$ & $\begin{array}{c}\text { \% Illegal \& } \\
\text { Medications } \\
\text { (Weighted) }\end{array}$ & $\begin{array}{c}\text { \%egative } \\
\text { (Weighted) }\end{array}$ \\
\hline Yes & 51 & $23.4 \%$ & $2.3 \%$ & $11.3 \%$ & $63.0 \%$ \\
No & 5,449 & $10.6 \%$ & $3.0 \%$ & $0.9 \%$ & $85.5 \%$ \\
Total & 5,500 & $10.6 \%$ & $3.0 \%$ & $1.0 \%$ & $85.4 \%$ \\
\hline
\end{tabular}

Of daytime drivers who responded to the question, "Have you ever been admitted to an outpatient drug or alcohol treatment program, NOT including meetings like AA or NA?" 
approximately 2.5 percent responded "Yes" (Table 75). Of these, the most prevalent drug was marijuana (15.4\%). Additionally, nearly 15 percent tested positive for narcotic-analgesics.

Table 75. Outpatient and Drug Class, Daytime (Oral Fluid): "Have you ever been admitted to an outpatient drug or alcohol treatment program, NOT including meetings like AA or NA?"

\begin{tabular}{|c|c|c|c|c|c|c|c|c|c|}
\hline & 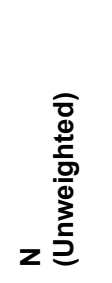 & 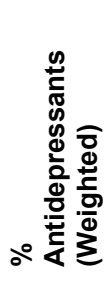 & 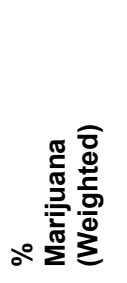 & 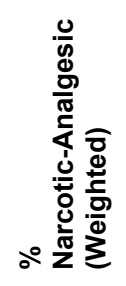 & 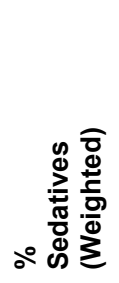 & 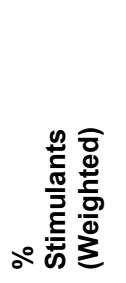 & 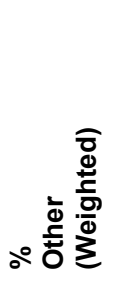 & 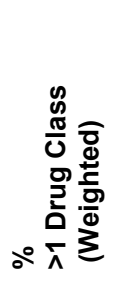 & 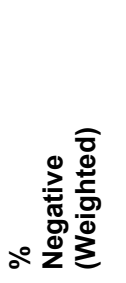 \\
\hline Yes & 44 & $3.4 \%$ & $15.4 \%$ & $14.7 \%$ & $0.0 \%$ & $3.7 \%$ & $0.0 \%$ & $1.1 \%$ & $61.6 \%$ \\
\hline No & 1,754 & $0.4 \%$ & $3.8 \%$ & $1.4 \%$ & $1.7 \%$ & $1.6 \%$ & $0.2 \%$ & $1.6 \%$ & $89.3 \%$ \\
\hline Total & 1,798 & $0.4 \%$ & $4.0 \%$ & $1.7 \%$ & $1.6 \%$ & $1.6 \%$ & $0.2 \%$ & $1.6 \%$ & $88.8 \%$ \\
\hline
\end{tabular}

Of the nighttime drivers who were asked the same question, nearly 3 percent responded "Yes" (Table 76), and nearly 14 percent tested positive for stimulants, which was more than any other drug category. Approximately 10 percent of those tested positive for marijuana, which was more than the daytime percentage; however, this difference was not statistically significant.

Table 76. Outpatient and Drug Class, Nighttime (Oral Fluid): "Have you ever been admitted to an outpatient drug or alcohol treatment program, NOT including meetings like AA or NA?"

\begin{tabular}{|c|c|c|c|c|c|c|c|c|c|}
\hline & 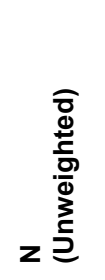 & 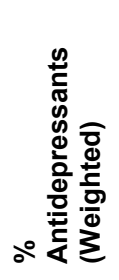 & ○ & 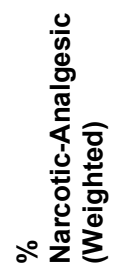 & 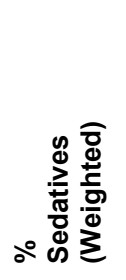 & 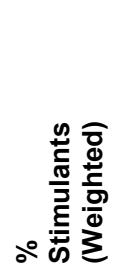 & 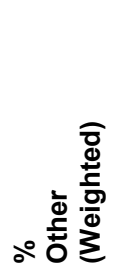 & 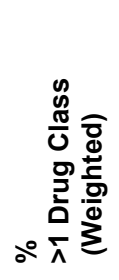 & 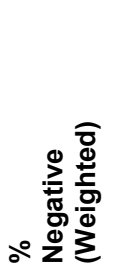 \\
\hline Yes & 159 & $1.6 \%$ & $10.1 \%$ & $6.5 \%$ & $1.7 \%$ & $13.8 \%$ & $0.0 \%$ & $2.3 \%$ & $63.9 \%$ \\
\hline No & 5,541 & $0.2 \%$ & $6.0 \%$ & $1.6 \%$ & $0.6 \%$ & $3.0 \%$ & $0.3 \%$ & $2.4 \%$ & $85.9 \%$ \\
\hline Total & 5,700 & $0.2 \%$ & $6.0 \%$ & $1.7 \%$ & $0.7 \%$ & $3.2 \%$ & $0.3 \%$ & $2.4 \%$ & $85.5 \%$ \\
\hline
\end{tabular}

Of daytime drivers who responded to the question, "Have you ever been admitted to an outpatient drug or alcohol treatment program, NOT including meetings like AA or NA?" approximately 2.5 percent responded "Yes" (Table 77). Of these, approximately 38 percent were drug positive, with nearly 20 percent testing positive for "Illegal" drugs. 
Table 77. Outpatient and Categories, Daytime (Oral Fluid): "Have you ever been admitted to an outpatient drug or alcohol treatment program, NOT including meetings like AA or NA?"

\begin{tabular}{lccccc}
\hline & $\begin{array}{c}\mathbf{N} \\
\text { (Unwtd) }\end{array}$ & $\begin{array}{c}\text { \% } \\
\text { (Weighted) }\end{array}$ & $\begin{array}{c}\text { Medications } \\
\text { (Weighted) }\end{array}$ & $\begin{array}{c}\text { \% Illegal \& } \\
\text { Medications } \\
\text { (Weighted) }\end{array}$ & $\begin{array}{c}\text { \%egative } \\
\text { (Weighted) }\end{array}$ \\
\hline Yes & 44 & $19.9 \%$ & $18.1 \%$ & $0.4 \%$ & $61.6 \%$ \\
No & 1,754 & $5.6 \%$ & $4.6 \%$ & $0.5 \%$ & $89.3 \%$ \\
Total & 1,798 & $5.9 \%$ & $4.9 \%$ & $0.5 \%$ & $88.8 \%$ \\
\hline
\end{tabular}

Of the nighttime drivers who were asked the same question, nearly 3 percent responded "Yes" (Table 78), and approximately 36 percent of those were drug positive, with nearly 25 percent testing positive for "Illegal" drugs. Although that percentage was higher for nighttime drivers than for daytime drivers, there was no statistical difference in the number of people testing positive for "Illegal" drugs between daytime and nighttime.

Table 78. Outpatient and Categories, Nighttime (Oral Fluid): "Have you ever been admitted to an outpatient drug or alcohol treatment program, NOT including meetings like AA or NA?"

\begin{tabular}{lccccc}
\hline & $\begin{array}{c}\text { N } \\
\text { (Unwtd) }\end{array}$ & $\begin{array}{c}\text { Illegal } \\
\text { (Weighted) }\end{array}$ & $\begin{array}{c}\text { Medications } \\
\text { (Weighted) }\end{array}$ & $\begin{array}{c}\text { \% Illegal \& } \\
\text { Medications } \\
\text { (Weighted) }\end{array}$ & $\begin{array}{c}\text { \%egative } \\
\text { (Weighted) }\end{array}$ \\
\hline Yes & 159 & $24.9 \%$ & $10.0 \%$ & $1.2 \%$ & $63.9 \%$ \\
No & 5,541 & $10.3 \%$ & $2.9 \%$ & $0.9 \%$ & $85.9 \%$ \\
Total & 5,700 & $10.5 \%$ & $3.1 \%$ & $0.9 \%$ & $85.5 \%$ \\
\hline
\end{tabular}

Of daytime drivers who responded to the question, "During the past 12 months, have you received treatment for your drug or alcohol use in a self-help group such as AA or NA?" approximately 1 percent responded "Yes" (Table 79). Of these, the most prevalent drug class was narcotic-analgesic $(23.3 \%)$.

Table 79. AA, NA and Classes, Daytime (Oral Fluid): "During the past 12 months, have you received treatment for your drug or alcohol use in a self-help group such as AA or NA?"

\begin{tabular}{|c|c|c|c|c|c|c|c|c|c|}
\hline & $z$ 氖 & 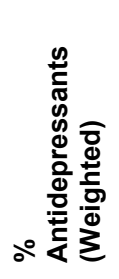 & 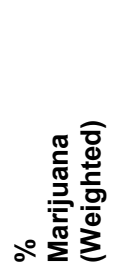 & 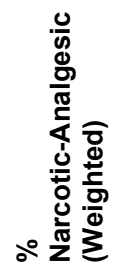 & 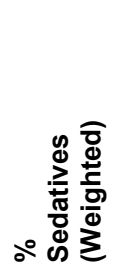 & 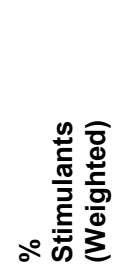 & 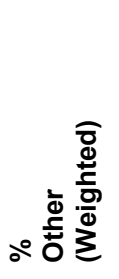 & 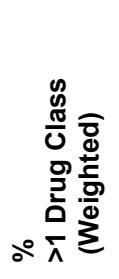 & 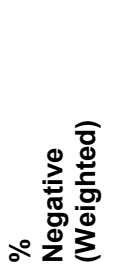 \\
\hline Yes & 17 & $2.1 \%$ & $17.7 \%$ & $23.3 \%$ & $0.0 \%$ & $0.0 \%$ & $0.0 \%$ & $0.0 \%$ & $56.9 \%$ \\
\hline No & 1,778 & $0.4 \%$ & $3.9 \%$ & $1.5 \%$ & $1.7 \%$ & $1.6 \%$ & $0.2 \%$ & $1.6 \%$ & $89.1 \%$ \\
\hline Total & 1,795 & $0.4 \%$ & $4.0 \%$ & $1.7 \%$ & $1.6 \%$ & $1.6 \%$ & $0.2 \%$ & $1.6 \%$ & $88.8 \%$ \\
\hline
\end{tabular}


Of the nighttime drivers who were asked the same question, nearly 2 percent responded "Yes" (Table 80), and nearly 10 percent tested positive for stimulants, which was more than any other drug category. Approximately 5 percent of those tested positive for marijuana, which was less than the daytime percentage of 18 percent; however, this difference was not statistically significant.

Table 80. AA, NA and Classes, Nighttime (Oral Fluid): "During the past 12 months, have you received treatment for your drug or alcohol use in a self-help group such as AA or NA?"

\begin{tabular}{|c|c|c|c|c|c|c|c|c|c|}
\hline & 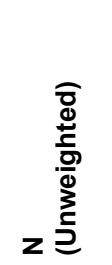 & 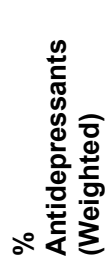 & ๙ & 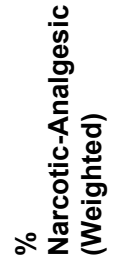 & 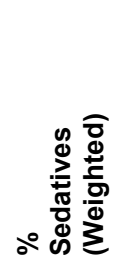 & 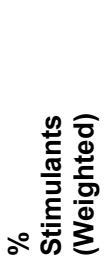 & 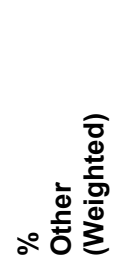 & 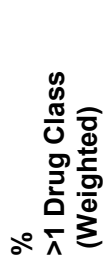 & ○゚ \\
\hline Yes & 107 & $0.4 \%$ & $5.3 \%$ & $0.4 \%$ & $0.5 \%$ & $9.5 \%$ & $0.0 \%$ & $2.2 \%$ & $81.7 \%$ \\
\hline No & 5,587 & $0.2 \%$ & $6.1 \%$ & $1.7 \%$ & $0.7 \%$ & $3.1 \%$ & $0.3 \%$ & $2.4 \%$ & $85.5 \%$ \\
\hline Total & 5,694 & $0.2 \%$ & $6.1 \%$ & $1.7 \%$ & $0.7 \%$ & $3.2 \%$ & $0.3 \%$ & $2.4 \%$ & $85.4 \%$ \\
\hline
\end{tabular}

Of daytime drivers who responded to the question, "During the past 12 months, have you received treatment for your drug or alcohol use in a self-help group such as AA or NA?" approximately 1 percent responded "Yes" (Table 81). Of these, slightly more than 25 percent tested positive for "Medications," and nearly 18 percent tested positive for "Illegal" drugs.

Table 81. NA, AA and Drug Categories, Daytime (Oral Fluid): "During the past 12 months, have you received treatment for your drug or alcohol use in a self-help group such as AA or NA?"

\begin{tabular}{lccccc}
\hline & $\begin{array}{c}\mathbf{N} \\
\text { (Unwtd) }\end{array}$ & $\begin{array}{c}\text { \% } \\
\text { (Weighted) }\end{array}$ & $\begin{array}{c}\text { Medications } \\
\text { (Weighted) }\end{array}$ & $\begin{array}{c}\text { \% Illegal \& } \\
\text { Medications } \\
\text { (Weighted) }\end{array}$ & $\begin{array}{c}\text { (Wegative } \\
\text { (Weighted) }\end{array}$ \\
\hline Yes & 17 & $17.7 \%$ & $25.4 \%$ & $0.0 \%$ & $56.9 \%$ \\
No & 1,778 & $5.8 \%$ & $4.7 \%$ & $0.5 \%$ & $89.1 \%$ \\
Total & 1,795 & $5.9 \%$ & $4.9 \%$ & $0.5 \%$ & $88.8 \%$ \\
\hline
\end{tabular}

Of the nighttime drivers who were asked the same question, nearly 2 percent responded "Yes" (Table 82), and nearly 15 percent tested positive for "Illegal" drugs. Although a greater percentage tested positive for "Illegal" drugs during the day than at night, this difference was not statistically significant. 
Table 82. NA, AA and Drug Categories, Nighttime (Oral Fluid): "During the past 12 months, have you received treatment for your drug or alcohol use in a self-help group such as AA or NA?"

\begin{tabular}{lccccc}
\hline & $\begin{array}{c}\mathbf{N} \\
\text { (Unwtd) }\end{array}$ & $\begin{array}{c}\text { \% } \\
\text { (Weighted) }\end{array}$ & $\begin{array}{c}\text { Medications } \\
\text { (Weighted) }\end{array}$ & $\begin{array}{c}\text { \% Illegal \& } \\
\text { Medications } \\
\text { (Weighted) }\end{array}$ & $\begin{array}{c}\text { \%egative } \\
\text { (Weighted) }\end{array}$ \\
\hline Yes & 107 & $14.9 \%$ & $3.0 \%$ & $0.4 \%$ & $81.7 \%$ \\
No & 5,587 & $10.5 \%$ & $3.1 \%$ & $0.9 \%$ & $85.5 \%$ \\
Total & 5,694 & $10.6 \%$ & $3.1 \%$ & $0.9 \%$ & $85.4 \%$ \\
\hline
\end{tabular}

\section{Blood Results (Nighttime Samples)}

\section{Driver Drug Use Prevalence Based on Blood Results}

This section of the report presents the overall results of blood analyses for all of the drugs indicated in the introductory section of this report. Blood samples were collected in addition to oral fluid samples because, typically, blood analyses are considered the "gold standard "and is the more established technique for gathering information on drugs and their metabolites, as oral fluid analyses are a more recently developed technique. As expected, the results between the oral fluid and blood results are very similar. These blood results are presented to provide more complete results from our data analyses for those who are interested in seeing the results from both approaches.

If a driver tested positive for one or more of the drugs for which we tested in blood, s/he was categorized as drug positive. Note that blood samples were only collected in the nighttime, and that more drivers provided oral fluid samples than blood samples.

About 14 percent of the 3,276 nighttime drivers who provided blood samples were drug-positive (Table 83).

Table 83. Drug Prevalence by Time of Day (Blood)

\begin{tabular}{lcc}
\hline \multicolumn{1}{c}{ Time of Day } & $\begin{array}{c}\text { N } \\
\text { (Unweighted) }\end{array}$ & $\begin{array}{c}\text { \% Drug Positive } \\
\text { (Weighted) }\end{array}$ \\
\hline Daytime & NA & NA \\
Nighttime & 3,276 & $13.8 \%$ \\
\hline NA = "Not Applicable" & &
\end{tabular}

Comparison of drug prevalence by session (Table 84) revealed that late-night (Sessions 3 and 5) drivers were significantly more likely to be drug-positive (17.9\% and $16.8 \%$ respectively), as opposed to the earlier nighttime (Sessions 2 and 4 ) drivers (13.6\% and $11.1 \%$ respectively) $(p<.01)$. 
Table 84. Drug Prevalence by Session (Blood)

\begin{tabular}{lcc}
\hline \multicolumn{1}{c}{ Session } & $\begin{array}{c}\text { N } \\
\text { (Unweighted) }\end{array}$ & $\begin{array}{c}\text { \% Drug Positive } \\
\text { (Weighted) }\end{array}$ \\
\hline 2: Friday, 10 p.m. - Midnight & 857 & $13.6 \%$ \\
\hline 3: Friday, 1 a.m. - 3 a.m. & 743 & $17.9 \%$ \\
\hline 4: Saturday, 10 p.m. - Midnight & 986 & $11.1 \%$ \\
\hline 5: Saturday, 1 a.m. - 3 a.m. & 690 & $16.8 \%$ \\
\hline
\end{tabular}

Although the Northeast region had the greatest percentage of drug-positive findings in the nighttime driving sample (Table 85), such differences were not statistically significant. Thus, no clear pattern of drug prevalence by region emerged from the blood sample results.

Table 85. Drug Prevalence by Region (Blood)

\begin{tabular}{lcc}
\hline \multicolumn{1}{c}{ Region } & $\begin{array}{c}\text { N } \\
\text { (Unweighted) }\end{array}$ & $\begin{array}{c}\text { \% Drug Positive } \\
\text { (Weighted) }\end{array}$ \\
\hline Midwest & 971 & $14.0 \%$ \\
Northeast & 584 & $14.5 \%$ \\
South & 862 & $13.4 \%$ \\
West & 859 & $13.5 \%$ \\
Overall & 3,276 & $13.8 \%$ \\
\hline
\end{tabular}

Comparison of blood samples by gender (Table 86) revealed that male drivers were more likely to be drug-positive (14.5\%) than female drivers (13.0\%); however, such differences were not statistically significant.

Table 86. Drug Prevalence by Gender (Blood)

\begin{tabular}{lcc}
\hline \multicolumn{1}{c}{ Gender } & $\begin{array}{c}\text { N } \\
\text { (Unweighted) }\end{array}$ & $\begin{array}{c}\text { \% Drug Positive } \\
\text { (Weighted) }\end{array}$ \\
\hline Males & 1,992 & $14.5 \%$ \\
Females & 1,278 & $13.0 \%$ \\
Overall & 3,270 & $13.9 \%$ \\
\hline
\end{tabular}

When examining drug prevalence by age, the prevalence of drug-positives was higher among young drivers (Table 87 ). Drivers aged 16-20 years showed a significantly higher prevalence than drivers aged 21-34 years and drivers aged 35-44 years $(p<.01)$. Drivers aged 35-44, 45-64, and $65+$ were significantly less likely to be drug positive than drivers in the combined age range of 16 to 34 years old $(p<.01)$. 
Table 87. Drug Prevalence by Age (Blood)

\begin{tabular}{ccc}
\hline Age & $\begin{array}{c}\mathbf{N} \\
\text { (Unweighted) }\end{array}$ & $\begin{array}{c}\text { \% Drug Positive } \\
\text { (Weighted) }\end{array}$ \\
\hline $16-20$ & 459 & $20.5 \%$ \\
$21-34$ & 1,372 & $15.2 \%$ \\
$35-44$ & 625 & $10.7 \%$ \\
$45-64$ & 697 & $11.2 \%$ \\
$65+$ & 91 & $6.0 \%$ \\
Overall & 3,244 & $14.0 \%$ \\
\hline
\end{tabular}

Comparisons between gender within age group (Table 88) showed that drug prevalence among male drivers ages 16-20 was significantly higher than female drivers ages 16-20 $(p<.01)$. Further, drug prevalence among male drivers aged 21-34 was also significantly higher than the same-aged female counterparts $(p<.05)$. Among drivers aged 45-64, however, drug prevalence was higher in females than in males $(p<.01)$.

Table 88. Drug Prevalence by Age and Gender (Blood)

\begin{tabular}{l|ccr}
\hline \multirow{2}{*}{ Gender } & Age & $\begin{array}{c}\text { N } \\
\text { (Unweighted) }\end{array}$ & $\begin{array}{c}\text { \% Drug Positive } \\
\text { (Weighted) }\end{array}$ \\
\hline \multirow{6}{*}{ Males } & $16-20$ & 301 & $22.8 \%$ \\
& $21-34$ & 825 & $16.9 \%$ \\
& $35-44$ & 368 & $11.2 \%$ \\
& $45-64$ & 413 & $8.3 \%$ \\
& $65+$ & 61 & $6.0 \%$ \\
\hline \multirow{6}{*}{ Females } & Overall Males & 1,968 & $14.6 \%$ \\
& $16-20$ & 158 & $16.5 \%$ \\
& $21-34$ & 547 & $12.2 \%$ \\
& $35-44$ & 254 & $10.5 \%$ \\
& $45-64$ & 283 & $16.7 \%$ \\
& $65+$ & 30 & $5.8 \%$ \\
& Overall Females & 1,272 & $13.0 \%$ \\
\hline
\end{tabular}

Comparing drug prevalence between race/ethnicity (Table 89), Asian drivers were significantly less likely to be drug positive (1.3\%) than drivers who identified themselves as African American, Hispanic, White, or Other $(p<.01)$.

Table 89. Drug Prevalence by Race/Ethnicity (Blood)

\begin{tabular}{lcc}
\hline Race/Ethnicity & $\begin{array}{c}\text { N } \\
\text { (Unweighted) }\end{array}$ & $\begin{array}{c}\text { \% Drug Positive } \\
\text { (Weighted) }\end{array}$ \\
\hline African American & 569 & $16.8 \%$ \\
Asian & 87 & $1.3 \%$ \\
Hispanic & 585 & $10.0 \%$ \\
White & 1,836 & $15.5 \%$ \\
Other & 165 & $19.7 \%$ \\
Overall & 3,242 & $14.0 \%$ \\
\hline Race/Ethnic groups other than "Hispanic" are always "non-Hispanic"
\end{tabular}


Looking at drug prevalence by education level (Table 90), drivers who identified themselves as college graduates or having some college experience were significantly less likely to be drugpositive $(p<.01)$ than drivers with other educational attainment.

Table 90. Drug Prevalence by Education Level (Blood)

\begin{tabular}{lcc}
\hline \multicolumn{1}{c}{ Education Level } & $\begin{array}{c}\text { N } \\
\text { (Unweighted) }\end{array}$ & $\begin{array}{c}\text { \% Drug Positive } \\
\text { (Weighted) }\end{array}$ \\
\hline Not a High School Graduate & 289 & $20.3 \%$ \\
High School Graduate & 831 & $16.5 \%$ \\
Some College & 1,318 & $12.5 \%$ \\
College Graduate & 594 & $10.8 \%$ \\
Some Graduate Work & 212 & $13.5 \%$ \\
Overall Nighttime & 3,245 & $14.0 \%$ \\
\hline
\end{tabular}

When examining drug prevalence by employment status (Table 91), drivers on disability showed drug prevalence that was significantly higher than employed drivers, as well as homemakers, students, unemployed drivers, and drivers who reported that they were retired $(p<.01)$. No statistical difference in drug prevalence was found between employed and unemployed drivers ( $p$ value $=.06)$. "Retired" drivers had significantly lower drug prevalence than employed drivers $(p<.05)$.

Table 91. Drug Prevalence by Employment Status (Blood)

\begin{tabular}{lcc}
\hline \multicolumn{1}{c}{ Gender } & $\begin{array}{c}\text { N } \\
\text { (Unweighted) }\end{array}$ & $\begin{array}{c}\text { \% Drug Positive } \\
\text { (Weighted) }\end{array}$ \\
\hline Employed/Self Employed & 2,592 & $13.6 \%$ \\
Homemaker & 67 & $12.0 \%$ \\
Student & 274 & $15.3 \%$ \\
Unemployed & 121 & $20.4 \%$ \\
Retired & 124 & $6.0 \%$ \\
On Disability & 47 & $41.4 \%$ \\
Other & 20 & $15.6 \%$ \\
Overall & 3,245 & $14.0 \%$ \\
\hline
\end{tabular}


Comparisons across vehicle type (Table 92) showed drug prevalence rates among drivers of passenger vehicles, SUV, and van/minivans were not statistically different ( $p$ value $=.12$ ). Note, however, that motorcyclists had the greatest percentage of drug-positive results $(p<.05)$, while pickup drivers had the smallest prevalence $(p<.05)$.

Table 92. Drug Prevalence by Vehicle Type (Blood)

\begin{tabular}{lcc}
\hline \multicolumn{1}{c}{ Vehicle Type } & $\begin{array}{c}\mathbf{N} \\
\text { (Unweighted) }\end{array}$ & $\begin{array}{c}\text { \% Drug Positive } \\
\text { (Weighted) }\end{array}$ \\
\hline Passenger Vehicle & 1,971 & $14.6 \%$ \\
Pickup & 401 & $9.3 \%$ \\
SUV & 586 & $11.6 \%$ \\
Van \& Minivan & 250 & $16.2 \%$ \\
Motorcycle & 48 & $24.0 \%$ \\
Overall & 3,256 & $13.9 \%$ \\
\hline
\end{tabular}

\section{Driver Drug Use Prevalence by Drug Class Based on Blood Results}

In this section of the report, we display driver drug use prevalence by class of drug, based on blood results. The classes of drugs tested for were antidepressants, marijuana, narcoticanalgesics, sedatives, stimulants, and other (see Tables 94-96).

\section{Drug Class}

Two percent of the blood-sampled drivers tested positive for more than one drug class (Table 93).

Table 93. Number and Distribution of Drug Classes (Blood)

\begin{tabular}{lcc}
\hline $\begin{array}{c}\text { Number of } \\
\text { Drug Classes }\end{array}$ & $\begin{array}{c}\mathbf{N} \\
\text { (Unweighted) }\end{array}$ & $\begin{array}{c}\text { \% } \\
\text { (Weighted) }\end{array}$ \\
\hline 1 & 398 & $11.8 \%$ \\
$2+$ & 68 & $2.0 \%$ \\
Negative & 2,810 & $86.2 \%$ \\
Overall & 3,276 & $100.0 \%$ \\
\hline
\end{tabular}


In comparing prevalence of drug classes by region (Table 94), marijuana was the most common drug class across all of the regions (6.7\%). However, drivers in the West region were less likely to test positive for marijuana than in the other regions $(p<.05)$.

Table 94. Drug Classes Distribution by Region (Blood)

\begin{tabular}{lrrrrc}
\hline \multicolumn{1}{c}{ Drug Class } & $\begin{array}{c}\text { Midwest } \\
\%\end{array}$ & $\begin{array}{c}\text { Northeast } \\
\%\end{array}$ & $\begin{array}{c}\text { South } \\
\%\end{array}$ & $\begin{array}{c}\text { West } \\
\%\end{array}$ & $\begin{array}{c}\text { All } \\
\%\end{array}$ \\
\hline & $\mathbf{N = 9 7 1}$ & $\mathbf{N = 5 8 4}$ & $\mathbf{N = 8 6 2}$ & $\mathbf{N = 8 5 9}$ & $\mathbf{N = 3 , 2 7 6}$ \\
Antidepressants & $0.7 \%$ & $0.4 \%$ & $1.3 \%$ & $1.5 \%$ & $1.1 \%$ \\
Marijuana & $7.9 \%$ & $9.5 \%$ & $6.0 \%$ & $4.7 \%$ & $6.7 \%$ \\
Narcotic-Analgesics & $1.1 \%$ & $0.4 \%$ & $1.4 \%$ & $0.8 \%$ & $0.9 \%$ \\
Sedatives & $0.9 \%$ & $0.4 \%$ & $1.6 \%$ & $1.4 \%$ & $1.1 \%$ \\
Stimulants & $2.1 \%$ & $1.0 \%$ & $1.5 \%$ & $2.2 \%$ & $1.9 \%$ \\
Other & $0.0 \%$ & $0.0 \%$ & $0.2 \%$ & $0.5 \%$ & $0.2 \%$ \\
More than 1 Class & $1.3 \%$ & $2.9 \%$ & $1.3 \%$ & $2.4 \%$ & $2.0 \%$ \\
Overall Drug Positive & $14.0 \%$ & $14.5 \%$ & $13.4 \%$ & $13.5 \%$ & $13.8 \%$ \\
Negative & $86.0 \%$ & $85.5 \%$ & $86.6 \%$ & $86.5 \%$ & $86.2 \%$ \\
\hline
\end{tabular}

"More than 1 Class" - Drivers testing positive for more than one drug are only counted in this category. In this table, percentages are weighted.

Comparison of drug class by gender (Table 95) revealed that male drivers were significantly more likely to test positive for marijuana than female drivers ( $7.4 \%$ males versus $5.6 \%$ females) $(p<.05)$.

Table 95. Drug Classes Distribution by Gender (Blood)

\begin{tabular}{lccc}
\hline \multicolumn{1}{c}{ Drug Class } & $\begin{array}{c}\text { Males } \\
\%\end{array}$ & $\begin{array}{c}\text { Females } \\
\%\end{array}$ & $\begin{array}{c}\text { Total } \\
\text { \% }\end{array}$ \\
\hline & $\begin{array}{c}\mathbf{N = 1 , 9 9 2} \\
\text { Antidepressants }\end{array}$ & $\begin{array}{c}\mathbf{N = 1 , 2 7 8} \\
\mathbf{N = 3 , 2 7 0}\end{array}$ & $1.1 \%$ \\
Marijuana & $1.0 \%$ & $1.2 \%$ & $6.7 \%$ \\
Narcotic-Analgesics & $7.4 \%$ & $5.6 \%$ & $0.9 \%$ \\
Sedatives & $0.8 \%$ & $1.0 \%$ & $1.1 \%$ \\
Stimulants & $0.7 \%$ & $1.8 \%$ & $1.9 \%$ \\
Other & $1.8 \%$ & $2.0 \%$ & $0.2 \%$ \\
More than 1 Class & $0.4 \%$ & $0.0 \%$ & $2.0 \%$ \\
Overall Drug Positive & $2.4 \%$ & $1.4 \%$ & $13.9 \%$ \\
Negative & $14.5 \%$ & $13.0 \%$ & $86.1 \%$ \\
\hline
\end{tabular}

In this table, percentages are weighted.

"More than 1 Class" - Drivers testing positive for more than one drug are only counted in this category. 
Comparison of drug class by age (Table 96) showed that drivers 34 or younger were more likely to test positive for marijuana than drives in other age groups $(p<.01)$. Among drivers aged 1634 , drivers aged 16-20 years had the highest marijuana positives $(15.2 \%)$. The prevalence of narcotic-analgesics was higher among the $16-20$ and $35-44$ year age group $(1.3 \%$ and $1.7 \%)$ than among any other age group $(p<.01)$.

Table 96. Drug Classes Distribution by Age (Blood)

\begin{tabular}{lrrrrrc}
\hline \multicolumn{1}{c}{ Drug Class } & $\begin{array}{c}\mathbf{1 6 - 2 0} \\
\mathbf{\%}\end{array}$ & $\begin{array}{c}\mathbf{2 1 - 3 4} \\
\mathbf{\%}\end{array}$ & $\begin{array}{c}\mathbf{3 5 - 4 4} \\
\mathbf{\%}\end{array}$ & $\begin{array}{c}\mathbf{4 5 - 6 4} \\
\mathbf{\%}\end{array}$ & $\begin{array}{c}\mathbf{6 5 +} \\
\mathbf{\%}\end{array}$ & $\begin{array}{c}\text { Total } \\
\mathbf{\%}\end{array}$ \\
\hline & $\mathbf{N = 4 5 9}$ & $\mathbf{N = 1 , 3 7 2}$ & $\mathbf{N = 6 2 5}$ & $\mathbf{N = 6 9 7}$ & $\mathbf{N = 9 1}$ & $\mathbf{N = 3 , 2 4 4}$ \\
Antidepressants & $0.3 \%$ & $0.6 \%$ & $0.9 \%$ & $2.8 \%$ & $1.0 \%$ & $1.1 \%$ \\
Marijuana & $15.2 \%$ & $8.8 \%$ & $3.1 \%$ & $1.0 \%$ & $0.0 \%$ & $6.8 \%$ \\
Narcotic-Analgesics & $1.3 \%$ & $0.7 \%$ & $1.7 \%$ & $0.4 \%$ & $0.0 \%$ & $0.9 \%$ \\
Sedatives & $0.0 \%$ & $0.8 \%$ & $1.0 \%$ & $2.1 \%$ & $4.8 \%$ & $1.1 \%$ \\
Stimulants & $0.7 \%$ & $1.8 \%$ & $2.0 \%$ & $2.7 \%$ & $0.0 \%$ & $1.8 \%$ \\
Other & $0.2 \%$ & $0.4 \%$ & $0.2 \%$ & $0.0 \%$ & $0.0 \%$ & $0.2 \%$ \\
More than 1 Class & $2.7 \%$ & $1.9 \%$ & $1.8 \%$ & $2.3 \%$ & $0.1 \%$ & $2.0 \%$ \\
Overall Drug Positive & $20.5 \%$ & $15.2 \%$ & $10.7 \%$ & $11.2 \%$ & $6.0 \%$ & $14.0 \%$ \\
Negative & $79.5 \%$ & $84.8 \%$ & $89.3 \%$ & $88.8 \%$ & $94.0 \%$ & $86.0 \%$ \\
\hline
\end{tabular}

"More than 1 Class" - Drivers testing positive for more than one drug are only counted in this category. In this table, percentages are weighted.

\section{Driver Drug Use Prevalence by Drug Category Based on Blood Results}

In this section of the report, we display drug use prevalence results from blood tests by drug category.

About 9 percent of the nighttime drivers providing blood tested positive for drugs in the "Illegal" category (Table 97). Four percent were positive for "Medications," and 0.7 percent were positive for both "Illegal and Medications."

Table 97. Drug Categories Distribution (Blood)

\begin{tabular}{lcc}
\hline \multicolumn{1}{c}{ Drug Category } & $\begin{array}{c}\text { N } \\
\text { (Unweighted) }\end{array}$ & $\begin{array}{c}\% \\
\text { (Weighted) }\end{array}$ \\
\hline Illegal & 267 & $9.1 \%$ \\
Medications & 169 & $4.0 \%$ \\
Illegal \& Medications & 30 & $0.7 \%$ \\
Negative & 2,810 & $86.2 \%$ \\
Overall & 3,276 & $100.0 \%$ \\
\hline "Medications" includes prescription and over-the-counter drugs.
\end{tabular}


The percentage of "Illegal" drug prevalence was slightly higher $(p<.05)$ in the Midwest and Northeast than in the remaining regions (Table 98).

Table 98. Drug Categories Distribution by Region (Blood)

\begin{tabular}{l|lrr}
\hline \multirow{2}{*}{ Region } & Drug Category & $\begin{array}{c}\text { N } \\
\text { (Unweighted) }\end{array}$ & $\begin{array}{c}\% \\
\text { (Weighted) }\end{array}$ \\
\hline \multirow{5}{*}{ Midwest } & Illegal & 81 & $10.2 \%$ \\
& Medications & 52 & $3.2 \%$ \\
& Illegal \& Medications & 8 & $0.6 \%$ \\
& Negative & 830 & $86.0 \%$ \\
\cline { 2 - 4 } Northeast & Overall & 971 & $100.0 \%$ \\
& Illegal & 57 & $11.0 \%$ \\
& Medications & 26 & $2.7 \%$ \\
& Illegal \& Medications & 4 & $0.8 \%$ \\
& Negative & 497 & $85.5 \%$ \\
\cline { 2 - 4 } South & Overall & 584 & $100.0 \%$ \\
\hline \multirow{5}{*}{ West } & Illegal & 56 & $7.6 \%$ \\
& Medications & 51 & $4.9 \%$ \\
& Illegal \& Medications & 12 & $0.9 \%$ \\
& Negative & 743 & $86.6 \%$ \\
& Overall & 862 & $100.0 \%$ \\
\hline & Illegal & 73 & $8.2 \%$ \\
& Medications & 40 & $4.9 \%$ \\
& Illegal \& Medications & 6 & $0.5 \%$ \\
& Negative & 740 & $86.5 \%$ \\
& Overall & 859 & $100.0 \%$ \\
\hline
\end{tabular}

"Medications" includes prescription and over-the-counter drugs.

When examining prevalence by drug category and gender (Table 99), we found that over 10 percent of male drivers had positive results for "Illegal" drugs, as did about 7 percent of female drivers $(p<.01)$. The difference in percentage of positive results for "Medications" between male and female drivers was not statistically significant. 
Table 99. Drug Categories Distribution by Gender (Blood)

\begin{tabular}{l|lrr}
\hline \multirow{2}{*}{ Gender } & \multicolumn{1}{c}{ Drug Category } & $\begin{array}{c}\text { N } \\
\text { (Unweighted) }\end{array}$ & $\begin{array}{c}\text { \% } \\
\text { (Weighted) }\end{array}$ \\
\hline \multirow{5}{*}{ Male } & Illegal & 191 & $10.4 \%$ \\
& Medications & 75 & $3.3 \%$ \\
& Illegal \& Medications & 19 & $0.8 \%$ \\
& Negative & 1,707 & $85.5 \%$ \\
& Overall & 1,992 & $100.0 \%$ \\
\hline \multirow{5}{*}{ Female } & Illegal & 76 & $7.2 \%$ \\
& Medications & 94 & $5.4 \%$ \\
& Illegal \& Medications & 11 & $0.4 \%$ \\
& Negative & 1,097 & $87.0 \%$ \\
& Overall & 1,278 & $100.0 \%$ \\
\hline
\end{tabular}

"Medications" includes prescription and over-the-counter drugs.

Examining drug use by age (Table 100), "Illegal" drug use was highest for drivers in the youngest age group (16-20 years) $(p<.01)$, followed by drivers aged 21-34. "Illegal" drug use among drivers 35 and older was significantly lower than among drivers younger than age 35 $(p<.01)$. "Medication" usage followed the opposite trend, with prevalence increasing with age. Prevalence of "Medication" was significantly higher for drivers aged 35 and older than for drivers younger than age $35(p<.01)$. 
Table 100. Drug Categories Distribution by Age (Blood)

\begin{tabular}{l|lrr}
\hline \multirow{2}{*}{ Age } & Drug Category & $\begin{array}{c}\text { N } \\
\text { (Unweighted) }\end{array}$ & $\begin{array}{c}\% \\
\text { (Weighted) }\end{array}$ \\
\hline \multirow{5}{*}{$16-20$} & Illegal & 56 & $17.7 \%$ \\
& Medications & 8 & $1.9 \%$ \\
& Illegal \& Medications & 4 & $0.9 \%$ \\
& Negative & 391 & $79.5 \%$ \\
& Overall & 459 & $100.0 \%$ \\
\hline \multirow{5}{*}{$21-34$} & Illegal & 141 & $11.7 \%$ \\
& Medications & 48 & $2.7 \%$ \\
& Illegal \& Medications & 13 & $0.7 \%$ \\
& Negative & 1,170 & $84.8 \%$ \\
& Overall & 1,372 & $100.0 \%$ \\
\hline \multirow{5}{*}{$35-44$} & Illegal & 43 & $5.3 \%$ \\
& Medications & 43 & $5.0 \%$ \\
& Illegal \& Medications & 7 & $0.4 \%$ \\
& Negative & 532 & $89.3 \%$ \\
& Overall & 625 & $100.0 \%$ \\
\hline \multirow{5}{*}{$45-64$} & Illegal & 26 & $3.1 \%$ \\
& Medications & 61 & $7.3 \%$ \\
& Illegal \& Medications & 6 & $0.8 \%$ \\
& Negative & 604 & $88.8 \%$ \\
& Overall & 697 & $100.0 \%$ \\
\hline \multirow{5}{*}{$65+$} & Illegal & 0 & $0.0 \%$ \\
& Medications & 9 & $6.0 \%$ \\
& Illegal \& Medications & $0.0 \%$ \\
& Negative & 82 & $100.0 \%$ \\
\hline & Overall & 91 &
\end{tabular}

"Medications" includes prescription and over-the-counter drugs.

\section{Driver Drug Use Prevalence from Blood and BAC Results}

The following section presents the results of the blood drug analyses combined with the BAC results from breath tests.

The numbers of drug-positive drivers by BAC level are shown in Tables 101 and 102. Table 101 shows BAC level with respect to the total number of drivers in each drug result category (positives, negatives, and overall). Table 102 shows drug prevalence with respect to the total number of drivers in each of the three BAC categories. A statistically significant association was found between drug-positive and alcohol-positive drivers. The percentage of drivers with BAC $\mathrm{g} / \mathrm{dL} .08+$ was significantly higher among drug-positive drivers than among drug-negative drivers $(p<.01)$. The percentage of drivers with a BAC between zero and .08 was also significantly higher for drug-positive drivers $(p<.01)$. 
Table 101. Drug Prevalence by BAC (Percentages Calculated by Row) (Blood)

\begin{tabular}{lcccc}
\hline & & \multicolumn{3}{c}{ BAC (g/dL) } \\
\cline { 3 - 5 } Drug & $\mathbf{N}$ & \multicolumn{3}{c}{ Between } \\
Result & (Unweighted) & Zero & Zero and .08 & .08+ \\
\hline Positive & 466 & $78.3 \%$ & $16.0 \%$ & $5.7 \%$ \\
Negative & 2,810 & $93.7 \%$ & $5.2 \%$ & $1.1 \%$ \\
Overall & 3,276 & $91.6 \%$ & $6.7 \%$ & $1.7 \%$ \\
\hline
\end{tabular}

In this table, percentages are weighted.

Table 102. Drug Prevalence by BAC (Percentages Calculated by Column) (Blood)

\begin{tabular}{ccccc}
\hline & \multicolumn{4}{c}{ BAC $(\mathbf{g} / \mathbf{d L})$} \\
\cline { 2 - 5 } Drug & \multicolumn{4}{c}{ Between } \\
Result & Zero & Zero and .08 & .08+ & All \\
\hline & $\mathbf{N}=\mathbf{2 , 9 8 4}$ & $\mathbf{N}=\mathbf{2 4 1}$ & $\mathbf{N}=\mathbf{5 1}$ & $\mathbf{N}=\mathbf{3 , 2 7 6}$ \\
Positive & $11.8 \%$ & $33.2 \%$ & $45.3 \%$ & $13.8 \%$ \\
Negative & $88.2 \%$ & $66.8 \%$ & $54.7 \%$ & $86.2 \%$ \\
\hline
\end{tabular}

In this table, percentages are weighted.

Examining BAC among drug-positive drivers by age (Table 103), a large percentage of alcoholpositives were found in drug-positive drivers aged 16-20 and 21-34 $(p<.01)$. Drivers aged 65 and older had the largest percentage of drivers at intermediate BAC (i.e., between zero and .08); however, the sample size of this category was quite small.

Table 103. BAC Among Drug-Positive Drivers by Age (Blood)

\begin{tabular}{l|cccc}
\hline & & \multicolumn{3}{c}{ BAC (g/dL) } \\
\cline { 3 - 5 } \multicolumn{1}{c}{ Age } & N & \multicolumn{3}{c}{ Between Zero } \\
(Unweighted) & Zero & and .08 & $.08+$ \\
\hline $16-20$ & 68 & $73.7 \%$ & $21.2 \%$ & $5.1 \%$ \\
$21-34$ & 202 & $73.3 \%$ & $18.7 \%$ & $8.0 \%$ \\
$35-44$ & 93 & $84.7 \%$ & $9.4 \%$ & $5.9 \%$ \\
$45-64$ & 93 & $95.5 \%$ & $4.5 \%$ & $0.0 \%$ \\
$65+$ & 9 & $59.9 \%$ & $40.1 \%$ & $0.0 \%$ \\
Overall Positive & 465 & $78.6 \%$ & $15.8 \%$ & $5.7 \%$ \\
\hline
\end{tabular}

In this table, percentages are weighted.

There were fewer alcohol-positive drivers among drug-positive drivers with 2+ classes of drugs than those with one class (Tables 104 and 105); however, due to the small sample size, this difference was statistically non-significant. 
Table 104. BAC Among Drug-Positive Drivers by Number of Drug Classes (Percentages Calculated by Column) (Blood)

\begin{tabular}{c|ccc}
\hline \multirow{2}{*}{$\begin{array}{c}\text { No. of Drug } \\
\text { Classes }\end{array}$} & Zero & BAC (g/dL) \\
\cline { 2 - 4 } & $\mathbf{N}=\mathbf{3 8 6}$ & $\mathbf{N}=\mathbf{6 2}$ & $\mathbf{N}=\mathbf{0 8 +}$ \\
\hline & $84.0 \%$ & $88.1 \%$ & $99.5 \%$ \\
$2+$ & $16.0 \%$ & $11.9 \%$ & $0.5 \%$ \\
$2+$ & $100.0 \%$ & $100.0 \%$ & $100.0 \%$ \\
\multicolumn{2}{l}{ Overall } & \multicolumn{3}{l}{} \\
\hline
\end{tabular}

Table 105. BAC Among Drug-Positive Drivers by Number of Drug Classes (Percentages Calculated by Row) (Blood)

\begin{tabular}{l|cccc}
\hline & & \multicolumn{3}{c}{ BAC (g/dL) } \\
\cline { 3 - 5 } $\begin{array}{c}\text { Number of } \\
\text { Drug Classes }\end{array}$ & N & \multicolumn{3}{c}{ Between } \\
\hline 1 & 398 & $76.9 \%$ & $16.5 \%$ & $6.6 \%$ \\
$2+$ & 68 & $86.7 \%$ & $13.1 \%$ & $0.2 \%$ \\
Overall & 466 & $78.3 \%$ & $16.0 \%$ & $5.7 \%$ \\
\hline
\end{tabular}

In this table, percentages are weighted.

The majority of drug-positive drivers who were also alcohol-positive tested positive more often were positive for "Illegal" drugs (Tables 106 and 107). More than 90 percent of those drivers having a BAC between zero and .08 tested positive for "Illegal" drugs (either alone or in conjunction with "Medications"). This percentage was significantly higher than the approximately 65 percent of non-drinking (BAC = zero) drug-positive drivers who also had an "Illegal" drug in their system (alone or combined with "Medications") $(p<.01)$.

Table 106. BAC Among Drug-Positive Drivers by Drug Category (Percentage by Row) (Blood)

\begin{tabular}{l|cccc}
\hline & & \multicolumn{3}{c}{ BAC (g/dL) } \\
\cline { 3 - 5 } \multicolumn{1}{c}{ Drug Category } & (Unweighted) & Zero & Between \\
Zero and .08 & $\mathbf{. 0 8 +}$ \\
\hline Illegal & 267 & $71.7 \%$ & $20.4 \%$ & $7.9 \%$ \\
Medications & 169 & $93.6 \%$ & $4.9 \%$ & $1.5 \%$ \\
Illegal \& Medications & 30 & $76.8 \%$ & $23.2 \%$ & $0.0 \%$ \\
\hline
\end{tabular}

"Medications" includes prescription and over-the-counter drugs.

In this table, percentages are weighted. 
Table 107. BAC Among Drug-Positive Drivers by Drug Category (Percentage by Column) (Blood)

\begin{tabular}{l|ccc}
\hline \multirow{2}{*}{\multicolumn{1}{c}{ Drug Category }} & Zero & Between Zero \\
\cline { 2 - 4 } and .08 &. $\mathbf{0 8 +}$ \\
\hline \multirow{2}{*}{ Illegal } & $\mathbf{N}=\mathbf{3 8 6}$ & $\mathbf{N}=\mathbf{6 2}$ & $\mathbf{N}=\mathbf{1 8}$ \\
Medications & $60.5 \%$ & $84.2 \%$ & $92.5 \%$ \\
Illegal \& Medications & $34.9 \%$ & $9.0 \%$ & $7.5 \%$ \\
\hline
\end{tabular}

"Medications" includes prescription and over-the-counter drugs.

In this table, percentages are weighted.

High alcohol-positive drivers (i.e., drivers with a $.08 \mathrm{BAC}$ g/dL or greater) who tested positive for "Illegal" drugs were more likely to be age 44 or younger $(p<.01)$. The sample size was very small for drivers aged 45 or older, in particular those aged 65 or older. (Note that, due to the number of groupings in Table 108 and the small sample sizes, caution should be exercised in interpretation of these findings.)

Table 108. BAC of Drivers by Drug Category and Age (Blood)

\begin{tabular}{|c|c|c|c|c|c|}
\hline \multirow[b]{2}{*}{ Age } & \multirow[b]{2}{*}{ Drug Category } & \multirow[b]{2}{*}{$\begin{array}{c}\mathrm{N} \\
\text { (Unweighted) }\end{array}$} & \multicolumn{3}{|c|}{ BAC (g/dL) } \\
\hline & & & Zero & $\begin{array}{c}\text { Between } \\
\text { Zero and .08 }\end{array}$ & $.08+$ \\
\hline \multirow{5}{*}{$16-20$} & Illegal & 56 & $69.8 \%$ & $24.3 \%$ & $5.9 \%$ \\
\hline & Medications & 8 & $100.0 \%$ & $0.0 \%$ & $0.0 \%$ \\
\hline & Illegal \& Medications & 4 & $95.6 \%$ & $4.4 \%$ & $0.0 \%$ \\
\hline & Negative & 391 & $97.8 \%$ & $1.9 \%$ & $0.3 \%$ \\
\hline & Overall & 459 & $92.9 \%$ & $5.9 \%$ & $1.3 \%$ \\
\hline \multirow{5}{*}{$21-34$} & Illegal & 141 & $69.3 \%$ & $20.9 \%$ & $9.7 \%$ \\
\hline & Medications & 48 & $96.3 \%$ & $1.0 \%$ & $2.7 \%$ \\
\hline & Illegal \& Medications & 13 & $49.0 \%$ & $51.0 \%$ & $0.0 \%$ \\
\hline & Negative & 1,170 & $91.7 \%$ & $7.0 \%$ & $1.3 \%$ \\
\hline & Overall & 1,372 & $88.9 \%$ & $8.7 \%$ & $2.3 \%$ \\
\hline \multirow{5}{*}{$35-44$} & Illegal & 43 & $78.1 \%$ & $12.6 \%$ & $9.3 \%$ \\
\hline & Medications & 43 & $90.6 \%$ & $6.6 \%$ & $2.8 \%$ \\
\hline & Illegal \& Medications & 7 & $100.0 \%$ & $0.0 \%$ & $0.0 \%$ \\
\hline & Negative & 532 & $95.6 \%$ & $3.4 \%$ & $1.0 \%$ \\
\hline & Overall & 625 & $94.4 \%$ & $4.1 \%$ & $1.5 \%$ \\
\hline \multirow{5}{*}{$45-64$} & Illegal & 26 & $91.8 \%$ & $8.2 \%$ & $0.0 \%$ \\
\hline & Medications & 61 & $96.6 \%$ & $3.4 \%$ & $0.0 \%$ \\
\hline & Illegal \& Medications & 6 & $100.0 \%$ & $0.0 \%$ & $0.0 \%$ \\
\hline & Negative & 604 & $92.5 \%$ & $6.0 \%$ & $1.5 \%$ \\
\hline & Overall & 697 & $92.8 \%$ & $5.8 \%$ & $1.3 \%$ \\
\hline \multirow{5}{*}{$65+$} & Illegal & 0 & $\mathrm{NA}$ & $\mathrm{NA}$ & $\overline{N A}$ \\
\hline & Medications & 9 & $59.9 \%$ & $40.1 \%$ & $0.0 \%$ \\
\hline & Illegal \& Medications & 0 & NA & NA & NA \\
\hline & Negative & 82 & $95.3 \%$ & $4.7 \%$ & $0.0 \%$ \\
\hline & Overall & 91 & $93.2 \%$ & $6.8 \%$ & $0.0 \%$ \\
\hline
\end{tabular}

"Medications" includes prescription and over-the-counter drugs.

NA = "Not Applicable."

In this table, percentages are weighted. 
Male drivers who tested positive for "Illegal" drugs (Table 109) had statistically greater percentages of alcohol-positive results than their female counterparts $(p<.05)$.

Table 109. BAC of Drivers by Drug Category and Gender (Blood)

\begin{tabular}{|c|c|c|c|c|c|}
\hline \multirow[b]{2}{*}{ Gender } & \multirow[b]{2}{*}{ Drug Category } & \multirow[b]{2}{*}{$\begin{array}{c}\mathrm{N} \\
\text { (Unweighted) }\end{array}$} & \multicolumn{3}{|c|}{ BAC (g/dL) } \\
\hline & & & Zero & $\begin{array}{c}\text { Between Zero } \\
\text { and } .08\end{array}$ & $.08+$ \\
\hline \multirow{5}{*}{ Males } & Illegal & 191 & $72.1 \%$ & $17.4 \%$ & $10.6 \%$ \\
\hline & Medications & 75 & $90.5 \%$ & $8.4 \%$ & $1.1 \%$ \\
\hline & Illegal \& Medications & 19 & $70.8 \%$ & $29.2 \%$ & $0.0 \%$ \\
\hline & Negative & 1,707 & $92.9 \%$ & $5.8 \%$ & $1.3 \%$ \\
\hline & Overall & 1,992 & $90.5 \%$ & $7.3 \%$ & $2.2 \%$ \\
\hline \multirow{5}{*}{ Females } & Illegal & 76 & $70.7 \%$ & $27.8 \%$ & $1.5 \%$ \\
\hline & Medications & 94 & $96.8 \%$ & $1.4 \%$ & $1.8 \%$ \\
\hline & Illegal \& Medications & 11 & $96.1 \%$ & $3.9 \%$ & $0.0 \%$ \\
\hline & Negative & 1,097 & $95.0 \%$ & $4.2 \%$ & $0.8 \%$ \\
\hline & Overall & 1,278 & $93.3 \%$ & $5.7 \%$ & $0.9 \%$ \\
\hline
\end{tabular}

"Medications" includes prescription and over-the-counter drugs.

In this table, percentages are weighted.

\section{Oral Fluid and/or Blood Results (Nighttime Samples)}

\section{Driver Drug Use Prevalence Based on Oral Fluid and/or Blood Results}

This section of the report presents the joint results of oral fluid and blood analyses for all of the drugs indicated in the introductory section (see Tables 17 and 18) for nighttime drivers. As noted earlier, blood was only obtained from nighttime drivers. The tables in this section are based on the 5,910 nighttime drivers from whom an oral fluid and/or a blood sample was obtained and analyzed. If a driver tested positive for one or more of the drugs in either the oral fluid and/or in the blood analyses, he/she was categorized as drug-positive. Thus, this section provides the most comprehensive nighttime drug prevalence estimates available using the biological specimens obtained in this study. Again, these are overall drug prevalence estimates, including illegal, prescription, and over-the-counter drugs or their metabolites and do not necessarily imply impairment. Within individual tables, overall counts may not total 5,910 because of missing values on some variables.

When we examine the test results from nighttime drivers providing oral fluid and/or blood, 16.3 percent of drivers were drug-positive, as indicated in Table 110. 
Table 110. Nighttime Drug Prevalence by Time of Day (Oral Fluid and/or Blood)

\begin{tabular}{lcc}
\hline \multicolumn{1}{c}{ Time of Day } & $\begin{array}{c}\mathbf{N} \\
\text { (Unweighted) }\end{array}$ & $\begin{array}{c}\text { \% Drug Positive } \\
\text { (Weighted) }\end{array}$ \\
\hline Daytime & NA & NA \\
Nighttime & 5,910 & $16.3 \%$ \\
\hline
\end{tabular}

When we examined drug prevalence by time of day (Table 111), we found that late-night (Sessions 3 and 5) drivers were significantly more likely to be drug positive (19.1\% and 18.3\% respectively) than Friday and Saturday earlier in the night (Sessions 2 and 4$)$ drivers (15.4\% and $15.2 \%$ respectively) $(p<.01)$.

Table 111. Drug Prevalence by Session (Oral Fluid and/or Blood)

\begin{tabular}{lcc}
\hline \multicolumn{1}{c}{ Session } & $\begin{array}{c}\text { N } \\
\text { (Unweighted) }\end{array}$ & $\begin{array}{c}\text { \% Drug Positive } \\
\text { (Weighted) }\end{array}$ \\
\hline 2: Friday, 10:00 p.m. - Midnight & 1,618 & $15.4 \%$ \\
\hline 3: Friday, 1:00 a.m. - 3:00 a.m. & 1,313 & $19.1 \%$ \\
\hline 4: Saturday, 10:00 p.m. - Midnight & 1,695 & $15.2 \%$ \\
\hline 5: Saturday, 1:00 a.m. - 3:00 a.m. & 1,284 & $18.3 \%$ \\
\hline Overall & 5,910 & $16.3 \%$ \\
\hline
\end{tabular}

Comparison of drug prevalence by region (Table 112) showed that the Northeast region had the greatest percentage of drug-positive findings, at 18.3 percent. However, this difference was not statistically significant. Thus, no clear pattern by region emerged.

Table 112. Drug Prevalence by Region (Oral Fluid and/or Blood)

\begin{tabular}{lcc}
\hline \multicolumn{1}{c}{ Region } & $\begin{array}{c}\text { N } \\
\text { (Unweighted) }\end{array}$ & $\begin{array}{c}\text { \% Drug Positive } \\
\text { (Weighted) }\end{array}$ \\
\hline Midwest & 1,708 & $16.9 \%$ \\
Northeast & 1,119 & $18.3 \%$ \\
South & 1,566 & $16.3 \%$ \\
West & 1,517 & $15.0 \%$ \\
Overall & 5,910 & $16.3 \%$ \\
\hline
\end{tabular}

Examining drug prevalence by gender (Table 113) revealed that male drivers were significantly more likely to be drug-positive than female drivers $(18.0 \%$ male versus $13.8 \%$ female $)(p<.01)$. 
Table 113. Drug Prevalence by Gender (Oral Fluid and/or Blood)

\begin{tabular}{lcc}
\hline Gender & $\begin{array}{c}\text { N } \\
\text { (Unweighted) }\end{array}$ & $\begin{array}{c}\text { \% Drug Positive } \\
\text { (Weighted) }\end{array}$ \\
\hline Males & 3,634 & $18.0 \%$ \\
Females & 2,262 & $13.8 \%$ \\
Overall & 5,896 & $16.4 \%$ \\
\hline
\end{tabular}

Comparison of drug prevalence by age (Table 114) indicated that drivers aged 16-44 showed statistically similar drug prevalence (i.e., no statistical difference among these age groups). Conversely, drivers aged 45-64 and 65+ were significantly less likely to be drug-positive than drivers aged 16-44 $(p<.01)$.

Table 114. Drug Prevalence by Age (Oral Fluid and/or Blood)

\begin{tabular}{lcc}
\hline \multicolumn{1}{c}{ Age } & $\begin{array}{c}\mathbf{N} \\
\text { (Unweighted) }\end{array}$ & $\begin{array}{c}\text { \% Drug Positive } \\
\text { (Weighted) }\end{array}$ \\
\hline $16-20$ & 974 & $18.8 \%$ \\
$21-34$ & 2,451 & $18.2 \%$ \\
$35-44$ & 1,046 & $17.0 \%$ \\
$45-64$ & 1,225 & $12.1 \%$ \\
$65+$ & 148 & $4.0 \%$ \\
Overall Nighttime & 5,844 & $16.5 \%$ \\
\hline
\end{tabular}

When examining drug prevalence by age and gender (Table 115), we found that drug prevalence among male drivers in the age categories 16-20 and 21-34 years was significantly higher than their same-aged female counterparts $(p<.01)$. Drug prevalence among male drivers in the age category 35-44 years was also significantly higher than their same-aged female counterparts $(p<.05)$. However, drug prevalence among female drivers aged 45-64 (15.4\%) was significantly higher than male drivers of the same age group $(10.0 \%)(p<.01)$. 
Table 115. Drug Prevalence by Age and Gender (Oral Fluid and/or Blood)

\begin{tabular}{l|ccc}
\hline \multirow{3}{*}{ Gender } & Age & $\begin{array}{c}\text { N } \\
\text { (Unweighted) }\end{array}$ & $\begin{array}{c}\text { \% Drug Positive } \\
\text { (Weighted) }\end{array}$ \\
\hline \multirow{6}{*}{ Males } & $16-20$ & 605 & $22.1 \%$ \\
& $21-34$ & 1502 & $21.1 \%$ \\
& $35-44$ & 634 & $19.4 \%$ \\
& $45-64$ & 741 & $10.0 \%$ \\
& $65+$ & 101 & $4.0 \%$ \\
& Overall Males & 3583 & $18.2 \%$ \\
\hline \multirow{6}{*}{ Females } & $16-20$ & 368 & $14.0 \%$ \\
& $21-34$ & 944 & $13.5 \%$ \\
& $35-44$ & 409 & $13.7 \%$ \\
& $45-64$ & 482 & $15.4 \%$ \\
& $65+$ & 47 & $4.2 \%$ \\
& Overall Females & 2250 & $13.8 \%$ \\
\hline
\end{tabular}

Table 116 shows drug prevalence by race/ethnicity. Drivers who identified themselves as Asian were significantly less likely to be drug positive $(1.9 \%)$ than drivers who identified themselves as African American, Hispanic, White, or Other $(p<.01)$. African American drivers were found to have the highest percentage of drug-positive results $(22.4 \%)$, which was a significantly higher rate than that of their Hispanic or White counterparts $(p<.01)$.

Table 116. Drug Prevalence by Race/Ethnicity (Oral Fluid and/or Blood)

\begin{tabular}{lcc}
\hline Race/Ethnicity & $\begin{array}{c}\text { N } \\
\text { (Unweighted) }\end{array}$ & $\begin{array}{c}\text { \% Drug Positive } \\
\text { (Weighted) }\end{array}$ \\
\hline African American & 980 & $22.4 \%$ \\
Asian & 191 & $1.9 \%$ \\
Hispanic & 1015 & $13.3 \%$ \\
White & 3,378 & $17.2 \%$ \\
Other & 273 & $18.1 \%$ \\
Overall & 5,837 & $16.5 \%$ \\
\hline Race/Ethnic groups other than "Hispanic" are always "non-Hispanic."
\end{tabular}

As shown in Table 117, drivers who identified themselves as having at least some college experience were statistically less likely to be drug-positive than those reporting being a high school graduate or less education $(p<.01)$. 
Table 117. Drug Prevalence by Education Level (Oral Fluid and/or Blood)

\begin{tabular}{lcc}
\hline \multicolumn{1}{c}{ Education Level } & $\begin{array}{c}\text { N } \\
\text { (Unweighted) }\end{array}$ & $\begin{array}{c}\text { \% Drug Positive } \\
\text { (Weighted) }\end{array}$ \\
\hline Not a High School Graduate & 579 & $20.3 \%$ \\
High School Graduate & 1482 & $24.0 \%$ \\
Some College & 2,234 & $14.0 \%$ \\
College Graduate & 1159 & $10.9 \%$ \\
Some Graduate Work & 389 & $16.9 \%$ \\
Overall & 5,843 & $16.5 \%$ \\
\hline
\end{tabular}

Comparison of drug prevalence by employment status (Table 118) indicated that drivers on disability showed a drug prevalence that was significantly higher than that of employed drivers $(p<.01)$. The prevalence of drug positives among employed drivers did not differ significantly from that of unemployed drivers. Retired drivers had significantly lower drug prevalence than employed drivers $(p<.01)$.

Table 118. Drug Prevalence by Employment Status (Oral Fluid and/or Blood)

\begin{tabular}{lcc}
\hline Employment Status & $\begin{array}{c}\text { N } \\
\text { (Unweighted) }\end{array}$ & $\begin{array}{c}\text { \% Drug Positive } \\
\text { (Weighted) }\end{array}$ \\
\hline Employed/Self Employed & 4,646 & $16.7 \%$ \\
Homemaker & 104 & $8.5 \%$ \\
Student & 593 & $15.9 \%$ \\
Unemployed & 206 & $18.2 \%$ \\
Retired & 206 & $8.3 \%$ \\
On Disability & 67 & $44.7 \%$ \\
Other & 23 & $15.0 \%$ \\
Overall & 5,845 & $16.5 \%$ \\
\hline
\end{tabular}

Table 119 shows drug prevalence by vehicle type. Drug prevalence rates among drivers of various vehicle types (passenger vehicle, pickup, SUV, and van/minivans) were statistically different from motorcyclists, who had the greatest percentage of drug-positive results $(p<.01)$.

Table 119. Drug Prevalence by Vehicle Type (Oral Fluid and/or Blood)

\begin{tabular}{lcc}
\hline \multicolumn{1}{c}{ Vehicle Type } & $\begin{array}{c}\text { N } \\
\text { (Unweighted) }\end{array}$ & $\begin{array}{c}\text { \% Drug Positive } \\
\text { (Weighted) }\end{array}$ \\
\hline Passenger Vehicle & 3,650 & $16.5 \%$ \\
Pickup & 703 & $15.9 \%$ \\
SUV & 1058 & $15.2 \%$ \\
Van \& Minivan & 381 & $17.4 \%$ \\
Motorcycle & 75 & $31.9 \%$ \\
Overall & 5,867 & $16.4 \%$ \\
\hline
\end{tabular}




\section{Driver Drug Use Prevalence by Drug Class Based on Oral Fluid and/or Blood Results}

In this section of the report, we display driver drug use prevalence by class of drug. The classes of drugs tested for were antidepressants, marijuana, narcotic-analgesics, sedatives, stimulants, and other (see Tables 17-18).

\section{Drug Class}

As indicated in Table 120, 13.5 percent of the drivers tested positive for one drug class and 2.8 percent tested positive for more than one drug class.

Table 120. Number and Distribution of Drug Classes (Oral Fluid and/or Blood)

\begin{tabular}{lcr}
\hline $\begin{array}{c}\text { Number of } \\
\text { Drug Classes }\end{array}$ & $\begin{array}{c}\mathbf{N} \\
\text { (Unweighted) }\end{array}$ & $\begin{array}{c}\text { \% } \\
\text { (Weighted) }\end{array}$ \\
\hline 1 & 792 & $13.5 \%$ \\
$2+$ & 184 & $2.8 \%$ \\
Negative & 4,934 & $83.7 \%$ \\
Overall & 5,910 & $100.0 \%$ \\
\hline
\end{tabular}

Further, drivers testing positive for only one drug class constituted about 83 percent of drugpositive drivers (Table 121).

Table 121. Number and Distribution of Drug Classes (Drug Positives Only) (Oral Fluid and/or Blood)

\begin{tabular}{lcc}
\hline $\begin{array}{c}\text { Number of } \\
\text { Drug Classes }\end{array}$ & $\begin{array}{c}\text { N } \\
\text { (Unweighted) }\end{array}$ & $\begin{array}{c}\text { \% Drug Positive } \\
\text { (Weighted) }\end{array}$ \\
\hline 1 & 792 & $82.8 \%$ \\
$2+$ & 184 & $17.2 \%$ \\
Overall & 976 & $100.0 \%$ \\
\hline
\end{tabular}


Table 122 presents distribution of drug classes by region. Generally, marijuana was the most common drug class across all the regions $(6.8 \%)$, followed by stimulants $(3.2 \%)$. Drivers in the West were less likely to test positive for marijuana than drivers from the other regions $(p<.01)$.

Table 122. Drug Classes Distribution by Region (Oral Fluid and/or Blood)

\begin{tabular}{lccccc}
\hline \multicolumn{1}{c}{ Drug Class } & $\begin{array}{c}\text { Midwest } \\
\mathbf{\%}\end{array}$ & $\begin{array}{c}\text { Northeast } \\
\mathbf{\%}\end{array}$ & $\begin{array}{c}\text { South } \\
\mathbf{\%}\end{array}$ & $\begin{array}{c}\text { West } \\
\mathbf{\%}\end{array}$ & $\begin{array}{c}\text { All } \\
\mathbf{\%}\end{array}$ \\
\hline & $\mathbf{N = 1 , 7 0 8}$ & $\mathbf{N = 1 , 1 1 9}$ & $\mathbf{N = 1 5 6 6}$ & $\mathbf{N = 1 , 5 1 7}$ & $\mathbf{N = 5 , 9 1 0}$ \\
Antidepressants & $0.7 \%$ & $0.4 \%$ & $0.7 \%$ & $0.7 \%$ & $0.7 \%$ \\
Marijuana & $8.8 \%$ & $7.8 \%$ & $7.2 \%$ & $4.7 \%$ & $6.8 \%$ \\
Narcotic-Analgesics & $1.0 \%$ & $2.9 \%$ & $1.6 \%$ & $1.6 \%$ & $1.6 \%$ \\
Sedatives & $1.2 \%$ & $0.3 \%$ & $0.8 \%$ & $0.8 \%$ & $0.8 \%$ \\
Stimulants & $3.1 \%$ & $1.8 \%$ & $2.6 \%$ & $4.2 \%$ & $3.2 \%$ \\
Other & $0.2 \%$ & $0.0 \%$ & $0.1 \%$ & $0.5 \%$ & $0.3 \%$ \\
More than 1 Class & $1.8 \%$ & $5.1 \%$ & $3.2 \%$ & $2.5 \%$ & $2.8 \%$ \\
Overall Drug Positive & $16.9 \%$ & $18.3 \%$ & $16.3 \%$ & $15.0 \%$ & $16.3 \%$ \\
Negative & $83.1 \%$ & $81.7 \%$ & $83.7 \%$ & $85.0 \%$ & $83.7 \%$ \\
\hline
\end{tabular}

"More than 1 Class" - Drivers testing positive for more than one drug are only counted in this category. In this table, percentages are weighted.

As is shown in Table 123, males were significantly more likely to be positive for marijuana than females $(8.0 \%$ males versus $5.0 \%$ females $)(p<.01)$.

Table 123. Drug Classes Distribution by Gender (Oral Fluid and/or Blood)

\begin{tabular}{lccc}
\hline \multicolumn{1}{c}{ Drug Class } & $\begin{array}{c}\text { Males } \\
\mathbf{\%}\end{array}$ & $\begin{array}{c}\text { Females } \\
\%\end{array}$ & $\begin{array}{c}\text { Total } \\
\%\end{array}$ \\
\hline & $\mathbf{N = 3 , 6 3 4}$ & $\mathbf{N = 2 , 2 6 2}$ & $\mathbf{N = 5 , 8 9 6}$ \\
Antidepressants & $0.7 \%$ & $0.7 \%$ & $0.7 \%$ \\
Marijuana & $8.0 \%$ & $5.0 \%$ & $6.9 \%$ \\
Narcotic-Analgesics & $1.7 \%$ & $1.5 \%$ & $1.6 \%$ \\
Sedatives & $0.6 \%$ & $1.2 \%$ & $0.8 \%$ \\
Stimulants & $3.1 \%$ & $3.5 \%$ & $3.3 \%$ \\
Other & $0.3 \%$ & $0.3 \%$ & $0.3 \%$ \\
More than 1 Class & $3.5 \%$ & $1.7 \%$ & $2.8 \%$ \\
Overall Drug Positive & $18.0 \%$ & $13.8 \%$ & $16.4 \%$ \\
Negative & $82.0 \%$ & $86.2 \%$ & $83.6 \%$ \\
"More than 1 Class" - Drivers testing positive for more than one drug are only \\
counted in this category. \\
In this table, percentages are weighted.
\end{tabular}

When we examined drug class prevalence by age (Table 124), we found that drivers aged 16-20 were more likely to use marijuana $(12.0 \%)$ than drivers in the $21-34$ age group $(p<.05)$ and any other age group $(p<.01)$. The age group with the second highest prevalence of marijuana was 21-34; the prevalence in this age group (9.2\%) was also significantly higher than in older age groups $(p<.01)$. 
Table 124. Drug Classes Distribution by Age (Oral Fluid and/or Blood)

\begin{tabular}{lcccccc}
\hline \multicolumn{1}{c}{ Drug Class } & $\begin{array}{c}\mathbf{1 6 - 2 0} \\
\mathbf{\%}\end{array}$ & $\begin{array}{c}\mathbf{2 1 - 3 4} \\
\mathbf{\%}\end{array}$ & $\begin{array}{c}\mathbf{3 5 - 4 4} \\
\mathbf{\%}\end{array}$ & $\begin{array}{c}\mathbf{4 5 - 6 4} \\
\mathbf{\%}\end{array}$ & $\begin{array}{c}\mathbf{6 5 +} \\
\mathbf{\%}\end{array}$ & $\begin{array}{c}\text { Total } \\
\mathbf{\%}\end{array}$ \\
\hline & $\mathbf{N = 9 7 4}$ & $\mathbf{N = 2 , 4 5 1}$ & $\mathbf{N = 1 , 0 4 6}$ & $\mathbf{N = 1 , 2 2 5}$ & $\mathbf{N = 1 4 8}$ & $\mathbf{N = 5 , 8 4 4}$ \\
Antidepressants & $0.4 \%$ & $0.3 \%$ & $0.9 \%$ & $1.5 \%$ & $0.6 \%$ & $0.7 \%$ \\
Marijuana & $12.0 \%$ & $9.2 \%$ & $4.6 \%$ & $1.1 \%$ & $0.0 \%$ & $6.9 \%$ \\
Narcotic-Analgesics & $1.2 \%$ & $0.8 \%$ & $4.3 \%$ & $1.4 \%$ & $0.4 \%$ & $1.6 \%$ \\
Sedatives & $0.0 \%$ & $0.6 \%$ & $1.5 \%$ & $1.2 \%$ & $3.0 \%$ & $0.9 \%$ \\
Stimulants & $2.2 \%$ & $3.3 \%$ & $3.1 \%$ & $4.7 \%$ & $0.0 \%$ & $3.3 \%$ \\
Other & $0.2 \%$ & $0.5 \%$ & $0.2 \%$ & $0.1 \%$ & $0.0 \%$ & $0.3 \%$ \\
More than 1 Class & $2.7 \%$ & $3.6 \%$ & $2.3 \%$ & $2.2 \%$ & $0.1 \%$ & $2.8 \%$ \\
Overall Drug Positive & $18.8 \%$ & $18.2 \%$ & $17.0 \%$ & $12.1 \%$ & $4.0 \%$ & $16.5 \%$ \\
Negative & $31.2 \%$ & $81.8 \%$ & $83.0 \%$ & $87.9 \%$ & $96.0 \%$ & $83.5 \%$ \\
\hline "More than 1 Class" - Drivers testing positive for more than one drug are only counted in this \\
category. \\
In this table, percentages are weighted.
\end{tabular}

\section{Driver Drug Use Prevalence by Drug Category Based on Oral Fluid and/or Blood Results}

In this section of the report, we display drug use prevalence results from the combined results of oral fluid and blood tests by drug category as described in Table 18.

Table 125 shows that 11.3 percent of drivers tested positive for "Illegal" drugs, and an additional 1.1 percent tested positive for "Illegal" drugs in conjunction with "Medications". Thus, a total of 12.4 percent tested positive for "Illegal" drugs, of which 1.1 percent also tested positive for a "Medication".

Table 125. Drug Categories Distribution (Oral Fluid and/or Blood)

\begin{tabular}{lcc}
\hline \multicolumn{1}{c}{ Drug Category } & $\begin{array}{c}\text { N } \\
\text { (Unweighted) }\end{array}$ & $\begin{array}{c}\text { \% } \\
\text { (Weighted) }\end{array}$ \\
\hline Illegal & 621 & $11.3 \%$ \\
Medications & 277 & $3.9 \%$ \\
Illegal \& Medications & 78 & $1.1 \%$ \\
Negative & 4,934 & $83.7 \%$ \\
Overall & 5,910 & $100.0 \%$ \\
\hline Medications" includes prescription and over-the-counter drugs.
\end{tabular}

Table 126 displays the drug category results by region. No statistically significant differences were found in the prevalence of "Illegal" drugs across regions. 
Table 126. Drug Categories Distribution by Region (Oral Fluid and/or Blood)

\begin{tabular}{lllrr}
\hline \multirow{3}{*}{ Region } & \multicolumn{1}{c}{ Drug Category } & $\begin{array}{c}\text { N } \\
\text { (Unweighted) }\end{array}$ & $\begin{array}{c}\text { \% } \\
\text { (Weighted) }\end{array}$ \\
\hline \multirow{5}{*}{ Midwest } & Illegal & 197 & $12.7 \%$ \\
& Medications & 97 & $3.5 \%$ \\
& Illegal \& Medications & 19 & $0.6 \%$ \\
& Negative & 1,395 & $83.1 \%$ \\
& Overall & 1,708 & $100.0 \%$ \\
\hline \multirow{5}{*}{ Northeast } & 121 & $11.3 \%$ \\
& Illegal & 43 & $4.6 \%$ \\
& Medications & 17 & $2.4 \%$ \\
& Illegal \& Medications & 938 & $81.7 \%$ \\
& Negative & 1,119 & $100.0 \%$ \\
\hline \multirow{5}{*}{ South } & Overall & 145 & $10.9 \%$ \\
& Illegal & 79 & $3.8 \%$ \\
& Medications & 28 & $1.6 \%$ \\
& Illegal \& Medications & 1314 & $83.7 \%$ \\
& Negative & 1,566 & $100.0 \%$ \\
\hline \multirow{5}{*}{ West } & Overall & 158 & $11.3 \%$ \\
& Illegal & 58 & $3.9 \%$ \\
& Medications & 14 & $1.1 \%$ \\
& Illegal \& Medications & 1287 & $83.7 \%$ \\
& Negative & 1,517 & $100.0 \%$ \\
\cline { 2 - 4 } & Overall & &
\end{tabular}

"Medications" includes prescription and over-the-counter drugs.

When examining prevalence by drug category and gender (Table 127), we found that male drivers were more likely to be positive for "Illegal" drugs (combining the categories for "Illegal" and "Illegal and Medications") than female drivers (14.4\% male versus $8.5 \%$ female $)(p<.01)$.

Table 127. Drug Categories by Gender (Oral Fluid and/or Blood)

\begin{tabular}{l|lrr}
\hline \multirow{2}{*}{ Gender } & \multicolumn{1}{c}{ Drug Category } & $\begin{array}{c}\text { N } \\
\text { (Unweighted) }\end{array}$ & $\begin{array}{c}\text { \% } \\
\text { (Weighted) }\end{array}$ \\
\hline \multirow{5}{*}{ Male } & Illegal & 444 & $13.1 \%$ \\
& Medications & 136 & $3.5 \%$ \\
& Illegal \& Medications & 53 & $1.3 \%$ \\
& Negative & 3,001 & $82.0 \%$ \\
\cline { 2 - 4 } Female & Overall & 3,634 & $100.0 \%$ \\
\hline \multirow{5}{*}{} & Illegal & 176 & $8.0 \%$ \\
& Medications & 141 & $6.6 \%$ \\
& Illegal \& Medications & 25 & $0.5 \%$ \\
& Negative & 1,920 & $84.9 \%$ \\
\cline { 2 - 4 } & Overall & 2,262 & $100.0 \%$ \\
\hline
\end{tabular}

"Medications" includes prescription and over-the-counter drugs. 
Comparison of drug categories by age (Table 128) revealed that drivers aged 16-20 and 21-34 had the highest percentage of drug-positive results for "Illegal" ("Illegal" plus "Illegal and Medications") drugs $(p<.01)$.

Table 128. Drug Categories Distribution by Age (Oral Fluid and/or Blood)

\begin{tabular}{|c|c|c|c|}
\hline Age & Drug Category & $\begin{array}{c}\mathrm{N} \\
\text { (Unweighted) }\end{array}$ & $\begin{array}{c}\% \\
\text { (Weighted) } \\
\end{array}$ \\
\hline \multirow{5}{*}{$16-20$} & Illegal & 131 & $15.5 \%$ \\
\hline & Medications & 15 & $1.9 \%$ \\
\hline & Illegal \& Medications & 14 & $1.4 \%$ \\
\hline & Negative & 814 & $81.2 \%$ \\
\hline & Overall & 974 & $100.0 \%$ \\
\hline \multirow{5}{*}{$21-34$} & Illegal & 329 & $14.8 \%$ \\
\hline & Medications & 70 & $2.2 \%$ \\
\hline & Illegal \& Medications & 37 & $1.2 \%$ \\
\hline & Negative & 2,015 & $81.8 \%$ \\
\hline & Overall & 2,451 & $100.0 \%$ \\
\hline \multirow{5}{*}{$35-44$} & Illegal & 91 & $8.2 \%$ \\
\hline & Medications & 78 & $8.1 \%$ \\
\hline & Illegal \& Medications & 15 & $0.8 \%$ \\
\hline & Negative & 862 & $83.0 \%$ \\
\hline & Overall & 1,046 & $100.0 \%$ \\
\hline \multirow{5}{*}{$45-64$} & Illegal & 68 & $5.7 \%$ \\
\hline & Medications & 101 & $5.4 \%$ \\
\hline & Illegal \& Medications & 12 & $1.0 \%$ \\
\hline & Negative & 1,044 & $87.9 \%$ \\
\hline & Overall & 1,225 & $100.0 \%$ \\
\hline \multirow{5}{*}{$65+$} & Illegal & 0 & $0.0 \%$ \\
\hline & Medications & 13 & $4.0 \%$ \\
\hline & Illegal \& Medications & 0 & $0.0 \%$ \\
\hline & Negative & 135 & $96.0 \%$ \\
\hline & Overall & 148 & $100.0 \%$ \\
\hline
\end{tabular}

"Medications" includes prescription and over-the-counter drugs.

\section{Driver Drug Use Prevalence from Oral Fluid and/or Blood and BAC Results}

The following section presents the results of the oral fluid and blood analyses combined with the blood alcohol concentration (BAC) results obtained through breath tests.

Tables 129 and 130 show the number of drug-positive drivers by BAC level. As seen in Table 129 , drug-positive drivers $(4.1 \%)$ were significantly more likely to have a BAC of .08 or higher than were drug negative drivers $(1.7 \%)(p<.01)$. 
Table 129. Drug Prevalence by BAC (Percentages Calculated by Row) (Oral Fluid and/or Blood)

\begin{tabular}{ccccc}
\hline & & \multicolumn{3}{c}{ BAC (g/dL) } \\
\cline { 3 - 5 } Drug & $\mathbf{N}$ & & Between \\
Result & (Unweighted) & Zero & Zero and .08 & .08+ \\
\hline Positive & 976 & $79.5 \%$ & $16.4 \%$ & $4.1 \%$ \\
Negative & 4,932 & $90.6 \%$ & $7.7 \%$ & $1.7 \%$ \\
Overall & 5,908 & $88.8 \%$ & $9.1 \%$ & $2.1 \%$ \\
\hline
\end{tabular}

In this table, percentages are weighted.

Table 130 provides another way of looking at this issue and indicates that among drivers with a BAC g/dL .08+, almost a third (31.8\%) were also positive for drugs. The difference in drug prevalence between BAC categories for drug positive drivers, however, was not statistically significant.

Table 130. Drug Prevalence by BAC (Percentages Calculated by Column) (Oral Fluid and/or Blood)

\begin{tabular}{ccccr}
\hline & \multicolumn{4}{c}{ BAC (g/dL) } \\
\cline { 2 - 5 } Drug & \multicolumn{4}{c}{ Between Zero } \\
Result & Zero & $\mathbf{~ a n d ~ . 0 8 ~}$ & $\mathbf{. 0 8 +}$ & \multicolumn{1}{c}{ All } \\
\hline & $\mathbf{N}=\mathbf{5 , 2 4 1}$ & $\mathbf{N}=\mathbf{5 3 6}$ & $\mathbf{N} \mathbf{1 3 1}$ & $\mathbf{N = 5 , 9 0 8}$ \\
Positive & $14.6 \%$ & $29.3 \%$ & $31.8 \%$ & $16.3 \%$ \\
Negative & $85.4 \%$ & $70.7 \%$ & $68.2 \%$ & $83.7 \%$ \\
\hline
\end{tabular}

In this table, percentages are weighted.

Table 131 shows that, among participants who were drug positive, drivers younger than 35 were the most likely to be alcohol-positive. The prevalence of drivers with a BAC greater than zero among drivers less than 35-years-old was significantly higher than among older driver groups $(p<.01)$. Though a high proportion of drug-positive drivers $65+$ were also alcohol positive, that pattern is not statistically significant compared to the other age groups due to the small sample size.

Table 131. BAC Among Drug-Positive Drivers by Age (Oral Fluid and/or Blood)

\begin{tabular}{|c|c|c|c|c|}
\hline \multirow[b]{2}{*}{ Age } & \multirow[b]{2}{*}{$\begin{array}{c}\mathrm{N} \\
\text { (Unweighted) }\end{array}$} & \multicolumn{3}{|c|}{ BAC (g/dL) } \\
\hline & & Zero & $\begin{array}{l}\text { Between Zero } \\
\text { and .08 }\end{array}$ & $.08+$ \\
\hline $16-20$ & 160 & $79.9 \%$ & $17.4 \%$ & $2.8 \%$ \\
\hline $21-34$ & 436 & $75.0 \%$ & $20.0 \%$ & $5.0 \%$ \\
\hline $35-44$ & 184 & $87.6 \%$ & $8.7 \%$ & $3.79 \%$ \\
\hline $45-64$ & 181 & $84.2 \%$ & $12.2 \%$ & $3.6 \%$ \\
\hline $65+$ & 13 & $58.7 \%$ & $41.3 \%$ & $0.0 \%$ \\
\hline Overall Positive & 974 & $79.6 \%$ & $16.3 \%$ & $4.1 \%$ \\
\hline
\end{tabular}

In this table, percentages are weighted. 
As shown in Table 132, the majority of alcohol-positive drivers among drug-positive drivers were positive for only one class of drug.

Table 132. BAC Among Drug-Positive Drivers by Number of Drug Classes (Percentages Calculated by Column) (Oral Fluid and/or Blood)

\begin{tabular}{lccc}
\hline \multirow{2}{*}{$\begin{array}{c}\text { Number of Drug } \\
\text { Classes }\end{array}$} & \multicolumn{3}{c}{ BAC (g/dL) } \\
\cline { 2 - 4 } \multicolumn{3}{c}{ Zero } & Between \\
1 & $\mathbf{N}=\mathbf{4 6 8}$ & $\mathbf{N}=\mathbf{7 1}$ & $\mathbf{N}=\mathbf{0 8}$ \\
\hline $2+$ & $81.9 \%$ & $83.7 \%$ & $96.1 \%$ \\
Overall & $18.1 \%$ & $16.3 \%$ & $3.9 \%$ \\
\hline In this table, percentages are weighted & $100.0 \%$ & $100.0 \%$ & $100.0 \%$ \\
\hline
\end{tabular}

In Table 133, those drivers with $2+$ classes of drugs were significantly less likely to be positive for alcohol than those drug-positive for one class $(p<.05)$.

Table 133. BAC Among Drug-Positive Drivers by Number of Drug Classes (Percentages Calculated by Row) (Oral Fluid and/or Blood)

\begin{tabular}{lcccc}
\hline \multirow{2}{*}{$\begin{array}{c}\text { Number of Drug } \\
\text { Classes }\end{array}$} & \begin{tabular}{c} 
N \\
\cline { 3 - 5 } (Unweighted)
\end{tabular} & Zero & $\begin{array}{c}\text { Between } \\
\text { Zero and .08 }\end{array}$ & $\mathbf{. 0 8 +}$ \\
\hline 1 & 792 & $78.6 \%$ & $16.6 \%$ & $4.8 \%$ \\
$2+$ & 184 & $83.6 \%$ & $15.5 \%$ & $0.9 \%$ \\
Overall & 976 & $79.5 \%$ & $16.4 \%$ & $4.1 \%$ \\
\hline
\end{tabular}

In this table, percentages are weighted.

As indicated in Table 134, drug-positive drivers who were also alcohol-positive were more likely to be positive for "Illegal" drugs than for "Medications" $(p<.01)$.

Table 134. BAC Among Drug-Positive Drivers by Drug Category (Oral Fluid and/or Blood)

\begin{tabular}{lcccc}
\hline & & \multicolumn{3}{c}{ BAC (g/dL) } \\
\cline { 3 - 5 } \multicolumn{1}{c}{ N Drug Category } & (Unweighted) & Zero & Zetween \\
\hline Illegal & 621 & $75.21 \%$ & $19.35 \%$ & $5.44 \%$ \\
Medications & 277 & $91.40 \%$ & $7.31 \%$ & $1.29 \%$ \\
Illegal \& Medications & 78 & $81.10 \%$ & $18.16 \%$ & $0.75 \%$ \\
Negative & 4,932 & $88.79 \%$ & $9.09 \%$ & $2.12 \%$ \\
\hline
\end{tabular}

"Medications" includes prescription and over-the-counter drugs.

In this table, percentages are weighted. 
Table 135 presents the BACs of drivers by drug category and age. Drivers with BAC a of .08 or higher who tested positive for drugs, were more likely to test positive for "Illegal" drugs than those in the "Medications" category across all age groups. However, this difference was not statistically significant.

Table 135. BAC of Drivers by Drug Category and Age (Oral Fluid and/or Blood)

\begin{tabular}{|c|c|c|c|c|c|}
\hline \multirow[b]{2}{*}{ Age } & \multirow[b]{2}{*}{ Drug Category } & \multirow[b]{2}{*}{$\begin{array}{c}\mathrm{N} \\
\text { (Unweighted) } \\
\end{array}$} & \multicolumn{3}{|c|}{ BAC (g/dL) } \\
\hline & & & Zero & $\begin{array}{c}\text { Between Zero } \\
\text { and .08 }\end{array}$ & $.08+$ \\
\hline \multirow{5}{*}{$16-20$} & Illegal & 131 & $75.9 \%$ & $20.8 \%$ & $3.3 \%$ \\
\hline & Medications & 15 & $100.0 \%$ & $0.0 \%$ & $0.0 \%$ \\
\hline & Illegal \& Medications & 14 & $97.5 \%$ & $2.5 \%$ & $0.0 \%$ \\
\hline & Negative & 814 & $96.1 \%$ & $3.4 \%$ & $0.5 \%$ \\
\hline & Overall & 974 & $93.0 \%$ & $6.0 \%$ & $1.0 \%$ \\
\hline \multirow{5}{*}{$21-34$} & Illegal & 329 & $73.1 \%$ & $20.9 \%$ & $6.0 \%$ \\
\hline & Medications & 70 & $83.7 \%$ & $14.6 \%$ & $1.7 \%$ \\
\hline & Illegal \& Medications & 37 & $81.2 \%$ & $18.8 \%$ & $0.0 \%$ \\
\hline & Negative & 2,014 & $88.0 \%$ & $9.6 \%$ & $2.4 \%$ \\
\hline & Overall & 2,450 & $85.6 \%$ & $11.5 \%$ & $2.9 \%$ \\
\hline \multirow{5}{*}{$35-44$} & Illegal & 91 & $79.4 \%$ & $14.7 \%$ & $5.9 \%$ \\
\hline & Medications & 78 & $95.3 \%$ & $2.7 \%$ & $2.0 \%$ \\
\hline & Illegal \& Medications & 15 & $93.2 \%$ & $6.8 \%$ & $0.0 \%$ \\
\hline & Negative & 862 & $92.1 \%$ & $6.6 \%$ & $1.3 \%$ \\
\hline & Overall & 1,046 & $91.3 \%$ & $7.0 \%$ & $1.7 \%$ \\
\hline \multirow{5}{*}{$45-64$} & Illegal & 68 & $80.8 \%$ & $12.6 \%$ & $6.6 \%$ \\
\hline & Medications & 101 & $93.4 \%$ & $6.1 \%$ & $0.4 \%$ \\
\hline & Illegal \& Medications & 12 & $53.6 \%$ & $42.4 \%$ & $4.0 \%$ \\
\hline & Negative & 1,044 & $89.9 \%$ & $8.8 \%$ & $1.3 \%$ \\
\hline & Overall & 1,225 & $89.2 \%$ & $9.2 \%$ & $1.6 \%$ \\
\hline \multirow{5}{*}{$65+$} & Illegal & 0 & NA & NA & NA \\
\hline & Medications & 13 & $58.7 \%$ & $41.3 \%$ & $0.0 \%$ \\
\hline & Illegal \& Medications & 0 & NA & NA & NA \\
\hline & Negative & 135 & $89.9 \%$ & $5.3 \%$ & $4.8 \%$ \\
\hline & Overall & 148 & $88.6 \%$ & $6.8 \%$ & $4.6 \%$ \\
\hline
\end{tabular}

In this table, percentages are weighted.

When examining BAC by drug category by gender (Table 136), male drivers that tested positive for "Illegal" drugs were more likely to have a BAC at or above $.08 \mathrm{~g} / \mathrm{dL}$ than their female counterparts $(p<.01)$. 
Table 136. BAC of Drivers by Drug Category and Gender (Oral Fluid and/or Blood)

\begin{tabular}{llrrrr}
\hline \multirow{2}{*}{ Gender } & & N & \multicolumn{3}{c}{ BAC (g/dL) } \\
\cline { 3 - 6 } & Drug Category & (Unweighted) & Zero & $\begin{array}{c}\text { Between Zero } \\
\text { and .08 }\end{array}$ & .08+ \\
\hline \multirow{5}{*}{ Males } & Illegal & 444 & $74.9 \%$ & $17.9 \%$ & $7.2 \%$ \\
& Medications & 136 & $92.8 \%$ & $6.4 \%$ & $0.8 \%$ \\
& Illegal \& Medications & 53 & $76.0 \%$ & $23.1 \%$ & $1.0 \%$ \\
& Negative & 3,001 & $90.2 \%$ & $7.8 \%$ & $2.1 \%$ \\
\cline { 3 - 6 } & Overall & 3,634 & $88.1 \%$ & $9.2 \%$ & $2.7 \%$ \\
\hline \multirow{5}{*}{ Females } & Illegal & 176 & $76.1 \%$ & $23.1 \%$ & $0.9 \%$ \\
& Medications & 141 & $89.6 \%$ & $8.4 \%$ & $2.0 \%$ \\
& Illegal \& Medications & 25 & $97.9 \%$ & $2.1 \%$ & $0.0 \%$ \\
& Negative & 1,919 & $91.2 \%$ & $7.6 \%$ & $1.2 \%$ \\
& Overall & 2,261 & $89.9 \%$ & $8.9 \%$ & $1.2 \%$ \\
\hline
\end{tabular}

In this table, percentages are weighted.

\section{Individual Drug Prevalence Estimates from Oral Fluid, and Oral Fluid and/or Blood Combined}

In this section of the report we present prevalence estimates for individual drugs, illegal, prescription, and over-the-counter drugs, obtained from the analyses of oral fluid and blood specimens. In Tables 137 and 139 there are three main columns. The first column lists the individual drugs for which we tested and at least one driver tested positive in oral fluid. The second main column presents the oral fluid results (unweighted $\mathrm{N}$ and weighted percentage) of samples obtained from daytime drivers on a drug-by-drug basis. The third column presents results of oral fluid analyses from nighttime drivers in a similar manner. Similarly, tables 138 and 140 present the combined analyses of oral fluid and/or blood samples provided by nighttime drivers. Note in these tables there were 5,910 nighttime drivers who provided either oral fluid, blood, or both oral fluid and blood for analysis. If a driver tested positive for a specific drug or a metabolite of that drug in either oral fluid, or blood, or in both substances, that driver was counted as positive for that drug once. Thus, these tables provide us with a robust estimate of nighttime drug prevalence available from the biological samples we collected because it takes advantage of the larger sample size of nighttime drivers providing oral fluid samples $(5,869)$, augmented with information obtained from analyses of blood samples obtained from 3,276 nighttime drivers. Most drivers who provided blood also provided oral fluid, so including the blood results only increased the sample size by 41 drivers, to 5,910. However, since in some cases specific drugs were found in oral fluid and not blood, and conversely in blood but not oral fluid, this dataset provides us with the most comprehensive estimates of individual drug prevalence.

The Ns in the tables represent the actual unweighted number of positive tests for the listed drug or a metabolite of that drug. The percentages are the weighted prevalence estimates for each drug. Since individual drug use was the unit of analysis and some drivers were positive for more than one drug, the sum of the individual drug prevalence estimates exceeds the overall prevalence estimates appearing elsewhere in this report. 
Of particular interest may be the prevalence estimates for relatively frequently encountered drugs such as marijuana. Marijuana (and its metabolites) appears as a separate drug class in the typology presented in Table 17 and used in the subsequent tabulations of results by drug class. However, a number of drivers tested positive for more than one drug class (sometimes including marijuana) and were classified as such in the tabulations. Thus, drivers who were positive for marijuana were split between the mutually exclusive classifications of "marijuana" and "more than one drug class" in those tables. Here, in these tables we present the prevalence estimates for a drug, such as marijuana, independent of whether other drugs were found in an individual driver. Thus, a driver, for example, who tested positive for marijuana and cocaine would appear twice in the tables in this section of the report. Finally, as indicated earlier in the report, in many instances we tested both for the parent drug and its metabolites. In cases where we found both the parent drug and its metabolite (for example, THC and 11-OH-THC), we only counted that as one drug positive for the parent drug. In the case in which a parent drug was identified alone, which could also be a metabolite of another drug, we only counted the observation as the parent drug itself, and not again as the drug for which it could be a metabolite.

Thus, the values in the tables in this section of the report represent estimates of individual drug prevalence based on the analytic techniques available.

\section{Overall Individual Drug Prevalence in Daytime and Nighttime}

Review of Tables 137 and 138 reveals that the two highest prevalence drugs found in the 2007 NRS were in the "Illegal" drug category.

The most frequently encountered single drug in oral fluid in both daytime and nighttime was THC (marijuana). Marijuana was detected in oral fluid in 4.46 percent of daytime drivers and 7.66 percent of nighttime drivers (Table 137). The results from nighttime drivers who provided oral fluid and/or blood indicated that 8.65 percent of drivers were positive for marijuana or its metabolites (Table 138).

The second most frequently encountered drug was cocaine, with either cocaine or a metabolite detected in oral fluid in 1.46 percent of daytime drivers and 3.90 percent of nighttime drivers. The corresponding nighttime figure for oral fluid and/or blood nighttime was 3.92 percent.

During the daytime, the next most frequently encountered drug was alprazolam at 1.12 percent. Alprazolam (a benzodiazepine) exhibited a nighttime prevalence rate in oral fluid of 0.61 percent.

Among opioids, oxycodone exhibited a daytime prevalence rate of 0.37 percent. Among the nighttime oral fluid samples, oxycodone had a prevalence rate of 0.80 percent. Another opioid, hydrocodone, had a 0.22 percent daytime and 0.61 percent nighttime oral fluid prevalence rate. The atypical opioid propoxyphene was detected in 0.93 percent of daytime oral fluid samples and 0.46 percent of nighttime oral fluid samples.

The daytime prevalence rate of methamphetamine was 0.32 percent and amphetamine was 0.23 percent. Among nighttime drivers providing oral fluid samples, methamphetamine had a prevalence rate of 0.80 percent. Amphetamine had a prevalence rate of 0.36 percent. 
Table 137. Prevalence of Drugs in Daytime and Nighttime Drivers (Oral Fluid)

\begin{tabular}{|c|c|c|c|c|}
\hline \multirow[b]{3}{*}{ Drug } & \multicolumn{4}{|c|}{ Oral Fluid } \\
\hline & \multicolumn{2}{|c|}{ Daytime } & \multicolumn{2}{|c|}{ Nighttime } \\
\hline & $\begin{array}{c}\mathrm{N} \\
\text { (Unweighted) }\end{array}$ & $\begin{array}{c}\% \\
\text { (Weighted) }\end{array}$ & $\begin{array}{c}\mathrm{N} \\
\text { (Unweighted) }\end{array}$ & $\begin{array}{c}\% \\
\text { (Weighted) }\end{array}$ \\
\hline Alprazolam & 18 & $1.12 \%$ & 36 & $0.61 \%$ \\
\hline Amitriptyline & 6 & $0.27 \%$ & 7 & $0.03 \%$ \\
\hline Amphetamine & 4 & $0.23 \%$ & 19 & $0.36 \%$ \\
\hline Butalbital & 5 & $0.26 \%$ & 8 & $0.17 \%$ \\
\hline Carisoprodol & 2 & $0.05 \%$ & 5 & $0.03 \%$ \\
\hline Chlordiazepoxide & 2 & $0.25 \%$ & 2 & $0.03 \%$ \\
\hline Clonazepam & 2 & $0.03 \%$ & 7 & $0.12 \%$ \\
\hline Cocaine & 38 & $1.46 \%$ & 222 & $3.90 \%$ \\
\hline Codeine & 4 & $0.13 \%$ & 7 & $0.44 \%$ \\
\hline Dextromethorphan & 3 & $0.23 \%$ & 16 & $0.22 \%$ \\
\hline Diazepam & 3 & $0.10 \%$ & 10 & $0.14 \%$ \\
\hline Fluoxetine & 11 & $0.34 \%$ & 14 & $0.23 \%$ \\
\hline Heroin & 2 & $0.09 \%$ & 8 & $0.17 \%$ \\
\hline Hydrocodone & 15 & $0.22 \%$ & 58 & $0.61 \%$ \\
\hline Hydromorphone & 2 & $0.09 \%$ & 0 & $0.00 \%$ \\
\hline Ketamine & 0 & $0.00 \%$ & 1 & $0.08 \%$ \\
\hline Lorazepam & 0 & $0.00 \%$ & 1 & $0.01 \%$ \\
\hline MDMA & 2 & $0.06 \%$ & 8 & $0.09 \%$ \\
\hline Meperidine & 1 & $0.01 \%$ & 2 & $0.00 \%$ \\
\hline Meprobamate & 0 & $0.00 \%$ & 1 & $0.01 \%$ \\
\hline Methadone & 3 & $0.21 \%$ & 11 & $0.18 \%$ \\
\hline Methamphetamine & 5 & $0.32 \%$ & 34 & $0.80 \%$ \\
\hline Methylphenidate & 0 & $0.00 \%$ & 3 & $0.01 \%$ \\
\hline Morphine & 0 & $0.00 \%$ & 1 & $0.00 \%$ \\
\hline Oxycodone & 14 & $0.37 \%$ & 43 & $0.80 \%$ \\
\hline PCP & 1 & $0.04 \%$ & 3 & $0.13 \%$ \\
\hline Phenobarbital & 1 & $0.00 \%$ & 1 & $0.00 \%$ \\
\hline Phentermine & 5 & $0.15 \%$ & 11 & $0.11 \%$ \\
\hline Propoxyphene & 22 & $0.93 \%$ & 34 & $0.46 \%$ \\
\hline Sertraline & 2 & $0.44 \%$ & 4 & $0.13 \%$ \\
\hline Temazepam & 2 & $0.12 \%$ & 2 & $0.02 \%$ \\
\hline THC (Marijuana) & 103 & $4.46 \%$ & 438 & $7.66 \%$ \\
\hline Tramadol & 12 & $0.19 \%$ & 34 & $0.46 \%$ \\
\hline Zolpidem & 2 & $0.12 \%$ & 1 & $0.01 \%$ \\
\hline All Tested Drivers ${ }^{\dagger}$ & 1,850 & $11.00 \%$ & 5,869 & $14.40 \%$ \\
\hline
\end{tabular}

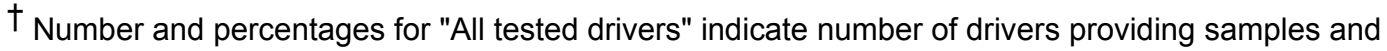
the percentage of those drivers who tested positive for at least one drug.

In this table, percentages are weighted. 


\section{Individual Drug Prevalence in Nighttime Oral Fluid and/or Blood}

Results for drivers who provided oral fluid and/or blood yielded an overall drug positive prevalence estimate of 16.3 percent (Table 138). Again, marijuana (8.65\%) and cocaine (3.92\%) were the most frequently encountered drugs. The next most frequently encountered drug was methamphetamine $(0.84 \%)$. Amphetamine was present in 0.45 percent of this nighttime driver population. The opioids oxycodone $(0.82 \%)$ and hydrocodone $(0.68 \%)$ and the benzodiazepine alprazolam $(0.64 \%)$ were the next most frequently encountered drugs in this nighttime driver population. The atypical opioid propoxyphene was present in $0.52 \%$ of these nighttime drivers. Note, however, as indicated in the introduction of this section, the unit of analysis in these tables is individual drug use. Some drivers were positive for more than one drug, thus the sum of the individual drug prevalence estimates exceed the overall prevalence estimates noted earlier in this report. 
Table 138. Prevalence of Drugs in All Drug-Tested Nighttime Drivers (Oral Fluid and/or Blood)

\begin{tabular}{|c|c|c|}
\hline Drug & $\begin{array}{c}\mathbf{N} \\
\text { (Unweighted) }\end{array}$ & $\begin{array}{c}\% \\
\text { (Weighted) }\end{array}$ \\
\hline Alprazolam & 40 & $0.64 \%$ \\
\hline Amitriptyline & 14 & $0.07 \%$ \\
\hline Amphetamine & 25 & $0.45 \%$ \\
\hline Butalbital & 9 & $0.17 \%$ \\
\hline Carisoprodol & 5 & $0.03 \%$ \\
\hline Chlordiazepoxide & 4 & $0.03 \%$ \\
\hline Clonazepam & 10 & $0.14 \%$ \\
\hline Cocaine & 225 & $3.92 \%$ \\
\hline Codeine & 7 & $0.44 \%$ \\
\hline Dextromethorphan & 16 & $0.22 \%$ \\
\hline Diazepam & 30 & $0.38 \%$ \\
\hline Fluoxetine & 25 & $0.37 \%$ \\
\hline Heroin & 8 & $0.17 \%$ \\
\hline Hydrocodone & 63 & $0.68 \%$ \\
\hline Hydromorphone & 0 & $0.00 \%$ \\
\hline Imipramine & 1 & $0.00 \%$ \\
\hline Ketamine & 1 & $0.08 \%$ \\
\hline Lorazepam & 2 & $0.03 \%$ \\
\hline MDMA & 8 & $0.09 \%$ \\
\hline Meperidine & 2 & $0.00 \%$ \\
\hline Meprobamate & 1 & $0.01 \%$ \\
\hline Methadone & 14 & $0.19 \%$ \\
\hline Methamphetamine & 37 & $0.84 \%$ \\
\hline Methylphenidate & 3 & $0.01 \%$ \\
\hline Morphine & 8 & $0.06 \%$ \\
\hline Oxycodone & 47 & $0.82 \%$ \\
\hline PCP & 3 & $0.13 \%$ \\
\hline Phenobarbital & 2 & $0.01 \%$ \\
\hline Phentermine & 21 & $0.26 \%$ \\
\hline Propoxyphene & 35 & $0.52 \%$ \\
\hline Sertraline & 36 & $0.50 \%$ \\
\hline Temazepam & 4 & $0.03 \%$ \\
\hline THC (Marijuana) & 499 & $8.65 \%$ \\
\hline Tramadol & 35 & $0.46 \%$ \\
\hline Zolpidem & 4 & $0.03 \%$ \\
\hline All Tested Drivers ${ }^{\dagger}$ & 5,910 & $16.30 \%$ \\
\hline
\end{tabular}

$\dagger$ Number and percentages for "All tested drivers" indicate number of drivers providing samples and percentage of those drivers who tested positive.

In this table, percentages are weighted. 


\section{Individual Drug Prevalence Sorted by Drug Type from Oral Fluid, and Oral Fluid and/or Blood Combined}

In Tables 139 and 140 we present prevalence estimates by drug within drug type for both daytime and nighttime drivers based on oral fluid analyses (Table 139) and for nighttime drivers based on the results of analyses of oral fluid and/or blood (Table 140). These tables contain the same information provided in Tables 137 and 138 except that the drugs are sorted by drug type. (Drug types are the subgrouping of similar drugs noted by class and category in Tables 17 and 18.) 
Table 139. Prevalence of Drugs in Daytime and Nighttime Drivers (Oral Fluid)

\begin{tabular}{|c|c|c|c|c|}
\hline \multirow[b]{3}{*}{ Drug } & \multicolumn{4}{|c|}{ Oral Fluid } \\
\hline & \multicolumn{2}{|c|}{ Daytime } & \multicolumn{2}{|c|}{ Nighttime } \\
\hline & $\begin{array}{c}\mathrm{N} \\
\text { (Unweighted) }\end{array}$ & $\begin{array}{c}\% \\
\text { (Weighted) } \\
\end{array}$ & \begin{tabular}{c|}
$\mathbf{N}$ \\
(Unweighted) \\
\end{tabular} & $\begin{array}{c}\% \\
\text { (Weighted) }\end{array}$ \\
\hline THC (Marijuana) & 103 & $4.46 \%$ & 438 & $7.66 \%$ \\
\hline Cocaine & 38 & $1.46 \%$ & 222 & $3.90 \%$ \\
\hline $\begin{array}{l}\text { Opioids } \\
\text { Codeine } \\
\text { Heroin } \\
\text { Hydrocodone } \\
\text { Hydromorphone } \\
\text { Meperidine } \\
\text { Methadone } \\
\text { Morphine } \\
\text { Oxycodone } \\
\text { Propoxyphene } \\
\text { Tramadol }\end{array}$ & $\begin{array}{r}4 \\
2 \\
15 \\
2 \\
1 \\
3 \\
0 \\
14 \\
22 \\
12\end{array}$ & $\begin{array}{l}0.13 \% \\
0.09 \% \\
0.22 \% \\
0.09 \% \\
0.01 \% \\
0.21 \% \\
0.00 \% \\
0.37 \% \\
0.93 \% \\
0.19 \%\end{array}$ & $\begin{array}{r}7 \\
8 \\
58 \\
0 \\
2 \\
11 \\
1 \\
43 \\
34 \\
34\end{array}$ & $\begin{array}{l}0.44 \% \\
0.17 \% \\
0.61 \% \\
0.00 \% \\
0.00 \% \\
0.18 \% \\
0.00 \% \\
0.80 \% \\
0.46 \% \\
0.46 \%\end{array}$ \\
\hline $\begin{array}{l}\text { Amphetamines/Stimulants } \\
\text { MDMA } \\
\text { Amphetamine } \\
\text { Methamphetamine } \\
\text { Methylphenidate } \\
\text { Phentermine } \\
\end{array}$ & $\begin{array}{l}2 \\
4 \\
5 \\
0 \\
5\end{array}$ & $\begin{array}{l}0.06 \% \\
0.23 \% \\
0.32 \% \\
0.00 \% \\
0.15 \% \\
\end{array}$ & $\begin{array}{r}8 \\
19 \\
34 \\
3 \\
11\end{array}$ & $\begin{array}{l}0.09 \% \\
0.36 \% \\
0.80 \% \\
0.01 \% \\
0.11 \% \\
\end{array}$ \\
\hline $\begin{array}{l}\text { Street Drugs } \\
\text { Ketamine } \\
\text { PCP }\end{array}$ & $\begin{array}{l}0 \\
1 \\
\end{array}$ & $\begin{array}{l}0.00 \% \\
0.04 \% \\
\end{array}$ & $\begin{array}{l}1 \\
3 \\
\end{array}$ & $\begin{array}{l}0.08 \% \\
0.13 \% \\
\end{array}$ \\
\hline $\begin{array}{l}\text { Benzodiazepines } \\
\text { Alprazolam } \\
\text { Chlordiazepoxide } \\
\text { Clonazepam } \\
\text { Diazepam } \\
\text { Lorazepam } \\
\text { Temazepam }\end{array}$ & $\begin{array}{r}18 \\
2 \\
2 \\
3 \\
0 \\
2\end{array}$ & $\begin{array}{l}1.12 \% \\
0.25 \% \\
0.03 \% \\
0.10 \% \\
0.00 \% \\
0.12 \%\end{array}$ & $\begin{array}{r}36 \\
2 \\
7 \\
10 \\
1 \\
2\end{array}$ & $\begin{array}{l}0.61 \% \\
0.03 \% \\
0.12 \% \\
0.14 \% \\
0.01 \% \\
0.02 \%\end{array}$ \\
\hline $\begin{array}{l}\text { Antidepressants } \\
\text { Amitriptyline } \\
\text { Fluoxetine } \\
\text { Imipramine } \\
\text { Sertraline } \\
\end{array}$ & $\begin{array}{r}6 \\
11 \\
0 \\
2 \\
\end{array}$ & $\begin{array}{r}0.27 \% \\
0.34 \% \\
0 \\
0.44 \% \\
\end{array}$ & $\begin{array}{r}7 \\
14 \\
0 \\
4 \\
\end{array}$ & $\begin{array}{r}0.03 \% \\
0.23 \% \\
0 \\
0.13 \% \\
\end{array}$ \\
\hline $\begin{array}{l}\text { Barbiturates } \\
\text { Butalbital } \\
\text { Phenobarbital } \\
\end{array}$ & $\begin{array}{l}5 \\
1 \\
\end{array}$ & $\begin{array}{l}0.26 \% \\
0.00 \% \\
\end{array}$ & $\begin{array}{l}8 \\
1 \\
\end{array}$ & $\begin{array}{l}0.17 \% \\
0.00 \% \\
\end{array}$ \\
\hline $\begin{array}{l}\text { Pain Drugs } \\
\text { Carisoprodol } \\
\text { Meprobamate } \\
\end{array}$ & $\begin{array}{l}2 \\
0 \\
\end{array}$ & $\begin{array}{l}0.05 \% \\
0.00 \% \\
\end{array}$ & $\begin{array}{l}5 \\
1 \\
\end{array}$ & $\begin{array}{l}0.03 \% \\
0.01 \% \\
\end{array}$ \\
\hline $\begin{array}{c}\text { Sleep Aids } \\
\text { Zolpidem }\end{array}$ & 2 & $0.12 \%$ & 1 & $0.01 \%$ \\
\hline $\begin{array}{c}\text { Cough Suppressants } \\
\text { Dextromethorphan }\end{array}$ & 3 & $0.23 \%$ & 16 & $0.22 \%$ \\
\hline All Tested Drivers ${ }^{\dagger}$ & 1,850 & $11.00 \%$ & 5,869 & $14.40 \%$ \\
\hline
\end{tabular}

$†$ Number and percentages for "All tested drivers" indicate number of drivers providing samples and percentage of those drivers who tested positive. In this table, percentages are weighted. 
Table 140. Prevalence of Drugs in All Drug-Tested Nighttime Drivers (Oral Fluid and/or Blood)

\begin{tabular}{|c|c|c|}
\hline Drug & $\begin{array}{c}\mathbf{N} \\
\text { (Unweighted) }\end{array}$ & $\begin{array}{c}\% \\
\text { (Weighted) }\end{array}$ \\
\hline THC (Marijuana) & 499 & $8.65 \%$ \\
\hline Cocaine & 225 & $3.92 \%$ \\
\hline \multicolumn{3}{|l|}{ Opioids } \\
\hline Codeine & 7 & $0.44 \%$ \\
\hline Heroin & 8 & $0.17 \%$ \\
\hline Hydrocodone & 63 & $0.68 \%$ \\
\hline Hydromorphone & 0 & $0.00 \%$ \\
\hline Meperidine & 2 & $0.00 \%$ \\
\hline Methadone & 14 & $0.19 \%$ \\
\hline Morphine & 8 & $0.06 \%$ \\
\hline Oxycodone & 47 & $0.82 \%$ \\
\hline Propoxyphene & 35 & $0.52 \%$ \\
\hline Tramadol & 35 & $0.46 \%$ \\
\hline \multicolumn{3}{|l|}{ Amphetamines/Stimulants } \\
\hline MDMA & 8 & $0.09 \%$ \\
\hline Amphetamine & 25 & $0.45 \%$ \\
\hline Methamphetamine & 37 & $0.84 \%$ \\
\hline Methylphenidate & 3 & $0.01 \%$ \\
\hline Phentermine & 21 & $0.26 \%$ \\
\hline \multicolumn{3}{|l|}{ Street Drugs } \\
\hline Ketamine & 1 & $0.08 \%$ \\
\hline PCP & 3 & $0.13 \%$ \\
\hline \multicolumn{3}{|l|}{ Benzodiazepines } \\
\hline Alprazolam & 40 & $0.64 \%$ \\
\hline Chlordiazepoxide & 4 & $0.03 \%$ \\
\hline Clonazepam & 10 & $0.14 \%$ \\
\hline Diazepam & 30 & $0.38 \%$ \\
\hline Lorazepam & 2 & $0.03 \%$ \\
\hline Temazepam & 4 & $0.03 \%$ \\
\hline \multicolumn{3}{|l|}{ Antidepressants } \\
\hline Amitriptyline & 14 & $0.07 \%$ \\
\hline Fluoxetine & 25 & $0.37 \%$ \\
\hline Imipramine & 1 & $0.00 \%$ \\
\hline Sertraline & 36 & $0.50 \%$ \\
\hline \multicolumn{3}{|l|}{ Barbiturates } \\
\hline Butalbital & 9 & $0.17 \%$ \\
\hline Phenobarbital & 2 & $0.01 \%$ \\
\hline \multicolumn{3}{|l|}{ Pain drugs } \\
\hline Carisoprodol & 5 & $0.03 \%$ \\
\hline Meprobamate & 1 & $0.01 \%$ \\
\hline \multicolumn{3}{|l|}{ Sleep Aids } \\
\hline Zolpidem & 4 & $0.03 \%$ \\
\hline Cough Suppressants & & \\
\hline Dextromethorphan & 16 & $0.22 \%$ \\
\hline All Tested Drivers ${ }^{\dagger}$ & 5,910 & $16.30 \%$ \\
\hline
\end{tabular}

† Number and percentages for "All tested drivers" indicate number of drivers providing samples and percentage of those drivers who tested positive.

In this table, percentages are weighted. 
Drugs that were infrequently encountered in the study population included the sedative pain drugs carisoprodol and meprobamate; the sleep aid zolpidem; and the street drugs ketamine and PCP. Barbiturates and cough suppressants were also infrequent in the studied driver population.

Examination of the results of the daytime and the nighttime oral fluid analyses, and the combination of oral fluid and/ or blood analyses (when either one or both types of samples were provided) indicates that similar relative patterns of prevalence estimates are realized in the daytime and nighttime. Marijuana is the most frequently encountered drug whether compared with other drugs individually or with drug types. Cocaine is the next most frequently encountered drug or drug type in the nighttime sample, but during the daytime, benzodiazepines and opioids exhibited higher prevalence rates as classes than cocaine. 


\section{Discussion}

This report summarizes the results of the first U.S. National Roadside Survey to estimate druginvolved driving prevalence based on biological measures. It should be emphasized that this is a prevalence study, and not a study that addresses the risk that may be presented by drug use among drivers. For many drug types, drug presence can be detected long after any impairment that might affect driving has passed. However, it is important to our understanding of drugs and driving to know the extent of the use of certain drugs in the driving population. That was the intent of this study.

As indicated earlier in the report, we gathered data from drivers on U.S. roadways during Friday daytime hours, as well as during Friday nights and Saturday nights. We obtained oral fluid samples (1,850 during daytime and 5,869 during nighttime) from drivers in each of those data collection periods, and collected blood samples $(3,276)$, as well, during the nighttime data collection periods (Table 10).

In this study, analyses of the oral fluid and blood samples were conducted to identify the presence of some 75 drugs and metabolites (Tables 17 and 18). To make the presentation of results most useful, we identified six classes of these drugs, including antidepressants, marijuana, narcotic-analgesics, sedatives, stimulants, and other, plus a "more than one drug" class. We also identified three broader categories: illegal, prescription, and over-the-counter. Because few overthe-counter drugs were found, the prescription and over-the-counter drugs were combined for many analyses and labeled "Medications."

\section{Oral Fluid Analyses}

Analyses of the oral fluid samples obtained from daytime drivers indicated an overall drug use prevalence of 11 percent, and for nighttime drivers, 14.4 percent (Table 19). This includes illegal, prescription, and over-the-counter drugs combined. This overall difference between day and night is statistically significant $(p<.01)$.

In examining the prevalence of drugs by class (Table 31), marijuana was identified in 3.9 percent of daytime drivers and 6.1 percent of nighttime drivers. Sedatives were found in 1.6 percent of daytime drivers and in 0.6 percent of nighttime drivers. Conversely, stimulants were found in 1.6 percent of daytime drivers but in 3.2 percent of nighttime drivers.

Comparison of drug classes by time of day indicated that nighttime drivers were significantly more likely to test positive for more than one drug class than daytime drivers $(2.3 \%$ nighttime versus $1.5 \%$ daytime $)(p<.01)$. Comparison of drug categories by time of day (Table 34$)$ revealed that almost 6 percent of daytime drivers tested positive for drugs in the "Illegal" category (primarily marijuana and cocaine) as did over 10 percent of nighttime drivers (there was a statistically significant difference between the two groups $[p<.01]$ ). Positive results in the "Medications" category (prescription and over-the-counter drugs combined) were found to be slightly higher among the daytime drivers (almost 5\%) than nighttime drivers (3\%), although this difference was not statistically significant.

When examining drug prevalence by time of day and gender (Table 22), the daytime driving sample showed no statistically significant difference in drug prevalence between males and 
females; however, in the nighttime driving sample, male drivers were significantly more likely to be drug-positive than female drivers $(16.5 \%$ males versus $11.3 \%$ females $)(p<.01)$.

Further, comparison of drug class by time and gender (Table 32) showed that males were significantly more likely to test positive for marijuana than females in both daytime $(5.9 \%$ males versus $1.7 \%$ females) and nighttime samples $(7.4 \%$ males versus $4.1 \%$ females $)(p<.01)$.

When examining prevalence by drug category by time of day and gender (Table 36), we found that, in the daytime sample, male drivers were more likely to test positive for "Illegal" drugs $(8.2 \%)$ than female drivers $(3.0 \%) \quad(p<.01)$. Conversely, daytime female drivers were more likely to show positive results for "Medications" (7.6\%) than daytime male drivers $(2.5 \%)(p<$ $.01)$. This pattern was similar in the nighttime sample, with 12.5 percent of male drivers testing positive for "Illegal" drugs, as opposed to 7.5 percent of female drivers $(p<.01)$. The difference in percentage of positive results for "Medications" between male $(2.8 \%)$ and female $(3.3 \%)$ drivers was not as striking in the nighttime sample as in the daytime sample.

Comparison of overall drug prevalence by time of day and age ${ }^{18}$ (Table 23) revealed that, within the daytime driving sample, drivers aged 45-64 showed the highest percentage of drug positives, and drivers aged 16-20 and aged 65+ were significantly less likely to be positive than other ages of drivers $(p<.05)$. In the nighttime driving sample, drivers aged 45-64 and 65+ were significantly less likely to be drug positive $(p<.01)$, while drivers aged 16-20 showed no difference in drug prevalence from drivers aged 21-34 years and drivers aged 35-44 years.

When we examined drug classes by time of day and age (Table 33), we found that daytime drivers aged 21-34 were more likely to use marijuana (7.4\%) than daytime drivers in other age groups $(p<.01)$. However, drivers aged 16-20 years had the highest marijuana use $(9.8 \%)$ in the nighttime sample, followed by the $21-34$ year age group $(8.5 \%)(p<.01)$. The prevalence of narcotic-analgesics among daytime drivers was highest among drivers aged 45-64 (2.9\%) $(p<.01)$; however, in the nighttime sample, this changed to the age $35-44$ group $(4.2 \%)(p<$ $.01)$.

In comparing drug categories by time of day and age (Table 37), it was clear that, within the daytime sample, "Illegal" drug use was highest for drivers aged 21-34 (9.9\%) followed by drivers aged 35-44 (6.5\%). The prevalence of "Illegal" drugs for these age groups differed significantly from that in the remaining age groups $(p<.01)$. In the nighttime sample, drivers in the 21-34 year age group still maintained the highest percentage of positive results for "Illegal" drugs $(14.2 \%)$; however, that group was then followed by the youngest age group (16-20 years) for "Illegal" drugs $(13.1 \%)(p<.01)$. "Medications" usage was highest among the 45-64 year age group $(8.8 \%)$ in the daytime sample (non-significant), and in the 35-44 year old age group in the nighttime sample $(6.9 \%)(p<.01)$.

In comparing the number of drug-positive drivers by time of day and BAC level (Tables 38 and 39), a statistically significant association was found between drug-positive and alcohol-positive drivers within the nighttime driving sample. In other words, the percentage of nighttime drivers with a BAC g/dL of .08+ was significantly higher among drug-positive drivers than among drugnegative drivers $(p<.01)$. However, for daytime drivers, no such statistical association was found, largely because of the small number of alcohol-positive drivers in the daytime sample.

18 Age ranges between groups are not equivalent. 
In both the daytime and nighttime samples, the majority of drug-positive drivers who were alcohol-positive were in the "Illegal" drug category (Table 43). This was particularly true in the nighttime sample, in which 17.3 percent in the "Illegal" drug category had BACs between zero and .08 (compared to $6.3 \%$ in the "Medications" category) and 5.7 percent had BACs greater than .08 (compared to $1.2 \%$ in the "Medications" category $[p<.01]$ ). In the daytime sample, however, the differences were statistically non-significant.

\section{Blood Analyses}

About 14 percent of the 3,276 blood samples obtained from nighttime drivers were drug-positive (Table 83). Two percent of the blood-sampled drivers tested positive for more than one drug class (Table 93 and about 9 percent of driver tested positive for drugs in the "Illegal" category (Table 97).

Review of blood sample findings by gender (Table 86 ) revealed that male drivers were more likely to be drug-positive than female drivers (14.5\% males versus $13.0 \%$ females). However, such differences were not statistically significant. Comparison of drug class by gender (Table 95) revealed that male drivers were significantly more likely to test positive for marijuana than female drivers $(7.4 \%$ males versus $5.6 \%$ females $)(p<.05)$. When examining prevalence by drug category and gender (Table 99), we found that over 10 percent of male drivers had positive results for "'Illegal" drugs, as did about 7 percent of female drivers $(p<.01)$. The difference in percentage of positive results for "Medications" between male and female drivers was not statistically significant.

When examining drug prevalence by age (Table 87), the prevalence of drug-positives was higher among young drivers. Drivers aged 16-20 years showed a significantly higher prevalence than drivers aged 21-34 years and drivers aged 35-44 years $(p<.01)$. Drivers aged 45-64 and 65+ were significantly less likely to be drug positive than drivers ages 16 to 34 years old $(p<.01)$.

Comparison of drug class by age (Table 96) showed that drivers younger than 35-years-old were more likely to test positive for marijuana than drivers in other age groups $(p<.01)$. Among drivers aged 16-34, drivers aged 16-20 years had the highest marijuana use (15.2\%). The prevalence of narcotic-analgesics was higher among the 16-20 and 35-44 year age groups (1.3\% and $1.7 \%$ respectively) than any other age group $(p<.01)$.

"Illegal" drug use was highest for drivers in the youngest age group (16-20 years), followed by drivers aged 21-34 years old $(p<.01)$. "Illegal" drug use among drivers older than 35-years-old was significantly lower than among drivers under the age of $35(p<.01)$. "Medication" usage followed the opposite trend, with prevalence increasing with age. Prevalence of "Medication" was higher for drivers aged 35 and older than for drivers younger than age $35(p<.01)$ (Table 100).

A statistically significant association was found between drug-positive and alcohol-positive drivers (Tables 101 and 102). The percentages of drivers with a BAC g/dL between zero and 08 and with a BAC g/dL .08+ were significantly higher among drug-positive drivers than among drug-negative drivers $(p<.01)$. 


\section{Oral Fluid and/or Blood Analyses Combined}

Similar patterns of results were obtained when we examined the drug prevalence for the 5,910 nighttime drivers who provided oral fluid and/or blood samples. If a driver tested positive for one or more of the drugs in either the oral fluid and/or in the blood analyses, he/she was categorized as drug-positive (Table 110). This yielded an overall drug positive rate of 16.3 percent.

When we examined individual drugs and their metabolites (Tables 137 and 138), we found that the most frequently encountered drug was marijuana, whether it was measured in oral fluid in the daytime (4.5\%), oral fluid at nighttime (7.7\%), or the combination of oral fluid and/or blood at nighttime (8.7\%). The next most frequently encountered individual drug (again by all measures) was cocaine, which was present in 1.5 percent of daytime oral fluid samples, 3.9 percent of nighttime oral fluid samples, and 3.9 percent of nighttime combined oral fluid and/or blood analyses.

During the daytime, the next most frequently encountered drug was alprazolam at 1.12 percent. Among nighttime drivers providing oral fluid samples, the most frequently encountered drugs, after marijuana and cocaine, were methamphetamine and oxycodone, each with a prevalence rate of 0.80percent. The data collected during the 2007 National Roadside Survey provides new insight into the extent and patterns of drug use, and the combination of drug and alcohol use, among our Nation's drivers. As noted earlier, the data collected can not determine whether the drug-use patterns we observed affected driver performance, For example, although all the drugs examined in this study can potentially impair driving skills, some of the drug-positive drivers could drive better with the therapeutic effects of medicinal drugs they are taking. What this study has provided is a careful estimate of the extent of alcohol-involved and drug-involved driving in the contiguous 48 States.

The next step in this process is to conduct a study that attempts to quantify the risk that druginvolved driving may pose for crash involvement. One way to establish that is to conduct a case control study where data including objective measures of drug use are gathered from crashinvolved drivers and non-crash-involved drivers matched to the time, location, and direction of travel of the crash-involved drivers. Those two sets of data can then be compared to estimate the risk posed by various drugs. 


\section{References}

Bates, M., Brick, J., \& White, H. (1993). Correspondence between saliva and breath estimates of blood alcohol concentration: advantages and limitations of the saliva method. Journal of Studies on Alcohol. 54(1): 17-22.

Beirness, D., Simpson, H. M., \& Williams, A. F. (2006). Role of Cannabis and Benzodiazepines in Motor Vehicle Crashes, Transportation Research Circular No. E-C096: Drugs and Traffic: A Symposium, June 20-21, 2005 (pp. 12-21). Woods Hole, MA: Transportation Research Board of the National Academies.

Blomberg, R.D.; Peck, R.C.; Moskowitz, H.; Burns, M.; and Fiorentino, D. (2005) Crash risk of alcohol involved driving: A case-control study. Report. Stanford, CT: Dunlap \& Associates, Inc., (p. 117).

Brogan, W. C., Kemp, P. M., Bost, R. O., Glamann, D. B., Lange, R. A., \& Hillis, L. D. (1992). Collection and handling of clinical blood samples to assure the accurate measurement of cocaine concentration. Journal of Analytic Toxicology. 16: 152-154.

Burns, M. M. (1993). Cocaine Effects on Performance. In H. Utzelmann, G. Berghause, \& G. Ktoj (Eds.), 12th Proceedings of the International Conference on Alcohol, Drugs, and Traffic Safety. Verlang TÜV Rheinland GmbH (pp. 612-619). Köln, Germany, Centers for Disease Control and Prevention. (2006). Alcohol and other drug use among victims of motor vehicle crashes West Virginia - 2004-2005. Morbidity and Mortality Weekly Report (MMWR) 55(48):1293-1296. Available online: http://www.cdc.gov/mmwr/preview/mmwrhtml/mm5548a2.htm.

Christophersen, A. S. (1986). Tetrahydrocannabinol stability in whole blood: plastic versus glass containers. Journal of Analytic Toxicology. 10: 129-131.

Cone, E. J., Presley, L., Lehrer, M., Seiter, W., Smith, M., Kardos, K., Fritch, D., Salamone, S. J., \& Niedbala, R. (2002). Oral fluid testing for drugs of abuse: positive prevalence rates by Intercept immunoassay screening and GC-MS-MS confirmation and suggested cutoff concentrations. Journal of Analytical Toxicology. 26(8): 541-546.

Coulter C, Miller E, Crompton K, Moore C. (2008) Tetrahydrocannabinol and two of its metabolites in whole blood using liquid chromatography-tandem mass spectrometry. Journal of Analytical Toxicology. 32: 653-658.

Coulter, C., Crompton, K., \& Moore, C. (2008). Detection of phencyclidine in human oral fluid using solid phase extraction and liquid chromatography with tandem mass spectrometric detection. Journal of Chromatography B: Biomedical Sciences and Applications. 873: 123 128.

Couper, F. J., \& Logan, B. K. (2004). Drugs and human performance fact sheet. DOT HS 809 725. Washington, DC: National Highway Traffic Safety Administration.

de Gier, H. (2006, June 20-21). Medicinal Drugs: Critical Review of Present Knowledge and Statements for Discussion. Paper presented at the Drugs in Traffic: A symposium, Transportation Research Board, Woods Hole, MA. 
Drummer, O. H. (2002). Benzodiazepines: Effects on human performance and behavior. Forensic Science Review. 14: 2-14.

Federal Highway Administration (2006). Highway Statistics 2006. Retrieved June 25, 2008, from: www.fhwa.dot.gov/policy/ohim/hs06/driver licensing.htm

Gieringer, D. H. (1988). Marijuana, driving, and accident safety. Journal of Psychoactive Drugs. 20(93): 101.

Heishman, S. J., Stitzer, M. L., \& Yingling, J. E. (1989). Effects of tetrahydrocannabinol content on marijuana smoking behavior, subjective reports, and performance. Pharmacology, Biochemistry and Behavior. 34(1): 173-179.

Hemmelgarn, B., Suissa, S., Huang, A., Boivin, J.-F., \& Pinard, G. (1997). Benzodiazepine use and the risk of motor vehicle crash in the elderly. Journal of the American Medical Association. 278: 27-31.

Higgins, S. T., Bickel, W. K., Hughes, J. R., Lynn, M., Capeless, M. A., \& Fenwick, J. W. (1990). Effects of intranasal cocaine on human learning, performance, and physiology. Psychopharmacology. 8: 451-485.

Hold, K., de Boer, D., Zuidema, J., \& Maes, R. (1999). Saliva as an analytical tool in toxicology. International Journal of Drug Testing, 1(1), 1-36.

Hurst, P. M. (1976). Amphetamines and driving behavior. Accident Analysis and Prevention. 8: 9-13.

Jones, R. K., Shinar, D., \& Walsh, J. M. (2003). State of knowledge of drug-impaired driving. DOT HS 809 642. Washington, DC: National Highway Traffic Safety Administration.

Kelly, E., Darke, S., \& Ross, J. (2004). A Review of drug use and driving: Epidemiology, impairment, risk factors, and risk perceptions. Drug and Alcohol Review. 23: 319-344.

Kiger, S., Lestina, D., \& Lund, A.K. (1993) Passive alcohol sensors in law enforcement screening for alcohol-impaired drivers. Alcohol, Drugs and Driving. 9: 7-18.

Kintz, P., Cirimele, V., \& Ludes, B. (2000). Detection of cannabis in oral fluid (saliva) and forehead wipes (sweat) from impaired drivers. International Journal of Drug Testing. 24(7): 557-561.

Lacey, J., Kelley-Baker, K., Furr-Holden, C., Brainard, K., and Moore, C. (2007). Pilot Test of New Roadside Survey Methodology for Impaired Driving. DOT HS 810 704. Washington, DC: National Highway Traffic Safety Administration.

Lacey, J. H., Kelley-Baker, T., Furr-Holden, C. D. M., Voas, R., Moore, C., Brainard, K., Tippetts, A. S., Romano, E, Torres, P., \& Berning, A. (2009a). 2007 National Roadside Survey of Alcohol and Drug Use by Drivers: Methodology. Washington, DC: National Highway Traffic Safety Administration (in press).

Lacey, J. H., Kelley-Baker, T., Furr-Holden, C. D. M., Voas, Romano, E, Tippetts, A. S., Brainard, K., \& Berning, A. (2009b). 2007 National Roadside Survey of Alcohol and Drug Use by Drivers: Alcohol Results. Washington, DC: National Highway Traffic Safety Administration (in press). 
Lamers, C. T. J., \& Ramaekers, J. G. (1999). Marijuana and alcohol effects on visual search and general driving proficiency. Journal of Psychopharmacology. 13(3 Suppl. A): A53.

Lestina, D. C., Greene, M., Voas, R. B., \& Wells, J. (1999). Sampling procedures and survey methodologies for the 1996 survey with comparisons to earlier National Roadside Surveys. Evaluation Review. 23(1): 28-46.

Leveille, S. G., Buchner, D. M., Koepsell, T. D., McCloskey, L. W., Wolf, M. E., \& Gagner, E. H. (1994). Psychoactive medications and injurious motor vehicle collisions involving older drivers. Epidemiology. 5: 591-598.

Lucki, I., Rickels, K., \& Geller, A. (1985). Psychomotor performance following long-term use of benzodiazepines. Psychopharmacology Bulletin. 21: 93-96.

Lund, A. K., Preusser, D. F., Blomberg, R. D., \& Williams, A. F. (1988). Drug use by tractortrailer drivers. Journal of Forensic Sciences, JFSCA. 33(3): 648-661.

Lund, A. K., \& Wolfe, A. C. (1991). Changes in the incidence of alcohol-impaired driving in the United States, 1973-1986. Journal of Studies on Alcohol. 52(4): 293-301.

Mathijssen, M. P., Movig, K. L., de Gier, J. J., Nagel, P. H., van Egmond, T., \& Egberts, A. C. (2002). Use of psychoactive medicines and drugs as a cause of road trauma. In D. R. Mayhew \& C. Dussault (Eds.), Proceedings of Alcohol, Drugs \& Traffic Safety - T 2002: 16th International Conference on Alcohol, Drugs \& Traffic Safety, August 4-9, 2002 Vol. 2, (pp. 451-457). Montreal, Canada: International Council on Alcohol, Drugs and Traffic Safety (ICADTS). Centers for Disease Control and Prevention. (2006). Alcohol and other drug use among victims of motor vehicle crashes - West Virginia - 2004-2005. Morbidity and Mortality Weekly Report (MMWR) 55(48):1293-1296. Available online: http://www.cdc.gov/mmwr/preview/mmwrhtml/mm5548a2.htm.

Moore, C., Coulter, C., \& Crompton, K. (2007). Achieving proposed Federal concentrations using reduced specimen volume for the extraction of amphetamines from oral fluid. Journal of Analytic Toxicology. 31(8): 442-446.

Moore, C., Coulter, C., Crompton, K., \& Zumwalt, M. (2007). Determination of benzodiazepines in oral fluid using LC/MS/MS. Journal of Analytic Toxicology. 31(9): 596-600.

Moore, C., Rana, S., \& Coulter, C. (2007a). Determination of meperidine, tramadol and oxycodone in human oral fluid using solid phase extraction and gas chromatography-mass spectrometry. Journal of Chromatography B: Biomedical Sciences and Applications. 850: 370-375.

Moore, C., Rana, S., \& Coulter, C. (2007b). Simultaneous identification of 2-carboxytetrahydrocannabinol, tetrahydrocannabinol, cannabinol and cannabidiol in oral fluid. Journal of Chromatography B: Biomedical Sciences and Applications. 852: 459-464.

Moore, C., Vincent, M., Rana, S., Coulter, C., Agrawal, A., \& Soares, J. (2006). Stability of Delta(9)-tetrahydrocannabinol (THC) in oral fluid using the QuantisalTM collection device. Forensic Science International. 164(2-3): 126-130.

Moskowitz, H. (1985). Marijuana and driving. Accident Analysis and Prevention. 17: 323-345. 
National Highway Traffic Safety Administration. (1995). National automotive sampling system: Crashworthiness data system 1991-1993. Washington, DC: National Highway Traffic Safety Administration.

National Highway Traffic Safety Administration (2001). National Automotive Sampling System: Crashworthiness Data System 1995-1997. Washington, DC: National Highway Traffic Safety Administration.

National Highway Traffic Safety Administration (2005). Fatality Analysis Reporting System: Fatal crash data overview. DOT HS 809 726. Washington, DC: National Highway Traffic Safety Administration.

Neutel, C. I. (1998). Benzodiazepine-related traffic accidents in young and elderly drivers. Human Psychopharmacology. 13(Suppl. 2): S115-S123.

O'Neal, C. L., Crouch, D. J., Rollins, D. E., \& Fatah, A. A. (2000). The effects of collection methods on oral fluid codeine concentrations. Journal of Analytic Toxicology, 24(7), 536542.

Perez-Reyes, M., Hicks, R. E., Bumberry, J., Jeffcoat, A. R., \& Cook, C. E. (1988). Interaction between marihuana and ethanol: Effects on psychomotor performance. Alcohol Clinical and Experimental Research. 12(2): 268-276.

Polkis, A., Maginn, D., \& Barr, J. L. (1987). Drug findings in 'driving under the influence of drugs' cases: a problem of illicit drug use. Drug and Alcohol Dependence. 20(1): 57-62.

Preusser, D. F., Ulmer, R. G., \& Preusser, C. W. (1992, December). Evaluation of the impact of the drug evaluation and classification system on enforcement and adjudication. DOT HS 808 058. Washington, DC: National Highway Traffic Safety Administration.

Quintela, O., Crouch, D. J., \& Andrenyak, D. M. (2006). Recovery of drugs of abuse from the Immunalysis QuantisalTM $^{\mathrm{TM}}$ oral fluid collection device. Journal of Analytic Toxicology. 30(8): 614-616.

Rana, S., Moore, C., Agrawal, A., Coulter, C., Vincent, M., \& Soares, J. (2006). Determination of propoxyphene in oral fluid. Journal of Analytic Toxicology. 30(8): 516-518.

Ray, W. A., Fought, R. L., \& Decker, M. D. (1992). Psychoactive drugs and the risk of injurious motor vehicle crashes in elderly drivers. American Journal of Epidemiology. 136: 873-883.

Robbe, H., \& O'Hanlon, J. (1993). Marijuana and actual driving performance. DOT HS 808 078. Washington, DC: National Highway Traffic Safety Administration, U.S. Department of Transportation.

Rodrigues, W., Wang, G., Moore, C., Agrawal, A., Vincent, M., \& Soares, J. (2008). Development and validation of ELISA and GC-MS procedures for the quantification of dextromethorphan and its main metabolite dextrorphan in urine and oral fluid. Journal of Analytic Toxicology. 32: 1-7.

Samyn, N., G. de Boeck, et al. (2002). "The use of oral fluid and sweat wipes for the detection of drugs of abuse in drivers." Journal of Forensic Science 47(6): 1380-1387. 
Samyn, N., \& van Haeren, C. (2000). On-site testing of saliva and sweat with Drugwipe, and determination of concentrations of drugs of abuse in saliva, plasma and urine of suspected users. International Journal of Legal Medicine. 113(3): 150-154.

Schramm, W., Smith, R. H., Craig, P. A., \& Kidwell, D. A. (1992). Drugs of abuse in saliva: A review. Journal of Analytic Toxicology. 16(1): 1-7.

Shinar, D. (2006). Drug Effects and Their Significance for Traffic Safety, Transportation Research Circular No. E-C096: Drugs and Traffic: A Symposium, June 20-21, 2005 (pp. 5264). Woods Hole, MA: Transportation Research Board of the National Academies.

Smiley, A. (1998). Marijuana: On road and driving simulator studies. Paper presented at the World Health Organization, Geneva, Switzerland.

StataCorp. (2006) Stata: Data Analysis and Statistical Software. (http:/www.stata.com)

Terhune, K., Ippolito, C., Hendricks, D., Michalovic, J., Bogema, S., Santinga, P., Blomberg, R, \& Preusser, D. (1992). The incidence and role of drugs in fatally injured drivers. DOT HS 808 065. Washington, DC: National Highway Traffic Safety Administration.

Toennes, S., \& Kauert, G. (2001). Importance of vacutainer selection in forensic toxicological analysis of drugs of abuse. Journal of Analytic Toxicology. 25(5): 339-343.

U.S. Department of Transportation. (1968). Alcohol and highway safety. Report to the U.S. Congress. Washington, DC: U.S. Government Printing Office.

Voas, R. B., Wells, J., Lestina, D., Williams, A., \& Greene, M. (1998). Drinking and driving in the United States: The 1996 National Roadside Survey. Accident Analysis and Prevention. 30(2): 267-275.

Waller, P; Blow, F; Maio, R; Hill, E; Singer, K; and Schaefer. (1995). Crash characteristics and injuries of drivers impaired by alcohol/drugs. In: TS-'95. Proceedings of the 13th International Conference on Alcohol, Drugs and Traffic Safety. August 13-August 18, 1995. Adelaide, Australia: NHMRC, Road Accident Unit, University of Adelaide. Walsh, J. M., Cangianelli, L. A., Buchan, B. J., \& Leaverton, P. E. (2000). DUI Officer detection of illegal drugs in drivers using rapid immunoassay devices. In the 15 th International Council on Alcohol, Drugs, and Traffic Safety (ICADTS). May 22-26, 2000. Stockholm, Sweden: ICADTS.

Ward, A. S., Kelly, T. H., Foltin, R. G., \& Fischman, M. W. (1997). Effects of d-amphetamine on task performance and social behavior of humans in a residential laboratory. Experimental and Clinical Psychopharmacology. 5(2): 130-136.

White, J. Z., Clardy, D. O., Graves, M. H., Kuo, M., MacDonald, B. J., Wiersema, S. J., et al. (1981). Testing for sedative-hypnotic drugs in the impaired driver: A survey of 72,000 arrests. Clinical Toxicology. 18(8): 945-957.

Wolfe, A. C. (1974). 1973 U.S. National roadside breath testing survey: procedures and results. DOT HS 801 241. Washington, DC: National Highway Traffic Safety Administration.

Yacoubian, G., Wish, E. D., \& Pérez, D. M. (2001). A comparison of saliva testing to urinalysis in an arrestee population. Journal of Psychoactive Drugs. 33(3): 289-294. 


\section{Appendix A}

2007 National Roadside Survey: Additional Tables 


\section{Appendix A}

\section{National Roadside Survey \\ Additional Tables}

Table 141. Nighttime: Blood Results and Agreement With Self-Reported by Drug Type (Blood)

\begin{tabular}{|c|c|c|c|}
\hline \multirow[b]{3}{*}{ Drug Category } & \multirow[b]{3}{*}{$\begin{array}{c}\text { Self-Reported } \\
\text { Drug Use }\end{array}$} & \multicolumn{2}{|c|}{ Blood } \\
\hline & & \multicolumn{2}{|c|}{ Positive for this Drug } \\
\hline & & $\begin{array}{c}\mathrm{N} \\
\text { (Unweighted) } \\
\end{array}$ & $\begin{array}{c}\% \\
\text { (Weighted) } \\
\end{array}$ \\
\hline \multirow{7}{*}{ Antidepressants } & Past 24 Hours & 41 & $81.4 \%$ \\
\hline & Past 2 Days & 1 & $0.8 \%$ \\
\hline & Past Month & 1 & $0.2 \%$ \\
\hline & Past Year & 0 & $0.0 \%$ \\
\hline & Over a Year & 1 & $2.4 \%$ \\
\hline & Never & 13 & $15.2 \%$ \\
\hline & Overall & 57 & $100.0 \%$ \\
\hline \multirow{7}{*}{ Amphetamines } & Past 24 Hours & 1 & $3.1 \%$ \\
\hline & Past 2 Days & 0 & $0.0 \%$ \\
\hline & Past Month & 3 & $12.9 \%$ \\
\hline & Past Year & 1 & $12.5 \%$ \\
\hline & Over a Year & 8 & $10.9 \%$ \\
\hline & Never & 38 & $60.5 \%$ \\
\hline & Overall & 51 & $100.0 \%$ \\
\hline \multirow{7}{*}{ Barbiturates } & Past 24 Hours & 2 & $1.3 \%$ \\
\hline & Past 2 Days & 0 & $0.0 \%$ \\
\hline & Past Month & 0 & $0.0 \%$ \\
\hline & Past Year & 0 & $0.0 \%$ \\
\hline & Over a Year & 0 & $0.0 \%$ \\
\hline & Never & 6 & $98.7 \%$ \\
\hline & Overall & 8 & $100.0 \%$ \\
\hline \multirow{7}{*}{ Benzodiazepines } & Past 24 Hours & 11 & $21.5 \%$ \\
\hline & Past 2 Days & 4 & $3.8 \%$ \\
\hline & Past Month & 4 & $8.0 \%$ \\
\hline & Past Year & 3 & $2.0 \%$ \\
\hline & Over a Year & 5 & $2.1 \%$ \\
\hline & Never & 36 & $62.6 \%$ \\
\hline & Overall & 63 & $100.0 \%$ \\
\hline \multirow[t]{5}{*}{ Cocaine } & Past 24 Hours & 4 & $2.9 \%$ \\
\hline & Past 2 Days & 2 & $10.8 \%$ \\
\hline & Past Month & 5 & $17.0 \%$ \\
\hline & Past Year & 1 & $1.0 \%$ \\
\hline & Over a Year & 6 & $10.6 \%$ \\
\hline
\end{tabular}




\begin{tabular}{|c|c|c|c|}
\hline \multirow{5}{*}{ Drug Category } & \multirow[b]{3}{*}{$\begin{array}{l}\text { Self-Reported } \\
\text { Drug Use }\end{array}$} & \multicolumn{2}{|c|}{ Blood } \\
\hline & & \multicolumn{2}{|c|}{ Positive for this Drug } \\
\hline & & $\begin{array}{c}\mathrm{N} \\
\text { (Unweighted) }\end{array}$ & $\begin{array}{c}\% \\
\text { (Weighted) }\end{array}$ \\
\hline & Never & 23 & $57.7 \%$ \\
\hline & Overall & 41 & $100.0 \%$ \\
\hline \multirow{7}{*}{$\begin{array}{l}\text { Cough } \\
\text { Suppressants }\end{array}$} & Past 24 Hours & 2 & $15.7 \%$ \\
\hline & Past 2 Days & 1 & $22.2 \%$ \\
\hline & Past Month & 1 & $60.6 \%$ \\
\hline & Past Year & 0 & $0.0 \%$ \\
\hline & Over a Year & 0 & $0.0 \%$ \\
\hline & Never & 1 & $1.4 \%$ \\
\hline & Overall & 5 & $100.0 \%$ \\
\hline \multirow{7}{*}{ Ketamine } & Past 24 hrs & 0 & $0.0 \%$ \\
\hline & Past 2 days & 0 & $0.0 \%$ \\
\hline & Past Month & 0 & $0.0 \%$ \\
\hline & Past Year & 0 & $0.0 \%$ \\
\hline & Over a Year & 0 & $0.0 \%$ \\
\hline & Never & 1 & $100.0 \%$ \\
\hline & Overall & 1 & $100.0 \%$ \\
\hline \multirow{7}{*}{ Marijuana } & Past 24 hrs & 59 & $37.1 \%$ \\
\hline & Past 2 days & 18 & $5.4 \%$ \\
\hline & Past Month & 38 & $16.2 \%$ \\
\hline & Past Year & 22 & $6.8 \%$ \\
\hline & Over a Year & 27 & $9.3 \%$ \\
\hline & Never & 63 & $25.2 \%$ \\
\hline & Overall & 227 & $100.0 \%$ \\
\hline \multirow{7}{*}{ Methadone } & Past 24 hrs & 6 & $98.0 \%$ \\
\hline & Past 2 days & 0 & $0.0 \%$ \\
\hline & Past Month & 0 & $0.0 \%$ \\
\hline & Past Year & 0 & $0.0 \%$ \\
\hline & Over a Year & 0 & $0.0 \%$ \\
\hline & Never & 1 & $2.0 \%$ \\
\hline & Overall & 7 & $100.0 \%$ \\
\hline \multirow{7}{*}{ Opiates } & Past 24 hrs & 7 & $22.7 \%$ \\
\hline & Past 2 days & 6 & $13.1 \%$ \\
\hline & Past Month & 3 & $24.0 \%$ \\
\hline & Past Year & 8 & $3.7 \%$ \\
\hline & Over a Year & 8 & $16.3 \%$ \\
\hline & Never & 17 & $20.4 \%$ \\
\hline & Overall & 49 & $100.0 \%$ \\
\hline \multirow{7}{*}{ Pain Killers } & Past 24 hrs & 13 & $73.0 \%$ \\
\hline & Past 2 days & 3 & $1.4 \%$ \\
\hline & Past Month & 5 & $23.0 \%$ \\
\hline & Past Year & 1 & $1.3 \%$ \\
\hline & Over a Year & 2 & $0.7 \%$ \\
\hline & Never & 2 & $0.6 \%$ \\
\hline & Overall & 26 & $100.0 \%$ \\
\hline
\end{tabular}




\begin{tabular}{c|l|cc}
\hline \multirow{2}{*}{ Drug Category } & & \multicolumn{2}{|c}{ Blood } \\
\cline { 3 - 4 } & Self-Reported & \multicolumn{2}{|c}{ Positive for this Drug } \\
\cline { 3 - 4 } & Drug Use & $\begin{array}{c}\text { N } \\
\text { (Unweighted) }\end{array}$ & $\begin{array}{c}\% \\
\text { (Weighted) }\end{array}$ \\
\hline \multirow{5}{*}{ PCP } & Past 24 hrs & 0 & NA \\
& Past 2 days & 0 & NA \\
& Past Month & 0 & NA \\
& Past Year & 0 & NA \\
& Over a Year & 0 & NA \\
& Never & 0 & NA \\
& Overall & 0 & NA \\
\hline
\end{tabular}

Table 142. Nighttime: Seat Belt Observation by Drug Prevalence (Blood)

\begin{tabular}{lrrr}
\hline & $\begin{array}{c}\text { N } \\
\text { (Unweighted) }\end{array}$ & $\begin{array}{c}\text { \% Drug } \\
\text { Negative } \\
\text { (Weighted) }\end{array}$ & $\begin{array}{c}\text { \% Drug } \\
\text { Positive } \\
\text { (Weighted }\end{array}$ \\
\hline $\begin{array}{l}\text { Driver Seat Belt Observation } \\
\text { Yes }\end{array}$ & 3,159 & $86.5 \%$ & \\
$\quad$ No & 106 & $75.8 \%$ & $24.5 \%$ \\
\hline
\end{tabular}

Table 143. Nighttime: Seat Belt Observation by Drug Class (Percentages Calculated by Row) (Blood)

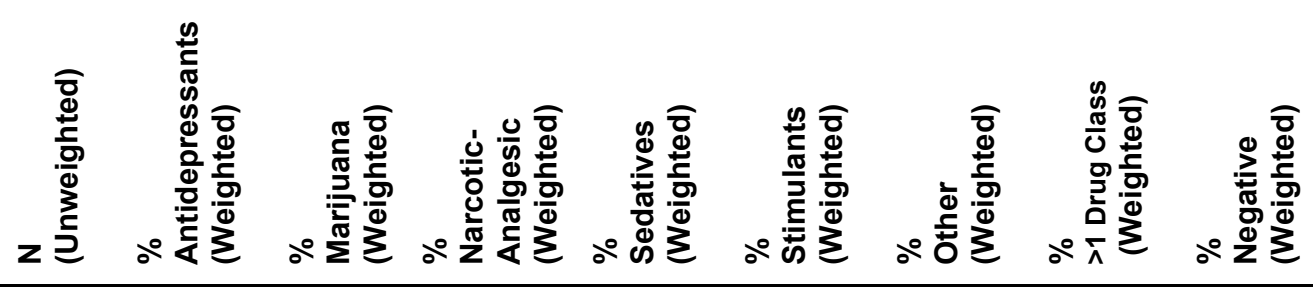

\begin{tabular}{|c|c|c|c|c|c|c|c|c|c|}
\hline \multicolumn{10}{|c|}{ Driver Seat Belt Observation } \\
\hline Yes & 3,156 & $1.1 \%$ & $6.5 \%$ & $0.8 \%$ & $1.2 \%$ & $1.8 \%$ & $0.3 \%$ & $1.9 \%$ & $86.5 \%$ \\
\hline No & 106 & $0.2 \%$ & $13.9 \%$ & $3.1 \%$ & $0.0 \%$ & $4.4 \%$ & $0.0 \%$ & $2.5 \%$ & $75.8 \%$ \\
\hline
\end{tabular}


Table 144. Nighttime: Seat Belt Observation by Drug Category (Blood)

\begin{tabular}{|c|c|c|c|c|c|}
\hline & $\begin{array}{c}\mathbf{N} \\
\text { (Unwtd) }\end{array}$ & $\begin{array}{c}\% \\
\text { Illegal } \\
\text { (Weighted) }\end{array}$ & $\begin{array}{c}\% \\
\text { Medications } \\
\text { (Weighted) }\end{array}$ & $\begin{array}{c}\% \text { Illegal \& } \\
\text { Medications } \\
\text { (Weighted) }\end{array}$ & $\begin{array}{c}\% \\
\text { Negative } \\
\text { (Weighted) }\end{array}$ \\
\hline \multicolumn{6}{|c|}{ Driver Seat Belt Observation } \\
\hline Yes & 3,156 & $8.81 \%$ & $4.00 \%$ & $0.66 \%$ & $86.53 \%$ \\
\hline No & 106 & $20.25 \%$ & $3.39 \%$ & $0.55 \%$ & $75.81 \%$ \\
\hline
\end{tabular}

Table 145. Nighttime: Helmet Use for Motorcycle Riders (Operators), by Drug Positive (Blood)

\begin{tabular}{lcc}
\hline & $\begin{array}{c}\text { N } \\
\text { (Unweighted) }\end{array}$ & $\begin{array}{c}\text { \% Drug Positive } \\
\text { (Weighted) }\end{array}$ \\
\hline Motorcycle Riders (Operators) & 48 & $24.00 \%$ \\
Helmet & 37 & $15.90 \%$ \\
No Helmet Use & 9 & $44.05 \%$ \\
Unknown & 2 & $0.00 \%$ \\
\hline
\end{tabular}

Table 146. Nighttime: Helmet Use for Motorcycle Riders (Operators), by Drug Class (Percentages Calculated by Row) (Blood)

\begin{tabular}{|c|c|c|c|c|c|c|c|c|c|}
\hline & $z$ 兽 & 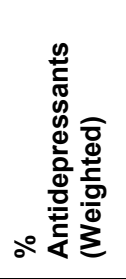 & 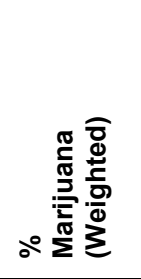 & 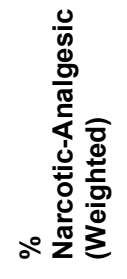 & 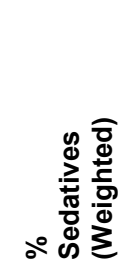 & 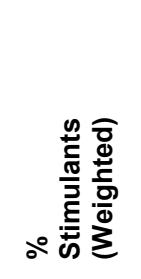 & 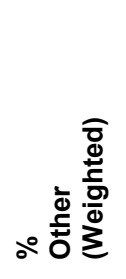 & 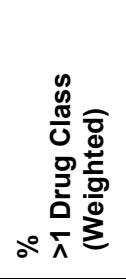 & 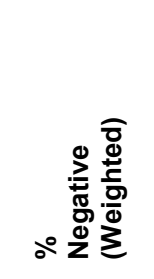 \\
\hline Motorcycle Riders (Operators) & 48 & $0.85 \%$ & $4.73 \%$ & $0.00 \%$ & $7.13 \%$ & $10.70 \%$ & $0.58 \%$ & $0.00 \%$ & $76.00 \%$ \\
\hline Helmet & 37 & $1.24 \%$ & $1.92 \%$ & $0.00 \%$ & $10.34 \%$ & $1.56 \%$ & $0.84 \%$ & $0.00 \%$ & $84.10 \%$ \\
\hline No Helmet Use & 9 & $0.00 \%$ & $11.52 \%$ & $0.00 \%$ & $0.00 \%$ & $32.53 \%$ & $0.00 \%$ & $0.00 \%$ & $55.95 \%$ \\
\hline Unknown & 2 & $0.00 \%$ & $0.00 \%$ & $0.00 \%$ & $0.00 \%$ & $0.00 \%$ & $0.00 \%$ & $0.00 \%$ & $100.00 \%$ \\
\hline
\end{tabular}

Table 147. Nighttime: Helmet Use for Motorcycle Riders (Operators), by Drug Category (Percentages Calculated by Row) (Blood)

\begin{tabular}{lccccc}
\hline & $\begin{array}{c}\text { N } \\
\text { (Unwt) }\end{array}$ & $\begin{array}{c}\text { Illegal } \\
\text { (Weighted) }\end{array}$ & $\begin{array}{c}\text { \% } \\
\text { Medications } \\
\text { (Weighted) }\end{array}$ & $\begin{array}{c}\text { \% Illegal \& } \\
\text { Medications } \\
\text { (Weighted) }\end{array}$ & $\begin{array}{c}\text { \%egative } \\
\text { (Weighted) }\end{array}$ \\
\hline Motorcycle Riders (Operators) & 48 & $15.43 \%$ & $8.57 \%$ & $0.00 \%$ & $76.00 \%$ \\
Helmet & 37 & $3.48 \%$ & $12.42 \%$ & $0.00 \%$ & $84.10 \%$ \\
No Helmet Use & 9 & $44.05 \%$ & $0.00 \%$ & $0.00 \%$ & $55.95 \%$ \\
Unknown & 2 & $0.00 \%$ & $0.00 \%$ & $0.00 \%$ & $100.00 \%$ \\
\hline
\end{tabular}


Table 148. Nighttime: Arrests and Drug Positives (Blood): "During the past 12 months, were you arrested and booked for driving under the influence of alcohol or drugs?"

\begin{tabular}{lcc}
\hline & $\begin{array}{c}\text { N } \\
\text { (Unweighted) }\end{array}$ & $\begin{array}{c}\text { \% Drug Positive } \\
\text { (Weighted) }\end{array}$ \\
\hline Yes & 122 & $31.7 \%$ \\
No & 3,080 & $13.2 \%$ \\
Total & 3,202 & $13.9 \%$ \\
\hline
\end{tabular}

$(p<.01)$

Table 149. Nighttime: Arrests and Drug Class (Blood): "During the past 12 months, were you arrested and booked for driving under the influence of alcohol or drugs?"

\begin{tabular}{|c|c|c|c|c|c|c|c|c|c|}
\hline & $z$ 氖 & 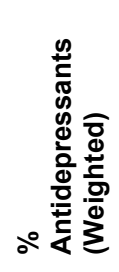 & 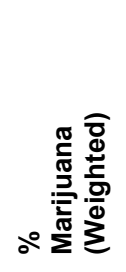 & 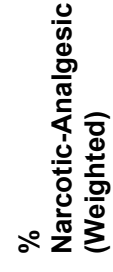 & 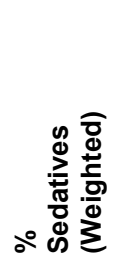 & 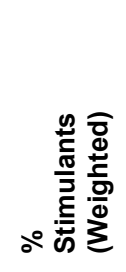 & 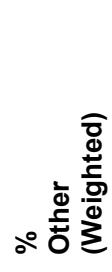 & 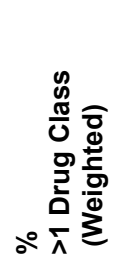 & 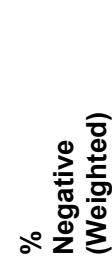 \\
\hline Yes & 122 & $1.6 \%$ & $10.9 \%$ & $0.4 \%$ & $0.2 \%$ & $10.4 \%$ & $0.0 \%$ & $8.2 \%$ & $68.3 \%$ \\
\hline No & 3,080 & $1.1 \%$ & $6.5 \%$ & $0.9 \%$ & $1.1 \%$ & $1.6 \%$ & $0.3 \%$ & $1.8 \%$ & $86.8 \%$ \\
\hline Total & 3,202 & $1.1 \%$ & $6.7 \%$ & $0.9 \%$ & $1.0 \%$ & $1.9 \%$ & $0.3 \%$ & $2.0 \%$ & $86.1 \%$ \\
\hline
\end{tabular}

Table 150. Nighttime: Arrests and Drug Categories (Blood): "During the past 12 months, were you arrested and booked for driving under the influence of alcohol or drugs?"

\begin{tabular}{lccccc}
\hline & $\begin{array}{c}\mathbf{N} \\
\text { (Unwt) }\end{array}$ & $\begin{array}{c}\text { \% } \\
\text { (Wegal }\end{array}$ & $\begin{array}{c}\text { \% } \\
\text { Medications } \\
\text { (Weighted) }\end{array}$ & $\begin{array}{c}\text { \% Illegal \& } \\
\text { Medications } \\
\text { (Weighted) }\end{array}$ & $\begin{array}{c}\text { \%egative } \\
\text { (Weighted) }\end{array}$ \\
\hline Yes & 122 & $22.3 \%$ & $3.6 \%$ & $5.8 \%$ & $68.3 \%$ \\
No & 3,080 & $8.7 \%$ & $4.1 \%$ & $0.4 \%$ & $86.8 \%$ \\
Total & 3,202 & $9.2 \%$ & $4.1 \%$ & $0.6 \%$ & $86.1 \%$ \\
\hline
\end{tabular}

Table 151. Nighttime: Past Treatment Program and Drug Positive (Blood): "During the past 12 months, did you ever stay at least overnight in an inpatient or residential drug or alcohol treatment program?"

\begin{tabular}{lcc}
\hline & $\begin{array}{c}\mathbf{N} \\
\text { (Unweighted) }\end{array}$ & $\begin{array}{c}\text { \% Drug Positive } \\
\text { (Weighted) }\end{array}$ \\
\hline Yes & 31 & $22.0 \%$ \\
No & 3,065 & $13.7 \%$ \\
Total & 3,096 & $13.8 \%$ \\
\hline
\end{tabular}


Table 152. Nighttime: Inpatient and Drug Class (Blood): "During the past 12 months, did you ever stay at least overnight in an impatient or residential drug or alcohol treatment program, for example, detox, rehab, a therapeutic community, or a hospital?"

\begin{tabular}{|c|c|c|c|c|c|c|c|c|c|}
\hline & 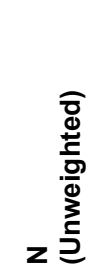 & 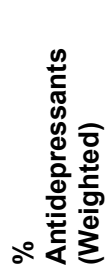 & 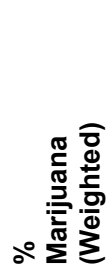 & 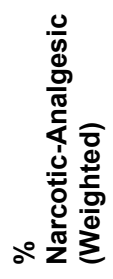 & 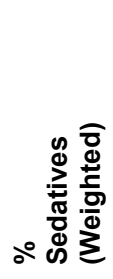 & 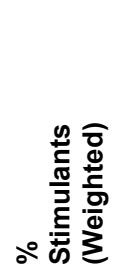 & 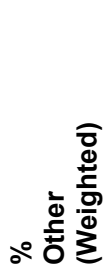 & 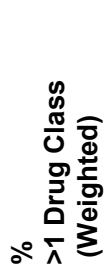 & 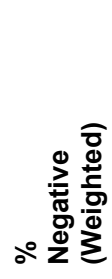 \\
\hline Yes & 31 & $0.0 \%$ & $2.2 \%$ & $1.5 \%$ & $0.9 \%$ & $2.4 \%$ & $0.0 \%$ & $15.0 \%$ & $78.0 \%$ \\
\hline No & 3,065 & $1.1 \%$ & $6.8 \%$ & $0.9 \%$ & $1.1 \%$ & $1.7 \%$ & $0.3 \%$ & $1.8 \%$ & $86.3 \%$ \\
\hline Total & 3,096 & $1.1 \%$ & $6.8 \%$ & $0.9 \%$ & $1.1 \%$ & $1.7 \%$ & $0.3 \%$ & $1.9 \%$ & $86.2 \%$ \\
\hline
\end{tabular}

Table 153. Nighttime: Inpatient and Drug Category (Blood): "During the past 12 months, did you ever stay at least overnight in an impatient or residential drug or alcohol treatment program, for example, detox, rehab, a therapeutic community, or a hospital?"

\begin{tabular}{lccccc}
\hline & $\begin{array}{c}\text { N } \\
\text { (Unwt) }\end{array}$ & $\begin{array}{c}\text { \% } \\
\text { (Weight } \\
\text { (Weight) }\end{array}$ & $\begin{array}{c}\text { Medications } \\
\text { (Weighted) }\end{array}$ & $\begin{array}{c}\text { \% Illegal \& } \\
\text { Medications } \\
\text { (Weighted) }\end{array}$ & $\begin{array}{c}\text { \% } \\
\text { (Wegative } \\
\text { (Weighted) }\end{array}$ \\
\hline Yes & 31 & $4.6 \%$ & $2.5 \%$ & $15.0 \%$ & $78.0 \%$ \\
No & 3,065 & $9.3 \%$ & $3.9 \%$ & $0.4 \%$ & $86.3 \%$ \\
Total & $\mathbf{3 , 0 9 6}$ & $9.3 \%$ & $3.9 \%$ & $0.6 \%$ & $86.2 \%$ \\
\hline
\end{tabular}

Table 154. Nighttime: Outpatient and Drug Positive (Blood): "Have you ever been admitted to an outpatient drug or alcohol treatment program, NOT including meetings like AA or NA?"

\begin{tabular}{lcc}
\hline & $\begin{array}{c}\mathbf{N} \\
\text { (Unweighted) }\end{array}$ & $\begin{array}{c}\text { \% Drug Positive } \\
\text { (Weighted) }\end{array}$ \\
\hline Yes & 109 & $22.3 \%$ \\
No & 3,089 & $13.5 \%$ \\
Total & 3,198 & $13.7 \%$ \\
\hline
\end{tabular}


Table 155. Nighttime: Outpatient and Drug Class (Blood): "Have you ever been admitted to an outpatient drug or alcohol treatment program, NOT including meetings like AA or NA?"

\begin{tabular}{|c|c|c|c|c|c|c|c|c|c|}
\hline & $\mathrm{z}$ & 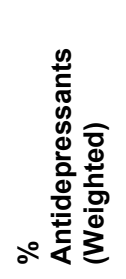 & ○゚ & 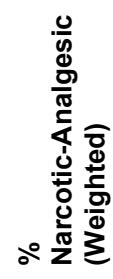 & 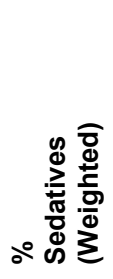 & 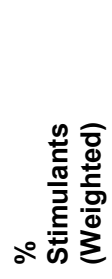 & 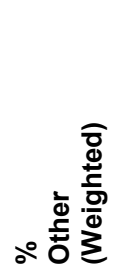 & 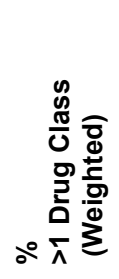 & ○ 료 \\
\hline Yes & 109 & $2.1 \%$ & $8.9 \%$ & $0.6 \%$ & $0.3 \%$ & $9.3 \%$ & $0.0 \%$ & $1.1 \%$ & $77.7 \%$ \\
\hline No & 3,089 & $1.1 \%$ & $6.6 \%$ & $0.9 \%$ & $1.1 \%$ & $1.5 \%$ & $0.3 \%$ & $2.0 \%$ & $86.5 \%$ \\
\hline Total & 3,198 & $1.1 \%$ & $6.7 \%$ & $0.9 \%$ & $1.0 \%$ & $1.7 \%$ & $0.3 \%$ & $2.0 \%$ & $86.3 \%$ \\
\hline
\end{tabular}

Table 156. Nighttime: Outpatient and Categories (Blood): "Have you ever been admitted to an outpatient drug or alcohol treatment program, NOT including meetings like AA or NA?"

\begin{tabular}{lrcccc}
\hline & $\begin{array}{c}\text { N } \\
\text { (Unwt) }\end{array}$ & $\begin{array}{c}\% \\
\text { Illegal } \\
\text { (Weighted) }\end{array}$ & $\begin{array}{c}\text { Medications } \\
\text { (Weighted) }\end{array}$ & $\begin{array}{c}\text { \% Illegal \& } \\
\text { Medications } \\
\text { (Weighted) }\end{array}$ & $\begin{array}{c}\text { \% } \\
\text { Negative } \\
\text { (Weighted) }\end{array}$ \\
\hline Yes & 109 & $18.5 \%$ & $3.0 \%$ & $0.8 \%$ & $77.7 \%$ \\
No & 3,089 & $8.9 \%$ & $4.0 \%$ & $0.6 \%$ & $86.5 \%$ \\
Total & 3,198 & $9.1 \%$ & $4.0 \%$ & $0.6 \%$ & $86.3 \%$ \\
\hline
\end{tabular}

Table 157. Nighttime: AA or NA, and Drug Positives (Blood): "During the past 12 months, have you received treatment for your drug or alcohol use in a self-help group such as AA or NA?"

\begin{tabular}{lcc}
\hline & $\begin{array}{c}\text { N } \\
\text { (Unweighted) }\end{array}$ & $\begin{array}{c}\text { \% Drug Positive } \\
\text { (Weighted) }\end{array}$ \\
\hline Yes & 74 & $26.2 \%$ \\
No & 3,120 & $13.4 \%$ \\
Total & 3,194 & $13.8 \%$ \\
\hline$(p<.01)$ &
\end{tabular}


Table 158. Nighttime: AA or NA, and Class (Blood): "During the past 12 months, have you received treatment for your drug or alcohol use in a self-help group such as AA or NA?"

\begin{tabular}{|c|c|c|c|c|c|c|c|c|c|}
\hline & 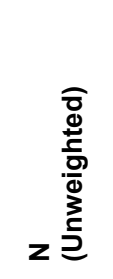 & 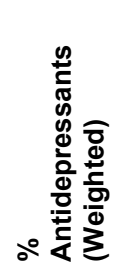 & ๙ & 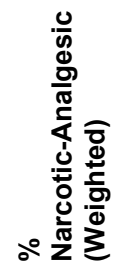 & 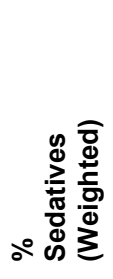 & 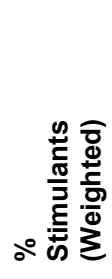 & 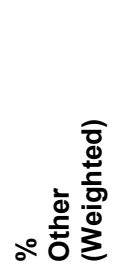 & 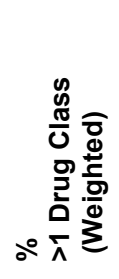 & ㅇ \\
\hline Yes & 74 & $0.0 \%$ & $17.1 \%$ & $1.1 \%$ & $0.3 \%$ & $5.3 \%$ & $0.0 \%$ & $2.3 \%$ & $73.8 \%$ \\
\hline No & 3,120 & $\begin{array}{c}1.1 \% \\
1 .\end{array}$ & $6.4 \%$ & $0.9 \%$ & $1.1 \%$ & $1.6 \%$ & $0.3 \%$ & $2.0 \%$ & $86.6 \%$ \\
\hline Total & 3,194 & $1 \%$ & $6.7 \%$ & $0.9 \%$ & $1.0 \%$ & $1.7 \%$ & $0.3 \%$ & $2.0 \%$ & $86.2 \%$ \\
\hline
\end{tabular}

Table 159. Nighttime: AA or NA, and Drug Categories (Blood): "During the past 12 months, have you received treatment for your drug or alcohol use in a self-help group such as AA or NA?"

\begin{tabular}{lccccc}
\hline & $\begin{array}{c}\text { N } \\
\text { (Unwtd) }\end{array}$ & $\begin{array}{c}\% \\
\text { Illegal } \\
\text { (Weighted) }\end{array}$ & $\begin{array}{c}\text { Medications } \\
\text { (Weighted) }\end{array}$ & $\begin{array}{c}\text { \% Illegal \& } \\
\text { Medications } \\
\text { (Weighted) }\end{array}$ & $\begin{array}{c}\text { \% } \\
\text { (Wegative } \\
\text { (Weighted) }\end{array}$ \\
\hline Yes & 74 & $22.5 \%$ & $3.3 \%$ & $0.4 \%$ & $73.8 \%$ \\
No & 3,120 & $8.8 \%$ & $4.0 \%$ & $0.6 \%$ & $86.6 \%$ \\
Total & 3,194 & $9.2 \%$ & $4.0 \%$ & $0.6 \%$ & $86.2 \%$ \\
\hline
\end{tabular}



DOT HS 811249

December 2009 